This manuscript has been for submitted for publication in GEOCHIMICA ET COSMOCHIMICA ACTA. The manuscript has undergone peer review but is yet to be formally published. Subsequent versions of this manuscript may have slightly different content. 


\title{
Global trends in novel stable isotopes in basalts: theory and
}

\section{observations}

\author{
Caroline R. Soderman ${ }^{\mathrm{a}}$, Oliver Shorttle ${ }^{\mathrm{a}, \mathrm{b}}$, Simon Matthews ${ }^{\mathrm{a}, 1}$, Helen M. Williams ${ }^{\mathrm{a}}$ \\ ${ }^{a}$ Department of Earth Sciences, University of Cambridge, Cambridge, CB2 3EQ \\ ${ }^{\mathrm{b}}$ Institute of Astronomy, University of Cambridge, Cambridge, CB3 0HA \\ ${ }^{1}$ Present address: Institute of Earth Sciences, University of Iceland
}

\begin{abstract}
The geochemistry of global mantle melts suggests that both mid-ocean ridge basalts (MORB) and ocean island basalts (OIB) sample lithological and temperature heterogeneities originating in both the upper and lower mantle. Recently, non-traditional stable isotopes have been suggested as a new tool to complement existing tracers of mantle heterogeneity (e.g., major and trace elements, radiogenic isotopes), because mineral- and redox-specific equilibrium stable isotope fractionation effects can link the stable isotope ratios of melts to their source mineralogy and melting degree. Here, we investigate five stable isotope systems (Mg-Ca-Fe-V-Cr) that have shown promise in models or natural samples as tracers of mantle temperature and/or lithological heterogeneity. We use a quantitative model, combining thermodynamically self-consistent mantle melting and equilibrium isotope fractionation models, to explore the behaviour of the isotope ratios of these elements during melting of three mantle lithologies (peridotite, and silica-excess and silica-deficient pyroxenites), responding to changes in mantle mineralogy, oxygen fugacity, temperature and pressure. We find that, given current analytical precision, the stable isotope systems examined here are not predicted to be sensitive to mantle potential temperature variations through equilibrium isotope fractionation processes. By contrast, source lithological heterogeneity is predicted to be detectable in some cases in the stable isotope ratios of erupted basalts, although generally only at proportions of $>10 \%$ MORB-like pyroxenite in the mantle source, given current analytical precision. Magnesium and Ca stable isotopes show most sensitivity to a garnet-bearing source lithology, and $\mathrm{Fe}$ and $\mathrm{Cr}$ stable isotopes are potentially sensitive
\end{abstract}


to the presence of MORB-like pyroxenite in the mantle source, although the behaviour of $\mathrm{Cr}$ isotopes is comparatively under-constrained and requires further work to be applied with confidence to mantle melts. When comparing the magnitude and direction of predicted equilibrium isotopic fractionation of peridotite and pyroxenite melts to natural MORB and OIB data, we find that aspects of the natural data (including the mean $\mathrm{Mg}-\mathrm{Ca}-\mathrm{Fe}-\mathrm{V}$ isotopic composition of MORB, the range of $\mathrm{Mg}-\mathrm{Ca}$ isotopic compositions seen in MORB data, the mean $\mathrm{Mg}-\mathrm{Ca}-\mathrm{Cr}$ isotopic composition of OIB, and the range of $\mathrm{Mg}-\mathrm{V}-\mathrm{Cr}$ isotopic compositions in OIB data) can be matched by equilibrium isotope fractionation during partial melting of peridotite and pyroxenite sources - with pyroxenite required even for some MORB data. However, even when considering analytical uncertainty on natural sample measurements, the range in stable isotope compositions seen across the global MORB and OIB datasets suggests that kinetic isotope fractionation, or processes modifying the isotopic composition of recycled crustal material such that it is distinct from MORB, may be required to explain all the natural data. We conclude that the five stable isotope systems considered here have potential to be powerful complementary tracers to other geochemical tracers of the source lithology of erupted basalts. However, continued improvements in analytical precision in conjunction with experimental and theoretical predictions of isotopic fractionation between mantle minerals and melts are required before these novel stable isotopes can be unambiguously used to understand source heterogeneity in erupted basalts.

\section{Introduction}

A key window into Earth's mantle is through the petrology and geochemistry of its melts, which include both mid-ocean ridge basalts (MORB) and ocean island basalts (OIB). MORB may be able to tell us about the composition and temperature of the upper mantle across multiple length scales (e.g., Allègre et al., 1984; Zindler and Hart, 1986; Mahoney et al., 1994; Agranier et al., 2005; Janney et al., 2005; Herzberg et al., 2007; Gale et al., 2013; Shorttle, 2015). Key questions about MORB-source mantle concern the various roles of temperature, crustal thickness, lithological heterogeneity, melt mixing and melt-rock reaction and the degree to which they can explain the trace, major element, and radiogenic isotope arrays of global MORB. Decades of investigation have produced a broad consensus that in the MORB-source mantle thermally-driven variations in melting degree create global signals in major and/or trace elements (Klein and Langmuir, 1987; Dalton et al., 2014; Gale et al., 2014). On a local scale MORB also show con- 
siderable isotopic and trace element variability, linked to small-scale lithological heterogeneity in the upper mantle (e.g., Zindler et al., 1984; Langmuir et al., 1986; Fornari et al., 1988; Hekinian et al., 1989; Schiano et al., 1997; Castillo et al., 2000; Waters et al., 2011; Gill et al., 2016; Liu and Liang, 2017; Jiang et al., 2021; Zhong et al., 2021). OIB also sample a heterogeneous mantle over short and long lengthscales including significant lithological heterogeneity (e.g., Cohen and O'Nions, 1982; Weaver, 1991; Chauvel et al., 1992; Kogiso et al., 2003; Sobolev et al., 2007; Jackson and Dasgupta, 2008; Dasgupta et al., 2010; Day and Hilton, 2011; Shorttle and Maclennan, 2011), elemental and isotopic heterogeneity (e.g., Zindler and Hart, 1986; Dupuy et al., 1988; Hauri and Hart, 1993; Hofmann, 1997, 2003; Stracke et al., 2005; Willbold and Stracke, 2006; Prytulak and Elliott, 2007; Jackson and Dasgupta, 2008; Maclennan, 2008; Dasgupta et al., 2010; Jackson et al., 2012; Mundl et al., 2017), and record large temperature variations relative to MORB (e.g., Putirka, 2005; Herzberg et al., 2007; Putirka, 2008a,b; Herzberg and Gazel, 2009; Herzberg and Asimow, 2015; Matthews et al., 2021).

In this study, we investigate the use of novel stable isotopes of major and minor elements in basalts (magnesium $\left[\delta^{26 / 24} \mathrm{Mg}\right]$, calcium $\left[\delta^{44 / 40} \mathrm{Ca}\right]$, iron $\left[\delta^{57 / 54} \mathrm{Fe}\right]$, vanadium $\left[\delta^{51 / 50} \mathrm{~V}\right]$, chromium $\left.\left[\delta^{53 / 52} \mathrm{Cr}\right]\right)$ as new tools for studying temperature and lithological heterogeneity in the mantle, complementary to existing work on MORB and OIB mantle sources using major and trace elements (e.g., Klein and Langmuir, 1987; Langmuir et al., 1992; McKenzie et al., 2004; Putirka, 2005; Herzberg et al., 2007; Jackson and Dasgupta, 2008; Niu and O'Hara, 2008; Dasgupta et al., 2010; Le Roux et al., 2011; Jackson et al., 2012; Lambart et al., 2013; Gale et al., 2014; Yang et al., 2019; Mallik et al., 2021). The chosen isotope systems may trace thermal and mineralogical heterogeneity in the source region of melts through their temperature and mineral-dependent equilibrium fractionation factors (e.g., Schauble, 2004; Young et al., 2015), and we include detail on the choice of these isotope systems in Section 1.3.

\subsection{Temperature and lithological heterogeneity in the mantle}

Mantle-derived melts, particularly MORB, show global geochemical arrays that can be explained by the conditions of melt generation in the mantle (e.g., temperature, lithology; Klein and Langmuir, 1987; Langmuir et al., 1992; Niu and O'Hara, 2008; Arevalo Jr and McDonough, 2010; Gale et al., 2014) and/or subsequent melt transport and storage processes (e.g., melt mixing, 
melt-rock reaction, fractional crystallisation; Devey et al., 1994; Arevalo Jr and McDonough, 2010; Liang et al., 2011; Kimura and Sano, 2012; Till et al., 2012; Shorttle, 2015; Bo et al., 2018; Mallik et al., 2021; Stracke, 2021). Once corrected for crystal fractionation, moderately incompatible element concentrations (e.g., $\mathrm{Na}, \mathrm{Al}$ ) in global MORB correlate positively with ridge depth, commonly interpreted to equate to a control by mantle potential temperature variations of around $220^{\circ} \mathrm{C}$ (Klein and Langmuir, 1987; Langmuir et al., 1992; Brandl et al., 2013; Gale et al., 2014). Correlations between fractionation-corrected major element compositions in MORB (e.g., FeO-Na $\mathrm{O}_{2} \mathrm{CaO}-\mathrm{Al}_{2} \mathrm{O}_{3}$ ) are consistent with the same mantle temperature variations (Langmuir et al., 1992; Gale et al., 2014). Although mantle composition has also been invoked instead of temperature variation to explain these trends (by applying a different fractionation correction; Niu and O'Hara, 2008), major element compositions measured in OIB and their constituent olivine, as well as olivine crystallisation thermometry and geophysical observations, argue in favour of there being regions of mantle up to $250{ }^{\circ} \mathrm{C}$ hotter than typical mid-ocean ridge mantle (e.g., Putirka, 2005; Herzberg et al., 2007; Putirka, 2008a; Dalton et al., 2014; Herzberg and Asimow, 2015; Spice et al., 2016; Ball et al., 2021; Matthews et al., 2021).

Although temperature may be a dominant control on MORB geochemical variability, mantle compositional heterogeneity is also clear in the elemental and isotopic compositions of both MORB and OIB. For example, in MORB highly incompatible element enrichment (e.g., fractionation-corrected $\mathrm{K}$ concentrations) correlates roughly with radiogenic isotopes, which must relate to source heterogeneity, such as through the addition or removal of low-degree melts (e.g., McKenzie and O'Nions, 1995; Donnelly et al., 2004; Gale et al., 2011, 2013, 2014). Radiogenic and stable isotopes and trace elements have also been used to argue for the presence of incompatible trace element-enriched, recycled components in the MORB source (e.g., Hirschmann and Stolper, 1996; Schiano et al., 1997; Salters and Dick, 2002; Bezard et al., 2016). In OIB, there is extensive evidence for mantle heterogeneity in the form of radiogenic and stable isotope compositions and the concentrations of major elements in basalt and trace elements in olivine (e.g., Zindler and Hart, 1986; Weaver, 1991; Hauri, 1996; Hofmann, 1997; Sobolev et al., 2005; Stracke et al., 2005; Sobolev et al., 2007; Jackson and Dasgupta, 2008; Day et al., 2009; Herzberg, 2011; Shorttle and Maclennan, 2011; Konter et al., 2016; Mundl et al., 2017; Neave et al., 2018; Nebel et al., 2019; Gleeson et al., 2020). This mantle heterogeneity is thought to relate largely to the recycling of crust, and the reaction between recycled lithologies (and their 
melts) and ambient mantle peridotite (e.g., Cohen and O'Nions, 1982; Hofmann and White, 1982; Allègre and Turcotte, 1986; Schiano et al., 1997; Sobolev et al., 2005, 2007; Herzberg, 2011; Mallik and Dasgupta, 2012; Stracke, 2012; Rosenthal et al., 2014; Lambart, 2017).

Many tools are available to study the contributions of temperature and lithological heterogeneity in these two types of basalts, for example: rare earth element inversion modelling (INVMEL: McKenzie and O'Nions, 1991, 1995), major element calculations (PRIMELT: Herzberg and Asimow, 2008, 2015; the thermodynamic model of Jennings and Holland, 2015; Jennings et al., 2016), trace element and radiogenic isotope composition forward modelling (REEBOX PRO: Brown and Lesher, 2016), and models combining trace elements, crystallisation temperatures and magma productivity (Shorttle et al., 2014; Matthews et al., 2016, 2021). However, achieving success in linking the elemental and radiogenic isotope variability in MORB and OIB to temperature and/or lithological heterogeneity is complicated by uncertainty in the nature of enriched lithologies, metasomatism by small volumes of melt (which are usually highly enriched in incompatible elements, so can overwhelm evidence of the original source lithology), magma recharge and mixing, diffusional re-equilibration and fractional crystallisation (e.g., Niu and O'Hara, 2003; Workman et al., 2004; Niu and O'Hara, 2008; Lambart et al., 2013; Matzen et al., 2017; Gleeson and Gibson, 2019). Stable isotopes of major and minor elements complement radiogenic isotopes and major element calculations and could provide new constraints on understanding global basalt chemistry: stable isotope systems are time-independent, and since their equilibrium partitioning is a function of mineral chemistry, they are the natural extension of major element calculations based on thermodynamic data. In addition, some of these stable isotopes are major elements whose budgets in the mantle source and subsequent erupted melts reflect contributions from both enriched and depleted lithologies, and are not dominated by small-degree melt metasomatism.

\subsection{Stable isotopes as a probe of mantle temperature and compositional heterogeneity}

Stable isotopes may trace thermal and mineralogical heterogeneity in the mantle through their temperature and mineral-dependent equilibrium fractionation factors (e.g., Schauble, 2004; Young et al., 2015). Our understanding of the equilibrium high temperature fractionation effects ex- 
perienced by novel stable isotope systems is improving, and many studies (both theoretical and from natural samples) suggest controls from mantle temperature and lithology on the isotopic composition of the melts produced. Previous studies have shown considerable variability in stable isotope ratios in MORB and OIB even where the geochemical signals of fractional crystallisation are considered to be negligible, or have been removed (Fig. 1), but understanding the origin of the variability remains challenging. For example, Fig. 1 shows that natural basalt stable isotope data for the isotope systems considered here have different systematics relative to the bulk silicate Earth (BSE). Magnesium and V stable isotope compositions in MORB and OIB scatter both sides of the BSE value, whereas Fe stable isotope compositions of basalts are heavier than the BSE, and for Cr and Ca basalts are (mostly) isotopically lighter than the BSE. The $\mathrm{Mg}$ and $\mathrm{Fe}$ stable isotope compositions of OIB show greater variability than MORB for the same isotope system, whereas the opposite is true for $\mathrm{V}$ stable isotopes (although this may be a sampling bias, given the greater amount of $\mathrm{V}$ isotope data for MORB than OIB).

Modelling of expected stable isotopic behaviour has led to questions about the origin of isotopic signatures observed in natural samples. For example, some studies have modelled Ca stable isotope fractionation using composition-dependent inter-mineral fractionation factors and concluded that partial melting of eclogite cannot produce the variability measured in OIB (Chen et al., 2020a), whereas others have predicted and measured that garnet has a higher $\delta^{44} \mathrm{Ca}$ than coexisting clinopyroxene (Antonelli et al., 2019; Huang et al., 2019; Kang et al., 2019; Wang et al., 2019; Chen et al., 2020a; Dai et al., 2020; Smart et al., 2021; Tappe et al., 2021), and have used this observation to predict that melts from recycled oceanic crust (garnet-bearing eclogite) will have low $\delta^{44} \mathrm{Ca}$, thus explaining the low $\delta^{44} \mathrm{Ca}$ measured in some OIB (Kang et al., 2019; Dai et al., 2020). Lithological heterogeneity (specifically, recycled pyroxenite) has also been linked to $\mathrm{Mg}$ and Fe isotope variability in MORB and OIB (e.g., Williams and Bizimis, 2014; Konter et al., 2016; Zhong et al., 2017; Stracke et al., 2018; Nebel et al., 2019; Gleeson et al., 2020; Sun et al., 2020; Zhong et al., 2021). However, some recent models of Fe and Mg isotope fractionation have led to uncertainty in whether equilibrium fractionation associated with the presence of garnet can unambiguously identify a garnet-bearing pyroxenite source lithology in natural OIB samples (Stracke et al., 2018; Soderman et al., 2021), and whether the heaviest Fe isotope data in the global dataset can be matched by models of mantle melting (Sun et al., 2020; Soderman et al., 2021). 


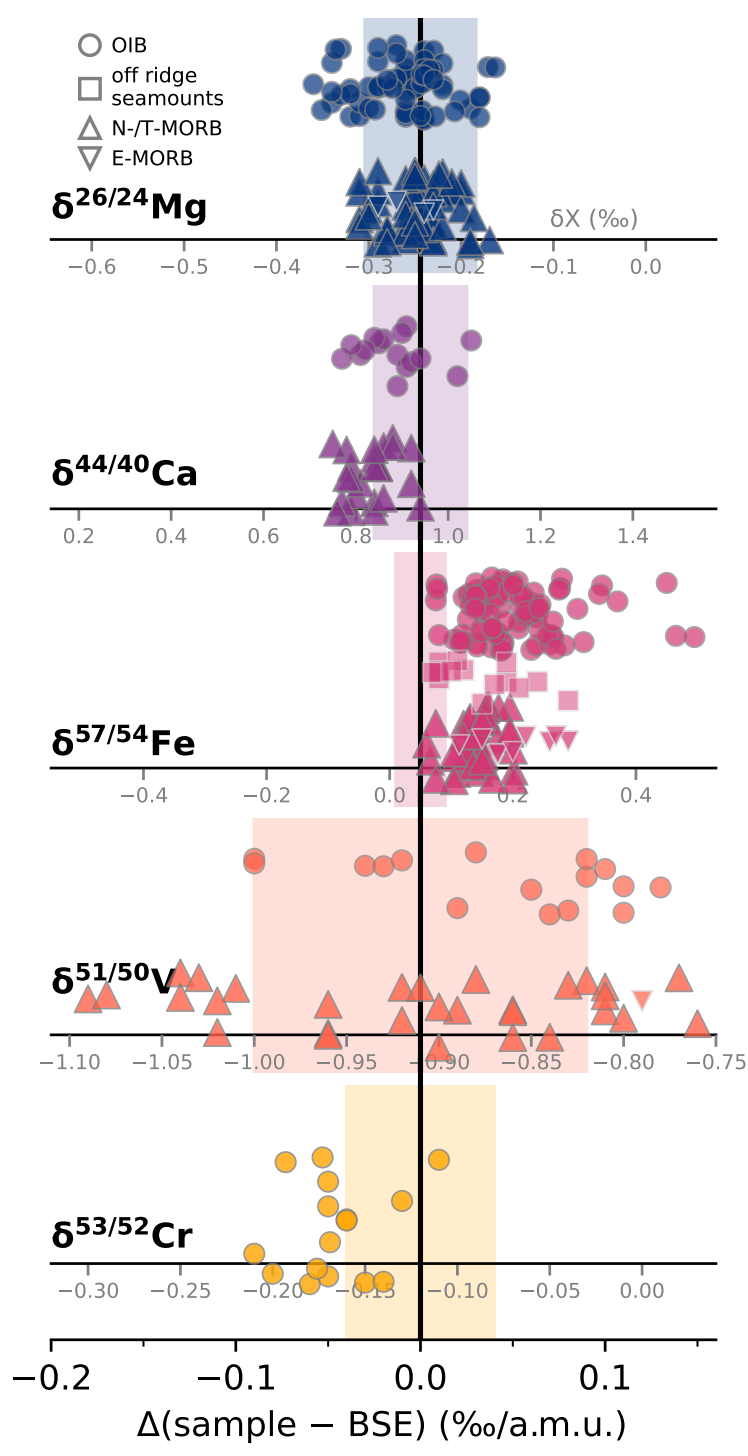

Figure 1: Literature MORB and OIB data for the isotope systems (for sources, see Table S1). Samples are filtered for $7.2<\mathrm{MgO}$ wt $\%<16$, but included if $\mathrm{MgO}$ is not known, to limit the effects of fractional crystallisation and olivine accumulation. Where MORB type is known, samples are classified as N-/T- or E-type (as classified by Teng et al., 2013); if classification is not known, samples are plotted as $\mathrm{N}$-/T-type. Ca and Mg isotope data is filtered to exclude samples with ${ }^{87} \mathrm{Sr} /{ }^{86} \mathrm{Sr}>0.7037$, which excludes samples with $>1 \%$ carbonate component in the source (Huang et al., 2011b). The main axis shows the variability in natural data from the BSE value for each isotope system, scaled by the difference in the atomic mass units (a.m.u.) of the isotopes being measured (e.g., for $\delta^{26 / 24} \mathrm{Mg}$, this a.m.u. factor is 2). The coloured bars show 2 S.D. on the BSE estimates. BSE values used are $\delta^{26} \mathrm{Mg}=-0.24 \pm 0.06 \%$ (Stracke et al., 2018), $\delta^{44} \mathrm{Ca}=0.94 \pm 0.10 \%$ (Kang et al., 2017; Chen et al., 2019), $\delta^{57} \mathrm{Fe}$ $=0.05 \pm 0.04 \%$ (Sossi et al., 2016), $\delta^{51} \mathrm{~V}=-0.91 \pm 0.09 \%$ (Qi et al., 2019), $\delta^{53} \mathrm{Cr}=-0.12 \pm 0.04 \%$ (Jerram et al., 2020). The pale secondary axis for each isotope shows the raw isotope ratios. The isotope ratios and reference materials used in the delta notation throughout are: $\delta^{26 / 24} \mathrm{Mg}$ [DSM3]; $\delta^{44 / 40} \mathrm{Ca}[\mathrm{SRM} 915 \mathrm{a}] ; \delta^{57 / 54} \mathrm{Fe}$ [IRMM-014]; $\delta^{51 / 50} \mathrm{~V}[\mathrm{AA}] ; \delta^{53 / 52} \mathrm{Cr}$ [NIST979].

Given the framework of MORB and OIB data that we now have (Fig. 1), growing theoretical information on bond strength and predicted inter-mineral fractionations for multiple stable isotope systems, and a variety of published isotope fractionation models that both can and cannot explain all the natural data, it is timely to develop a self-consistent model for the behaviour of 
multiple stable isotopes during mantle melting. Here we use a thermodynamically self-consistent model for mantle melting of three lithologies (peridotite and two different pyroxenites), combined with a model for equilibrium $\mathrm{Mg}-\mathrm{Ca}-\mathrm{Fe}-\mathrm{V}-\mathrm{Cr}$ stable isotope fractionation responding to changes in mantle mineralogy, intrinsic variations in oxygen fugacity (i.e., at constant $\mathrm{O}$ content), temperature and pressure. These models allow us to investigate the potential for the stable isotope composition of basalts to be a tracer of mantle temperature and lithological heterogeneity.

\subsection{Approach}

This contribution explores the behaviour of $\mathrm{Mg}-\mathrm{Ca}-\mathrm{Fe}-\mathrm{V}-\mathrm{Cr}$ stable isotopes during mantle melting, expanding on work on Fe stable isotope behaviour presented in Soderman et al. (2021). These isotope systems were chosen as they have been documented to show resolvable mineralspecific fractionation effects that may make them sensitive to partial melting or source lithology effects (e.g., Konter et al., 2016; Xia et al., 2017; Stracke et al., 2018; Wu et al., 2018; Kang et al., 2019; Nebel et al., 2019; Dai et al., 2020; Gleeson et al., 2020; Shen et al., 2020; Novella et al., 2020), and their bonding environments and/or expected isotopic fractionation in mantle minerals and melt are sufficiently well-studied to provide reasonable inputs for an isotopic fractionation model. The isotope systems represent both major and trace elements in basalts, and monovalent and heterovalent elements. The major elements $(\mathrm{Mg}, \mathrm{Ca}, \mathrm{Fe})$ are abundant in the mantle with comparable or lower concentrations in pelitic sediments and crustal material (Plank and Langmuir, 1998; Rudnick and Gao, 2003; Workman and Hart, 2005), meaning the isotopic signatures of mantle components are not easily affected by metasomatism, and their isotopic compositions in basalts should track the bulk mass contributions of both fertile and depleted mantle lithologies to the melt. This is an important property of major element stable isotope systems that contrasts with radiogenic isotope systems of incompatible trace elements, which cannot probe the proportions of different lithologies directly, as incompatible element concentration vary widely between enriched and depleted mantle lithologies. We note that carbonates, whose presence have been invoked in the source regions of mantle melts (e.g., Huang et al., 2011b; Liu et al., 2017a; Wang et al., 2018), have Ca concentrations $~ 10$ times higher than the mantle (e.g., Huang et al., 2011b), but we do not discuss carbonates here; instead we filter natural data used in this study by ${ }^{87} \mathrm{Sr} /{ }^{86} \mathrm{Sr}$ to exclude significant contributions from carbonate 
components.

Section 2 contains a description of the combined thermodynamic melting and equilibrium isotope fractionation model. The model was used to calculate the equilibrium isotopic composition of mantle melts from different lithologies over P-T space, and a summary of the results is presented in this section.

Sections 3 and 4 address the degree to which different stable isotope measurements (individual isotope systems, or in combination) can identify the relative importance of mantle temperature variability and mantle lithological heterogeneity in generating the observed variability in basalts. We also discuss where stable isotope systems have the potential to be useful in identifying these processes, if measurement uncertainties can be reduced.

Finally, Section 5 combines MORB and OIB data for the isotope systems studied with the modelled equilibrium melts, to assess to what extent our present understanding of the isotope behaviour can explain global basalt variability. We do not include arc basalts in our discussion for a number of reasons, including but not limited to the complicating effects of $\mathrm{H}_{2} \mathrm{O}$, slab fluids and redox variability in an arc setting, which have been linked to stable $\mathrm{Fe}$ and $\mathrm{Mg}$ isotope variability recorded in arc basalts (e.g., Dauphas et al., 2009; Nebel et al., 2013, 2015; Sossi et al., 2016; Teng et al., 2016; Li et al., 2017; Brewer et al., 2018; Hu et al., 2020) and which are beyond the applicable scope of the modelling presented here.

\section{Modelling equilibrium isotopic composition of mantle melts}

We calculated the equilibrium melting isotopic fractionation over P-T space for $\delta^{26 / 24} \mathrm{Mg}$, $\delta^{44 / 40} \mathrm{Ca}, \delta^{57 / 54} \mathrm{Fe}, \delta^{51 / 50} \mathrm{~V}$ and $\delta^{53 / 52} \mathrm{Cr}$ for three representative mantle lithologies, following the model outlined in Soderman et al. (2021). We used the calculated modal mineralogies over P-T space of KLB1 peridotite (a commonly used experimental composition used as an analogue for the upper mantle; Davis et al., 2009) and G2 silica-excess pyroxenite (an important MORBlike bulk composition in melting experiments and models from Pertermann and Hirschmann, $2003 a, b$ and Lambart et al., 2016) presented in Soderman et al. (2021). Following the methods used for KLB1 and G2, we also calculated the P-T-dependent modal mineralogy of MIX1G, a 
silica-deficient pyroxenite which plots close to the average global pyroxenite composition and can be considered as a mixture between KLB1 and MORB (Lambart et al., 2016), i.e., recycled crust mixed with ambient mantle. Calculations were performed using the dataset of Holland and Powell (2011) and activity-composition (a-X) models of Holland et al. (2018), implemented in THERMOCALC (Powell et al., 1998); see Section 2 in Appendix for details. This set of lithologies spans a range of fertile compositions, both ambient mantle and those derived from recycled crust, thought to be present in the mantle (Hirschmann and Stolper, 1996; Shorttle and Maclennan, 2011; Lambart et al., 2016; Mallik et al., 2021).

The THERMOCALC output includes the proportion of each phase present and information on the composition of each phase at any P-T point, including the distribution of elements on available cation sites. These results allow the equilibrium isotopic composition of the phases present (including melts) to be calculated for each isotope system, based on calculated equilibrium isotope fractionation factors, $\alpha^{\mathrm{A}-\mathrm{B}}$, between the phases $\mathrm{A}$ and $\mathrm{B}$ that are present, where

$$
\alpha^{\mathrm{A}-\mathrm{B}}=\frac{\left(\frac{\mathrm{X}_{2}}{\mathrm{X}_{1}}\right)_{\mathrm{A}}}{\left(\frac{\mathrm{X}_{2}}{\mathrm{X}_{1}}\right)_{\mathrm{B}}},
$$

and $\mathrm{X}$ represents the amount of each isotope 1 or 2 of an element. To facilitate comparisons between different lithologies and isotope systems, results are all expressed relative to a bulk system of $0 \%$, for convenience (although we recognise that different mantle components may have non-zero initial bulk stable isotope compositions for the stable isotope systems considered here). Iron isotope compositions of minerals and melts were calculated for MIX1G, following Soderman et al. (2021); and Ca, Mg, Cr and V isotope compositions were newly calculated for all three lithologies (full set of results for isotopes and lithologies in Section 3 of the Appendix, and Electronic Annex). The approach of the model for each isotope is described briefly below, with full details in the Appendix.

We cannot consider $\mathrm{H}_{2} \mathrm{O}$ in our phase-equilibrium calculations, as the THERMOCALC peridotite dataset used does not account for $\mathrm{H}_{2} \mathrm{O}$ accommodation in the mantle phases (Holland et al., 2018). However, for the comparison of our models to MORB and OIB, we consider this dry system to be suitable: non-arc mantle is generally considered to have small amounts of water stored in nominally anhydrous minerals (Bell and Rossman, 1992; Hirschmann et al., 2005). 
While $\mathrm{H}_{2} \mathrm{O}$, if present in the mantle source, would result in a deeper onset of melting than in dry melting, it does not result in significant changes to the maximum extent of melting and most water would be extracted in the first degrees of melting (e.g., Hirth and Kohlstedt, 1996; Hirschmann et al., 1999; Katz et al., 2003), so we consider that the $\mathrm{H}_{2} \mathrm{O}$ concentrations will be very low throughout most of the melting region. Therefore, the conclusions reached here will not be significantly changed by the inclusion of water in the thermodynamic system.

\section{$2.1 \mathrm{Ca}, \mathrm{Mg}$ and $\mathrm{Fe}$}

The partitioning of $\mathrm{Ca}, \mathrm{Mg}$ and $\mathrm{Fe}\left(\mathrm{Fe}^{2+}\right.$ and $\left.\mathrm{Fe}^{3+}\right)$ between the phases present at any $\mathrm{P}-\mathrm{T}$ point was taken from the THERMOCALC results. To calculate the isotope fractionation factors $(\alpha)$ for $\mathrm{Ca}$ and $\mathrm{Mg}$ isotopes between each phase, published temperature-dependent $\beta$-values (a reduced partition function ratio; Young et al., 2015) are used, where

$$
\alpha^{\mathrm{A}-\mathrm{B}}=\frac{\beta(\mathrm{T})_{\mathrm{A}}}{\beta(\mathrm{T})_{\mathrm{B}}} .
$$

Bulk $\beta$-values for each mineral (i.e., not using crystal site occupancy information) are calculated based on vibrational frequencies from first-principle calculations, and are taken from Antonelli et al. (2019) for Ca isotopes and Huang et al. (2013) for Mg isotopes. Where suitable $\beta$-values are not published, as for Fe, $\alpha$ factors can be calculated using cation-oxygen bond force constants in each crystal site for the minerals,

$$
\ln \left(\alpha^{\mathrm{A}-\mathrm{B}}\right)=\mathrm{C} \frac{\left[\mathrm{K}_{\mathrm{A}}-\mathrm{K}_{\mathrm{B}}\right]}{\mathrm{T}^{2}},
$$

where $\mathrm{C}$ is a constant dependent on the isotopes and element being considered (e.g., Sossi and O'Neill, 2017), $\mathrm{T}$ is the temperature in Kelvin, and $\mathrm{K}_{\mathrm{A}}$ and $\mathrm{K}_{\mathrm{B}}$ refer to the cation-oxygen force constants in minerals A and B. These force constants are based on an ionic bonding model for Fe (Sossi and O'Neill, 2017), as employed in Macris et al. (2015); Young et al. (2015); Soderman et al. (2021); Williams et al. (2021). 


\section{$2.2 \mathrm{~V}$ and $\mathrm{Cr}$}

The THERMOCALC a-X models of Holland et al. (2018) do not model V partitioning, nor heterovalent $\mathrm{Cr}$ ( $\mathrm{Cr}$ is assumed to have a valence of 3+ in the Holland et al., 2018 models). Therefore, the proportion of $\mathrm{V}^{3+/ 4+/ 5+}$ was calculated following Toplis and Corgne (2002), using the $\mathrm{FeO} / \mathrm{Fe}_{2} \mathrm{O}_{3}$ ratio of the melt (calculated in THERMOCALC) at each point in P-T space. The proportion of $\mathrm{Cr}^{2+/ 3+}$ was calculated using the parameterisation of Berry et al. (2021), with $\mathrm{fO}_{2}$ at each point calculated using the ' $\mathrm{fO}_{2}$ melt' software (Holland et al., 2018), hence Cr speciation also depends on the Fe redox equilibria. Here, we note that the requirement to handle heterovalent $\mathrm{Cr}$ and $\mathrm{V}$ outside of the THERMOCALC calculations means that the calculations of the redox state (hence, ultimately isotopic fractionation) are not fully self-consistent for the redox-sensitive elements. The $\mathrm{Cr}^{3+} / \mathrm{Cr}_{\mathrm{T}}, \mathrm{V}^{4+} / \mathrm{V}_{\mathrm{T}}$ and $\mathrm{V}^{5+} / \mathrm{V}_{\mathrm{T}}$ ratios change across $\mathrm{P}-\mathrm{T}$ space without taking oxygen from anywhere else (i.e., the $\mathrm{Fe}^{3+} / \mathrm{Fe}_{\mathrm{T}}$ ratio calculated at each $\mathrm{P}-\mathrm{T}$ point does not vary when $\mathrm{Cr}$ and $\mathrm{V}$ redox equilibria are considered). Instead, the calculations of the valence states of $\mathrm{Cr}$ and $\mathrm{V}$ at each $\mathrm{P}-\mathrm{T}$ point are dictated by the calculated Fe redox equilibria at that point. Nonetheless, tying the redox equilibria of $\mathrm{Cr}$ and $\mathrm{V}$ to that of $\mathrm{Fe}$ is a reasonable approximation of the natural system, given that the abundance of Fe in the mantle is significantly greater than that of the other redox-variable elements (Anenburg and O'Neill, 2019; see also Appendix Section 3.5 for the oxygen distribution in our models). As a consequence of our model's implentation of $\mathrm{Cr} / \mathrm{V}$ redox, the changes in $\mathrm{Cr} / \mathrm{V}$ speciation in the model will represent upper limits: i.e., in a more complex system coupled Fe-Cr-V redox equilbria will dampen the variability of $\mathrm{Fe}^{3+} / \mathrm{Fe}_{\mathrm{T}}, \mathrm{Cr}^{3+} / \mathrm{Cr}_{\mathrm{T}}$ and $\mathrm{V}^{4+, 5+} / \mathrm{V}_{\mathrm{T}}$ compared to our models.

The total $\mathrm{V}$ and $\mathrm{Cr}$ in the system were partitioned, dependent on the relative proportions of each valence state, between the phases present based on valence-specific partition coefficients from Mallmann and O'Neill (2009). The $\alpha$ factors for V were calculated following the approach used for $\mathrm{Mg}$ and $\mathrm{Ca}$ above, using $\beta^{\mathrm{V}}$ values for $\mathrm{V}$ in solution systems from $\mathrm{Wu}$ et al. (2015), extrapolated to magmatic systems at high temperature following Wu et al. (2018). For $\mathrm{Cr}, \alpha$ factors were calculated from Cr-O force constants following an ionic model (Shen et al., 2018, 2020), as for Fe isotopes (Soderman et al., 2021). 


\section{$2.3 \quad$ Results}

The results of the THERMOCALC calculations and subsequent melt stable isotope composition calculations are given in the Electronic Annex and Section 3 of the Appendix. A summary of the modelled equilibrium isotopic fractionation of peridotite melts (relative to the source), is shown in Fig. 2. Melt isotope ratios are shown along isentropic decompression melting paths calculated from THERMOCALC output - the isentropic approach (McKenzie, 1984; McKenzie and Bickle, 1988) assumes the adiabatic upwelling of the mantle is reversible, which is generally considered to be a good approximation of decompression melting in the mantle (e.g., McKenzie, 1984; McKenzie and Bickle, 1988; Asimow, 2002).

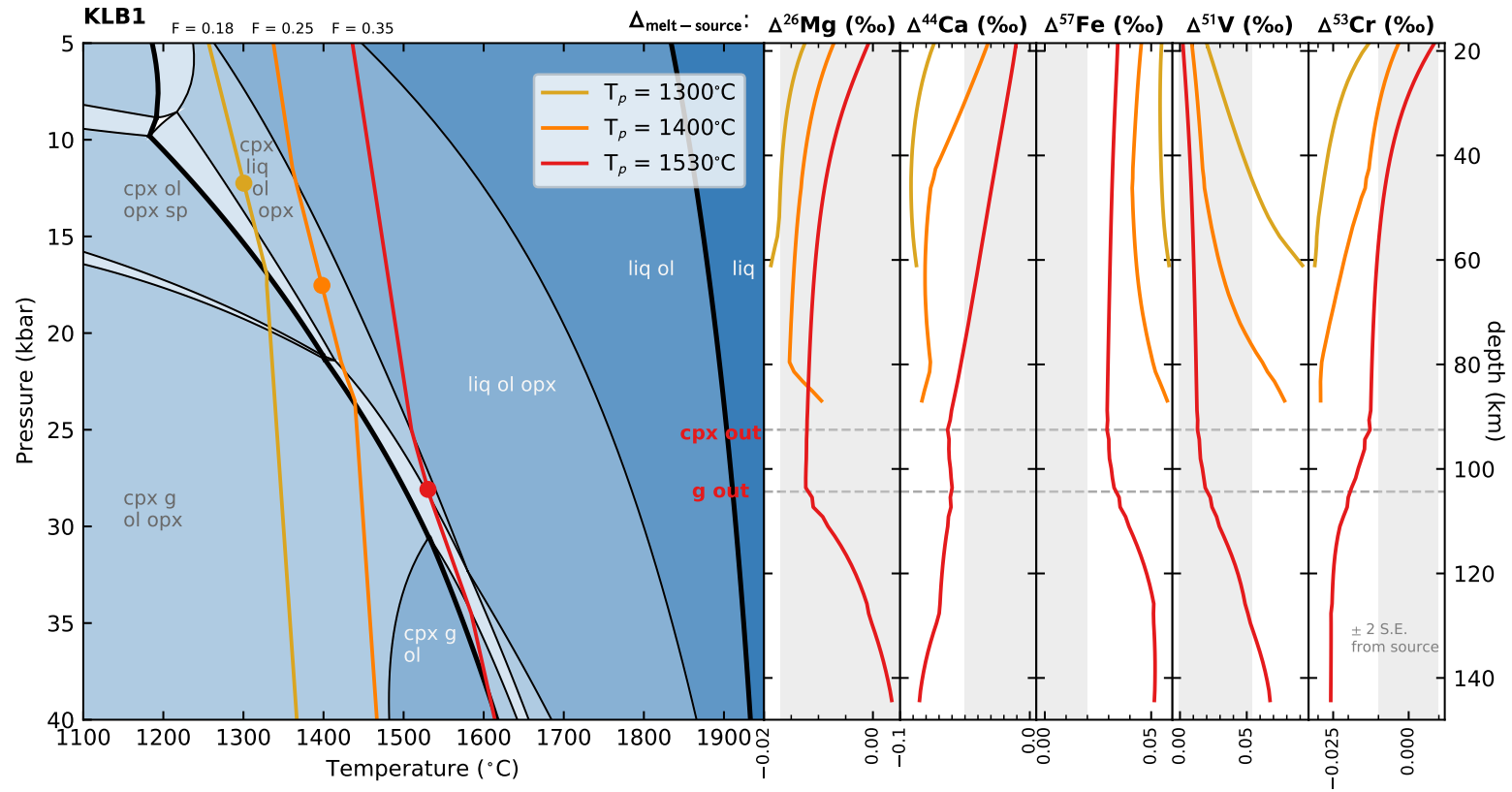

Figure 2: The left hand panel shows the pseudosection for KLB1 peridotite calculated in THERMOCALC, with the solidus and liquidus marked in bold, and three isentropic melting paths also calculated using THERMOCALC. The average pressure of melting for each isentrope (see Appendix Section 6) is shown by the small circles, and maximum melt fraction (F) labelled at the top of each isentrope. The right hand panels show the modelled instantaneous equilibrium melt isotopic fractionation relative to the bulk isotopic composition along both isentropes. Key mineralogical controls on the isotopic composition of the melt are highlighted (colour-coded by the isentropic path they refer to; here both for $\left.\mathrm{T}_{p}=1530^{\circ} \mathrm{C}\right)$. Vertical grey bars show the source composition $(0 \%)$ with typical sample 2 S.E. analytical precision for each isotope system. The analytical precisions used are based on representative errors from recent studies: for Mg from Wang et al. (2021), for Ca from Zhu et al. (2018, 2020a); Chen et al. (2020a), for Fe from Soderman et al. (2021), for V from Wu et al. (2018); Novella et al. (2020), for Cr from Sossi et al. (2018). Note that long-term analytical 2 S.D. uncertainty is usually greater than sample 2 S.E. for each isotope system; see Table 1.

Table 1 summarises how the modelled stable isotope compositions of pyroxenite melts compare to the peridotite melts from Fig. 2. Due to the wider range of melting degrees reached by pyroxenites compared to peridotite for a given $\mathrm{T}_{p}$, generally the pyroxenite melts show a wider 
range of isotope ratios than peridotite melts for the same $\mathrm{T}_{p}$.

Table 1: Maximum magnitude $\Delta_{\text {melt-source }}$ for modelled isentropic decompression melting of KLB1 (peridotite), MIX1G (silica-deficient pyroxenite) and G2 (silica-excess pyroxenite), all following KLB1 isentropes, when $\mathrm{T}_{p}=$ $1300{ }^{\circ} \mathrm{C}$ ('cold'), $\mathrm{T}_{p}=1400^{\circ} \mathrm{C}$ ('mid') and $\mathrm{T}_{p}=1530{ }^{\circ} \mathrm{C}$ ('hot'). Typical analytical uncertainties used throughout this study are also given.

\begin{tabular}{|c|c|c|c|c|c|c|}
\hline Lithology & Temperature & $\begin{array}{l}\text { Maximu } \\
\Delta^{26} \mathrm{Mg}\end{array}$ & $\begin{array}{l}n \text { modell } \\
\Delta^{44} \mathrm{Ca}\end{array}$ & $\begin{array}{l}\text { melt-s } \\
\Delta^{57} \mathrm{Fe}\end{array}$ & $\begin{array}{l}\text { arce fra } \\
\Delta^{51} \mathrm{~V}\end{array}$ & $\begin{aligned} \text { onation } \\
\Delta^{53} \mathrm{Cr}\end{aligned}$ \\
\hline \multirow{3}{*}{ KLB1 } & cold & -0.019 & -0.092 & 0.058 & 0.092 & -0.031 \\
\hline & mid & -0.015 & -0.083 & 0.058 & 0.078 & -0.029 \\
\hline & hot & -0.012 & -0.085 & 0.052 & 0.067 & -0.026 \\
\hline \multirow{3}{*}{ MIX1G } & cold & -0.081 & -0.081 & 0.050 & 0.093 & -0.058 \\
\hline & mid & -0.024 & -0.137 & 0.045 & 0.090 & -0.049 \\
\hline & hot & 0.099 & -0.087 & 0.026 & 0.022 & -0.036 \\
\hline \multirow{3}{*}{ G2 } & cold & 0.088 & -0.125 & 0.048 & 0.074 & -0.095 \\
\hline & $\operatorname{mid}$ & 0.088 & -0.113 & 0.036 & 0.041 & -0.054 \\
\hline & hot & 0.00 & 0.00 & 0.00 & 0.00 & 0.00 \\
\hline \multirow{2}{*}{\multicolumn{2}{|c|}{$\begin{array}{l}1 \text { S.D. long-term analytical precision } \\
2 \text { S.E. typical sample error }\end{array}$}} & 0.03 & 0.07 & 0.025 & 0.04 & 0.02 \\
\hline & & 0.02 & 0.05 & 0.02 & 0.05 & 0.01 \\
\hline
\end{tabular}

\section{Stable isotope sensitivity to mantle temperature variations}

To explore the sensitivity of stable isotopes in basalts to variations in mantle potential temperature, we use the results of the equilibrium melt fractionation model for KLB1, since for MORB, the dominant source lithology is peridotite (Hirschmann and Stolper, 1996; Sobolev et al., 2007). Generally, all equilibrium source-melt isotopic fractionations are expected to decrease in magnitude with increased temperature (e.g., Bigeleisen and Mayer, 1947), although this effect will be small at high temperatures (typically scaling with $1 / \mathrm{T}^{2}$ ). However, the complexity of mineral reactions during melting and the mineral-specific fractionation effects shown by the stable isotope systems means some isotopes may show larger temperature (and extent of melting) sensitivity than others as modal mineralogy and mineral chemistry changes across P-T space. When using stable isotopes as a tool to understand mantle melting processes and source compositions, we are interested in two aspects of equilibrium stable isotope fractionation: 1) the mineralogy-dependent fractionation on melting, and 2) the degree-of-melting-dependent fractionation.

MORB generated from different mantle potential temperatures will vary in 1) the modal mineralogy of their mantle source, 2) source oxygen fugacity $\left(\mathrm{fO}_{2}\right)$, as this changes with pressure and temperature (e.g., Stolper et al., 2020), and 3) the degree of partial melting of the mantle source 
(Fig. 2; also Fig. S9). For MORB, the mean pressure and composition of melts produced in the mantle, hence the aggregate MORB composition, can be calculated using equations for 2D melting regimes (e.g., Klein and Langmuir, 1987; McKenzie and Bickle, 1988; Langmuir et al., 1992; Asimow et al., 2001), and show that the mean melting pressure varies from $\approx 12 \mathrm{kbar}$ for mantle potential temperatures around $1300{ }^{\circ} \mathrm{C}$, to $>25 \mathrm{kbar}$ for potential temperatures over $1500^{\circ} \mathrm{C}$. The THERMOCALC results show that increasing mantle temperature, with a corresponding deepening of the average pressure of melting reflecting the 'aggregate' melt, leads to progressively increasing melt fraction and progressively decreasing $\mathrm{Fe}^{3+} / \mathrm{Fe}_{\mathrm{T}}$ in the melt (due to changing mineral chemistry; Stolper et al., 2020), with minimal changes in the proportions of solid phases in the stable assemblage at the mean melting pressure for each $\mathrm{T}_{p}$ (Figs. 2, 3: see Section 6 in Appendix for details of the average melt pressure calculation). Therefore, the stable isotope compositions of melts could be dependent on mantle temperature through an $\mathrm{fO}_{2}$ dependence, which will arise due to the existence of multiple valence states, and the different melt partitioning behaviour of each valence state of the cation (e.g., Fe, $\mathrm{Cr}$ and $\mathrm{V}$ ). Isotopes that are most sensitive to melting degree, such as those with large magnitude meltsource isotope fractionations at low melting degrees, may also show temperature-related melt isotope composition variations.

Fig. 4 shows how the estimated isotopic composition of aggregate melts relative to the source, taken as the isotope ratio of the melt at the mean pressure of melting for each temperature, varies with mantle potential temperature. Using the mean melting pressure approach, which is a simplification of polybaric melting occurring in the Earth (Langmuir et al., 1992), gives similar results to polybaric decompression melting (see Appendix Section 6 for a comparison of the approaches). The approach used here does not reflect accumulated fractional melting - the mean pressure of melting is in the spinel stability field, and therefore the isotope ratios of the final aggregate melts do not show a clear garnet signature. The isotope fractionation models show that relatively large magnitude temperature-related effects are seen in the heterovalent Fe and $\mathrm{V}$ isotope systems, in agreement with predictions above that $\mathrm{fO}_{2}$ sensitivity will be the driver of $\mathrm{T}_{p}$-related isotopic fractionation variation. The $\mathrm{Cr}$ isotope ratio of the melt does not show large variability with potential temperature despite being a heterovalent system - this is because the $\mathrm{Cr}^{2+} / \mathrm{Cr}_{\mathrm{T}}$ ratio in the system is dependent on pressure and temperature, as well as $\mathrm{fO}_{2}$ (Berry et al., 2021). Therefore, the $\mathrm{fO}_{2}$ effect is not dominant when changing $\mathrm{T}_{p}$, in contrast 


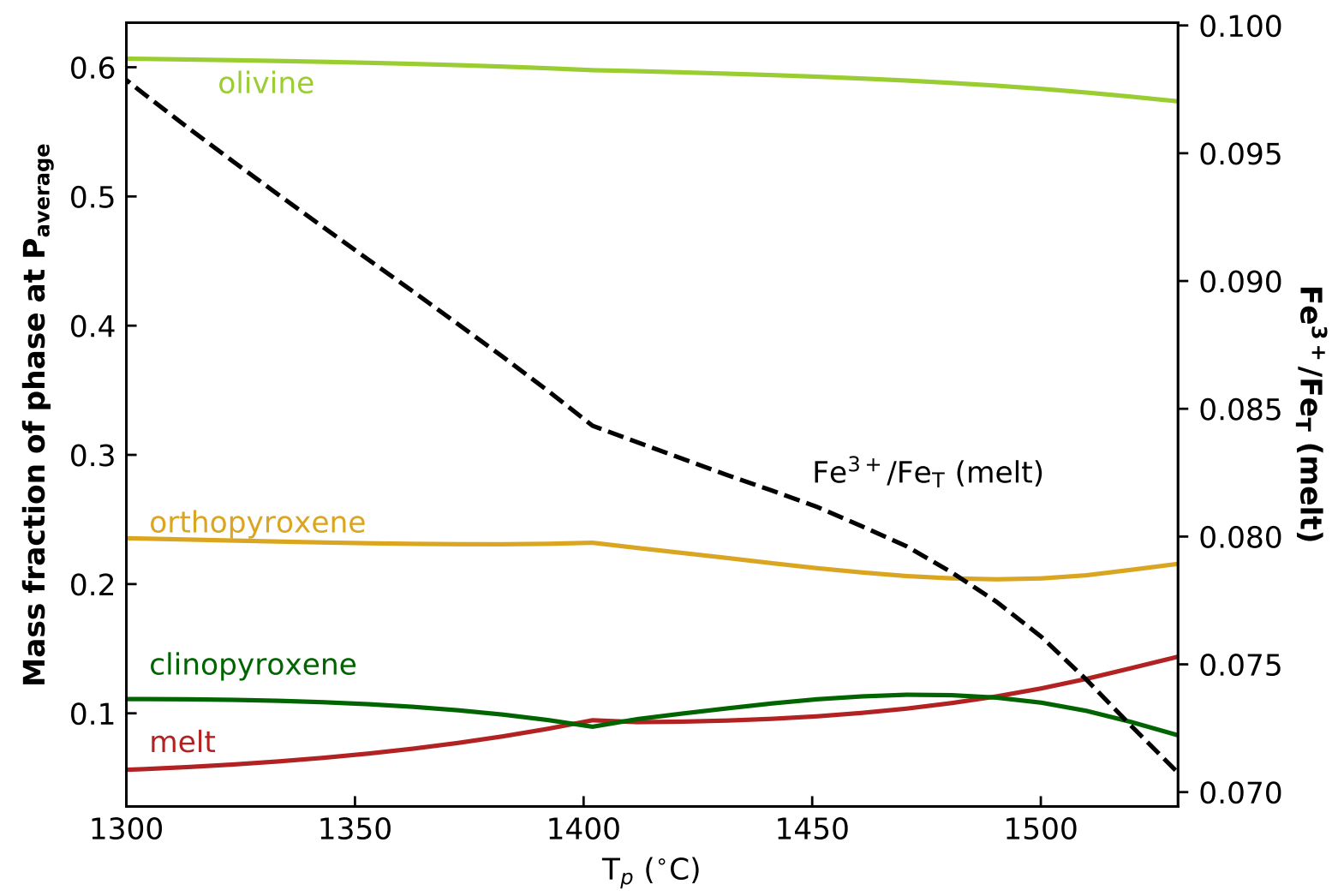

Figure 3: The mass fraction of phases present in the equilibrium KLB1 mineral assemblage and melt $\mathrm{Fe}^{3+} / \mathrm{Fe}_{\mathrm{T}}$, at the mean pressure of melt generation calculated for increasing mantle potential temperature. Mantle potential temperature, $\mathrm{T}_{p}$, is calculated by assuming a linear interpolation between the isentropes calculated in THERMOCALC for $\mathrm{T}_{p}=1300,1400$ and $1530^{\circ} \mathrm{C}$. The solid phase proportions are fractions of the whole assemblage (including melt). The average pressure of melting was calculated for $\mathrm{T}_{p}=1300,1400$ and $1530{ }^{\circ} \mathrm{C}$ (see details in Appendix Section 6), and interpolated between.

to $\mathrm{V}$ stable isotopes where the $\mathrm{V}$ valence state parameterisation is only linked to the $\mathrm{Fe}^{3+} / \mathrm{Fe}_{\mathrm{T}}$ at any point. Calcium isotope compositions of accumulated mantle melts also show dependence on temperature. This variation is linked to the increase in average melt fraction with increasing temperature; this effect is large for Ca compared to $\mathrm{Mg}$ isotopes, the other monovalent system, because of the much larger magnitude of melt-source Ca isotope fractionation (nearly $0.1 \%$ at low melt fraction), which results in an increased sensitivity to melting degree.

The relative enrichment of the heavy stable isotopes of $\mathrm{Fe}$ and $\mathrm{V}$ in the melt relative to the source (because oxidised, isotopically heavy cations behave more incompatibly during mantle melting than the reduced, isotopically lighter cations of the same element; Canil, 1999; Toplis and Corgne, 2002; Williams et al., 2004; Dauphas et al., 2009; Mallmann and O'Neill, 2009, 2013; Davis et al., 2013) decreases with increasing $\mathrm{T}_{p}$ (Fig. 4), and is qualitatively consistent with the positive $\delta^{51} \mathrm{~V}-\mathrm{Na}_{8.0}$ correlation in global MORB (Wu et al., 2018; Qi et al., 2019; 
Novella et al., 2020; $\mathrm{Na}_{8.0}$ is the $\mathrm{Na}_{2} \mathrm{O}$ content corrected for crystallisation to $\mathrm{MgO}=8$ wt \%, and therefore removes the variable chemical effects of low-pressure processes allowing for more direct comparison between samples). However, the predicted magnitude of $\mathrm{V}$ isotope variability with $\mathrm{T}_{p}$ is smaller than the range of MORB V isotope data presented by Wu et al. (2018). Due to the enrichment of melts with heavy isotopes, MORB should have a higher $\delta^{51} \mathrm{~V}$ than fertile mantle. This is in agreement with observed data: Wu et al. (2018) measure an average global MORB value of $-0.84 \pm 0.10 \%$ (2 S.D.), Qi et al. (2019) propose BSE is $-0.91 \pm 0.09 \%$ (2 S.D.) based on the isotopic composition of peridotite xenoliths and komatiites. Similar behaviour is observed for Fe isotopes: global MORB, after correction for fractional crystallisation, has $\delta^{57} \mathrm{Fe}=0.10 \pm$ $0.01 \%$ (2 S.E.); BSE is estimated at $0.05 \pm 0.01 \%$ (2 S.E.) from primitive lherzolites (Sossi et al., 2016). The magnitude of the modelled $\Delta^{51} \mathrm{~V}_{\text {melt-source }}$ and $\Delta^{57} \mathrm{Fe}_{\text {melt-source }}$ of aggregate KLB1 melts at $\mathrm{T}_{p} \approx 1300^{\circ} \mathrm{C}(\sim 0.055 \%$ for both isotope systems $)$ is similar to the $0.07 \%$ o and $0.05 \%$ difference observed between BSE and average MORB for $\mathrm{V}$ and Fe, respectively. However, we note that the large uncertainties on the $\delta^{51} \mathrm{~V}$ values estimated for the BSE and MORB mean that the $\Delta^{51} \mathrm{~V}_{\text {melt-source }}$ predicted by the model would match the BSE and MORB data for all $\mathrm{T}_{p}$.

Fig. $4 \mathrm{~b}$ shows how the magnitude of isotopic variability across the $\mathrm{T}_{p}$ range compares to typical long-term analytical precision for each isotope system (see Table 1 for the errors used), highlighting that the magnitude of variability in the isotope ratio of melts produced between $\mathrm{T}_{p}=1300^{\circ} \mathrm{C}$ and $1530{ }^{\circ} \mathrm{C}$ (a reasonable $\mathrm{T}_{p}$ range for melt generation at mid-ocean ridges and mantle plumes) is currently analytically unresolvable. Even considering analytical uncertainty in individual measurement sessions (i.e., the typical sample 2 S.E. rather than the long-term uncertainty; Table 1), the temperature-related variations associated with varying melt $\mathrm{Fe}^{3+} / \mathrm{Fe}_{\mathrm{T}}$ and modal mineralogy are not resolvable in the modelled average melt isotope ratios. The analytical precision therefore currently precludes mantle temperature variations in the global MORB dataset being resolved; this is consistent with Sossi et al. (2016) finding a homogenous global MORB $\delta^{57} \mathrm{Fe}$, despite global MORB major element chemistry indicating $200{ }^{\circ} \mathrm{C}$ variability (Gale et al., 2014). We note that the $\mathrm{Mg}$ and $\mathrm{Cr}$ stable isotope compositions of basalts are unlikely to be sensitive to temperature effects even with improved analytical precision; significant improvements in $\mathrm{V}$ and $\mathrm{Ca}$ analytical precision (both currently systems with relatively large errors), down to 2 S.D. of $<0.04 \%$, offer the most potential to resolve the predicted temperature- 


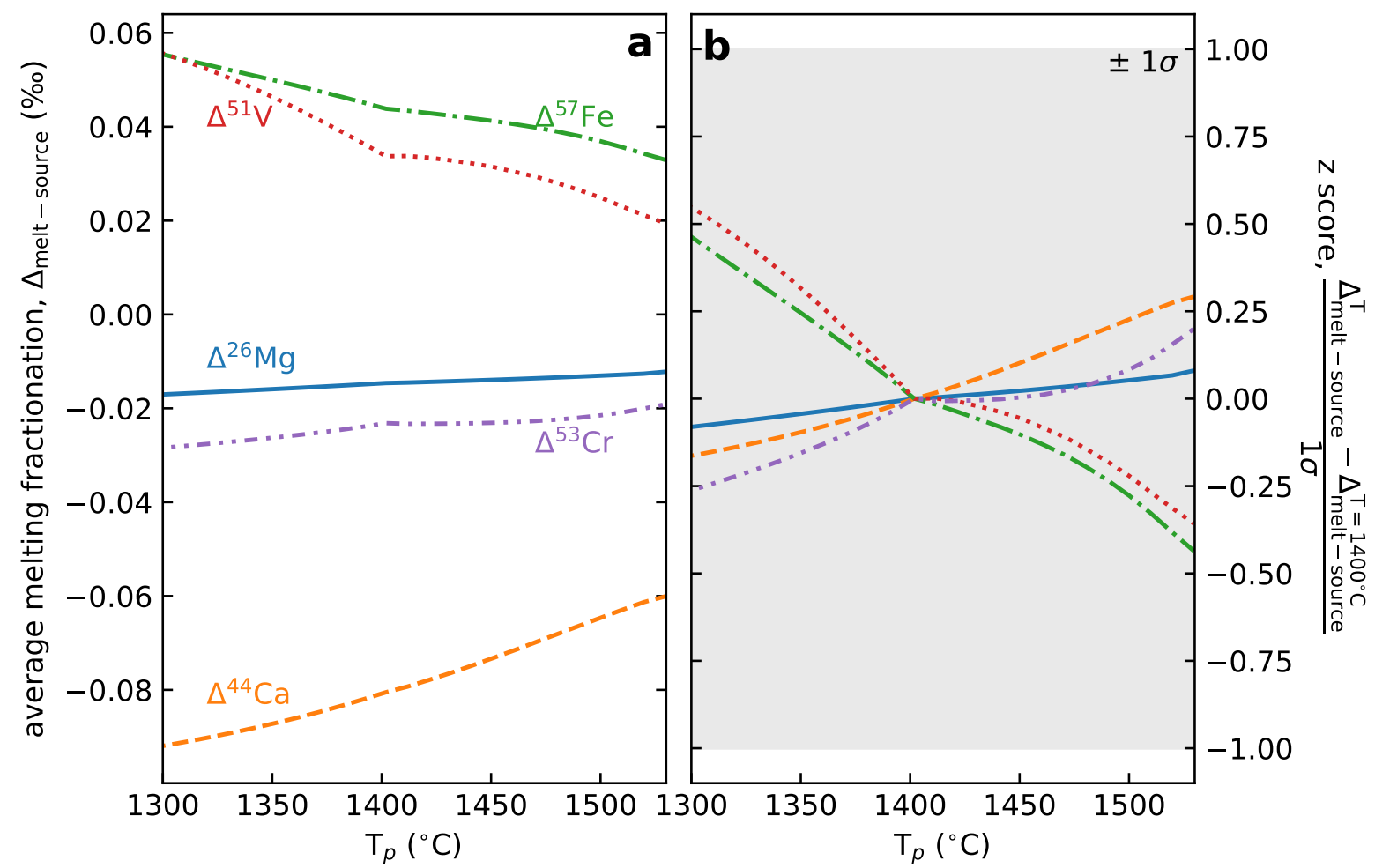

Figure 4: a) The estimated average isotopic fractionation of accumulated model peridotite melts relative to the source, across reasonable mid-ocean ridge and mantle plume temperatures. Mantle potential temperature, $\mathrm{T}_{p}$, is calculated as in Fig. 3, and the average melt fractionation is taken as the fractionation at the mean melting pressure at each temperature (see details in the text, Fig. 3, Appendix Section 6). b) The z score is calculated as $\left(\Delta_{\text {melt-source }}(\mathrm{T})-\Delta_{\text {melt-source }}\left(\mathrm{T}=1400^{\circ} \mathrm{C}\right)\right) / 1 \sigma$ typical analytical precision, for each isotope system. This calculation reflects how the magnitude of expected isotopic variability compares to reasonable measurable isotopic differences: a z score of 1 represents predicted isotopic variability resolvable at typical $1 \sigma$ uncertainty. The errors used are the representative long-term analytical uncertainty for each isotope system; see Table S2.

\section{Lithological heterogeneity}

We next investigate the use of stable isotopes as tracers of lithological heterogeneity in the mantle, using two pyroxenite lithologies, MIX1G (silica deficient, SD pyroxenite) and G2 (silica excess, SE pyroxenite). Silica-deficient pyroxenites may be the most representative type of pyroxenites found in the convecting mantle (the majority of pyroxenite xenoliths sampled in OIB are SD; Lambart et al., 2016 - natural SD pyroxenites are considered to be formed by metasomatism of peridotite by eclogite melts, as shown in experiments; Yaxley and Green, 1998; Yaxley, 2000; Mallik and Dasgupta, 2012). Natural SE pyroxenites include eclogites (Lambart et al., 2016). 


\subsection{Mineralogic control on melt isotope composition}

Fig. 5 shows the pseudosections and melt isotope ratios along peridotite isentropic decompression melting paths (see Fig. 2) for the two pyroxenite lithologies considered in this study. We have used peridotite isentropes since the thermal budget of multi-lithologic mantle will be buffered by melting of the dominant lherzolitic peridotite lithology, not pyroxenite melting (Phipps Morgan, 2001; Katz and Rudge, 2011). For example, peridotite (lherzolite + harzburgite) is estimated to make up $\geq 95 \%$ of the multi-lithologic mantle in the MORB mantle source (e.g., Hirschmann and Stolper, 1996; Matthews et al., 2016), and > $90 \%$ of the Icelandic mantle source (e.g., Shorttle et al., 2014). While a multi-lithologic mantle will not follow pure peridotite isentropic decompression paths, we consider this approach the most realistic reflection of mantle melting processes. Isentropic decompression melting paths for pure MIX1G and G2 are shown in Figs. S10 and S11 for reference. The melt isotope ratios shown in Fig. 5 are all calculated relative to a bulk system isotopic composition of $0 \%$, for convenience. In this respect Fig. 5 is strictly looking at the direct lithological (i.e., mineralogic) control on the stable isotope composition of melts independent of any additional source compositional effects that may have been imprinted by the processes forming the source in the first place. For example, MORBs (and hence MORB-derived mantle components) are isotopically distinct from the BSE, due to their formation by partial melting (Fig. 2), crystal fractionation, and low temperature alteration by the time of their subduction (e.g., as for $\delta^{57} \mathrm{Fe}$; Teng et al., 2013; Sossi et al., 2016, $\delta^{44} \mathrm{Ca}$; Zhu et al., 2018; Chen et al., 2020b; Antonelli and Simon, 2020 and $\delta^{51} \mathrm{~V}$; Wu et al., 2018). If MORB, or MORB-derived components, then form part of the mantle source during a subsequent melting episode, the new melts will be isotopically fractionated compared to lherzolite melts both because of their distinct mineralogy and their inherited initial isotope compositions. This subject is considered further in Sections 4.2 and 5 .

We first consider how the isotopic composition of pyroxenite melts compares to peridotite melts (Table 1) in the context of the two questions posed in Section 3: the magnitude of melt-source isotopic fractionation, and how melt-source isotopic fractionation varies with progressive melting. Generally, the pyroxenite melts show a wider range of melt isotope ratios than peridotite melts for the same $\mathrm{T}_{p}$ (compare Figs. 2 and 5; see also Fig. S13), because the pyroxenite melts represent a wider range of melting degrees than the peridotite and a greater proportion of 

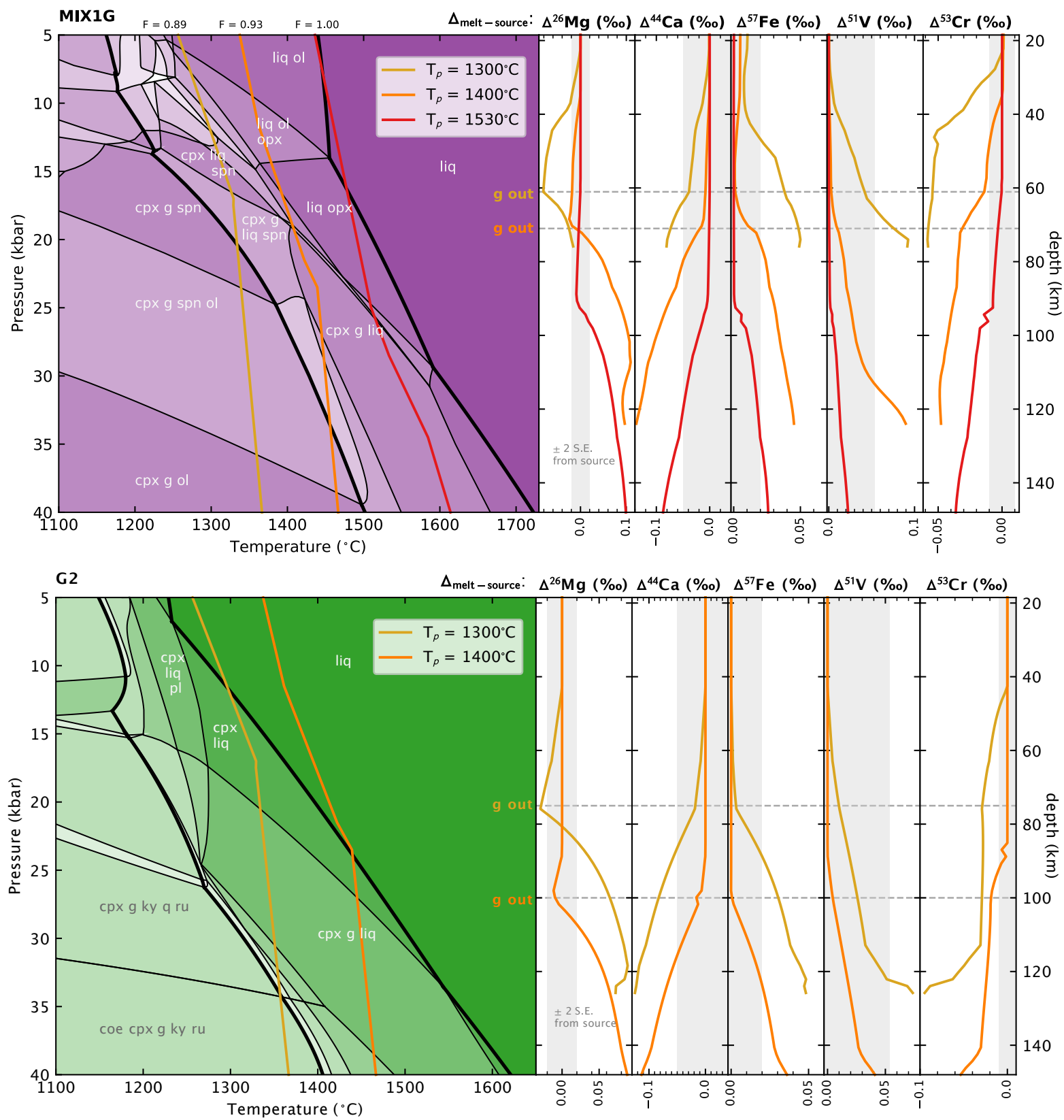

Figure 5: As in Fig. 2, the left hand panels show the pseudosections calculated in THERMOCALC for MIX1G (top) and G2 (bottom) pyroxenites, with the solidus and liquidus marked in bold. Isentropic melting paths for peridotite calculated using THERMOCALC for $\mathrm{T}_{p}=1300^{\circ} \mathrm{C}, 1400^{\circ} \mathrm{C}$ and $1530^{\circ} \mathrm{C}$ are superimposed. For MIX1G, maximum melt fractions $(\mathrm{F})$ are marked at the top of each isentrope (for G2 $\mathrm{F}=1$ ). The right hand panels show the modelled instantaneous equilibrium melt isotopic fractionation relative to the bulk isotopic composition $\left(\Delta_{\text {melt-source }}\right)$ along the isentropes. The $\mathrm{T}_{p}=1530^{\circ} \mathrm{C}$ isentrope has not been shown on $\mathrm{G} 2$ as the isentrope sits hotter than the liquidus. Key mineralogical controls on the isotopic composition of the melt are highlighted (colour-coded by the isentropic path they refer to). Vertical grey bars show the source composition $(0 \%$ for convenience) with typical 2 S.E. sample error for each isotope system - see Table S2 for details.

these melts are generated in the garnet stability field (garnet generally imparts a large isotopic fractionation compared to olivine and pyroxene; see full results in Appendix). While we find that $\mathrm{V}$ stable isotopes are predicted to have no direct sensitivity to different source lithologies 
(because the modelled $\Delta^{51} \mathrm{~V}_{\text {melt-source }}$ for peridotite and pyroxenite lithologies are both similar to each other and well within current analytical precision), our results show that $\mathrm{Fe}, \mathrm{Cr}, \mathrm{Ca}$ and Mg could show some direct sensitivity to mantle lithology (Fig. S13). Progressive melting of a garnet-bearing source (such as G2, or MIX1G at depth) produces the opposite sense of meltsource isotope fractionation in $\mathrm{Mg}$ and $\mathrm{Ca}$ isotopes (both in direction, i.e., positive or negative $\Delta_{\text {melt-source }}$, and trend, i.e., $\Delta_{\text {melt-source }}$ becoming more negative or more positive; Figs. 2,5 ) due to the presence of isotopically light and heavy garnet respectively $\left(\Delta^{26} \mathrm{Mg}_{\text {garnet-source }} \sim\right.$ $-0.3 \%$; $\Delta^{44} \mathrm{Ca}_{\text {garnet-source }} \sim 0.25 \%$ ). Therefore, if lithological heterogeneity (specifically, the proportion of garnet in a melt source) is the principal control on the chemical heterogeneity of a suite of basalts, the two isotope systems should show a negative correlation. This relationship is shown in Fig. 6 for MIX1G melts. Fig. 6 also shows how the isotopic compositions of the melts might be predicted to relate to a more traditional geochemical tracer of garnet in the source region, Sm/Yb ratio (e.g., Pertermann et al., 2004; details of the calculation in Appendix Section 7), and similar patterns would be predicted for other garnet tracers such as $\mathrm{Dy} / \mathrm{Yb}$ (Fig. S10). The correlation between Ca isotopes and garnet-sensitive trace element ratios is in agreement with measurements and predictions by Wang et al. (2019); Antonelli et al. (2021). Magnesium-Ca isotope systematics of basalts could therefore have future potential as a tracer of garnet (hence, depth of melting and/or lithological heterogeneity) in the mantle source, as predicted for both stable isotope systems individually (e.g., Stracke et al., 2018; Kang et al., 2019; Wang et al., 2019; Dai et al., 2020; Antonelli et al., 2021).

However, further work on the effect of garnet on $\Delta^{44} \mathrm{Ca}$ melt-source by taking garnet composition into account, following measurements by Chen et al. (2020a) and predicted compositiondependent $\beta^{\mathrm{Ca}}$ from Antonelli et al. (2019), is required. We note that Antonelli et al. (2019) predict that composition-dependent isotope fractionation effects ('concentration effects') for other mineral solid solutions (olivine, pyroxene) are smaller using their PBE (Perdew, Burke, Ernzerhof) functionals to calculate $\beta$ relative to previous studies that have employed different approaches (LDA functionals; e.g., Feng et al., 2014; Wang et al., 2017), which supports only small concentration effects in garnet. Currently, typical analytical precision on $\mathrm{Ca}$ isotope measurements (long-term external 2 S.D. of $\delta^{44} \mathrm{Ca}=0.14 \%$ on the SRM915b standard, although typical 2 S.E. on measurements of individual samples is smaller, average 0.05\%, Chen et al., 2019; Dai et al., 2020) precludes some of the predicted equilibrium variability in $\Delta^{44} \mathrm{Ca}_{\text {melt-source }}$ due to 


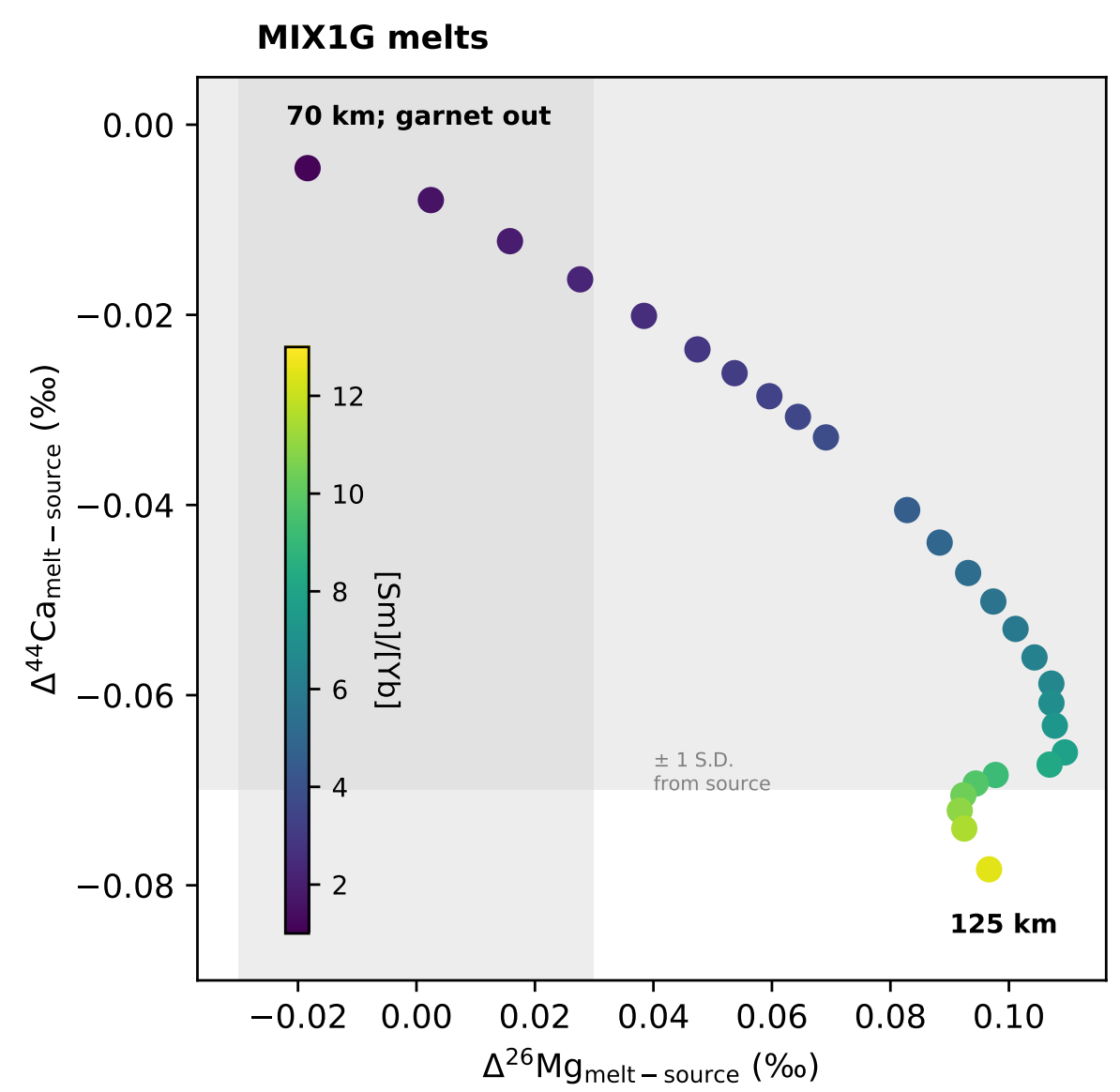

Figure 6: Instantaneous equilibrium melt-source $\mathrm{Mg}$ and $\mathrm{Ca}$ stable isotope fractionation for MIX1G melts produced at depths greater than $70 \mathrm{~km}$ (i.e., where garnet is present in the source) along a peridotitic isentropic decompression melting path $\left(\mathrm{T}_{p}=1400^{\circ} \mathrm{C}\right)$. Grey shading shows the source $(0 \% 0) \pm$ typical 1 S.D. long-term analytical error (Table S2). Details of trace element modelling in Section 7 of the Appendix.

the presence of garnet from being resolved (Fig. 6). However, as analytical precision improves, the garnet signature in $\mathrm{Mg}-\mathrm{Ca}$ isotopes could be further tested.

However, whether melts from pyroxenite lithologies will ultimately be resolvable in an erupted melt will depend on two factors in addition to the direct mineralogic control: the bulk isotope composition of a pyroxenite lithology relative to peridotite, and the amount of each element that each of the melting lithologies contributes to the final melt.

\subsection{Resolving pyroxenite source components in erupted melts}

Fig. 7 shows the results of mass balance calculations for the aggregate bulk melt-source isotope fractionation of a multi-lithologic mantle relative to a pure pyroxenite source, with varying proportions of pyroxenite. The peridotite lithology is taken to have a bulk isotope composition 
equal to BSE (see Fig. 5 caption for data sources; isotopic reference materials used are DSM3, SRM915a, IRMM-014, AA, NIST979 for Mg-Ca-Fe-V-Cr respectively); pyroxenite lithologies are taken to have a bulk isotope composition of average MORB for each isotope, except for Cr where no known MORB data are published and the modelled aggregate KLB1 melt isotope composition for $\mathrm{T}_{p}=1300^{\circ} \mathrm{C}$ is used. Full details of the mass balance calculation are found in Section 9 of the Appendix. The right hand panels show the same data referenced to the pure peridotite melt, allowing a simple assessment of the required analytical precision if pyroxenite is to be detected by each system. Fig. S14 shows the same data as Fig. 7, instead scaled to typical current 1 S.D. analytical precision. Each isotope system is shown with a range of isotope compositions, reflecting two end-member conditions of thermal behaviour of the pyroxenite in multi-lithologic mantle. The bold line reflects a pyroxenite decompressing along a peridotite decompression path, as used in Fig. 5. This approximation will be most valid for small (< $10 \%$ ) pyroxenite fractions. The other end-member is pyroxenite following its own decompression melting path (the paths shown in Figs. S10 and S11). We acknowledge that these results are still an approximation, as peridotite is assumed to be melting along its own geotherm regardless of pyroxenite fraction. From Figs. 7 and S14, we find that none of the considered isotope systems will be able to resolve the presence of minor (less than $\sim 5 \%$ ) pyroxenite components in mantle source regions, given levels of current analytical precision as given in Table S2.

\subsubsection{Isotope systems with minimal sensitivity to pyroxenite: $\mathrm{V}$ and Ca}

Our results show that the presence of even moderate amounts of pyroxenite in the mantle source cannot be resolved using $\mathrm{V}$ stable isotopes, assuming a MORB-like bulk pyroxenite isotope composition. This result is consistent with Novella et al. (2020) who show that $\delta^{51} \mathrm{~V}$ cannot detect pyroxenite in the source of Reykjanes Ridge basalts. Given the similar predicted $\mathrm{V}$ isotope compositions of pyroxenite and peridotite melts, with pyroxenite fractions up to $40 \%$ producing bulk melt isotope compositions that only differ from a peridotite source by $<0.03 \%$ (Fig. 7), improvements in $\mathrm{V}$ stable isotope analytical precision are unlikely to make $\mathrm{V}$ isotopes sensitive to the pyroxenite lithologies modelled here.

We also predict that partial melting of peridotite and pyroxenite produces unresolvable Ca isotopic fractionation relative to the source (for peridotite, $\Delta^{44} \mathrm{Ca}$ melt-source smaller than $-0.09 \%$; 


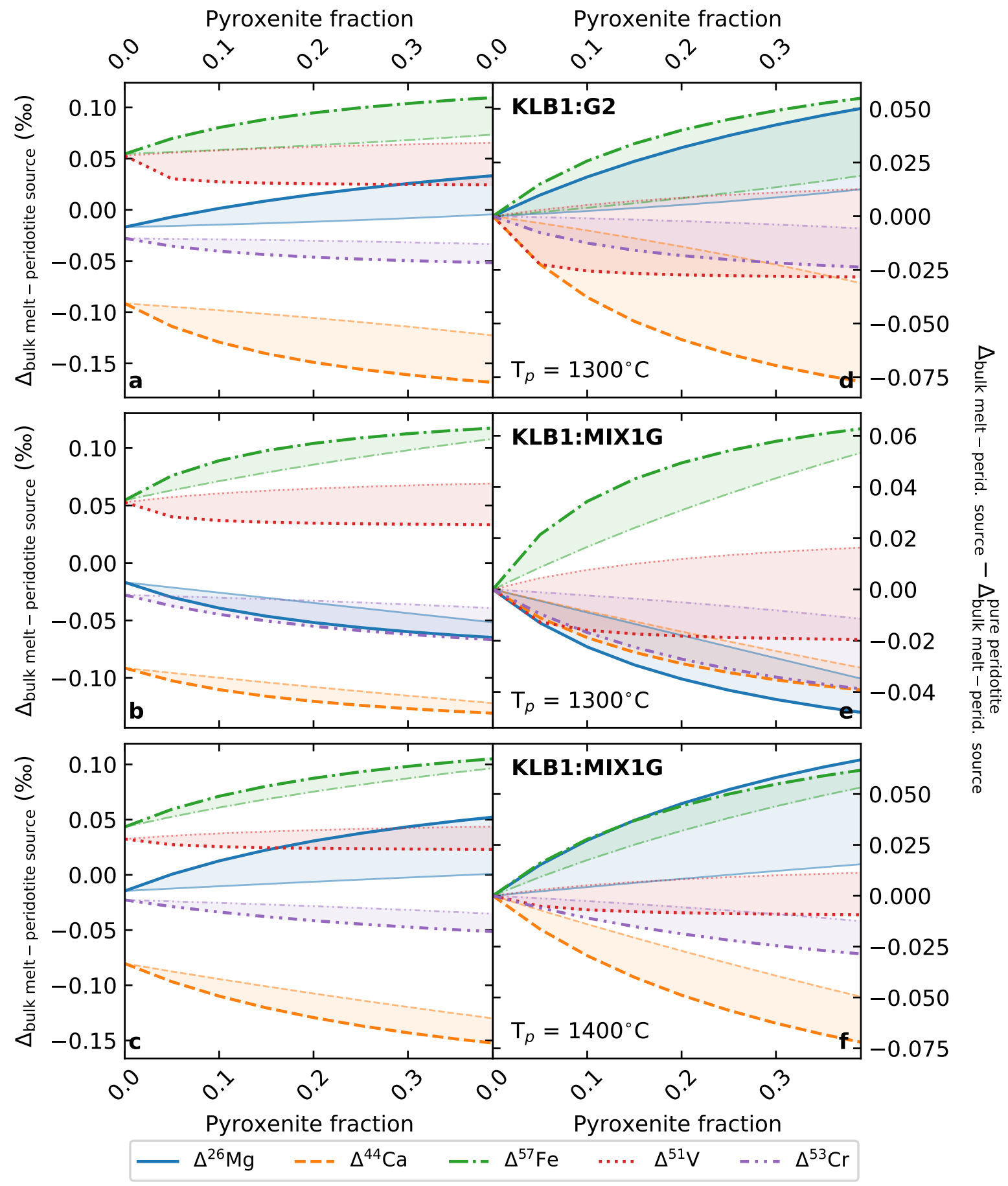

Figure 7: Aggregate bulk melt isotope fractionation (relative to a pure peridotite source, left hand panels; relative to pure peridotite melt; right hand panels) for multi-lithologic mantle. At each $\mathrm{T}_{p}$, the aggregate melt composition (including isotope composition, and element proportion) at the average pressure and temperature of melting for each lithology is used to calculate the resulting bulk melt isotope composition by mass balance. A range of bulk melt-source isotope fractionations are given for each isotope system, reflecting two endmembers for the thermal behaviour of pyroxenite upwelling in a peridotite host. The bolder line represents the case for pyroxenite following peridotite geotherms (as used throughout this study); the paler line reflects pyroxenite following its own geotherm, as in Figs. S10 and S11. 
Fig. 2, in agreement with Kang et al., 2017; Chen et al., 2019 but smaller than $\Delta^{44} \mathrm{Ca}_{\text {melt-residue }}$ $=-0.09--0.2 \%$ suggested by Zhu et al., 2018; Ionov et al., 2019; Chen et al., 2020b). Although bulk MORB-like pyroxenite may have an isotopically lighter composition than peridotite (see Fig. 8), which is further amplified by negative melt-source isotopic fractionation to produce pyroxenite melts that are isotopically lighter than peridotite melts, Fig. 7 suggests that Ca isotope ratios measured with current typical long-term uncertainty will only be able to detect MORB-like pyroxenite in a mantle source if the proportion of pyroxenite is greater than $30 \%$ (which may be unrealistic of multi-lithologic mantle, e.g., Sobolev et al., 2005; Pietruszka et al., 2013; Shorttle et al., 2014; Matthews et al., 2016; Brown et al., 2020). When considering a current best 2 S.E., this detection limit only improves to $\sim 20 \%$ of pyroxenite in the source. The small variability in melt isotope ratios with increasing pyroxenite fraction compared to resolvable variability is consistent with DMM, EM1 and HIMU basalts recording no resolvable $\delta^{44} \mathrm{Ca}$ variability (Valdes et al., 2014), and measured mantle pyroxenites and associated peridotites recording indistinguishable $\delta^{44} \mathrm{Ca}$ (Dai et al., 2020). However, even a small improvement in analytical precision could enable greater sensitivity to pyroxenite fraction: for example Figs. 7a and S14 show that $~ 15 \%$ of G2 pyroxenite in a mantle source produces an isotopic offset in the bulk melt of $-0.05 \%$ relative to a pure peridotite source. Given that the typical 2 S.E. for $\delta^{44} \mathrm{Ca}$ is around $0.05 \%$ (Table S2), there is potential for these small pyroxenite fraction signatures to be theoretically resolved with only minor improvements in analytical precision. We note that currently resolvable variability in the measured $\delta^{44} \mathrm{Ca}$ of igneous rocks is found (specifically in ultramafic rocks including dunites and komatiites), but that pyroxenite source contributions are not proposed to be the origin of this $\delta^{44} \mathrm{Ca}$ heterogeneity (Antonelli and Simon, 2020).

\subsubsection{Distinguishing lithologies: $\mathrm{Fe}, \mathrm{Mg}, \mathrm{Cr}$}

The Fe isotope variability of MORB and OIB has been previously linked to source heterogeneity (e.g., Williams and Bizimis, 2014; Konter et al., 2016; Nebel et al., 2019; Sun et al., 2020; Zhong et al., 2021), through the inherent (initial; presumably derived from its formation or protolith) Fe isotope compositions of the different source components, rather than directly through any large mineralogy-dependent partial melting Fe isotope fractionation. Consistent with these conclusions, we find that the calculated partial melting $\Delta^{57} \mathrm{Fe}$ fractionations are small $(\lesssim 0.06 \%$ ) 
for peridotite and pyroxenite lithologies (in agreement with previous studies, e.g., Dauphas et al., 2009; Williams and Bizimis, 2014; Sossi et al., 2016; Gleeson et al., 2020; Soderman et al., 2021). We also find that the main driver of melt Fe isotope ratio sensitivity to pyroxenite fraction (Fig. 7) is the expectation that MORB-like pyroxenite will have a heavier bulk Fe isotope ratio than peridotite, which in combination with a positive melt-source isotopic fractionation drives pyroxenite melts to heavier isotope compositions than peridotite melts. The contribution of high $\delta^{57} \mathrm{Fe}$ pyroxenite melts (from both $\mathrm{SD}$ and $\mathrm{SE}$ pyroxenites) compared to melting of a pure peridotite source is resolvable at greater than $8-9 \%$ pyroxenite with current typical 1 S.D. (Figs. 7, S14), making Fe isotopes one of the most sensitive systems to source considered here, although it should be noted that equilibrium isotopic fractionation associated with pyroxenite sources cannot generate the full range of natural stable isotope OIB data from a single stage melting model (Soderman et al., 2021, see Section 5). For G2 pyroxenite however, the choice of thermal behaviour of the pyroxenite (i.e., whether the upwelling pyroxenite component follows a peridotite or pyroxenite decompression path) strongly affects the sensitivity to pyroxenite fraction. At high proportions of G2 pyroxenite, when a pyroxenite decompression path becomes more appropriate, the multi-lithologic mantle melt may no longer be resolvable from a pure peridotite source (Fig. 7d).

In agreement with most existing studies (e.g., Teng et al., 2007, 2010; Huang et al., 2011a; Stracke et al., 2018), but in contrast to Zhong et al. (2017), we find that partial melting of peridotite produces unresolvable $\mathrm{Mg}$ isotopic fractionation $\left(\Delta^{26} \mathrm{Mg}<0.02 \%\right.$; Fig. 2). Melting of MIX1G and G2 pyroxenite lithologies produces larger magnitude melt-source fractionations than peridotite (Fig. 5) due to the presence of isotopically light garnet and isotopically heavy clinopyroxene in the source, in varying proportions over P-T space (Fig. S1). By comparison, olivine and orthopyroxene, which dominate peridotite melting, have less extreme $\delta^{26} \mathrm{Mg}$ compositions. The presence of garnet producing more extreme isotopic fractionations than a non-garnet-bearing source is consistent with melting models from Stracke et al. (2018); however, a key difference is that the modelled melting of garnet pyroxenite by Stracke et al. (2018) produces isotopically light melts (i.e., a negative $\Delta_{\text {melt-source), compared to the mostly isotopically }}$ heavy $\left(\Delta_{\text {melt-source }}>0 \%\right.$ melts at depths where garnet is present in the source in this model (Fig. 5). This difference in behaviour is due to the choice of initial $\alpha_{\text {melt-source }}=1$ in Stracke et al. (2018). We do not use this initial condition, and in the melting assemblage considered 
here, garnet is largely a residual phase (i.e., not contributing to melting), and therefore initial melts are isotopically heavy relative to the source. Both models agree that with progressive melting of isotopically light garnet in the source, melts will become isotopically lighter. Some isotopically light (i.e., $\Delta^{26} \mathrm{Mg}_{\text {melt-source }}<0 \%$ ) melts are produced by melting G2 and MIX1G in this model, but these are at depths where garnet is nearly or completely absent from the stable assemblage (Fig. 5). It is this garnet effect that is responsible for the opposite behaviours of $\Delta^{26} \mathrm{Mg}$ melt-source in Fig. $7 \mathrm{~d}, \mathrm{f}$ compared to Fig. 7e: the aggregate pyroxenite melt sits in the spinel stability field for MIX1G at $\mathrm{T}_{p}=1300^{\circ} \mathrm{C}$ (Fig. $7 \mathrm{~b}$ ), but in the garnet stability field for MIX1G at $\mathrm{T}_{p}=1400{ }^{\circ} \mathrm{C}$ (Fig. 7c) and $\mathrm{G} 2$ at $\mathrm{T}_{p}=1300^{\circ} \mathrm{C}$ (Fig. 7d). Melting of multi-lithologic mantle (with MIX1G pyroxenite) is resolvable from pure peridotite at current 1 S.D. at $\sim 10-15 \%$ pyroxenite fraction (Fig. S14); our results show that Mg isotopes are more sensitive to MIX1G than G2 pyroxenite. With continued improvements in analytical precision, such as the $0.02 \% 02$ S.E. reported by Wang et al. (2021), pyroxenite fractions $<10 \%$ could be resolved in the $\mathrm{Mg}$ isotope composition of the bulk melt, as a $10 \%$ pyroxenite fraction produces a bulk melt $>0.02 \%$ different from a pure peridotite melt (Figs. 7e, f).

Chromium stable isotope fractionation during partial melting of different lithologies is relatively understudied compared to $\mathrm{Mg}$ and Fe, however Fig. 7 shows that melt $\mathrm{Cr}$ isotopic composition could show resolvable sensitivity to the fraction of pyroxenite in the source. This is due both to variable modelled melting fractionations dependent on lithology, and comparatively small analytical uncertainty. Equilibrium Cr stable isotope fractionation is controlled by both bonding environment and redox conditions (e.g., Shen et al., 2018, 2020; Bonnand et al., 2020). Chromium stable isotope fractionation during partial melting of peridotite is probably small (magnitude of $\Delta^{53} \mathrm{Cr}<0.07 \%$; Schoenberg et al., 2016; Xia et al., 2017; Shen et al., 2018; Bonnand et al., 2020), in agreement with our results. Isotopically heavy spinel, where present, has a large influence on the isotopic fractionation between melt and residue due to the compatibility of $\mathrm{Cr}$ in spinel, and this has been used to explain observations from peridotite xenoliths that partial melting appears to generate isotopically light melts $\left(\Delta^{53} \mathrm{Cr}_{\text {melt-source }}<0\right)$ and heavy residues (Xia et al., 2017; Shen et al., 2020). However, due to the small area of the KLB1 melting regime in which spinel is stable in our model (Figs. 2, S4), spinel does not control the magnitude of stable isotope fractionation associated with melting in this case. We find a slightly larger magnitude of melting-induced Cr stable isotope fractionation for MIX1G pyroxenite than 
for peridotite (as large as $-0.06 \%$ ). Like MIX1G, G2 pyroxenite melts all have a negative $\Delta^{53} \mathrm{Cr}$ with respect to the source, with melting fractionations as large as $\Delta^{53} \mathrm{Cr}=-0.1 \%$ (Fig. 5). This is because the main $\mathrm{Cr}$ bearing phase in much of the melting region is isotopically heavy (relative to olivine) clinopyroxene, and this produces consistently isotopically light melts, consistent with observations by Xia et al. (2017); Shen et al. (2020). Therefore, combined with a predicted bulk pyroxenite isotope composition that is also isotopically lighter than peridotite, bulk melts are predicted to become progressively $\mathrm{Cr}$-isotopically lighter with increasing pyroxenite fraction in the mantle source. This effect is generally small $(<0.04 \%$ offset from pure peridotite melts even at $30 \%$ pyroxenite; Fig. 7) and at current typical 2 S.D. is only resolvable at more than $20 \%$ MIX1G in the source at comparatively low temperatures $\left(\mathrm{T}_{p}=1300^{\circ} \mathrm{C}\right)$. However, as with $\mathrm{Mg}$, recent improvements in analytical precision for $\mathrm{Cr}$ isotopes (Sossi et al., 2018; Wagner et al., 2021) may permit greater sensitivity to pyroxenite components: for a 2 S.E. of $0.01 \%$, multi-lithologic mantle melts become resolvable from pure peridotite melts at around $8 \%$ pyroxenite upwards, assuming upwelling pyroxenite follows the peridotite geotherm (Figs. 7, S14).

\section{Comparisons to natural data}

Fig. 8 shows how literature MORB and OIB data compare to modelled melts. The modelled melts are filtered for those produced at cooler temperatures than the $\mathrm{T}_{p}=1530^{\circ} \mathrm{C}$ peridotite isentrope for a given pressure, to limit the contribution of unrealistic high melt fraction and high pressure melts. The same potential temperature isentrope has been chosen for all lithologies for consistency, although because of its fusibility this filter includes some $100 \%$ melts of G2 at all pressures. Natural samples are filtered for those with $7.2<\mathrm{MgO}(\mathrm{wt} \%)<16$ to minimise the effects of fractional crystallisation and olivine accumulation, which can result in measurable isotopic fractionations in several isotope systems (e.g., Sossi et al., 2016; McCoy-West et al., 2018; Nebel et al., 2019; Shen et al., 2020). The KLB1 melts are shown as the calculated melting fractionation applied to an accessible mantle isotopic composition (presumptive bulk silicate earth, BSE); G2 and MIX1G melts are shown as the melting fractionation applied to the average fresh MORB isotopic composition, since G2 is a MORB-like eclogite in composition. For $\mathrm{Cr}$, where we can find no published MORB data, we use the isotope ratio of BSE + the 
aggregate $\mathrm{KLB} 1$ melt isotope ratio for $\mathrm{T}_{p}=1300^{\circ} \mathrm{C}$ (Fig. 4) to predict the isotopic composition of fresh MORB, and reference G2 and MIX1G melts to this value.

\subsection{Can peridotite melting explain MORB $\mathrm{Mg}-\mathrm{Ca}-\mathrm{Fe}-\mathrm{V}$ isotope ratios?}

The mean MORB Mg isotope ratio agrees well with the average peridotite melt produced (BSE plus the melt-source isotope fractionation) when $\mathrm{T}_{p}=1300^{\circ} \mathrm{C}$. The mean MORB Ca and V isotope ratios are also well within analytical uncertainty of the average peridotite melt produced (BSE plus the melt-source isotope fractionation) when $\mathrm{T}_{p}=1300^{\circ} \mathrm{C}$ (see Figs. 4,8 ), since both $\mathrm{Ca}$ and $\mathrm{V}$ have relatively large analytical uncertainties. For Fe, the isotope ratios of mean MORB and average peridotite melt at $\mathrm{T}_{p}=1300{ }^{\circ} \mathrm{C}$ agree just within analytical uncertainty, requiring almost the maximum long-term error on natural sample measurements to match. Considering typical 2 S.E. analytical precision, mean MORB $\delta^{57} \mathrm{Fe}$ are slightly higher than predicted by the model even when considering only extremely small melt fractions (hence maximum partial melting isotopic fractionation). This discrepancy could be due to the effect of fractional crystallisation on the Fe isotope ratio of melts, since even high $\mathrm{MgO}$ MORB are almost never primary liquids (e.g., Langmuir et al., 1992), and fractional crystallisation produces isotopically heavy residual melts compared to the primary liquid (Teng et al., 2008; Chen et al., 2019b). Sossi et al. (2016) use a fractional crystallisation correction on the MORB dataset and calculate an average primitive MORB liquid with $\delta^{57} \mathrm{Fe}=0.10 \%$, compared to $0.15 \%$ in the uncorrected (and non-MgO filtered) dataset (maximum correction on individual samples is $\sim 0.07 \%$ ). This result matches well with our calculated average peridotite melt at $\mathrm{T}_{p}=1300^{\circ} \mathrm{C}$. However, the fractional crystallisation correction applied by Sossi et al. (2016) (e.g., $\Delta^{57} \mathrm{Fe}_{\text {ol-melt }} \sim-0.18 \%$ at $\mathrm{T}=1200^{\circ} \mathrm{C}$ ) is likely to represent the maximum limit of isotopic fractionation during olivine differentiation (Soderman et al., 2021).

In addition to comparing our results with mean MORB isotope compositions, we also examine how the ranges of measured MORB stable isotope compositions (for the systems Mg-Ca-FeV) compares to the spread of modelled melts. MORB samples have a wider range of isotopic compositions than the equilibrium KLB1 model melts (Fig. 8). In the Ca isotope system, some of this variability may be attributed to analytical uncertainty on measurements: here the width of the measured distributions of MORB data are within long-term analytical precision of 

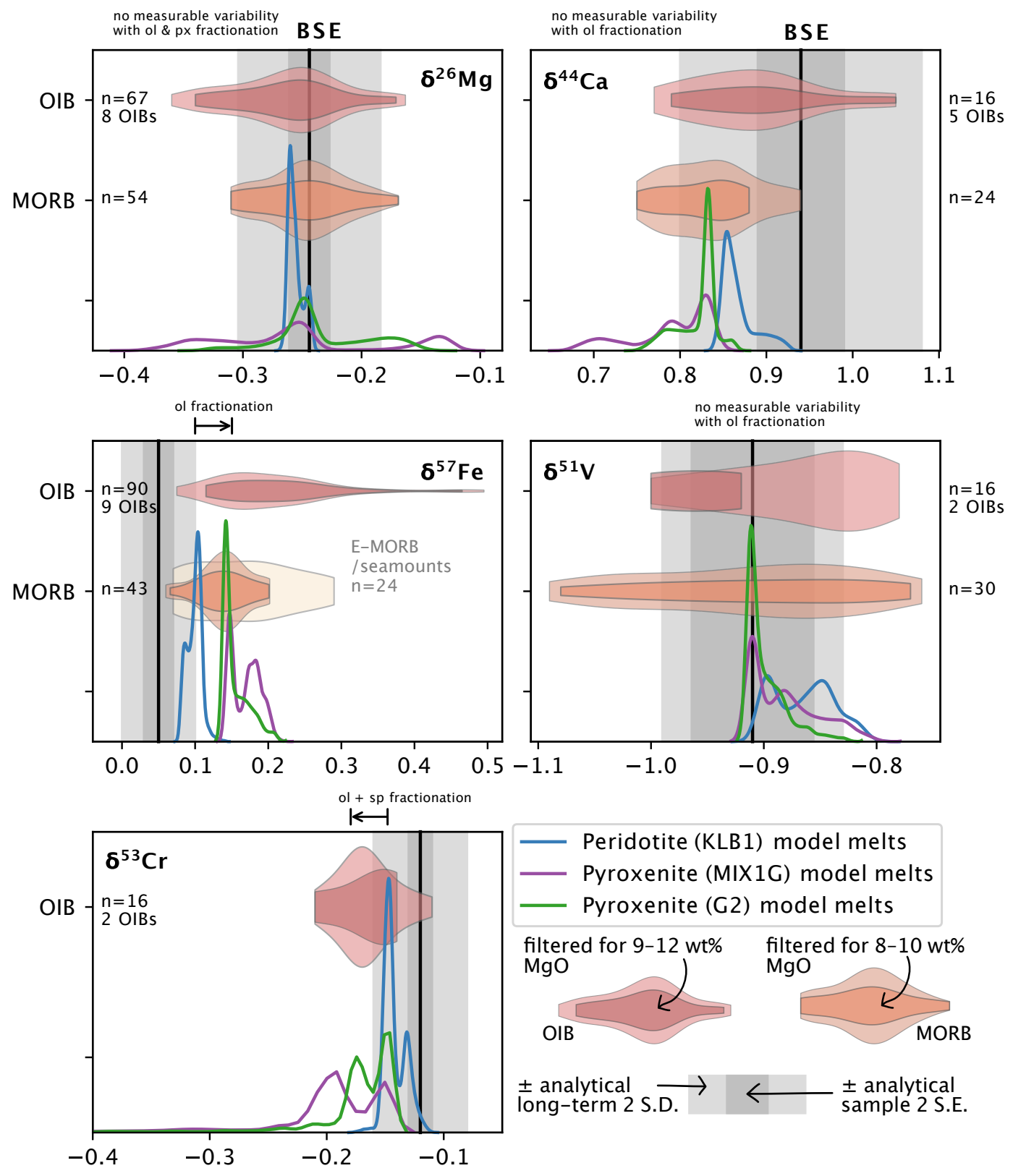

Figure 8: Literature MORB (N- and T- MORB, if classification is known) and OIB data for the isotope systems (data sources in Table S1), compared to the model instantaneous melts (all data shown as \%o variation from the reference materials outlined in Fig. 1). Samples are filtered for $7.2<\mathrm{MgO}$ wt $\%<16$, but included if $\mathrm{MgO}$ is not known. ' $n$ ' refers to the total number of samples included, and the number of OIBs given shows how many unique ocean island settings are sampled. The central darker violin shows a more limited subset of samples: 9-12 wt $\% \mathrm{MgO}$ in OIB, $8-10$ wt $\% \mathrm{MgO}$ in MORB, to highlight isotope compositions of the most primitive lavas. Ca and $\mathrm{Mg}$ isotope data is filtered to exclude samples with ${ }^{87} \mathrm{Sr} /{ }^{86} \mathrm{Sr}>0.7037$, which excludes samples with $>1 \%$ carbonate component in the source (Huang et al., 2011b). Modelled melts are filtered for those cooler than the $\mathrm{T}_{p}=1530^{\circ} \mathrm{C}$ peridotite isentrope at any given pressure. KLB1 melts are shown assuming a bulk source isotope composition of BSE; G2 and MIX1G melts are shown assuming a bulk source isotope composition of average MORB (for Cr, the isotope ratio of BSE + the aggregate KLB1 melt isotope ratio for $\mathrm{T}_{p}=1300^{\circ} \mathrm{C}$ is used due to the lack of published MORB data). BSE values are $\delta^{26} \mathrm{Mg}=-0.24 \%$ (Stracke et al., 2018), $\delta^{44} \mathrm{Ca}=0.94 \%$ (Kang et al., 2017; Chen et al., 2019), $\delta^{57} \mathrm{Fe}=0.05 \%$ (Sossi et al., 2016), $\delta^{51} \mathrm{~V}=-0.91 \%$ (Qi et al., 2019), $\delta^{53} \mathrm{Cr}$ $=-0.12 \%$ (Jerram et al., 2020). The pale outer shaded grey region shows typical long term 2 S.D. analytical uncertainty in recent studies, the darker inner shaded grey region shows typical sample 2 S.E. (S.E. $=$ S.D. $/ \sqrt{n}$ ) in recent studies (see Table 1). The fractionation arrows for $\mathrm{Fe}$ and $\mathrm{Cr}$ isotopes represent the direction and approximate magnitude of isotopic fractionation associated with differentiation to form samples with minimum 7 wt \% MgO. Fractionation information from Sossi et al. (2016) for Fe, Teng et al. (2007, 2010); Wang et al. (2021) for Mg, Zhang et al. (2018) for Ca, Shen et al. (2020) for Cr, Ding et al. (2020) for V. 
the modelled KLB1 melt compositions (although, the errors on individual sample Ca isotope measurements are smaller and hence cannot account for all the difference between MORB and peridotite melts). In the $\mathrm{Fe}, \mathrm{Mg}$ and $\mathrm{V}$ systems, the variability of measured MORB isotope compositions relative to the single-stage equilibrium peridotite melts is greater than can be explained by analytical uncertainty alone (Sossi et al., 2016) - this is particularly evident in $\delta^{51} \mathrm{~V}$ (Fig. 8). Stable isotope fractionation during differentiation may play a role, as discussed for Fe isotopes above, but $\mathrm{V}$ isotopes are not thought to be significantly fractionated by olivine differentiation (Prytulak et al., 2013; Ding et al., 2020). Fractional crystallisation of clinopyroxene and Fe-Ti oxides, although unlikely for the MgO-filtered data here, is shown to drive melts to higher $\delta^{51} \mathrm{~V}$ (Wu et al., 2018; Ding et al., 2020), which may explain some of the samples with high $\delta^{51} \mathrm{~V}$. However, the isotopically light (relative to BSE) MORB $\delta^{51} \mathrm{~V}$ values remain unexplained by our calculations of peridotite melting. For Fe, even with a large Fe isotope fractionation correction applied (up to $0.07 \%$ for some MORB samples; Sossi et al., 2016) some MORB samples with extreme high $\delta^{57} \mathrm{Fe}$ values still remain isotopically heavy relative to modelled KLB1 melts that we consider most realistic of mantle melting (Soderman et al., 2021; see also Chen et al., 2019b). We find that neither long-term analytical uncertainty nor equilibrium peridotite partial melting from realistic regions of P-T space (see Fig. 6 in Soderman et al., 2021) can reproduce the heaviest MORB Fe isotope ratios.

The Mg-Ca-Fe- $\mathrm{V}-\mathrm{Cr}$ stable isotope compositions of mantle-derived melts are not expected to show large heterogeneity as a consequence of the mantle potential temperature variability (with associated changes in mineralogy and melt redox state; Fig. 4) of around $220^{\circ} \mathrm{C}$ known from major and trace element studies in MORB (Klein and Langmuir, 1987; Langmuir et al., 1992; Gale et al., 2014). Therefore, we do not predict that the differences in either mean MORB stable isotope composition or the variance in MORB isotope ratios from predicted peridotite melts generated at $\mathrm{T}_{p}=1300^{\circ} \mathrm{C}$ can be explained by potential temperature variability. Instead, additional processes beyond single-stage equilibrium peridotite partial melting are required to explain the full range of $\mathrm{Mg}-\mathrm{Ca}-\mathrm{Fe}-\mathrm{V}$ stable isotope ratios of MORB. In some cases, the addition of single-stage pyroxenite melts (derived from a source with a MORB-like bulk isotope composition) may explain some of the MORB range, and small amounts of pyroxenite in the MORB source is consistent with conclusions using other tracers of lithological heterogeneity (e.g., Zindler et al., 1984; Langmuir et al., 1986; Castillo et al., 2000; Waters et al., 2011). For 
example, $10 \%$ pyroxenite in the MORB source (at $\mathrm{T}_{p}=1300^{\circ} \mathrm{C}$ ) could produce melts with $\delta^{26} \mathrm{Mg}=0.02 \%$ and $\delta^{44} \mathrm{Ca}=0.04 \%$ (using G2 pyroxenite) lower than, and $\delta^{57} \mathrm{Fe}=0.03 \%$ higher than (using MIX1G pyroxenite), pure peridotite melts (Fig. 7), explaining some but not all of the MORB data range for these three isotope systems. However, some of the MORB Fe isotope data (including the seamounts and E-MORB data), would require the source of pyroxenite melts to be isotopically fractionated relative to a protolith of pristine MORB $(\sim 0.05-0.15 \%$ heavier than mean MORB to explain the full range of data, depending on proportion of pyroxenite contributing to the final melt and P-T conditions of melting). A pyroxenite component in the MORB source that is isotopically fractionated from pristine recycled MORB has previously been proposed to explain MORB Fe and Mg isotope data (Sun et al., 2020; Zhong et al., 2021). Multi-stage melting processes and reaction of pyroxenite-derived melts with ambient peridotite have also been proposed to fractionate the bulk Fe isotope composition of mantle pyroxenite away from that of the subducted material (e.g., Konter et al., 2016; Nebel et al., 2019; Sun et al., 2020 ), although achieving the suggested large isotopic fractionations (e.g., $\Delta^{57} \mathrm{Fe}_{\text {melt-source }} \geq$ $0.1 \%$; Konter et al., 2016) during repeated partial melting events may be unrealistic (Soderman et al., 2021).

We note that the large range in MORB $\mathrm{V}$ isotope ratios cannot be explained by pyroxenite in the source, and that the lowest $\delta^{44} \mathrm{Ca}$ pyroxenite melts (which appear able to explain the full range of Ca isotope MORB data not matched by peridotite melting, Fig. 8) are only generated at pressures $>35 \mathrm{kbar}$. For $\mathrm{T}_{p}=1300^{\circ} \mathrm{C}$, pyroxenite fractions in the MORB source would need to be $\geq 40 \%$ to match all the Ca isotope MORB data (Fig. 7); alternatively, a pyroxenite component with a bulk isotope composition $\sim 0.05 \%$ lighter than average pristine MORB could reduce the pyroxenite fraction required in the source to explain the Ca isotope data to lower levels. While the ${ }^{87} \mathrm{Sr} /{ }^{86} \mathrm{Sr}$ filter we use where $\mathrm{Sr}$ isotope data is available attempts to remove effects from recycled carbonates, we also note that since marine carbonates can have very light $\delta^{44} \mathrm{Ca}$ (up to $2 \%$ lighter than BSE; e.g., DePaolo, 2004; Fantle and DePaolo, 2005; Antonelli and Simon, 2020), a contribution from recycled carbonates could also be involved in the generation of light Ca isotopic compositions of basalts, as reported by e.g., Huang et al. (2011b); Liu et al. (2017a).

The range of $\mathrm{Mg}-\mathrm{Ca}-\mathrm{Fe}-\mathrm{V}$ isotopic compositions of MORB with respect to modelled equilibrium 
melts leaves open the possibility of disequilibrium processes playing a role in the erupted stable isotope composition of MORB. Disequilibrium associated with melt transport can arise as low melt fractions are extracted from the mantle and rapidly migrate (Faul, 2001; Connolly et al., 2009), as has been recorded using U-series disequilibria in MORB (e.g., McKenzie, 1985; Lundstrom, 2003; Van Orman et al., 2006), and could be responsible for some major element trends in the global MORB dataset (Oliveira et al., 2020). As disequilibrium during melt extraction and transport is related to the timescales of chemical diffusion of major and trace elements in the melt, disequilibrium could generate kinetic (rather than equilibrium) stable isotope fractionation as seen in chemical diffusion studies (e.g., Richter et al., 2003, 2009; Watkins et al., 2017). Disequilibrium processes could therefore influence both the isotopic composition of melt source regions via metasomatism, and the isotopic composition of melts as they migrate and erupt. In samples recording kinetic isotope fractionation signatures, the direction of isotopic fractionation from the source isotope ratio will be the same for all isotope systems which behave similarly during mantle melting, as the light isotopes of a given element will diffuse faster than the heavier isotopes of the same element (e.g., Dauphas, 2007; Richter et al., 2008, 2009; Teng et al., 2011), and the recorded isotopic fractionation should scale with the mass of the isotopes considered. Kinetic processes in melts can produce much larger isotopic fractionations than equilibrium processes (see Watkins et al., 2017) even for small concentration gradients in the diffusing element (and therefore can be seen even in the diffusion of major elements in silicate melts; Richter et al., 2003; Xiao et al., 2013; Watkins et al., 2014; Kang et al., 2020). We would expect to see positive correlations between all isotope ratios measured for the same samples if their isotope ratio was controlled by kinetic fractionation and chemical diffusion during disequilibrium (for pairs of elements diffusing in the same direction, such as solid to melt), as reported in e.g., Zhao et al. (2017a,b); Kang et al. (2020). Key pairs of isotopes to investigate to identify a kinetic vs equilibrium process recorded in suites of natural samples would be those that behave similarly (from an elemental perspective) during partial melting but would show opposite directions of isotopic fractionation from the source under equilibrium conditions (e.g., Fe and $\mathrm{Ca}$, with positive and negative melt-source isotopic fractionation respectively). Supporting this prediction, kinetic effects during metasomatism have been proposed to generate positively correlated $\delta^{44} \mathrm{Ca}-\delta^{57} \mathrm{Fe}$ values measured in ultramafic rocks (with a low $\delta^{44} \mathrm{Ca}, \delta^{57} \mathrm{Fe}$ metasomatic endmember; Zhao et al., 2017a). 
Low temperature alteration (relative to mantle temperatures) could also be responsible for causing significant stable isotope variability in measured MORB. Due to the $1 / \mathrm{T}^{2}$ dependence of equilibrium stable isotope fractionations (Bigeleisen and Mayer, 1947), low temperature processes generate larger magnitude isotope fractionation effects than magmatic processes. For example, Fe leaching during hydrothermal fluid circulation is generally shown to preferentially remove light Fe isotopes from the host rock, recorded in low $\delta^{57} \mathrm{Fe}$ hydrothermal fluids (e.g., Rouxel et al., 2003; Severmann et al., 2004). Correspondingly high $\delta^{57} \mathrm{Fe}$ is measured in heavily leached basalts (up to $2.05 \%$ with $80 \%$ Fe loss; Rouxel et al., 2003), although Rouxel et al. (2003) also show that on a scale larger than a few metres, bulk hydrothermally altered oceanic crust is indistinguishable in $\delta^{57} \mathrm{Fe}$ from MORB. Without significant Fe loss, altered crust may not show such extreme Fe isotope variations (Williams et al., 2009), although alteration can generate measurable Fe isotope fractionation in komatiites (Dauphas et al., 2010). By contrast, Ca isotope data from mid-ocean ridge hydrothermal fluids suggest that the fluids and MORB have similar $\delta^{44} \mathrm{Ca}$ (Schmitt et al., 2003; Amini et al., 2008; Scheuermann et al., 2018). A Mg isotope study of altered oceanic crust from the East Pacific Rise also shows that limited bulk rock $\mathrm{Mg}$ isotope fractionation occurs during alteration, irrespective of alteration temperature (Huang et al., 2015), but we note that the measured $\delta^{26} \mathrm{Mg}$ range of altered crustal samples does exceed the range of MORB data. Altered oceanic crust also records MORB-like $\delta^{51} \mathrm{~V}$ (Wu et al., 2018), and Prytulak et al. (2013) show that $\delta^{51} \mathrm{~V}$ is generally insensitive to the range of common alteration processes (serpentinisation, seafloor weathering - although an effect of increased $\delta^{51} \mathrm{~V}$ by $0.2-0.3 \%$ may be seen in extreme cases - and hydrothermal alteration) in the oceanic crust. By contrast, alteration and serpentinisation in near-surface settings generate large variations in $\delta^{53} \mathrm{Cr}$ in ultramafic rocks (Farkaš et al., 2013; Wang et al., 2016), but altered oceanic crust does not show the same isotopic variability (Wang et al., 2016). Given these studies, for the isotope systems considered here mildly altered MORB is not expected to show significant isotopic fractionation from erupted values, but given the potential for large low temperature isotopic fractionations, alteration (both of the basaltic rocks analysed and oceanic crustal material that serves as a protolith for mantle pyroxenite components) remains a consideration. 


\subsection{Understanding the diversity of OIB Mg-Ca-Fe- $\mathrm{V}-\mathrm{Cr}$ stable isotope com- positions}

For $\mathrm{Mg}, \mathrm{Ca}$ and $\mathrm{Fe}$, measured $\mathrm{OIB}$ stable isotope ratios are more variable relative to those measured in MORB (Fig. 8). This variability in OIB compared to MORB has been interpreted as a potential signature of lithological heterogeneity in the OIB source (Mg: Zhong et al., 2017; Stracke et al., 2018; Wang et al., 2018, Ca: Kang et al., 2019; Wang et al., 2019, Fe: Williams and Bizimis, 2014; Konter et al., 2016; Nebel et al., 2019; Gleeson et al., 2020). Carbonates and/or their derived melts have also been invoked for $\mathrm{Mg}$ and $\mathrm{Ca}$ isotopic heterogeneity in OIB (e.g., Huang et al., 2011b; Liu et al., 2017a; Wang et al., 2018) but this topic is not discussed here. An important caveat of interpreting data from Fig. 8 is that the ocean islands sampled for each isotope system are different, and therefore the same localities are not present in each OIB dataset - $\mathrm{Mg}, \mathrm{Ca}$ and $\mathrm{Fe}$ have data for a wider range of OIBs than $\mathrm{V}$ and $\mathrm{Cr}$, and so it is possible that more variability would be seen in both $\mathrm{V}$ and $\mathrm{Cr}$ if more OIB are explored. However, despite the wide variability, the mean OIB is analytically indistinguishable (using long-term 2 S.D.) from mean MORB for $\mathrm{Mg}$, Ca and V isotopes.

The mean measured OIB values can be explained both by modelled peridotite and pyroxenite melts for the $\mathrm{Mg}, \mathrm{Ca}, \mathrm{V}$ and $\mathrm{Cr}$ stable isotope systems. For Fe, modelled pyroxenite melts match mean OIB isotopic compositions better than peridotite melts, due to the use of mean MORB as the bulk isotopic composition for the pyroxenites, offsetting the resulting pyroxenite melts to heavier isotope ratios than peridotite melts. This potential Fe isotope signature of lithological heterogeneity in some OIB data due to a bulk isotopic offset of the source relative to ambient mantle has been suggested for several mantle plume systems (e.g., Hawaii, Williams and Bizimis, 2014; Samoa, Konter et al., 2016; Pitcairn, Nebel et al., 2019; Galapagos, Gleeson et al., 2020).

The greater diversity of OIB Mg-Ca-Fe- $\mathrm{V}-\mathrm{Cr}$ stable isotope compositions displayed in OIB compared to MORB and the modelled melts raises further questions, and we discuss only a few here. Firstly, for $\mathrm{Cr}$, the contribution of isotopically light pyroxenite melts to multi-lithologic mantle melting means that a peridotite + pyroxenite mantle source is better able to explain the measured OIB data range than pure peridotite melts, especially considering the good analytical 
precision (2 S.D. $<0.04 \%$ ) compared to sample variability achieved in the $\mathrm{Cr}$ isotope studies shown in Fig. 8. However, it is possible that the apparently better fit of a pyroxenite model seen here is instead a result of fractionation from a peridotite-derived melt, as cotectic crystallisation of olivine and spinel in basalts has been proposed to drive residual melts to lighter $\mathrm{Cr}$ isotope ratios (Shen et al., 2020). Given the MgO filter used for OIB data in Fig. 8 however, spinel crystallisation is unlikely to have affected all the OIB samples. The Cr stable isotope data therefore provide tantalising evidence for the presence of lithological heterogeneity in OIB mantle source regions, particularly in the case of the lightest measured Cr isotope compositions. Nonetheless, without equivalent MORB Cr isotope data for comparison, and with a very limited published sample set, it is difficult to confirm how well natural $\mathrm{Cr}$ isotope data matches equilibrium isotope fractionation models. Fig. 7f suggests that even $20 \%$ SD pyroxenite in a mantle source melting at $\mathrm{T}_{p}=1400{ }^{\circ} \mathrm{C}$ will produce a bulk melt only $0.02 \%$ lighter than a pure peridotite melt, which would not be able to explain the full range of $\mathrm{Cr}$ isotope OIB data. An expanded study of MORB and OIB Cr isotope ratios would be an important step in both learning more about $\mathrm{Cr}$ isotope behaviour and exploring stable isotopes as a new tool for studying mantle melting conditions, given the potential for Cr isotope sensitivity to lithology discussed in this study.

For $\mathrm{Mg}$ stable isotopes, the extra range in isotope composition displayed by OIB relative to MORB is small $(< \pm 0.05 \%)$ relative to analytical precision, and the extreme MORB and OIB isotope ratios are only resolvable from each other using a typical sample 2 S.E., rather than values quoted for long-term reproducibility (see Table S2). The pyroxenite melts show a much wider range of melt stable $\mathrm{Mg}$ isotope ratios than peridotite melts, and therefore could be contributing to the small extra variability in OIB compared to MORB: for example, Fig. 7 shows that $10-$ $20 \%$ pyroxenite could generate melt isotopic variability of $\pm 0.04-0.05 \%$ compared to a pure peridotite source. Noticeably in the Mg isotope data, and particularly in comparison to Fe, the natural data is less variable than the full range predicted for pyroxenite melts by our models (Fig. 8). This is despite the sampled OIB including St Helena, Society and the Cook-Austral Islands, thought to sample various recycled crustal components (which will form pyroxenites in the mantle) based on multiple studies including radiogenic isotopes, trace elements and other stable isotopes (e.g., Chauvel et al., 1992; Stracke et al., 2005; Kawabata et al., 2011; Teng et al., 2013; Hanyu et al., 2014). The limited Mg isotope variability in OIB compared to possible pyroxenite 
melts could relate to the location of the melting region, and the dilution of pyroxenite melts with peridotite, as highlighted in Fig. 7. For example, the most negative $\Delta^{26} \mathrm{Mg}$ melt-source for MIX1G is generated at low melt fraction close to the solidus, at temperatures of around $1200-1250{ }^{\circ} \mathrm{C}$ and pressures of $8-15 \mathrm{kbar}$, and the most positive $\Delta^{26} \mathrm{Mg}$ melt-source at depths of over $100 \mathrm{~km}$ (Fig. S1). The isotopically lightest melts are not sampled by pyroxenite decompressing along a peridotite isentrope even at $\mathrm{T}_{p}=1300^{\circ} \mathrm{C}$ (Fig. 5), and it is unlikely that deep, isotopically heavy melts will be extracted without mixing with shallower, isotopically lighter melts. This is in agreement with Fig. 7, which shows that typical aggregate melts from melting of multilithologic mantle at $1300-1400^{\circ} \mathrm{C}$ will have a much narrower range in isotopic composition than the full range of pyroxenite melts shown in Fig. 8. Therefore, the process of melt extraction and mixing from a multi-lithologic mantle will act to minimise the isotopic signature from any deep pyroxenite melts, and result in relatively homogeneous OIB $\mathrm{Mg}$ isotope ratios seen in the OIB erupted at the surface.

In contrast to the $\mathrm{Mg}$ isotope system, OIB isotope ratios for $\mathrm{Fe}, \mathrm{Ca}$ and $\mathrm{V}$ extend outside the range of any of the modelled peridotite or pyroxenite melts. For Ca and V isotopes, some OIB data fall to the opposite side of BSE than expected for mantle melting. In both cases, measurement uncertainties (particularly long-term 2 S.D.) are large and could account for all the difference between modelled melts and natural data, and it will be important to continue to improve analytical precision to better understand the natural data and be able to make comparisons between OIB sample sets, especially given the minimal sensitivity to lithology predicted for these isotope systems (Section 4.2.1). In the case of $\mathrm{V}$, fractional crystallisation of Fe-Ti oxides has been shown to drive melts up to $0.3 \%$ higher than their initial isotope composition, therefore able to match the spread of $\mathrm{V}$ isotope data to values higher than BSE, although this effect has only been recorded in basalts with $<5$ wt \% $\mathrm{MgO}$ (Wu et al., 2018; Ding et al., 2020). Therefore it is unlikely that the basalts with $\mathrm{V}$ isotope ratios heavier than BSE shown in Fig. 8 reflect Fe-Ti oxide crystallisation. For Ca, non-pyroxenitic origins of isotopic variability have been proposed for komatiite data, such as the generation of $\delta^{44} \mathrm{Ca}$ as low as $0.64 \%$ from serpentinised oceanic crust in the mantle source (John et al., 2012; Amsellem et al., 2019). If improved analytical precision confirms the Ca isotope data variability shown in Fig. 8 is real, similar non-pyroxenitic origins may be able to explain some or all of the spread of OIB data. 
For Fe, measurement uncertainties are small compared to the variability in the OIB Fe isotope data, which extends to much higher $\delta^{57} \mathrm{Fe}$ values than matched by the melts presented here (Fig. 7; see also Soderman et al., 2021). Heavier Fe stable isotope compositions than can be explained by single-stage melting of garnet-bearing lithologies are also seen in seamounts from close to the EPR (Sun et al., 2020) - the heaviest isotope ratios are found in samples with < 7 wt \% MgO, and therefore not shown in Fig. 8, but Sun et al. (2020) find that these are still isotopically heavier than can be explained by single-stage melting once they correct their samples for differentiation. One solution to explaining the heavy Fe isotope data could be to invoke a mantle source with unusually high $\delta^{57} \mathrm{Fe}$ (i.e., Fe-isotopically heavier than average MORB as assumed in Figs. 7 and 8), generated for example as a frozen melt that has been through multiple melting and remobilisation stages, and now stalled in the lithosphere. While the limitations of multiple melting events with regards to mass balance and plausible melting degrees are discussed in Soderman et al. (2021), multiple melting stages of garnet-bearing lithologies and reaction with ambient mantle have been proposed to generate the required isotopically heavy mantle sources $\left(\delta^{57} \mathrm{Fe}>0.3 \%\right)$ to explain some of the highest $\delta^{57} \mathrm{Fe}$ in the global dataset (Nebel et al., 2019; Sun et al., 2020), although based on our modelled small melt-source isotope fractionations the isotopically heaviest Fe isotope OIB data would require a mantle source with an even heavier overall bulk composition of $\delta^{57} \mathrm{Fe}>0.4 \%$. Alternatively, large stable isotope effects may be attributed to disequilibrium and/or low temperature alteration processes, as discussed for MORB above. A further possibility to explain heavy $\mathrm{Fe}$ isotope ratios in OIB could be the mixing of isotopically heavy components derived from the lower mantle (such as bridgmanite cumulates with $\delta^{57} \mathrm{Fe} \sim 0.3 \%$, Williams et al., 2021) into upwelling plumes. High $\delta^{44} \mathrm{Ca}$ lower mantle components from Ca-perovskite crystallisation related to early Earth magma ocean processes have also been proposed as the origin of isotopically heavy Ca isotope komatiite data (up to 1.54\%; Amsellem et al., 2019).

\section{Summary}

We have combined a thermodynamically self-consistent model for mantle melting of peridotite and pyroxenite with a model for equilibrium $\mathrm{Mg}-\mathrm{Ca}-\mathrm{Fe}-\mathrm{V}-\mathrm{Cr}$ stable isotope fractionation to quantitatively predict melt-source stable isotope fractionation over P-T conditions relevant to 
mantle melting at mid-ocean ridges and within mantle plumes. The results allow us to assess the potential of these stable isotope systems for investigating mantle temperature variations, source heterogeneity, and their record in the erupted basalts (MORB, OIB).

We used our results for the melting of KLB1 peridotite to explore the sensitivity of melt stable $\mathrm{Mg}-\mathrm{Ca}-\mathrm{Fe}-\mathrm{V}-\mathrm{Cr}$ isotope compositions in each isotope system to variations in mantle potential temperature. Redox-sensitive isotopes (Fe, V) show most variability in accumulated melt isotopic composition with potential temperature, due to the variation in $\mathrm{Fe}^{3+} / \mathrm{Fe}_{\mathrm{T}}$ (and $\left.\mathrm{V}^{4+, 5+} / \mathrm{V}_{\mathrm{T}}\right)$ as the average depth of melting increases with $\mathrm{T}_{p}$. The predicted variability in the $\mathrm{V}$ isotopic composition of melts is qualitatively consistent with $\delta^{51} \mathrm{~V}-\mathrm{Na} 8.0$ trends in natural data. However, analytical precision improvements upon current levels would be necessary for variability to be clearly resolved in the compositions of erupted basalts. At present, the equilibrium fractionation of the stable isotopes considered here during peridotitic mantle melting is not predicted to be a useful tool in identifying temperature variations in MORB or OIB melting regimes.

We also obtained model results for $\mathrm{Mg}-\mathrm{Ca}-\mathrm{Fe}-\mathrm{V}-\mathrm{Cr}$ fractionation during melting of MIX1G silica-deficient pyroxenite and G2 silica-excess pyroxenite. Our results show that $\mathrm{Mg}$ and $\mathrm{Ca}$ isotopes have the most sensitivity to the presence of garnet in a melt source, with melts predicted to record a negative $\mathrm{Mg}$-Ca isotope correlation if garnet is present in the mantle source, although improvements in analytical precision would be needed to clearly resolve this trend. Our results also demonstrate that $\mathrm{Fe}, \mathrm{Mg}$ and $\mathrm{Cr}$ stable isotopes are sensitive to the proportion of pyroxenite (with a MORB-like bulk isotope composition) in a mantle source, although with current analytical precision only pyroxenite fractions greater than around $10 \%$ are resolvable. Moderate improvements in analytical precision could result in Ca stable isotopes being added to this list, and potentially allow pyroxenite fractions $<10 \%$ to be identified in these isotope systems. However, Cr stable isotope partitioning in the mantle is generally understudied (both in measurements of natural samples, and studies of its bonding and fractionation in relevant mantle phases): while this system has the potential to be sensitive to lithological heterogeneity, we require improvements in the certainty of model inputs and/or more natural data to confidently use this isotopic tool in the mantle.

Comparison of the global datasets of stable isotope data for MORB and OIB with modelled 
melt isotope ratios generated by equilibrium fractionation highlight both agreements and disagreements between equilibrium melting models and measured data. Generally, mean MORB $\mathrm{Mg}-\mathrm{Ca}-\mathrm{Fe}-\mathrm{V}-\mathrm{Cr}$ stable isotope compositions, within typical long-term analytical precision, can be matched to the mean peridotite melt isotope ratio produced for a mantle potential temperature of $1300^{\circ} \mathrm{C}$. However, the range of MORB data is wide compared to modelled peridotite melts - even after analytical uncertainty on data and fractional crystallisation are considered, some MORB record stable isotope ratios that appear unable to be matched by equilibrium peridotite melting (notably in $\mathrm{Mg}, \mathrm{Fe}$ and $\mathrm{V}$, and Ca may show a similar result as measurement precision improves). Lithological heterogeneity (pyroxenite) in the MORB source can contribute to some of this variability but not all, and disequilibrium and/or low temperature processes may also be required to match the observed data. For OIB, the variability in natural data, even for isotope systems such as $\mathrm{Fe}$ and $\mathrm{Cr}$ where analytical precision is good compared to the data variability, could suggest that the involvement of pyroxenite may be recorded in the existing $\mathrm{Mg}, \mathrm{Fe}$ and $\mathrm{Cr}$ stable isotope datasets. However, differences between the range of natural data and modelled pyroxenite melts suggest that additional processes such as the offset of the isotope ratio of recycled components from pristine MORB values and kinetic fractionations may also be important in understanding the current $\mathrm{Mg}-\mathrm{Ca}-\mathrm{Fe}-\mathrm{V}-\mathrm{Cr}$ stable isotope datasets available for primitive global oceanic basalts.

We conclude that stable isotopes in basalts have variable potential as a tracer of heterogeneity in the mantle, complementing existing tools well - however there are knowledge and data gaps that need to be filled before we can use these systems to their full potential.

\section{Acknowledgements}

We thank Andreas Stracke, Michael Antonelli and an anonymous reviewer whose comments greatly improved this manuscript, and Stefan Weyer for editorial handling. C. R. S. also thanks William Miller for valuable discussions throughout this project, Tim Holland for support with THERMOCALC, and Michael Carpenter and Ross Angel for helpful guidance regarding ionic bonding models. This work was supported by a NERC Studentship NE/L002507/1 to C.R.S., and ERC Consolidator Grant 306655 'HabitablePlanet', a NERC Consortia Grant ('Deep Volatiles' 
NE/M000303/1) and a NERC Standard Grant (NE/V000411/1) to H.M.W.

\section{References}

Agranier, A., Blichert-Toft, J., Graham, D., Debaille, V., Schiano, P. and Albarède, F. (2005), 'The spectra of isotopic heterogeneities along the mid-Atlantic Ridge', Earth and Planetary Science Letters 238(1-2), 96-109.

Allègre, C. J., Hamelin, B. and Dupré, B. (1984), 'Statistical analysis of isotopic ratios in MORB: the mantle blob cluster model and the convective regime of the mantle', Earth and Planetary Science Letters 71(1), 71-84.

Allègre, C. J. and Turcotte, D. L. (1986), 'Implications of a two-component marble-cake mantle', Nature 323(6084), 123-127.

Amini, M., Eisenhauer, A., Böhm, F., Fietzke, J., Bach, W., Garbe-Schönberg, D., Rosner, M., Bock, B., Lackschewitz, K. S. and Hauff, F. (2008), 'Calcium isotope $(\delta 44 / 40 \mathrm{Ca})$ fractionation along hydrothermal pathways, Logatchev field (Mid-Atlantic Ridge, $14^{\circ} 45^{\prime}$ N)', Geochimica et Cosmochimica Acta 72(16), 41074122.

Amsellem, E., Moynier, F. and Puchtel, I. S. (2019), 'Evolution of the Ca isotopic composition of the mantle', Geochimica et Cosmochimica Acta 258, 195-206.

Anenburg, M. and O'Neill, H. S. C. (2019), 'Redox in Magmas: Comment on a Recent Treatment of the Kaiserstuhl Volcanics (Braunger et al., Journal of Petrology, 59, 1731-1762, 2018) and Some Other Misconceptions', Journal of Petrology 60(9), 1825-1832.

Antonelli, M. A., Kendrick, J., Yakymchuk, C., Guitreau, M., Mittal, T. and Moynier, F. (2021), 'Calcium isotope evidence for early Archaean carbonates and subduction of oceanic crust', Nature Communications 12(1), 1-8.

Antonelli, M. A., Schiller, M., Schauble, E. A., Mittal, T., DePaolo, D. J., Chacko, T., Grew, E. S. and Tripoli, B. (2019), 'Kinetic and equilibrium Ca isotope effects in high-T rocks and minerals', Earth and Planetary Science Letters 517, 71-82.

Antonelli, M. A. and Simon, J. I. (2020), 'Calcium isotopes in high-temperature terrestrial processes', Chemical Geology 548, 119651.

Arevalo Jr, R. and McDonough, W. F. (2010), 'Chemical variations and regional diversity observed in MORB', Chemical Geology 271(1-2), 70-85.

Asimow, P. D. (2002), 'Steady-state mantle-melt interactions in one dimension: II. Thermal interactions and irreversible terms', Journal of Petrology 43(9), 1707-1724.

Asimow, P. D., Hirschmann, M. M. and Stolper, E. M. (2001), 'Calculation of peridotite partial melting from thermodynamic models of minerals and melts, IV. Adiabatic decompression and the composition and mean properties of mid-ocean ridge basalts', Journal of Petrology 42(5), 963-998. 
Ball, P. W., White, N. J., Maclennan, J. and Stephenson, S. N. (2021), 'Global influence of mantle temperature and plate thickness on intraplate volcanism', Nature Communications 12(1), 1-13.

Bell, D. R. and Rossman, G. R. (1992), 'Water in Earth's mantle: the role of nominally anhydrous minerals', Science 255(5050), 1391-1397.

Berry, A. J., O'Neill, H. S. C. and Foran, G. J. (2021), 'The effects of temperature and pressure on the oxidation state of chromium in silicate melts', Contributions to Mineralogy and Petrology 176(5), 1-14.

Bezard, R., Fischer-Gödde, M., Hamelin, C., Brennecka, G. A. and Kleine, T. (2016), 'The effects of magmatic processes and crustal recycling on the molybdenum stable isotopic composition of mid-ocean ridge basalts', Earth and Planetary Science Letters 453, 171-181.

Bigeleisen, J. and Mayer, M. G. (1947), 'Calculation of equilibrium constants for isotopic exchange reactions', The Journal of Chemical Physics 15(5), 261-267.

Bo, T., Katz, R. F., Shorttle, O. and Rudge, J. F. (2018), 'The melting column as a filter of mantle trace-element heterogeneity', Geochemistry, Geophysics, Geosystems 19(12), 4694-4721.

Bonnand, P., Doucelance, R., Boyet, M., Bachèlery, P., Bosq, C., Auclair, D. and Schiano, P. (2020), 'The influence of igneous processes on the chromium isotopic compositions of Ocean Island basalts', Earth and Planetary Science Letters 532, 116028.

Brandl, P. A., Regelous, M., Beier, C. and Haase, K. M. (2013), 'High mantle temperatures following rifting caused by continental insulation', Nature Geoscience 6(5), 391-394.

Brewer, A. W., Teng, F.-Z. and Mullen, E. (2018), 'Magnesium isotopes as a tracer of crustal materials in volcanic arc magmas in the Northern Cascade Arc', Frontiers in Earth Science 6, 21.

Brown, E. L. and Lesher, C. E. (2016), 'REEBOX PRO: A forward model simulating melting of thermally and lithologically variable upwelling mantle', Geochemistry, Geophysics, Geosystems 17(10), 3929-3968.

Brown, E. L., Petersen, K. D. and Lesher, C. E. (2020), 'Markov chain Monte Carlo inversion of mantle temperature and source composition, with application to Reykjanes Peninsula, Iceland', Earth and Planetary Science Letters 532, 116007.

Canil, D. (1999), 'Vanadium partitioning between orthopyroxene, spinel and silicate melt and the redox states of mantle source regions for primary magmas', Geochimica et Cosmochimica Acta 63(3-4), 557-572.

Castillo, P. R., Klein, E., Bender, J., Langmuir, C., Shirey, S., Batiza, R. and White, W. (2000), 'Petrology and $\mathrm{Sr}, \mathrm{Nd}$, and $\mathrm{Pb}$ isotope geochemistry of mid-ocean ridge basalt glasses from the $1145^{\prime} \mathrm{N}$ to $1500^{\prime} \mathrm{N}$ segment of the East Pacific Rise', Geochemistry, Geophysics, Geosystems 1(11).

Chauvel, C., Hofmann, A. W. and Vidal, P. (1992), 'HIMU-EM: the French Polynesian connection', Earth and Planetary Science Letters 110(1-4), 99-119. 
Chen, C., Ciazela, J., Li, W., Dai, W., Wang, Z., Foley, S. F., Li, M., Hu, Z. and Liu, Y. (2020b), 'Calcium isotopic compositions of oceanic crust at various spreading rates', Geochimica et Cosmochimica Acta 278, 272-288.

Chen, C., Dai, W., Wang, Z., Liu, Y., Li, M., Becker, H. and Foley, S. F. (2019), 'Calcium isotope fractionation during magmatic processes in the upper mantle', Geochimica et Cosmochimica Acta 249, 121-137.

Chen, C., Huang, J.-X., Foley, S. F., Wang, Z., Moynier, F., Liu, Y., Dai, W. and Li, M. (2020a), 'Compositional and pressure controls on calcium and magnesium isotope fractionation in magmatic systems', Geochimica et Cosmochimica Acta 290, 257-270.

Chen, S., Niu, Y., Guo, P., Gong, H., Sun, P., Xue, Q., Duan, M. and Wang, X. (2019b), 'Iron isotope fractionation during mid-ocean ridge basalt (MORB) evolution: Evidence from lavas on the East Pacific Rise at $10^{\circ} 30^{\prime} \mathrm{N}$ and its implications', Geochimica et Cosmochimica Acta 267, 227-239.

Cohen, R. S. and O'Nions, R. K. (1982), 'Identification of recycled continental material in the mantle from Sr, $\mathrm{Nd}$ and $\mathrm{Pb}$ isotope investigations', Earth and Planetary Science Letters 61(1), 73-84.

Connolly, J. A. D., Schmidt, M. W., Solferino, G. and Bagdassarov, N. (2009), 'Permeability of asthenospheric mantle and melt extraction rates at mid-ocean ridges', Nature 462(7270), 209-212.

Dai, W., Wang, Z., Liu, Y., Chen, C., Zong, K., Zhou, L., Zhang, G., Li, M., Moynier, F. and Hu, Z. (2020), 'Calcium isotope compositions of mantle pyroxenites', Geochimica et Cosmochimica Acta 270, 144-159.

Dalton, C. A., Langmuir, C. H. and Gale, A. (2014), 'Geophysical and geochemical evidence for deep temperature variations beneath mid-ocean ridges', Science 344(6179), 80-83.

Dasgupta, R., Jackson, M. G. and Lee, C.-T. A. (2010), 'Major element chemistry of ocean island basaltsConditions of mantle melting and heterogeneity of mantle source', Earth and Planetary Science Letters 289(34), 377-392.

Dauphas, N. (2007), 'Diffusion-driven kinetic isotope effect of Fe and Ni during formation of the Widmanstätten pattern', Meteoritics \& Planetary Science 42(9), 1597-1613.

Dauphas, N., Craddock, P. R., Asimow, P. D., Bennett, V. C., Nutman, A. P. and Ohnenstetter, D. (2009), 'Iron isotopes may reveal the redox conditions of mantle melting from Archean to Present', Earth and Planetary Science Letters 288(1-2), 255-267.

Dauphas, N., Teng, F.-Z. and Arndt, N. T. (2010), 'Magnesium and iron isotopes in 2.7 Ga Alexo komatiites: mantle signatures, no evidence for Soret diffusion, and identification of diffusive transport in zoned olivine', Geochimica et Cosmochimica Acta 74(11), 3274-3291.

Davis, F. A., Humayun, M., Hirschmann, M. M. and Cooper, R. S. (2013), 'Experimentally determined mineral/melt partitioning of first-row transition elements (FRTE) during partial melting of peridotite at 3 GPa', Geochimica et Cosmochimica Acta 104, 232-260. 
Davis, F. A., Tangeman, J. A., Tenner, T. J. and Hirschmann, M. M. (2009), 'The composition of KLB-1 peridotite', American Mineralogist 94(1), 176-180.

Day, J. M. D. and Hilton, D. R. (2011), 'Origin of 3He/4He ratios in HIMU-type basalts constrained from Canary Island lavas', Earth and Planetary Science Letters 305(1-2), 226-234.

Day, J. M. D., Pearson, D. G., Macpherson, C. G., Lowry, D. and Carracedo, J.-C. (2009), 'Pyroxenite-rich mantle formed by recycled oceanic lithosphere: Oxygen-osmium isotope evidence from Canary Island lavas', Geology 37(6), 555-558.

DePaolo, D. J. (2004), 'Calcium isotopic variations produced by biological, kinetic, radiogenic and nucleosynthetic processes', Reviews in Mineralogy and Geochemistry 55(1), 255-288.

Devey, C. W., Garbe-Schönberg, C.-D., Stoffers, P., Chauvel, C. and Mertz, D. F. (1994), 'Geochemical effects of dynamic melting beneath ridges: Reconciling major and trace element variations in Kolbeinsey (and global) mid-ocean ridge basalt', Journal of Geophysical Research: Solid Earth 99(B5), 9077-9095.

Ding, X., Helz, R. T., Qi, Y. and Huang, F. (2020), 'Vanadium isotope fractionation during differentiation of Kilauea Iki lava lake, Hawaii', Geochimica et Cosmochimica Acta 289, 114-129.

Donnelly, K. E., Goldstein, S. L., Langmuir, C. H. and Spiegelman, M. (2004), 'Origin of enriched ocean ridge basalts and implications for mantle dynamics', Earth and Planetary Science Letters 226(3-4), 347-366.

Dupuy, C., Barsczus, H. G., Liotard, J. M. and Dostal, J. (1988), 'Trace element evidence for the origin of ocean island basalts: an example from the Austral Islands (French Polynesia)', Contributions to Mineralogy and Petrology 98(3), 293-302.

Fantle, M. S. and DePaolo, D. J. (2005), 'Variations in the marine Ca cycle over the past 20 million years', Earth and Planetary Science Letters 237(1-2), 102-117.

Farkaš, J., Chrastnỳ, V., Novák, M., Čadkova, E., Pašava, J., Chakrabarti, R., Jacobsen, S. B., Ackerman, L. and Bullen, T. D. (2013), 'Chromium isotope variations $(\delta 53 / 52 \mathrm{Cr})$ in mantle-derived sources and their weathering products: Implications for environmental studies and the evolution of $\delta 53 / 52 \mathrm{Cr}$ in the Earth's mantle over geologic time', Geochimica et Cosmochimica Acta 123, 74-92.

Faul, U. H. (2001), 'Melt retention and segregation beneath mid-ocean ridges', Nature 410(6831), 920-923.

Feng, C., Qin, T., Huang, S., Wu, Z. and Huang, F. (2014), 'First-principles investigations of equilibrium calcium isotope fractionation between clinopyroxene and Ca-doped orthopyroxene', Geochimica et Cosmochimica Acta 143, $132-142$.

Fornari, D. J., Perfit, M. R., Allan, J. F. and Batiza, R. (1988), 'Small-scale heterogeneities in depleted mantle sources: near-ridge seamount lava geochemistry and implications for mid-ocean-ridge magmatic processes', Nature 331(6156), 511-513. 
Gale, A., Escrig, S., Gier, E. J., Langmuir, C. H. and Goldstein, S. L. (2011), 'Enriched basalts at segment centers: The Lucky Strike (37 17' N) and Menez Gwen (37 50' N) segments of the Mid-Atlantic Ridge', Geochemistry, Geophysics, Geosystems 12(6).

Gale, A., Langmuir, C. H. and Dalton, C. A. (2014), 'The global systematics of ocean ridge basalts and their origin', Journal of Petrology 55(6), 1051-1082.

Gale, A., Laubier, M., Escrig, S. and Langmuir, C. H. (2013), 'Constraints on melting processes and plume-ridge interaction from comprehensive study of the FAMOUS and North Famous segments, Mid-Atlantic Ridge', Earth and Planetary Science Letters 365, 209-220.

Gill, J., Michael, P., Woodcock, J., Dreyer, B., Ramos, F., Clague, D., Kela, J., Scott, S., Konrad, K. and Stakes, D. (2016), 'Spatial and temporal scale of mantle enrichment at the Endeavour Segment, Juan de Fuca Ridge', Journal of Petrology 57(5), 863-896.

Gleeson, M. L. M. and Gibson, S. A. (2019), 'Crustal controls on apparent mantle pyroxenite signals in oceanisland basalts', Geology 47(4), 321-324.

Gleeson, M. L. M., Gibson, S. A. and Williams, H. M. (2020), 'Novel insights from Fe-isotopes into the lithological heterogeneity of Ocean Island Basalts and plume-influenced MORBs', Earth and Planetary Science Letters 535.

Hanyu, T., Kawabata, H., Tatsumi, Y., Kimura, J.-I., Hyodo, H., Sato, K., Miyazaki, T., Chang, Q., Hirahara, Y., Takahashi, T. et al. (2014), 'Isotope evolution in the HIMU reservoir beneath St. Helena: Implications for the mantle recycling of U and Th', Geochimica et Cosmochimica Acta 143, 232-252.

Hauri, E. H. (1996), 'Major-element variability in the Hawaiian mantle plume', Nature 382(6590), 415-419.

Hauri, E. H. and Hart, S. R. (1993), 'ReOs isotope systematics of HIMU and EMII oceanic island basalts from the south Pacific Ocean', Earth and Planetary Science Letters 114(2-3), 353-371.

Hekinian, R., Thompson, G. and Bideau, D. (1989), 'Axial and off-axial heterogeneity of basaltic rocks from the East Pacific Rise at $12^{\circ} 35^{\prime} \mathrm{N}-12^{\circ} 51^{\prime} \mathrm{N}$ and $11^{\circ} 26^{\prime} \mathrm{N}-11^{\circ} 30^{\prime} \mathrm{N}^{\prime}$, Journal of Geophysical Research: Solid Earth 94(B12), 17437-17463.

Herzberg, C. (2011), 'Identification of source lithology in the Hawaiian and Canary Islands: Implications for origins', Journal of Petrology 52(1), 113-146.

Herzberg, C. and Asimow, P. D. (2008), 'Petrology of some oceanic island basalts: PRIMELT2. XLS software for primary magma calculation', Geochemistry, Geophysics, Geosystems 9(9).

Herzberg, C. and Asimow, P. D. (2015), 'PRIMELT 3 MEGA. XLSM software for primary magma calculation: peridotite primary magma $\mathrm{MgO}$ contents from the liquidus to the solidus', Geochemistry, Geophysics, Geosystems 16(2), 563-578. 
Herzberg, C., Asimow, P. D., Arndt, N., Niu, Y., Lesher, C. M., Fitton, J. G., Cheadle, M. J. and Saunders, A. D. (2007), 'Temperatures in ambient mantle and plumes: Constraints from basalts, picrites, and komatiites', Geochemistry, Geophysics, Geosystems 8(2).

Herzberg, C. and Gazel, E. (2009), 'Petrological evidence for secular cooling in mantle plumes', Nature 458(7238), 619-622.

Hirschmann, M. M., Asimow, P. D., Ghiorso, M. S. and Stolper, E. M. (1999), 'Calculation of peridotite partial melting from thermodynamic models of minerals and melts. III. Controls on isobaric melt production and the effect of water on melt production', Journal of Petrology 40(5), 831-851.

Hirschmann, M. M., Aubaud, C. and Withers, A. C. (2005), 'Storage capacity of $\mathrm{H}_{2} \mathrm{O}$ in nominally anhydrous minerals in the upper mantle', Earth and Planetary Science Letters 236(1-2), 167-181.

Hirschmann, M. M. and Stolper, E. M. (1996), 'A possible role for garnet pyroxenite in the origin of the "garnet signature" in MORB', Contributions to Mineralogy and Petrology 124(2), 185-208.

Hirth, G. and Kohlstedt, D. L. (1996), 'Water in the oceanic upper mantle: implications for rheology, melt extraction and the evolution of the lithosphere', Earth and Planetary Science Letters 144(1-2), 93-108.

Hofmann, A. W. (1997), 'Mantle geochemistry: the message from oceanic volcanism', Nature 385(6613), 219-229.

Hofmann, A. W. (2003), 'Sampling mantle heterogeneity through oceanic basalts: isotopes and trace elements', Treatise on geochemistry $\mathbf{2}, 568$.

Hofmann, A. W. and White, W. M. (1982), 'Mantle plumes from ancient oceanic crust', Earth and Planetary Science Letters 57(2), 421-436.

Holland, T. J. B., Green, E. C. R. and Powell, R. (2018), 'Melting of Peridotites through to Granites: A Simple Thermodynamic Model in the System KNCFMASHTOCr', Journal of Petrology 59(5), 881-900.

Holland, T. J. B. and Powell, R. (2011), 'An improved and extended internally consistent thermodynamic dataset for phases of petrological interest, involving a new equation of state for solids', Journal of Metamorphic Geology $\mathbf{2 9}(3), 333-383$.

Hu, Y., Teng, F.-Z. and Ionov, D. A. (2020), 'Magnesium isotopic composition of metasomatized upper sub-arc mantle and its implications to Mg cycling in subduction zones', Geochimica et Cosmochimica Acta 278, 219234 .

Huang, F., Chen, L., Wu, Z. and Wang, W. (2013), 'First-principles calculations of equilibrium Mg isotope fractionations between garnet, clinopyroxene, orthopyroxene, and olivine: implications for Mg isotope thermometry', Earth and Planetary Science Letters 367, 61-70.

Huang, F., Zhang, Z., Lundstrom, C. C. and Zhi, X. (2011a), 'Iron and magnesium isotopic compositions of peridotite xenoliths from Eastern China', Geochimica et Cosmochimica Acta 75(12), 3318-3334. 
Huang, F., Zhou, C., Wang, W., Kang, J. and Wu, Z. (2019), 'First-principles calculations of equilibrium Ca isotope fractionation: Implications for oldhamite formation and evolution of lunar magma ocean', Earth and Planetary Science Letters 510, 153-160.

Huang, J., Ke, S., Gao, Y., Xiao, Y. and Li, S. (2015), 'Magnesium isotopic compositions of altered oceanic basalts and gabbros from IODP site 1256 at the East Pacific Rise', Lithos 231, 53-61.

Huang, S., Farkaš, J. and Jacobsen, S. B. (2011b), 'Stable calcium isotopic compositions of Hawaiian shield lavas: evidence for recycling of ancient marine carbonates into the mantle', Geochimica et Cosmochimica Acta 75(17), 4987-4997.

Ionov, D. A., Qi, Y.-H., Kang, J.-T., Golovin, A. V., Oleinikov, O. B., Zheng, W., Anbar, A. D., Zhang, Z.-F. and Huang, F. (2019), 'Calcium isotopic signatures of carbonatite and silicate metasomatism, melt percolation and crustal recycling in the lithospheric mantle', Geochimica et Cosmochimica Acta 248, 1-13.

Jackson, M. G. and Dasgupta, R. (2008), 'Compositions of HIMU, EM1, and EM2 from global trends between radiogenic isotopes and major elements in ocean island basalts', Earth and Planetary Science Letters 276(12), $175-186$.

Jackson, M. G., Weis, D. and Huang, S. (2012), 'Major element variations in Hawaiian shield lavas: Source features and perspectives from global ocean island basalt (OIB) systematics', Geochemistry, Geophysics, Geosystems 13(9)

Janney, P. E., Le Roex, A. P. and Carlson, R. W. (2005), 'Hafnium isotope and trace element constraints on the nature of mantle heterogeneity beneath the central Southwest Indian Ridge (13 E to 47 E)', Journal of Petrology 46(12), 2427-2464.

Jennings, E. S. and Holland, T. J. B. (2015), 'A simple thermodynamic model for melting of peridotite in the system NCFMASOCr', Journal of Petrology 56(5), 869-892.

Jennings, E. S., Holland, T. J. B., Shorttle, O., Maclennan, J. and Gibson, S. A. (2016), 'The composition of melts from a heterogeneous mantle and the origin of ferropicrite: application of a thermodynamic model', Journal of Petrology 57(11-12), 2289-2310.

Jerram, M., Bonnand, P., Kerr, A. C., Nisbet, E. G., Puchtel, I. S. and Halliday, A. N. (2020), 'The $\delta^{53}$ Cr isotope composition of komatiite flows and implications for the composition of the bulk silicate Earth', Chemical Geology 551, 119761.

Jiang, Q., Merle, R. E., Jourdan, F., Olierook, H. K. H., Chiaradia, M., Evans, K. A., Wang, X.-C., Conway, C. E., Bostock, H. C. and Wysoczanski, R. J. (2021), 'Origin of geochemically heterogeneous mid-ocean ridge basalts from the Macquarie Ridge Complex, SW Pacific', Lithos 380, 105893.

John, T., Gussone, N., Podladchikov, Y. Y., Bebout, G. E., Dohmen, R., Halama, R., Klemd, R., Magna, T. and Seitz, H.-M. (2012), 'Volcanic arcs fed by rapid pulsed fluid flow through subducting slabs', Nature Geoscience 5(7), 489-492. 
Kang, J.-T., Ionov, D. A., Liu, F., Zhang, C.-L., Golovin, A. V., Qin, L.-P., Zhang, Z.-F. and Huang, F. (2017), 'Calcium isotopic fractionation in mantle peridotites by melting and metasomatism and Ca isotope composition of the Bulk Silicate Earth', Earth and Planetary Science Letters 474, 128-137.

Kang, J.-T., Ionov, D. A., Zhu, H.-L., Liu, F., Zhang, Z.-F., Liu, Z. and Huang, F. (2019), 'Calcium isotope sources and fractionation during melt-rock interaction in the lithospheric mantle: Evidence from pyroxenites, wehrlites, and eclogites', Chemical Geology 524, 272-282.

Kang, J.-T., Zhou, C., Huang, J.-Y., Hao, Y.-T., Liu, F., Zhu, H.-L., Zhang, Z.-F. and Huang, F. (2020), 'Diffusion-driven Ca-Fe isotope fractionations in the upper mantle: Implications for mantle cooling and melt infiltration', Geochimica et Cosmochimica Acta 290, 41-58.

Katz, R. F. and Rudge, J. F. (2011), 'The energetics of melting fertile heterogeneities within the depleted mantle', Geochemistry, Geophysics, Geosystems 12(10).

Katz, R. F., Spiegelman, M. and Langmuir, C. H. (2003), 'A new parameterization of hydrous mantle melting', Geochemistry, Geophysics, Geosystems 4(9).

Kawabata, H., Hanyu, T., Chang, Q., Kimura, J.-I., Nichols, A. R. and Tatsumi, Y. (2011), 'The petrology and geochemistry of St. Helena alkali basalts: evaluation of the oceanic crust-recycling model for HIMU OIB', Journal of Petrology 52(4), 791-838.

Kimura, J.-I. and Sano, S. (2012), 'Reactive melt flow as the origin of residual mantle lithologies and basalt chemistries in mid-ocean ridges: Implications from the Red Hills peridotite, New Zealand', Journal of Petrology 53(8), 1637-1671.

Klein, E. M. and Langmuir, C. H. (1987), 'Global correlations of ocean ridge basalt chemistry with axial depth and crustal thickness', Journal of Geophysical Research: Solid Earth 92(B8), 8089-8115.

Kogiso, T., Hirschmann, M. M. and Frost, D. J. (2003), 'High-pressure partial melting of garnet pyroxenite: possible mafic lithologies in the source of ocean island basalts', Earth and Planetary Science Letters 216(4), 603617.

Konter, J. G., Pietruszka, A. J., Hanan, B. B., Finlayson, V. A., Craddock, P. R., Jackson, M. G. and Dauphas, N. (2016), 'Unusual $\delta^{56} \mathrm{Fe}$ values in Samoan rejuvenated lavas generated in the mantle', Earth and Planetary Science Letters 450, 221-232.

Lambart, S. (2017), 'No direct contribution of recycled crust in Icelandic basalts', Geochemical Perspectives Letters 4, 7-12.

Lambart, S., Baker, M. B. and Stolper, E. M. (2016), 'The role of pyroxenite in basalt genesis: Melt-PX, a melting parameterization for mantle pyroxenites between 0.9 and 5 GPa', Journal of Geophysical Research: Solid Earth 121(8), 5708-5735. 
Lambart, S., Laporte, D. and Schiano, P. (2013), 'Markers of the pyroxenite contribution in the major-element compositions of oceanic basalts: Review of the experimental constraints', Lithos 160, 14-36.

Langmuir, C. H., Bender, J. F. and Batiza, R. (1986), 'Petrological and tectonic segmentation of the East Pacific Rise, 5 30'-14 30' N', Nature 322(6078), 422-429.

Langmuir, C. H., Klein, E. M. and Plank, T. (1992), Petrological systematics of mid-ocean ridge basalts: constraints on melt generation beneath ocean ridges, in J. Phipps Morgan, D. K. Blackman and S. J. M, eds, 'Mantle Flow and Melt Generation at Mid-Ocean Ridges', Vol. 71, AGU American Geophysical Union, pp. 183280 .

Le Roux, V., Dasgupta, R. and Lee, C.-T. A. (2011), 'Mineralogical heterogeneities in the Earth's mantle: Constraints from Mn, Co, Ni and Zn partitioning during partial melting', Earth and Planetary Science Letters 307(3-4), 395-408.

Li, S.-G., Yang, W., Ke, S., Meng, X., Tian, H., Xu, L., He, Y., Huang, J., Wang, X.-C., Xia, Q. et al. (2017), 'Deep carbon cycles constrained by a large-scale mantle Mg isotope anomaly in eastern China', National Science Review 4(1), 111-120.

Liang, Y., Schiemenz, A., Hesse, M. A. and Parmentier, E. M. (2011), 'Waves, channels, and the preservation of chemical heterogeneities during melt migration in the mantle', Geophysical Research Letters 38(20).

Liu, B. and Liang, Y. (2017), 'The prevalence of kilometer-scale heterogeneity in the source region of MORB upper mantle', Science Advances 3(11), e1701872.

Liu, F., Li, X., Wang, G., Liu, Y., Zhu, H., Kang, J., Huang, F., Sun, W., Xia, X. and Zhang, Z. (2017a), 'Marine carbonate component in the mantle beneath the southeastern Tibetan Plateau: Evidence from magnesium and calcium isotopes', Journal of Geophysical Research: Solid Earth 122(12), 9729-9744.

Lundstrom, C. C. (2003), 'Uranium-series disequilibria in mid-ocean ridge basalts: observations and models of basalt genesis', Reviews in Mineralogy and Geochemistry 52(1), 175-214.

Maclennan, J. (2008), 'Lead isotope variability in olivine-hosted melt inclusions from Iceland', Geochimica et Cosmochimica Acta 72(16), 4159-4176.

Macris, C. A., Manning, C. E. and Young, E. D. (2015), 'Crystal chemical constraints on inter-mineral Fe isotope fractionation and implications for Fe isotope disequilibrium in San Carlos mantle xenoliths', Geochimica et Cosmochimica Acta 154, 168-185.

Mahoney, J. J., Sinton, J. M., Kurz, M. D., Macdougall, J. D., Spencer, K. J. and Lugmair, G. W. (1994), 'Isotope and trace element characteristics of a super-fast spreading ridge: East Pacific Rise, 13-23 S', Earth and Planetary Science Letters 121(1-2), 173-193.

Mallik, A. and Dasgupta, R. (2012), 'Reaction between morb-eclogite derived melts and fertile peridotite and generation of ocean island basalts', Earth and Planetary Science Letters 329, 97-108. 
Mallik, A., Lambart, S. and Chin, E. J. (2021), Mantle convection and surface processes, Vol. 263, Wiley Online Library, chapter 6, pp. 151-177.

Mallmann, G. and O'Neill, H. S. C. (2009), 'The crystal/melt partitioning of V during mantle melting as a function of oxygen fugacity compared with some other elements (Al, P, Ca, Sc, Ti, Cr, Fe, Ga, Y, Zr and Nb)', Journal of Petrology 50(9), 1765-1794.

Mallmann, G. and O’Neill, H. S. C. (2013), 'Calibration of an empirical thermometer and oxybarometer based on the partitioning of Sc, Y and V between olivine and silicate melt', Journal of Petrology 54(5), 933-949.

Matthews, S., Shorttle, O. and Maclennan, J. (2016), 'The temperature of the Icelandic mantle from olivine-spinel aluminum exchange thermometry', Geochemistry, Geophysics, Geosystems 17(11), 4725-4752.

Matthews, S., Wong, K., Shorttle, O., Edmonds, M. and Maclennan, J. (2021), 'Do olivine crystallization temperatures faithfully record mantle temperature variability?', Geochemistry, Geophysics, Geosystems p. e2020GC009157.

Matzen, A. K., Baker, M. B., Beckett, J. R., Wood, B. J. and Stolper, E. M. (2017), 'The effect of liquid composition on the partitioning of Ni between olivine and silicate melt', Contributions to Mineralogy and Petrology 172(3).

McCoy-West, A. J., Fitton, J. G., Pons, M.-L., Inglis, E. C. and Williams, H. M. (2018), 'The Fe and Zn isotope composition of deep mantle source regions: Insights from Baffin Island picrites', Geochimica et Cosmochimica Acta 238, 542-562

McKenzie, D. (1984), 'The generation and compaction of partially molten rock', Journal of Petrology 25(3), 713765.

McKenzie, D. (1985), 'The extraction of magma from the crust and mantle', Earth and Planetary Science Letters $\mathbf{7 4}(1), 81-91$.

McKenzie, D. and Bickle, M. J. (1988), 'The volume and composition of melt generated by extension of the lithosphere', Journal of petrology 29(3), 625-679.

McKenzie, D. and O'Nions, R. K. (1991), 'Partial melt distributions from inversion of rare earth element concentrations', Journal of Petrology 32(5), 1021-1091.

McKenzie, D. and O'Nions, R. K. (1995), 'The source regions of ocean island basalts', Journal of Petrology 36(1), 133-159.

McKenzie, D., Stracke, A., Blichert-Toft, J., Albarède, F., Grönvold, K. and O'Nions, R. K. (2004), 'Source enrichment processes responsible for isotopic anomalies in oceanic island basalts', Geochimica et Cosmochimica Acta 68(12), 2699-2724.

Mundl, A., Touboul, M., Jackson, M. G., Day, J. M. D., Kurz, M. D., Lekic, V., Helz, R. T. and Walker, R. J. (2017), 'Tungsten-182 heterogeneity in modern ocean island basalts', Science 356(6333), 66-69. 
Neave, D. A., Shorttle, O., Oeser, M., Weyer, S. and Kobayashi, K. (2018), 'Mantle-derived trace element variability in olivines and their melt inclusions', Earth and Planetary Science Letters 483, 90-104.

Nebel, O., Arculus, R. J., Sossi, P. A., Jenner, F. E. and Whan, T. H. (2013), 'Iron isotopic evidence for convective resurfacing of recycled arc-front mantle beneath back-arc basins', Geophysical Research Letters 40(22), 58495853.

Nebel, O., Sossi, P. A., Bénard, A., Arculus, R. J., Yaxley, G. M., Woodhead, J. D., Davies, D. R. and Ruttor, S. (2019), 'Reconciling petrological and isotopic mixing mechanisms in the Pitcairn mantle plume using stable Fe isotopes', Earth and Planetary Science Letters 521, 60-67.

Nebel, O., Sossi, P. A., Bénard, A., Wille, M., Vroon, P. Z. and Arculus, R. J. (2015), 'Redox-variability and controls in subduction zones from an iron-isotope perspective', Earth and Planetary Science Letters 432, 142151.

Niu, Y. and O'Hara, M. J. (2003), 'Origin of ocean island basalts: A new perspective from petrology, geochemistry, and mineral physics considerations', Journal of Geophysical Research: Solid Earth 108(B4).

Niu, Y. and O'Hara, M. J. (2008), 'Global correlations of ocean ridge basalt chemistry with axial depth: a new perspective', Journal of Petrology 49(4), 633-664.

Novella, D., Maclennan, J., Shorttle, O., Prytulak, J. and Murton, B. J. (2020), 'A multi-proxy investigation of mantle oxygen fugacity along the Reykjanes Ridge', Earth and Planetary Science Letters 531, 115973.

Oliveira, B., Afonso, J. C. and Tilhac, R. (2020), 'A disequilibrium reactive transport model for mantle magmatism', Journal of Petrology 61(9).

Pertermann, M. and Hirschmann, M. M. (2003a), 'Anhydrous partial melting experiments on MORB-like eclogite: phase relations, phase compositions and mineral-melt partitioning of major elements at 2-3 GPa', Journal of Petrology 44(12), 2173-2201.

Pertermann, M. and Hirschmann, M. M. (2003b), 'Partial melting experiments on a MORB-like pyroxenite between 2 and $3 \mathrm{GPa}$ : Constraints on the presence of pyroxenite in basalt source regions from solidus location and melting rate', Journal of Geophysical Research: Solid Earth 108(B2).

Pertermann, M., Hirschmann, M. M., Hametner, K., Günther, D. and Schmidt, M. W. (2004), 'Experimental determination of trace element partitioning between garnet and silica-rich liquid during anhydrous partial melting of MORB-like eclogite', Geochemistry, Geophysics, Geosystems 5(5).

Phipps Morgan, J. (2001), 'Thermodynamics of pressure release melting of a veined plum pudding mantle', Geochemistry, Geophysics, Geosystems 2(4).

Pietruszka, A. J., Norman, M. D., Garcia, M. O., Marske, J. P. and Burns, D. H. (2013), 'Chemical heterogeneity in the Hawaiian mantle plume from the alteration and dehydration of recycled oceanic crust', Earth and Planetary Science Letters 361, 298-309. 
Plank, T. and Langmuir, C. H. (1998), 'The chemical composition of subducting sediment and its consequences for the crust and mantle', Chemical geology 145(3-4), 325-394.

Powell, R., Holland, T. J. B. and Worley, B. (1998), 'Calculating phase diagrams involving solid solutions via non-linear equations, with examples using THERMOCALC', Journal of Metamorphic Geology 16(4), 577-588.

Prytulak, J. and Elliott, T. (2007), 'TiO2 enrichment in ocean island basalts', Earth and Planetary Science Letters 263(3-4), 388-403.

Prytulak, J., Nielsen, S. G., Ionov, D. A., Halliday, A. N., Harvey, J., Kelley, K. A., Niu, Y. L., Peate, D. W., Shimizu, K. and Sims, K. W. W. (2013), 'The stable vanadium isotope composition of the mantle and mafic lavas', Earth and Planetary Science Letters 365, 177-189.

Putirka, K. (2008a), 'Excess temperatures at ocean islands: Implications for mantle layering and convection', Geology 36(4), 283-286.

Putirka, K. D. (2005), 'Mantle potential temperatures at Hawaii, Iceland, and the mid-ocean ridge system, as inferred from olivine phenocrysts: Evidence for thermally driven mantle plumes', Geochemistry, Geophysics, Geosystems 6(5).

Putirka, K. D. (2008b), 'Thermometers and barometers for volcanic systems', Reviews in mineralogy and geochemistry 69(1), 61-120.

Qi, Y.-H., Wu, F., Ionov, D. A., Puchtel, I. S., Carlson, R. W., Nicklas, R. W., Yu, H.-M., Kang, J.-T., Li, C.-H. and Huang, F. (2019), 'Vanadium isotope composition of the Bulk Silicate Earth: Constraints from peridotites and komatiites', Geochimica et Cosmochimica Acta 259, 288-301.

Richter, F. M., Davis, A. M., DePaolo, D. J. and Watson, E. B. (2003), 'Isotope fractionation by chemical diffusion between molten basalt and rhyolite', Geochimica et Cosmochimica Acta 67(20), 3905-3923.

Richter, F. M., Watson, E. B., Mendybaev, R. A., Teng, F.-Z. and Janney, P. E. (2008), 'Magnesium isotope fractionation in silicate melts by chemical and thermal diffusion', Geochimica et Cosmochimica Acta 72(1), 206220.

Richter, F. M., Watson, E. B., Mendybaev, R., Dauphas, N., Georg, B., Watkins, J. and Valley, J. (2009), 'Isotopic fractionation of the major elements of molten basalt by chemical and thermal diffusion', Geochimica et Cosmochimica Acta 73(14), 4250-4263.

Rosenthal, A., Yaxley, G. M., Green, D. H., Hermann, J., Kovács, I. and Spandler, C. (2014), 'Continuous eclogite melting and variable refertilisation in upwelling heterogeneous mantle', Scientific Reports 4(1), 1-6.

Rouxel, O., Dobbek, N., Ludden, J. and Fouquet, Y. (2003), 'Iron isotope fractionation during oceanic crust alteration', Chemical Geology 202(1-2), 155-182.

Rudnick, R. L. and Gao, S. (2003), The Crust (Treatise on Geochemistry), Vol. 3, Elsevier, chapter Composition of the continental crust, pp. 1-64. 
Salters, V. J. M. and Dick, H. J. B. (2002), 'Mineralogy of the mid-ocean-ridge basalt source from neodymium isotopic composition of abyssal peridotites', Nature 418(6893), 68-72.

Schauble, E. A. (2004), 'Applying stable isotope fractionation theory to new systems', Reviews in Mineralogy and Geochemistry 55(1), 65-111.

Scheuermann, P. P., Syverson, D. D., Higgins, J. A., Pester, N. J. and Seyfried Jr, W. E. (2018), 'Calcium isotope systematics at hydrothermal conditions: Mid-ocean ridge vent fluids and experiments in the CaSO4-NaCl-H2O system', Geochimica et Cosmochimica Acta 226, 18-35.

Schiano, P., Birck, J.-L. and Allègre, C. J. (1997), 'Osmium-strontium-neodymium-lead isotopic covariations in mid-ocean ridge basalt glasses and the heterogeneity of the upper mantle', Earth and Planetary Science Letters 150(3-4), 363-379.

Schmitt, A.-D., Chabaux, F. and Stille, P. (2003), 'The calcium riverine and hydrothermal isotopic fluxes and the oceanic calcium mass balance', Earth and Planetary Science Letters 213(3-4), 503-518.

Schoenberg, R., Merdian, A., Holmden, C., Kleinhanns, I. C., Haßler, K., Wille, M. and Reitter, E. (2016), 'The stable Cr isotopic compositions of chondrites and silicate planetary reservoirs', Geochimica et Cosmochimica Acta 183, 14-30.

Severmann, S., Johnson, C. M., Beard, B. L., German, C. R., Edmonds, H. N., Chiba, H. and Green, D. R. H. (2004), 'The effect of plume processes on the Fe isotope composition of hydrothermally derived Fe in the deep ocean as inferred from the Rainbow vent site, Mid-Atlantic Ridge, 36 14' N', Earth and Planetary Science Letters 225(1-2), 63-76.

Shen, J., Qin, L., Fang, Z., Zhang, Y., Liu, J., Liu, W., Wang, F., Xiao, Y., Yu, H. and Wei, S. (2018), 'Hightemperature inter-mineral $\mathrm{Cr}$ isotope fractionation: A comparison of ionic model predictions and experimental investigations of mantle xenoliths from the North China Craton', Earth and Planetary Science Letters 499, 278290.

Shen, J., Xia, J., Qin, L., Carlson, R. W., Huang, S., Helz, R. T. and Mock, T. D. (2020), 'Stable chromium isotope fractionation during magmatic differentiation: Insights from Hawaiian basalts and implications for planetary redox conditions', Geochimica et Cosmochimica Acta 278, 289-304.

Shorttle, O. (2015), 'Geochemical variability in MORB controlled by concurrent mixing and crystallisation', Earth and Planetary Science Letters 424, 1-14.

Shorttle, O. and Maclennan, J. (2011), 'Compositional trends of Icelandic basalts: Implications for short-length scale lithological heterogeneity in mantle plumes', Geochemistry, Geophysics, Geosystems 12(11).

Shorttle, O., Maclennan, J. and Lambart, S. (2014), 'Quantifying lithological variability in the mantle', Earth and Planetary Science Letters 395, 24-40. 
Smart, K. A., Tappe, S., Woodland, A. B., Greyling, D. R., Harris, C. and Gussone, N. (2021), 'Constraints on Archean crust recycling and the origin of mantle redox variability from the $\delta 44 / 40 \mathrm{Ca}-\delta 18 \mathrm{O}-\mathrm{fO} 2$ signatures of cratonic eclogites', Earth and Planetary Science Letters 556, 116720.

Sobolev, A. V., Hofmann, A. W., Kuzmin, D. V., Yaxley, G. M., Arndt, N. T., Chung, S.-L., Danyushevsky, L. V., Elliott, T., Frey, F. A., Garcia, M. O. et al. (2007), 'The amount of recycled crust in sources of mantle-derived melts', Science 316(5823), 412-417.

Sobolev, A. V., Hofmann, A. W., Sobolev, S. V. and Nikogosian, I. K. (2005), 'An olivine-free mantle source of Hawaiian shield basalts', Nature 434(7033), 590-597.

Soderman, C. R., Matthews, S., Shorttle, O., Jackson, M. G., Ruttor, S., Nebel, O., Turner, S., Beier, C., Millet, M.-A., Widom, E. et al. (2021), 'Heavy $\delta^{57} \mathrm{Fe}$ in ocean island basalts: A non-unique signature of processes and source lithologies in the mantle', Geochimica et Cosmochimica Acta 292, 309-332.

Sossi, P. A., Moynier, F. and Van Zuilen, K. (2018), 'Volatile loss following cooling and accretion of the Moon revealed by chromium isotopes', Proceedings of the National Academy of Sciences 115(43), 10920-10925.

Sossi, P. A., Nebel, O. and Foden, J. (2016), 'Iron isotope systematics in planetary reservoirs', Earth and Planetary Science Letters 452, 295-308.

Sossi, P. A. and O'Neill, H. S. C. (2017), 'The effect of bonding environment on iron isotope fractionation between minerals at high temperature', Geochimica et Cosmochimica Acta 196, 121-143.

Spice, H. E., Fitton, J. G. and Kirstein, L. A. (2016), 'Temperature fluctuation of the Iceland mantle plume through time', Geochemistry, Geophysics, Geosystems 17(2), 243-254.

Stolper, E. M., Shorttle, O., Antoshechkina, P. M. and Asimow, P. D. (2020), 'The effects of solid-solid phase equilibria on the oxygen fugacity of the upper mantle', American Mineralogist 105(10), 1445-1471.

Stracke, A. (2012), 'Earth's heterogeneous mantle: A product of convection-driven interaction between crust and mantle', Chemical Geology 330, 274-299.

Stracke, A. (2021), 'A process-oriented approach to mantle geochemistry', Chemical Geology p. 120350.

Stracke, A., Hofmann, A. W. and Hart, S. R. (2005), 'FOZO, HIMU, and the rest of the mantle zoo', Geochemistry, Geophysics, Geosystems 6(5).

Stracke, A., Tipper, E. T., Klemme, S. and Bizimis, M. (2018), 'Mg isotope systematics during magmatic processes: Inter-mineral fractionation in mafic to ultramafic Hawaiian xenoliths', Geochimica et Cosmochimica Acta 226, 192-205.

Sun, P., Niu, Y., Guo, P., Duan, M., Chen, S., Gong, H., Wang, X. and Xiao, Y. (2020), 'Large iron isotope variation in the eastern Pacific mantle as a consequence of ancient low-degree melt metasomatism', Geochimica et Cosmochimica Acta 286, 269-288. 
Tappe, S., Massuyeau, M., Smart, K. A., Woodland, A. B., Gussone, N., Milne, S. and Stracke, A. (2021), 'Sheared peridotite and megacryst formation beneath the Kaapvaal craton: a snapshot of tectonomagmatic processes across the lithosphere-asthenosphere transition', Journal of Petrology 62(8).

Teng, F.-Z., Dauphas, N. and Helz, R. T. (2008), 'Iron Isotope Fractionation During Magmatic Differentiation in Kilauea Iki Lava Lake', Science 320(5883), 1620-1622.

Teng, F.-Z., Dauphas, N., Helz, R. T., Gao, S. and Huang, S. (2011), 'Diffusion-driven magnesium and iron isotope fractionation in Hawaiian olivine', Earth and Planetary Science Letters 308(3-4), 317-324.

Teng, F.-Z., Dauphas, N., Huang, S. and Marty, B. (2013), 'Iron isotopic systematics of oceanic basalts', Geochimica et Cosmochimica Acta 107, 12-26.

Teng, F.-Z., Hu, Y. and Chauvel, C. (2016), 'Magnesium isotope geochemistry in arc volcanism', Proceedings of the National Academy of Sciences 113(26), 7082-7087.

Teng, F.-Z., Li, W.-Y., Ke, S., Marty, B., Dauphas, N., Huang, S., Wu, F.-Y. and Pourmand, A. (2010), 'Magnesium isotopic composition of the Earth and chondrites', Geochimica et Cosmochimica Acta 74(14), 4150-4166.

Teng, F.-Z., Wadhwa, M. and Helz, R. T. (2007), 'Investigation of magnesium isotope fractionation during basalt differentiation: implications for a chondritic composition of the terrestrial mantle', Earth and Planetary Science Letters 261(1-2), 84-92.

Till, C. B., Grove, T. L. and Krawczynski, M. J. (2012), 'A melting model for variably depleted and enriched lherzolite in the plagioclase and spinel stability fields', Journal of Geophysical Research: Solid Earth 117(B6).

Toplis, M. J. and Corgne, A. (2002), 'An experimental study of element partitioning between magnetite, clinopyroxene and iron-bearing silicate liquids with particular emphasis on vanadium', Contributions to Mineralogy and Petrology 144(1), 22-37.

Valdes, M. C., Moreira, M., Foriel, J. and Moynier, F. (2014), 'The nature of Earth's building blocks as revealed by calcium isotopes', Earth and Planetary Science Letters 394, 135-145.

Van Orman, J. A., Saal, A. E., Bourdon, B. and Hauri, E. H. (2006), 'Diffusive fractionation of U-series radionuclides during mantle melting and shallow-level melt-cumulate interaction', Geochimica et Cosmochimica Acta 70(18), 4797-4812.

Wagner, L. J., Kleinhanns, I. C., Weber, N., Babechuk, M. G., Hofmann, A. and Schoenberg, R. (2021), 'Coupled stable chromium and iron isotopic fractionation tracing magmatic mineral crystallization in Archean komatiitetholeiite suites', Chemical Geology 576, 120121.

Wang, W., Zhou, C., Qin, T., Kang, J.-T., Huang, S., Wu, Z. and Huang, F. (2017), 'Effect of Ca content on equilibrium $\mathrm{Ca}$ isotope fractionation between orthopyroxene and clinopyroxene', Geochimica et Cosmochimica Acta 219, 44-56. 
Wang, X.-J., Chen, L.-H., Hanyu, T., Zhong, Y., Shi, J.-H., Liu, X.-W., Kawabata, H., Zeng, G. and Xie, L.-W. (2021), 'Magnesium isotopic fractionation during basalt differentiation as recorded by evolved magmas', Earth and Planetary Science Letters 565, 116954.

Wang, X.-J., Chen, L.-H., Hofmann, A. W., Hanyu, T., Kawabata, H., Zhong, Y., Xie, L.-W., Shi, J.-H., Miyazaki, T., Hirahara, Y. et al. (2018), 'Recycled ancient ghost carbonate in the Pitcairn mantle plume', Proceedings of the National Academy of Sciences 115(35), 8682-8687.

Wang, X., Planavsky, N. J., Reinhard, C. T., Zou, H., Ague, J. J., Wu, Y., Gill, B. C., Schwarzenbach, E. M. and Peucker-Ehrenbrink, B. (2016), 'Chromium isotope fractionation during subduction-related metamorphism, black shale weathering, and hydrothermal alteration', Chemical Geology 423, 19-33.

Wang, Y., He, Y., Wu, H., Zhu, C., Huang, S. and Huang, J. (2019), 'Calcium isotope fractionation during crustal melting and magma differentiation: Granitoid and mineral-pair perspectives', Geochimica et Cosmochimica Acta 259, 37-52.

Waters, C. L., Sims, K. W. W., Perfit, M. R., Blichert-Toft, J. and Blusztajn, J. (2011), 'Perspective on the genesis of E-MORB from chemical and isotopic heterogeneity at 9-10 N East Pacific Rise', Journal of Petrology $\mathbf{5 2}(3), 565-602$.

Watkins, J. M., DePaolo, D. J. and Watson, E. B. (2017), 'Kinetic fractionation of non-traditional stable isotopes by diffusion and crystal growth reactions', Reviews in Mineralogy and Geochemistry 82(1), 85-125.

Watkins, J. M., Liang, Y., Richter, F., Ryerson, F. J. and DePaolo, D. J. (2014), 'Diffusion of multi-isotopic chemical species in molten silicates', Geochimica et Cosmochimica Acta 139, 313-326.

Weaver, B. L. (1991), 'The origin of ocean island basalt end-member compositions: trace element and isotopic constraints', Earth and Planetary Science Letters 104(2-4), 381-397.

Willbold, M. and Stracke, A. (2006), 'Trace element composition of mantle end-members: Implications for recycling of oceanic and upper and lower continental crust', Geochemistry, Geophysics, Geosystems 7(4).

Williams, H. M. and Bizimis, M. (2014), 'Iron isotope tracing of mantle heterogeneity within the source regions of oceanic basalts', Earth and Planetary Science Letters 404, 396-407.

Williams, H. M., Matthews, S., Rizo, H. and Shorttle, O. (2021), 'Iron isotopes trace primordial magma ocean cumulates melting in Earth's upper mantle', Science Advances 7(11), eabc7394.

Williams, H. M., McCammon, C. A., Peslier, A. H., Halliday, A. N., Teutsch, N., Levasseur, S. and Burg, J.-P. (2004), 'Iron isotope fractionation and the oxygen fugacity of the mantle', Science 304(5677), 1656-1659.

Williams, H. M., Nielsen, S. G., Renac, C., Griffin, W. L., O'Reilly, S. Y., McCammon, C. A., Pearson, N., Viljoen, F., Alt, J. C. and Halliday, A. N. (2009), 'Fractionation of oxygen and iron isotopes by partial melting processes: implications for the interpretation of stable isotope signatures in mafic rocks', Earth and Planetary Science Letters 283(1-4), 156-166. 
Workman, R. K. and Hart, S. R. (2005), 'Major and trace element composition of the depleted MORB mantle (DMM)', Earth and Planetary Science Letters 231(1-2), 53-72.

Workman, R. K., Hart, S. R., Jackson, M., Regelous, M., Farley, K. A., Blusztajn, J., Kurz, M. and Staudigel, H. (2004), 'Recycled metasomatized lithosphere as the origin of the Enriched Mantle II (EM2) end-member: Evidence from the Samoan Volcanic Chain', Geochemistry, Geophysics, Geosystems 5(4).

Wu, F., Qi, Y., Perfit, M. R., Gao, Y., Langmuir, C. H., Wanless, V. D., Yu, H. and Huang, F. (2018), 'Vanadium isotope compositions of mid-ocean ridge lavas and altered oceanic crust', Earth and Planetary Science Letters 493, 128-139.

Wu, F., Qin, T., Li, X., Liu, Y., Huang, J.-H., Wu, Z. and Huang, F. (2015), 'First-principles investigation of vanadium isotope fractionation in solution and during adsorption', Earth and Planetary Science Letters 426, 216-224.

Xia, J., Qin, L., Shen, J., Carlson, R. W., Ionov, D. A. and Mock, T. D. (2017), 'Chromium isotope heterogeneity in the mantle', Earth and Planetary Science Letters 464, 103-115.

Xiao, Y., Teng, F.-Z., Zhang, H.-F. and Yang, W. (2013), 'Large magnesium isotope fractionation in peridotite xenoliths from eastern North China craton: Product of melt-rock interaction', Geochimica et Cosmochimica Acta 115, 241-261.

Yang, Z.-F., Li, J., Jiang, Q.-B., Xu, F., Guo, S.-Y., Li, Y. and Zhang, J. (2019), 'Using major element logratios to recognize compositional patterns of basalt: Implications for source lithological and compositional heterogeneities', Journal of Geophysical Research: Solid Earth 124(4), 3458-3490.

Yaxley, G. M. (2000), 'Experimental study of the phase and melting relations of homogeneous basalt+ peridotite mixtures and implications for the petrogenesis of flood basalts', Contributions to Mineralogy and Petrology 139(3), 326-338.

Yaxley, G. M. and Green, D. H. (1998), 'Reactions between eclogite and peridotite: mantle refertilisation by subduction of oceanic crust', Schweiz. Mineral. Petrogr. Mitt 78(2), 243-255.

Young, E. D., Manning, C. E., Schauble, E. A., Shahar, A., Macris, C. A., Lazar, C. and Jordan, M. (2015), 'High-temperature equilibrium isotope fractionation of non-traditional stable isotopes: Experiments, theory, and applications', Chemical Geology 395, 176-195.

Zhang, H., Wang, Y., He, Y., Teng, F.-Z., Jacobsen, S. B., Helz, R. T., Marsh, B. D. and Huang, S. (2018), 'No measurable calcium isotopic fractionation during crystallization of Kilauea Iki lava lake', Geochemistry, Geophysics, Geosystems 19(9), 3128-3139.

Zhao, X. M., Cao, H. H., Mi, X., Evans, N. J., Qi, Y. H., Huang, F. and Zhang, H. F. (2017b), 'Combined iron and magnesium isotope geochemistry of pyroxenite xenoliths from hannuoba, north china craton: implications for mantle metasomatism', Contributions to Mineralogy and Petrology 172(6), 40. 
Zhao, X., Zhang, Z., Huang, S., Liu, Y., Li, X. and Zhang, H. (2017a), 'Coupled extremely light Ca and Fe isotopes in peridotites', Geochimica et Cosmochimica Acta 208, 368-380.

Zhong, Y., Chen, L.-H., Wang, X.-J., Zhang, G.-L., Xie, L.-W. and Zeng, G. (2017), 'Magnesium isotopic variation of oceanic island basalts generated by partial melting and crustal recycling', Earth and Planetary Science Letters 463, $127-135$.

Zhong, Y., Zhang, G.-L., Lv, W.-X. and Huang, F. (2021), 'Iron isotope constraints on the lithological heterogeneity of the upper mantle in the South China Sea', Journal of Asian Earth Sciences p. 104934.

Zhu, H., Du, L., Zhang, Z. and Sun, W. (2020a), 'Calcium isotopic signatures of depleted mid-ocean ridge basalts from the northeastern Pacific', Journal of Oceanology and Limnology 38, 1476-1487.

Zhu, H., Liu, F., Li, X., Wang, G., Zhang, Z. and Sun, W. (2018), 'Calcium isotopic compositions of normal MidOcean Ridge basalts from the southern Juan de Fuca Ridge', Journal of Geophysical Research: Solid Earth 123(2), 1303-1313.

Zindler, A. and Hart, S. (1986), 'Chemical geodynamics', Annual Review of Earth and Planetary Sciences $\mathbf{1 4}(1), 493-571$.

Zindler, A., Staudigel, H. and Batiza, R. (1984), 'Isotope and trace element geochemistry of young Pacific seamounts: implications for the scale of upper mantle heterogeneity', Earth and Planetary Science Letters 70(2), 175-195. 
Supplementary Material to 'Global trends in novel stable isotopes in basalts: theory and observations' by Soderman et al.

\section{${ }_{3} 1$ Data sources}

4 The data sources used in the natural data compilation in Figs. 1 and 8 in the main text are

5 given in Table $\mathrm{S} 1$.

Table S1: Literature data sources for stable isotope data compilation.

\begin{tabular}{lll}
\hline Isotope & Type & Literature sources \\
\hline$\delta^{26} \mathrm{Mg}$ & MORB & Wiechert and Halliday (2007); Bourdon et al. (2010); Teng et al. (2010); Zhong et al. (2021b) \\
& OIB & Bourdon et al. (2010); Teng et al. (2010); Zhong et al. (2017); Wang et al. (2021) \\
\hline$\delta^{44} \mathrm{Ca}$ & MORB & Zhu et al. (2018); Chen et al. (2020b); Zhu et al. (2020a) \\
& OIB & Huang et al. (2011b); Valdes et al. (2014, 2019); Feng et al. (2017); Chen et al. (2020b) \\
\hline$\delta^{57} \mathrm{Fe}$ & MORB & Teng et al. (2013); Nebel et al. (2013); Zhong et al. (2021) (seamounts: Sun et al., 2020) \\
& OIB & $\begin{array}{l}\text { Teng et al. (2008); Schuessler et al. (2009); Konter et al. (2016); Nebel et al. (2019) } \\
\text { Peters et al. (2019); Gleeson et al. (2020); Soderman et al. (2021) }\end{array}$ \\
\hline$\delta^{51} \mathrm{~V}$ & MORB & $\begin{array}{l}\text { Prytulak et al. (2013); Wu et al. (2018); Novella et al. (2020) } \\
\end{array}$ \\
\hline$\delta^{53} \mathrm{Cr}$ & OIB & Prytulak et al. (2013); Ding et al. (2020) \\
\hline
\end{tabular}

6 Table S2 gives the references for the typical sample 2 S.E. and long-term 2 S.D. used throughout the manuscript.

Table S2: Literature data sources for stable isotope data errors.

\begin{tabular}{llrl}
\hline Isotope & Type & Value (\%o) & Literature sources \\
\hline$\delta^{26} \mathrm{Mg}$ & sample 2 S.E. & 0.02 & Wang et al. (2021) \\
& long-term 2 S.D. & 0.06 & Wang et al. (2021) \\
\hline$\delta^{44} \mathrm{Ca}$ & sample 2 S.E. & 0.05 & Zhu et al. (2018, 2020a) \\
& long-term 2 S.D. & 0.14 & Chen et al. (2019) \\
\hline$\delta^{57} \mathrm{Fe}$ & sample 2 S.E. & 0.02 & Soderman et al. (2021) \\
& long-term 2 S.D. & 0.05 & Soderman et al. (2021) \\
\hline$\delta^{51} \mathrm{~V}$ & sample 2 S.E. & 0.05 & Wu et al. (2018); Novella et al. (2020) \\
& long-term 2 S.D. & 0.08 & Qi et al. (2019) \\
\hline$\delta^{53} \mathrm{Cr}$ & sample 2 S.E. & 0.01 & Sossi et al. (2018) \\
& long-term 2 S.D. & 0.04 & Xia et al. (2017); Sossi et al. (2018) \\
\hline
\end{tabular}




\section{Phase equilibria calculations}

9 In order to explore stable isotope fractionation taking place during the melting of pyroxenite and peridotite lithologies within the mantle, we first constructed pseudosections and calculated mineral chemistries for MIX1G (KLB1 and G2 calculations are presented in Soderman et al., 2021). The calculations were performed in the KNCFMASTOCr system using THERMOCALC v3.47 (Powell et al., 1998), and the latest version of the thermodynamic dataset of Holland and Powell (2011) with the a-X models of Holland et al. (2018).

The composition of the MIX1G lithology (Hirschmann et al., 2003; Lambart et al., 2016) used in the phase-equilibria calculations is given in Table S3. The ferric iron content is taken as between that of KLB1 peridotite and MORB, following the approach used for KG1 by Jennings et al. (2016), where $\mathrm{Fe}^{3+} / \mathrm{Fe}_{\mathrm{T}}=0.1$.

Table S3: MIX1G composition, in KNCFMASTOCr system (mol \% oxides). Composition from Lambart et al. (2016), renormalised without $\mathrm{MnO}$.

\begin{tabular}{cccccccccc}
\hline & \multicolumn{1}{c}{ mole \% oxide } & & & & \\
$\mathrm{SiO}_{2}$ & $\mathrm{Al}_{2} \mathrm{O}_{3}$ & $\mathrm{CaO}$ & $\mathrm{MgO}$ & $\mathrm{FeO}_{t}$ & $\mathrm{~K}_{2} \mathrm{O}$ & $\mathrm{Na}_{2} \mathrm{O}$ & $\mathrm{TiO}_{2}$ & $\mathrm{Cr}_{2} \mathrm{O}_{3}$ & $\mathrm{O}$ \\
\hline 38.5 & 1.78 & 2.82 & 50.58 & 5.52 & 0.01 & 0.25 & 0.07 & 0.11 & 0.09 \\
\hline
\end{tabular}

After calculation of the phase boundaries, THERMOCALC was run over a grid of P-T space, from $5-40 \mathrm{kbar}$ and $1100-1730^{\circ} \mathrm{C}$.

\section{Details and results of the main stable isotope fractionation model}

The equilibrium isotopic composition of the phases present at any point in P-T space (including melts) was calculated for each isotope system, based on calculated equilibrium isotope fractionation factors, $\alpha^{\mathrm{A}-\mathrm{B}}$, between the phases that are present. $\alpha^{\mathrm{A}-\mathrm{B}}$ was calculated either from reduced partition function ratios ( $\beta$ factors), or from calculated cation-oxygen force constants, as outlined for $\mathrm{Mg}, \mathrm{Ca}, \mathrm{V}$ and $\mathrm{Cr}$ isotopes below. The Fe isotope fractionation input parameters are presented in the supplementary information of Soderman et al. (2021). The mineral abbreviations used in the figures in the following subsections are: olivine (ol), clinopyroxene (cpx), orthopyroxene (opx), spinel (spn), garnet (g), plagioclase (pl).

\section{1 $\mathrm{Mg}$}

The $\beta^{\mathrm{Mg}}$ factors used for Mg-bearing mantle minerals (spinel, clinopyroxene, orthopyroxene, olivine, garnet) are given in Table S4. These $\beta^{\mathrm{Mg}}$ factors are taken from Huang et al. (2013), with the exception of spinel, which is taken from Schauble (2011) and scaled relative to a reference $\beta^{\mathrm{Mg}}$ of olivine which is calculated in both studies. Pigeonite (a stable phase in MIX1G) is modelled with the same $\beta^{\mathrm{Mg}}$ as clinopyroxene; liquid (melt) is taken as having no fractionation from olivine in the main model (Stracke et al., 2018, see Appendix Section 4 for discussion), so $\beta_{\text {melt }}^{\mathrm{Mg}}=\beta_{\text {olivine }}^{\mathrm{Mg}}$.

The full results of the Mg model, showing the isotopic composition of each phase calculated in 
Table S4: Parameters for $\beta^{\mathrm{Mg}}$ factors from Huang et al. (2013). $1000 \ln \beta=\mathrm{a} / \mathrm{T}^{6}+\mathrm{b} / \mathrm{T}^{4}+\mathrm{c} / \mathrm{T}^{2}$, where $\mathrm{T}=$ temperature (Kelvin).

\begin{tabular}{lrrr}
\hline Mineral & $\mathrm{a}$ & $\mathrm{b}$ & $\mathrm{c}$ \\
\hline spinel & $-2.74 \times 10^{16}$ & $2.08 \times 10^{11}$ & $2.93 \times 10^{6}$ \\
orthopyroxene & $-8.10 \times 10^{15}$ & $6.65 \times 10^{10}$ & $2.25 \times 10^{6}$ \\
clinopyroxene & $-1.17 \times 10^{16}$ & $1.03 \times 10^{11}$ & $2.24 \times 10^{6}$ \\
olivine & $-1.19 \times 10^{16}$ & $1.05 \times 10^{11}$ & $2.07 \times 10^{6}$ \\
garnet & $-5.50 \times 10^{15}$ & $4.92 \times 10^{10}$ & $1.30 \times 10^{6}$ \\
melt & $-1.19 \times 10^{16}$ & $1.05 \times 10^{11}$ & $2.07 \times 10^{6}$ \\
\hline
\end{tabular}

KLB1, MIX1G and G2, are in Fig. S1.

KLB1
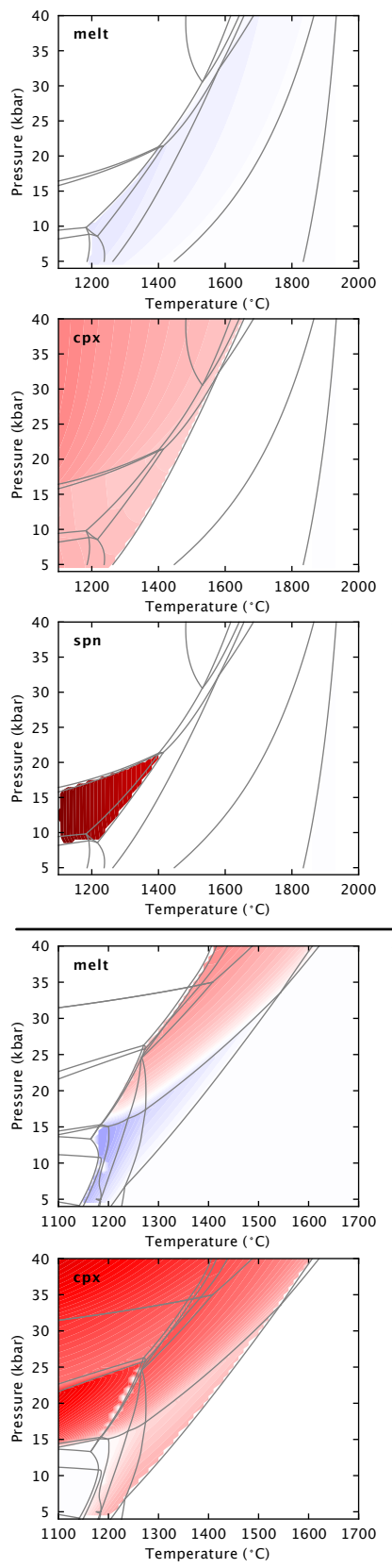
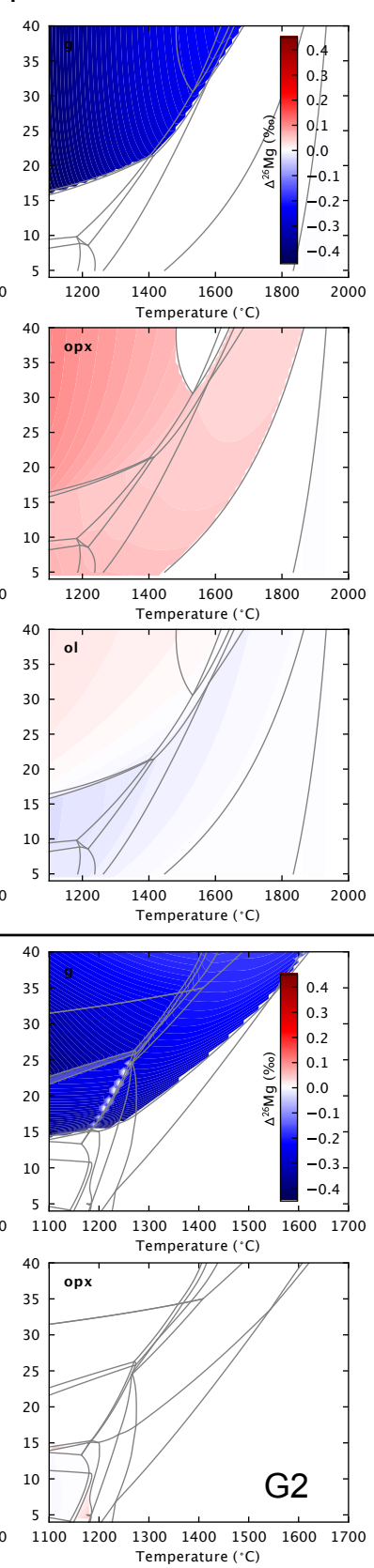

MIX1G
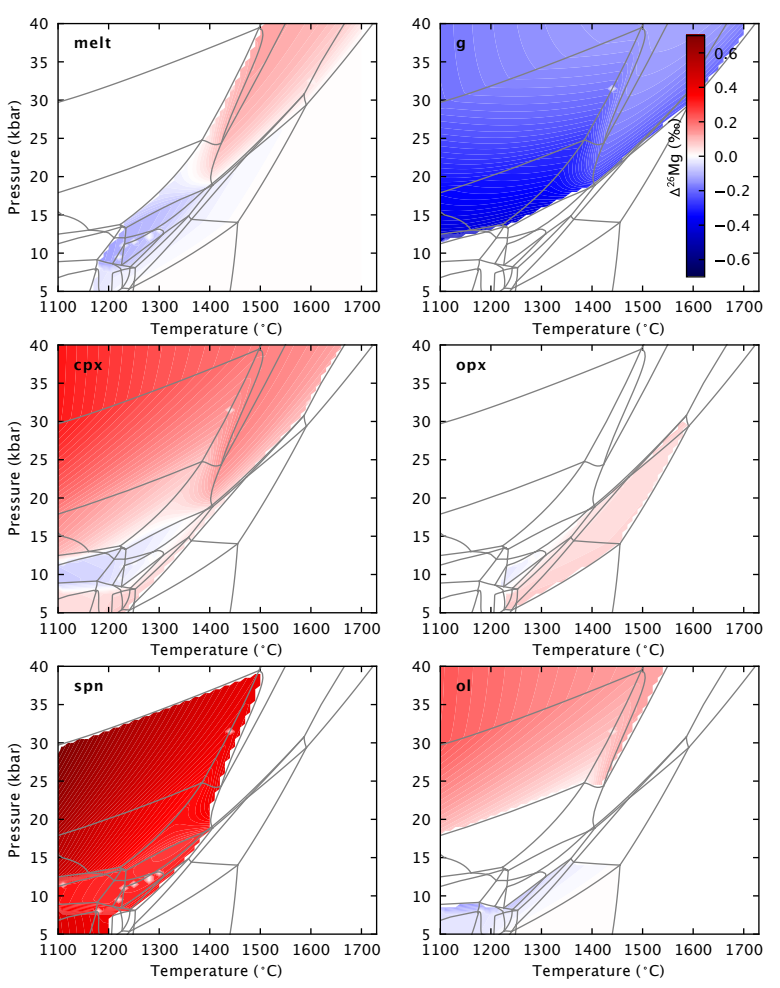

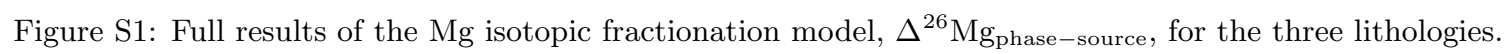


Table S5: $\beta^{\mathrm{Ca}}$ factors (given as $1000 \ln \beta$, at a temperature of $1000 \mathrm{~K}$ ) from Antonelli et al. (2019).

\begin{tabular}{llr}
\hline Mineral & Structure used & $1000 \ln \beta$ \\
\hline plagioclase & anorthite & 1.06 \\
orthopyroxene & $\mathrm{Ca} / \mathrm{Mg}=1 / 32$ & 1.84 \\
clinopyroxene & diopside & 1.32 \\
olivine & forsterite $\mathrm{Ca} / \mathrm{Mg}=1 / 64$ & 2.11 \\
garnet & pyrope $\mathrm{Ca} / \mathrm{Mg}=1 / 24$ & 2.00 \\
liquid & & 1.19 \\
\hline
\end{tabular}

\section{$3.2 \mathrm{Ca}$}

42 The $\beta^{\mathrm{Ca}}$ factors used for Ca-bearing mantle minerals (plagioclase, clinopyroxene, orthopyroxene, 43 olivine, garnet) are given in Table S5, and are taken from Antonelli et al. (2019). Where options 44 exist for minerals with different structures and/or compositions, we use those with most similar $45 \mathrm{Ca} / \mathrm{Mg}$ to the typical phase compositions calculated by THERMOCALC for KLB1. Pigeonite (a 46 stable phase in MIX1G) is modelled with the same $\beta^{\mathrm{Ca}}$ as clinopyroxene; liquid is taken as having ${ }_{47} \quad \beta^{\mathrm{Ca}}$ intermediate between clinopyroxene and plagioclase (anorthite), following observations from 48 natural samples (Zhang et al., 2018; Antonelli et al., 2019b) and consistent with the approach 49 used by Antonelli et al. (2021). $\beta^{\text {Ca }}$ factors are made temperature-dependent by

$$
\ln \beta_{(\mathrm{T})}=\ln \beta_{(1000 \mathrm{~K})} \times \frac{10^{6}}{\mathrm{~T}^{2}}
$$

following Antonelli et al. (2021).

The full results of the Ca model, showing the isotopic composition of each phase calculated in KLB1, MIX1G and G2, are in Fig. S2. 
KLB1
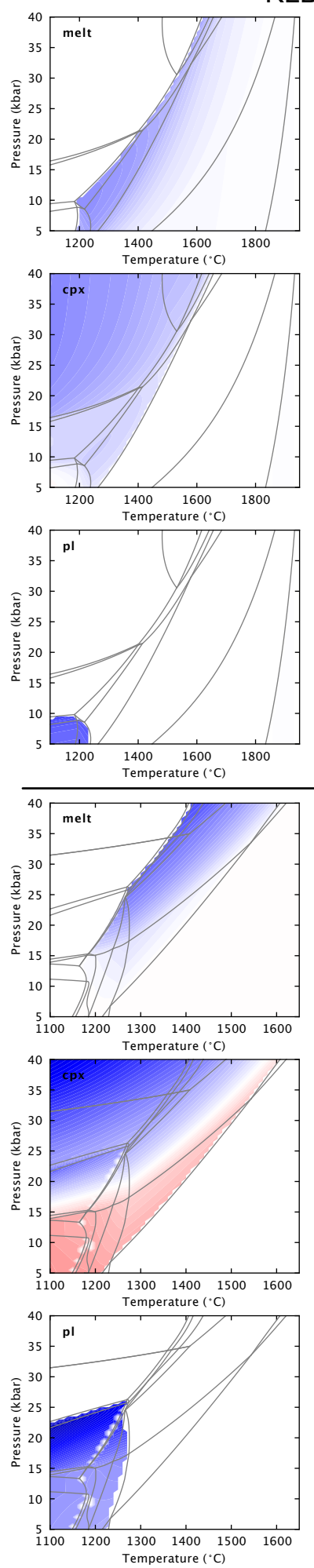

\section{MIX1G}
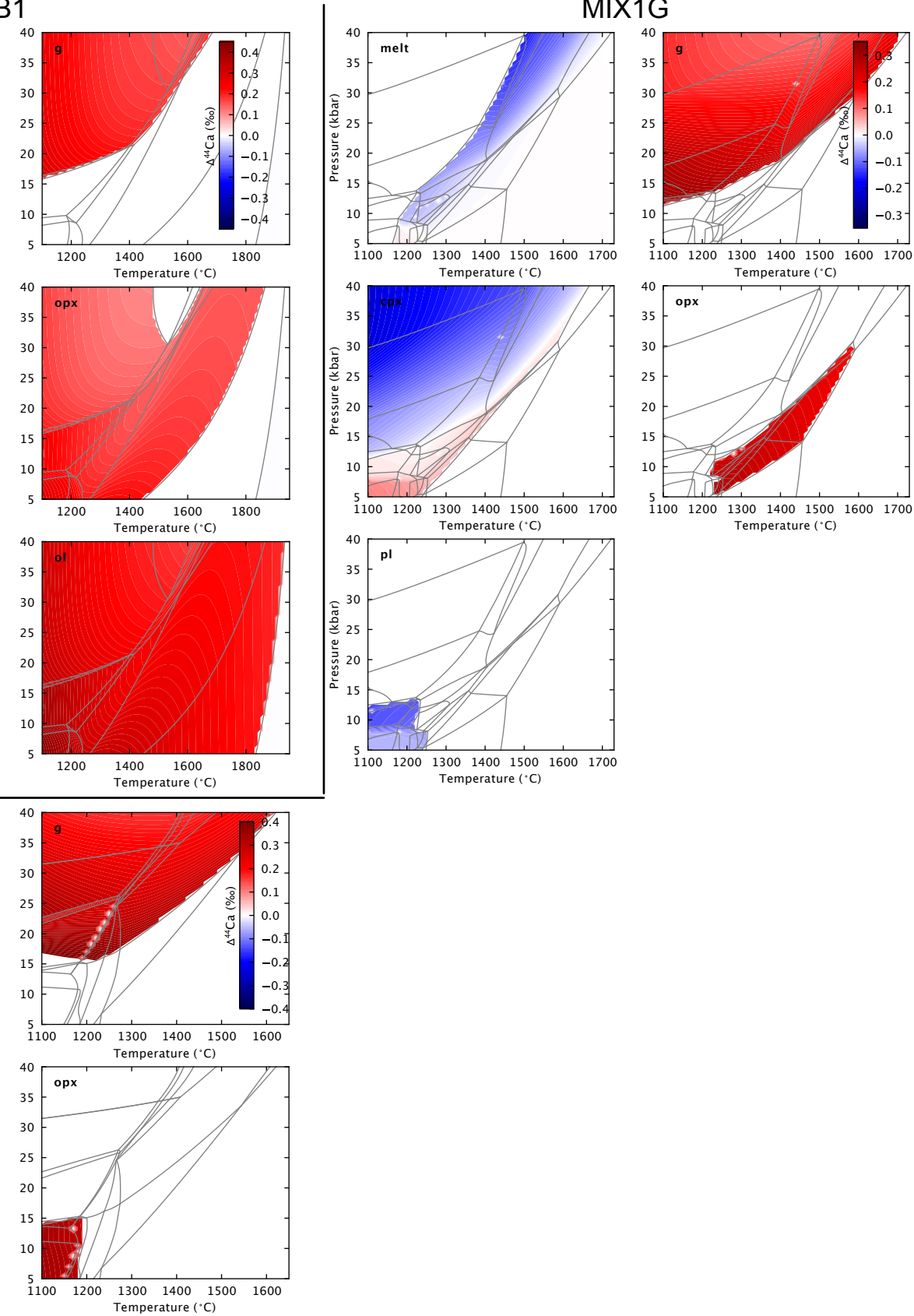

G2

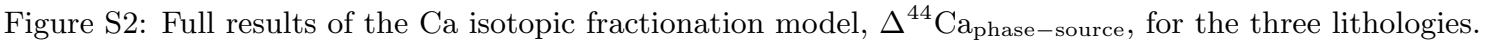




\section{$3.3 \mathrm{~V}$}

The proportion of $\mathrm{V}^{3+/ 4+/ 5+}$ was calculated following Toplis and Corgne (2002), using the $\mathrm{FeO} / \mathrm{Fe}_{2} \mathrm{O}_{3}$ ratio of the melt (calculated by THERMOCALC) at each point in P-T space with

$$
\log \left(\mathrm{XV}^{3+} / \mathrm{XV}^{4+}\right)=\log \left(\mathrm{XFe}^{2+} / \mathrm{XFe}^{3+}\right)-2.4
$$

and

$$
\log \left(\mathrm{XV}^{4+} / \mathrm{XV}^{5+}\right)=\log \left(\mathrm{XFe}^{2+} / \mathrm{XFe}^{3+}\right)-0.3
$$

where $\mathrm{X}$ is the mole fraction of cation.

The partition coefficients and $\beta^{\mathrm{V}}$ factors of each valence state of $\mathrm{V}$ in the $\mathrm{V}$-bearing mantle minerals (olivine, clinopyroxene, orthopyroxene, garnet, spinel) are given in Table S6. Partition coefficients are from Mallmann and O'Neill (2009), with garnet assumed to have similar V partitioning to clinopyroxene (Mallmann and O'Neill, 2007, 2009). The $\beta^{\mathrm{V}}$ factors are taken from Wu et al. (2015) for $\mathrm{V}$ in different coordination environments in solution systems; alternative choices of $\beta^{\mathrm{V}}$ due to uncertainties in $\mathrm{V}$ coordination number are discussed in Section 4 below. Pigeonite (a stable phase in MIX1G) is modelled as clinopyroxene.

Table S6: Parameters for V partitioning and isotopic fractionation. Partition coefficients (D) from Mallmann and O'Neill (2009). $\beta^{\mathrm{V}}$ factors are from Wu et al. (2015). $1000 \ln \beta=\mathrm{a} / \mathrm{T}^{6}+\mathrm{b} / \mathrm{T}^{4}+\mathrm{c} / \mathrm{T}^{2}$, where $\mathrm{T}=$ temperature (Kelvin).

\begin{tabular}{lcrrrrr}
\hline Mineral & Valence & $\mathrm{D}_{\text {min-liq }}$ & $\mathrm{a}$ & $\mathrm{b}$ & $\mathrm{c}$ \\
\hline olivine & $\mathrm{V}^{3+}$ & 0.18 & $1.0 \times 10^{14}$ & $-7.70 \times 10^{9}$ & $6.28 \times 10^{5}$ \\
& $\mathrm{~V}^{4+}$ & 0.0227 & $4.0 \times 10^{14}$ & $-1.80 \times 10^{10}$ & $9.43 \times 10^{5}$ \\
\multirow{3}{*}{ orthopyroxene } & $\mathrm{V}^{5+}$ & 0.00255 & $7.0 \times 10^{14}$ & $-3.06 \times 10^{10}$ & $1.26 \times 10^{6}$ \\
& $\mathrm{~V}^{3+}$ & 1 & $1.0 \times 10^{14}$ & $-7.70 \times 10^{9}$ & $6.28 \times 10^{5}$ \\
& $\mathrm{~V}^{4+}$ & 0.674 & $4.0 \times 10^{14}$ & $-1.80 \times 10^{10}$ & $9.43 \times 10^{5}$ \\
clinopyroxene & $\mathrm{V}^{5+}$ & 0.00338 & $7.0 \times 10^{14}$ & $-3.06 \times 10^{10}$ & $1.26 \times 10^{6}$ \\
& $\mathrm{~V}^{3+}$ & 3.88 & $1.0 \times 10^{14}$ & $-7.70 \times 10^{9}$ & $6.28 \times 10^{5}$ \\
& $\mathrm{~V}^{4+}$ & 1.13 & $4.0 \times 10^{14}$ & $-1.80 \times 10^{10}$ & $9.43 \times 10^{5}$ \\
spinel & $\mathrm{V}^{5+}$ & 0.0142 & $7.0 \times 10^{14}$ & $-3.06 \times 10^{10}$ & $1.26 \times 10^{6}$ \\
& $\mathrm{~V}^{3+}$ & 15.3 & $1.0 \times 10^{14}$ & $-7.70 \times 10^{9}$ & $6.28 \times 10^{5}$ \\
& $\mathrm{~V}^{4+}$ & 1.44 & $4.0 \times 10^{14}$ & $-1.80 \times 10^{10}$ & $9.43 \times 10^{5}$ \\
garnet & $\mathrm{V}^{5+}$ & 0.00303 & $7.0 \times 10^{14}$ & $-3.06 \times 10^{10}$ & $1.26 \times 10^{6}$ \\
& $\mathrm{~V}^{3+}$ & 3.88 & $1.0 \times 10^{14}$ & $-7.70 \times 10^{9}$ & $6.28 \times 10^{5}$ \\
melt & $\mathrm{V}^{4+}$ & 1.13 & $4.0 \times 10^{14}$ & $-1.80 \times 10^{10}$ & $9.43 \times 10^{5}$ \\
& $\mathrm{~V}^{5+}$ & 0.0142 & $7.0 \times 10^{14}$ & $-3.06 \times 10^{10}$ & $1.26 \times 10^{6}$ \\
& $\mathrm{~V}^{3+}$ & 1 & $1.0 \times 10^{14}$ & $-7.70 \times 10^{9}$ & $6.28 \times 10^{5}$ \\
& $\mathrm{~V}^{4+}$ & 1 & $4.0 \times 10^{14}$ & $-1.80 \times 10^{10}$ & $9.43 \times 10^{5}$ \\
& $\mathrm{~V}^{5+}$ & 1 & $7.0 \times 10^{14}$ & $-3.06 \times 10^{10}$ & $1.26 \times 10^{6}$ \\
\hline
\end{tabular}

The full results of the $\mathrm{V}$ isotope model, showing the isotopic composition of each phase calculated in KLB1, MIX1G and G2, are in Fig. S3. Note that stable isotope fractionation can only be calculated where there is liquid present, i.e., where the proportion of each $\mathrm{V}$ valence state can be calculated.

\section{$3.4 \mathrm{Cr}$}

The proportion of $\mathrm{Cr}^{2+/ 3+}$ was calculated using the parameterisation given in Berry et al. (2021)

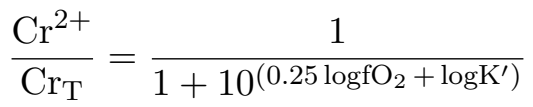



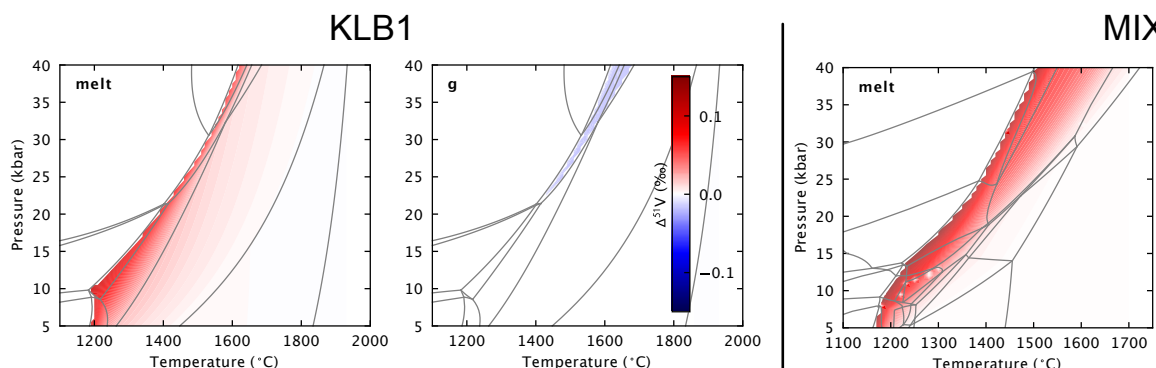

MIX1G
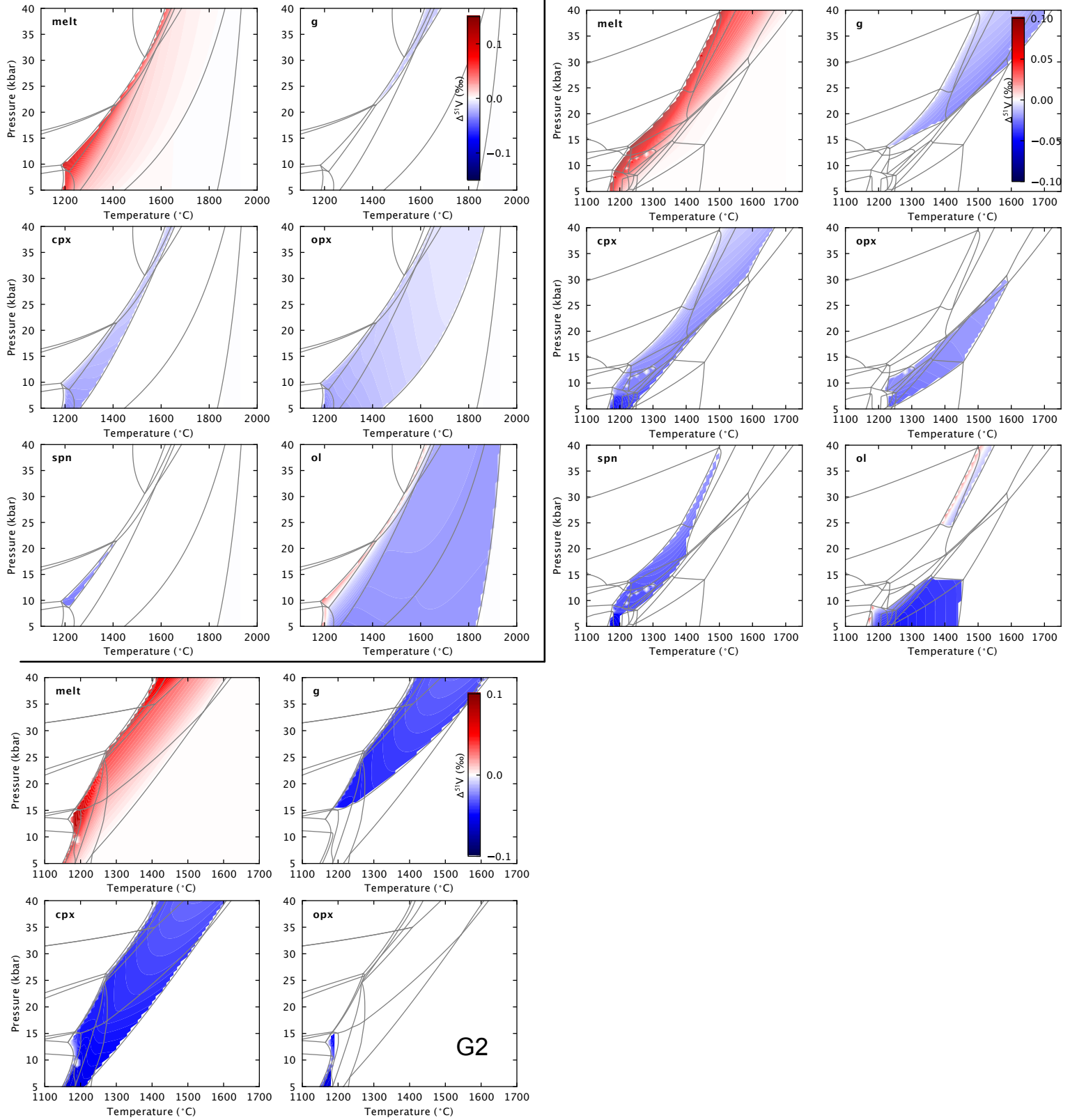

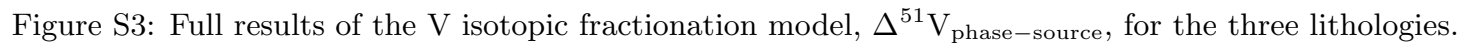


Table S7: Optical basicity values for each oxide, from Mills (1993).

\begin{tabular}{cccccccccc}
\hline \multicolumn{8}{c}{ optical basicity, $\Lambda$} \\
$\mathrm{SiO}_{2}$ & $\mathrm{TiO}_{2}$ & $\mathrm{Al}_{2} \mathrm{O}_{3}$ & $\mathrm{Fe}_{2} \mathrm{O}_{3}$ & $\mathrm{Cr}_{2} \mathrm{O}_{3}$ & $\mathrm{FeO}$ & $\mathrm{CaO}$ & $\mathrm{MgO}$ & $\mathrm{Na}_{2} \mathrm{O}$ & $\mathrm{K}_{2} \mathrm{O}$ \\
\hline 0.48 & 0.61 & 0.60 & 0.75 & 0.58 & 1 & 1 & 0.78 & 1.15 & 1.4 \\
\hline
\end{tabular}

with $\mathrm{fO}_{2}$ calculated at each P-T point using the $\mathrm{fO}_{2}$ melt software (Holland et al., 2018), and the modified equilibrium constant calculated by

$$
\log \mathrm{K}^{\prime}=\frac{9770}{\mathrm{~T}}-7.69+6.22 \Lambda+\frac{\left(900 \mathrm{P}-172 \mathrm{P}^{2}\right)}{\mathrm{T}}
$$

where $\mathrm{T}$ is in Kelvin, $\mathrm{P}$ is in GPa. $\Lambda$ is the optical basicity, a composition-dependent term (Duffy, 1993) which reflects equilibrium between bridging oxygens, non-bridging oxygens and free oxide anions in a melt (Humphreys et al., 2015). Since optical basicity values can be assigned to individual oxides (Duffy, 1993), an ideal optical basicity for a melt can be calculated, following Mills (1993), as

$$
\Lambda=\frac{\sum \mathrm{X}_{\mathrm{i}} \mathrm{n}_{\mathrm{i}} \Lambda_{\mathrm{i}}}{\sum \mathrm{X}_{\mathrm{i}} \mathrm{n}_{\mathrm{i}}}
$$

where $\mathrm{X}_{\mathrm{i}}$ is the mole fraction of oxide $\mathrm{i}, \mathrm{n}$ is the number of $\mathrm{O}$ associated with oxide $\mathrm{i}$, and $\Lambda$ is the theoretical $\Lambda$ of oxide i (see Table S7). At each P-T point, the calculated $\Lambda$ was used with equations 3 and 4 to calculate $\mathrm{Cr}$ redox state.

The partition coefficients of each valence state of $\mathrm{Cr}$ in the Cr-bearing mantle minerals (olivine, clinopyroxene, orthopyroxene, garnet, spinel) are given in Table S8. Partition coefficients for olivine, clinopyroxene, orthopyroxene are from (Mallmann and O'Neill, 2009); for spinel from the supplement of Shen et al. (2018), for garnet from Sutton et al. (2008). The ionic model inputs (Table S8) are based on the supplement of Shen et al. (2018); for garnet, where no ionic inputs are presented in Shen et al. (2018), we take coordination information from Deer et al. (2013), and use the relevant ionic radii as used by Shen et al. (2018). The force constants for Cr-O bonds were then calculated based on the equations presented in Sossi and O'Neill (2017) for Fe isotopes.

Table S8: Parameters for Cr partitioning and isotopic fractionation model. Partition coefficients (D) from Mallmann and O'Neill (2009); Shen et al. (2018); Sutton et al. (2008). Mineral site and bonding information is based

\begin{tabular}{|c|c|c|c|c|c|c|c|}
\hline Mineral & Cr species & $\mathrm{D}_{\min -\text { melt }}$ & Site & Cr coordination & Bond length $(\AA)$ & O coordination & No. sites \\
\hline spinel & $2+$ & 0 & $\mathrm{n} / \mathrm{a}$ & $\mathrm{n} / \mathrm{a}$ & $\mathrm{n} / \mathrm{a}$ & $\mathrm{n} / \mathrm{a}$ & $\mathrm{n} / \mathrm{a}$ \\
\hline spinel & $3+$ & 220 & M & 6 & 1.995 & 4 & 2 \\
\hline garnet & $2+$ & 0 & $\mathrm{n} / \mathrm{a}$ & $\mathrm{n} / \mathrm{a}$ & $\mathrm{n} / \mathrm{a}$ & $\mathrm{n} / \mathrm{a}$ & $\mathrm{n} / \mathrm{a}$ \\
\hline garnet & $3+$ & 12 & M2 & 6 & 1.995 & 4 & 2 \\
\hline olivine & $2+$ & 0.85 & $\mathrm{M} 2$ & 6 & 2.18 & 4 & 1 \\
\hline olivine & $3+$ & 0.85 & M1 & 6 & 1.995 & 4 & 1 \\
\hline opx & $2+$ & 0.843 & M2 & 7 & 2.305 & 3.57 & 1 \\
\hline opx & $3+$ & 3.52 & M1 & 6 & 1.988 & 3.67 & 1 \\
\hline $\operatorname{cpx}$ & $2+$ & 0.587 & M2 & 7 & 2.305 & 3.57 & 1 \\
\hline $\operatorname{cpx}$ & $3+$ & 12.6 & M1 & 6 & 1.988 & 3.67 & 1 \\
\hline liquid & $2+$ & 1 & & 4 & 1.913 & 4 & \\
\hline liquid & $3+$ & 1 & & 6 & 1.995 & 4 & \\
\hline
\end{tabular}
on Shen et al. (2018). cpx = clinopyroxene, opx = orthopyroxene.

The full results of the $\mathrm{Cr}$ model, showing the isotopic composition of each phase calculated in KLB1, MIX1G and G2, are in Fig. S4. Note that stable isotope fractionation can only be calculated where there is liquid present, i.e., where the proportion of each $\mathrm{Cr}$ valence state can be calculated. 
KLB1
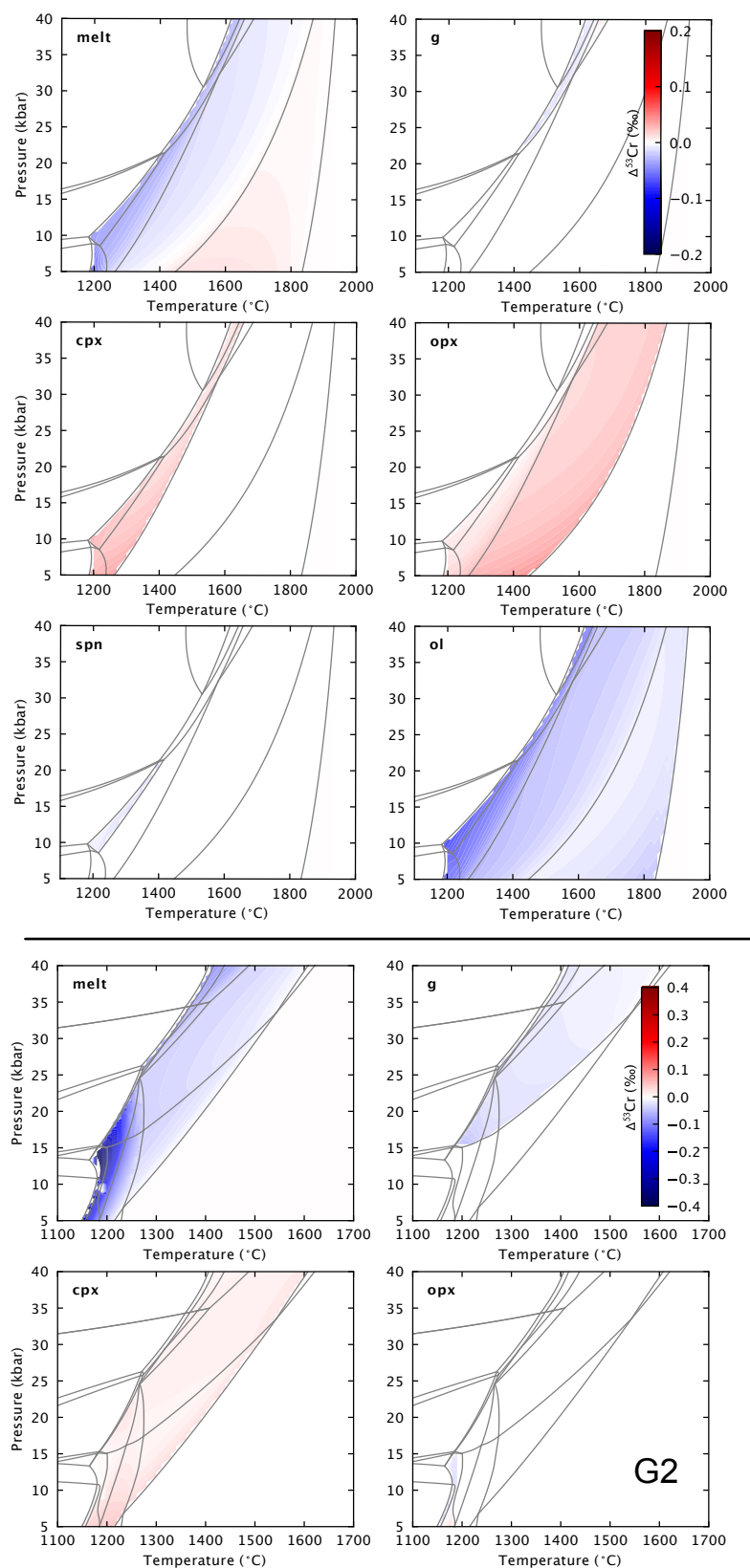

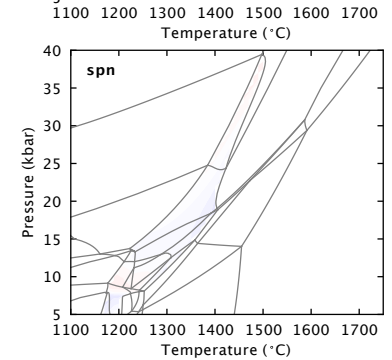

Temperature $\left({ }^{\circ} \mathrm{C}\right)$

MIX1G
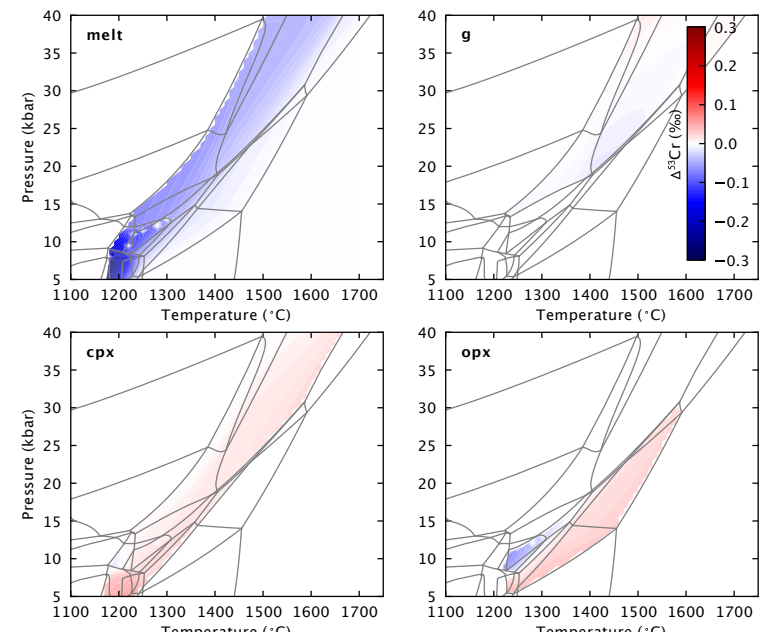

$11001200 \quad 130014001500$
Temperature $\left({ }^{\circ} \mathrm{C}\right)$
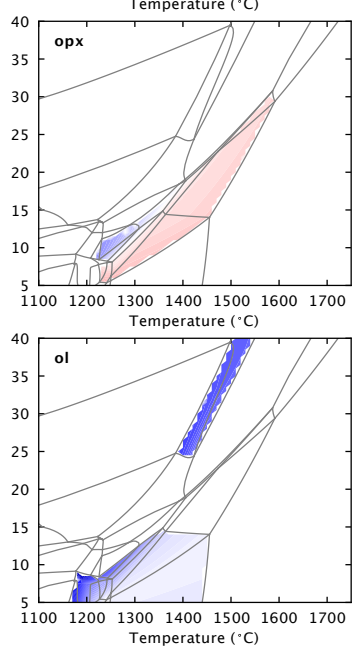

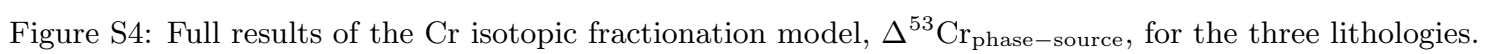




\subsection{Consistency of valence state calculations}

As discussed in the main text, the calculated $\mathrm{Fe}^{3+} / \mathrm{Fe}_{\mathrm{T}}, \mathrm{Cr}^{3+} / \mathrm{Cr}_{\mathrm{T}}$ and $\mathrm{V}^{4+, 5+} / \mathrm{V}_{\mathrm{T}}$ are not fully self-consistent, as the speciation of both $\mathrm{Cr}$ and $\mathrm{V}$ are calculated based on the $\mathrm{Fe}^{3+} / \mathrm{Fe}_{\mathrm{T}}$ at any point. This means that $\mathrm{O}$ (oxygen) is being partitioned into the oxidised $\mathrm{Cr}$ and $\mathrm{V}$ oxides without affecting Fe redox state. We consider tying the $\mathrm{Cr}$ and $\mathrm{V}$ valence states to the Fe redox equilibria to be reasonable, as $\mathrm{Fe}$ is the dominant redox-sensitive element in the mantle with an abundance considerably greater than that of $\mathrm{Cr}$ or $\mathrm{V}$. To quantify this, we have calculated the fraction of oxygen associated with oxidised valence states of the each redox-sensitive element out of the total oxygen associated with the oxidised valence states, e.g.,

$$
\frac{\mathrm{O}_{\mathrm{Fe}^{3+}}}{\mathrm{O}_{\mathrm{Fe}^{3+}}+\mathrm{O}_{\mathrm{Cr}^{3+}}+\mathrm{O}_{\mathrm{V}^{4+}}+\mathrm{O}_{\mathrm{V}^{5+}}}
$$

where $\mathrm{O}_{\mathrm{X}}$ represents the number of moles of oxygen associated with cation $\mathrm{X}$ at any given $\mathrm{P}-\mathrm{T}$ point. At $\mathrm{T}=1300{ }^{\circ} \mathrm{C}$ and $\mathrm{P}=12 \mathrm{kbar}$, we calculate that $73 \%$ of the oxygen associated with oxidised cations is associated with $\mathrm{Fe}^{3+}, 27 \%$ with $\mathrm{Cr}^{3+}$, and $<0.01 \%$ with $\mathrm{V}^{4+, 5+}$, for total Fe, Cr and V contents in peridotite (Davis et al., 2009; Salters and Stracke, 2004).

However, although our use of the Fe redox equilibria to calculate $\mathrm{Cr}$ and $\mathrm{V}$ speciation is a reasonable approximation, it is important to note that considering the combined Fe-Cr-V redox equilibria as in real systems would reduce the variability in the redox state of each element across P-T space compared to our model. This is because the combined effect of considering three redox equilibria able to accommodate oxygen via their oxidised cations together is that each system will have to shift its redox equilibria less compared to a scenario where only one redox-sensitive element is considered. To approximately quantify the effect of this redox feedback, we took an extreme case of reducing all the $\mathrm{Cr}_{2} \mathrm{O}_{3}$ in the melt at a given P-T point, accommodating the released oxygen by increasing the amount of $\mathrm{Fe}_{2} \mathrm{O}_{3}$ and reducing the amount of $\mathrm{FeO}$ accordingly. We then calculated the $\mathrm{fO}_{2}$ of this new composition through the $\mathrm{fO}_{2}$ melt software (Holland et al., 2018), and recalculated the expected $\mathrm{Cr}^{3+} / \mathrm{Cr}_{\mathrm{T}}$ given the new $\mathrm{fO}_{2}$. We find that, for this calculation performed using at $\mathrm{T}=1350{ }^{\circ} \mathrm{C}$ and $\mathrm{P}=12 \mathrm{kbar}$, the $\mathrm{fO}_{2}$ change produces a $1 \%$ change in $\mathrm{Cr}^{3+} / \mathrm{Cr}_{\mathrm{T}}$ and negligible impact on the calculated $\delta^{53} \mathrm{Cr}$.

\section{Alternative input parameters and results}

The inputs into the isotope fractionation models are better constrained for some of the stable isotope systems considered relative to others. These uncertainties limit our ability to predict the behaviour of some isotope systems in high temperature settings, and therefore limit the utility of stable isotopes as a tool for exploring global basalt systematics. Here we discuss the results of using alternative inputs.

\subsection{Mg: $\alpha_{\text {orthopyroxene-melt }}=1$}

While the bonding of $\mathrm{Mg}$ in crystal lattices can be used to calculate a self-consistent set of $\beta^{\mathrm{Mg}}$ factors (Schauble, 2011; Huang et al., 2013) to input into the melting model, $\beta^{\mathrm{Mg}}$ factors do not exist for silicate liquid. However, Stracke et al. (2018) show that $\alpha_{\text {olivine, orthopyroxene-melt }} \sim 1$ based on equilibrated peridotite xenoliths. $\mathrm{Mg}$ is also similarly coordinated ([5-6] fold) in melt and olivine/orthopyroxene (George and Stebbins, 1998; Shimoda et al., 2007; Stracke et al., 
2018), providing further evidence for minimal olivine/orthopyroxene - melt Mg stable isotope fractionation at magmatic temperatures.

We have chosen to use $\alpha_{\text {olivine-melt }}=1$; i.e., using the same $\beta^{\mathrm{Mg}}$ values for liquid as for olivine. The alternative is to use $\alpha_{\text {orthopyroxene-melt }}=1$. Fig. S5 compares the $\Delta^{26} \mathrm{Mg}$ melt-source for an input of $\alpha_{\text {olivine-melt }}=1$ (left hand panels; these are the results used in the main text) with an input of $\alpha_{\text {orthopyroxene-melt }}=1$ (right hand panels). The new input parameters replace the melt in Table S4 with Table S9.

Table S9: Alternate parameters for $\mathrm{Mg}$ isotope $\beta^{\mathrm{Mg}}$ factors from Huang et al. (2013). 1000ln $\beta=\mathrm{a} / \mathrm{T}^{6}+\mathrm{b} / \mathrm{T}^{4}$ $+\mathrm{c} / \mathrm{T}^{2}$, where $\mathrm{T}=$ temperature (Kelvin).

\begin{tabular}{lrrr}
\hline Mineral & $\mathrm{a}$ & $\mathrm{b}$ & $\mathrm{c}$ \\
\hline melt & $-8.10 \times 10^{15}$ & $6.65 \times 10^{10}$ & $2.25 \times 10^{6}$ \\
\hline
\end{tabular}

For KLB1 peridotite, the magnitude of the difference in melt isotope composition between the two models is $\approx 0.05 \%$ (small compared to the average analytical uncertainty of $0.1 \%$ suggested in Stracke et al., 2018, and similar to the long-term 2 S.D. of $0.06 \%$ given in Wang et al., 2021), however the direction of partial melting fractionation is different. In the case of $\alpha_{\text {olivine-melt }}=1$, KLB1 melts are isotopically lighter than the bulk, and get heavier with increasing degree of melting (the latter part of this behaviour is consistent with fractional melting modelled by Stracke et al., 2018). For $\alpha_{\text {orthopyroxene-melt }}=1$, partial melts are isotopically heavier than the bulk, and get progressively lighter with increasing degree of melting (the former part of this behaviour is consistent with Stracke et al., 2018).

For KLB1, the similar differences in modelled melting isotopic fractionation relative to the analytical uncertainty means that the choice of $\alpha_{\text {olivine-melt }}=1$ or $\alpha_{\text {orthopyroxene-melt }}=1$ for liquid does not greatly alter any conclusions drawn from the peridotite melting. Minimal difference between the models is also seen for MIX1G. However, low pressure melts from G2 $(<15 \mathrm{kbar})$ show effectively no stable isotope fractionation when $\alpha_{\text {orthopyroxene-melt }}=1$ is used, compared to fractionations as large as $\Delta^{26} \mathrm{Mg}=-0.1 \%$ with $\alpha_{\text {olivine-melt }}=1$. This is because, for these shallow depths, the only stable Mg-bearing phases in G2 are clinopyroxene and liquid (garnet is not stable). Orthopyroxene and clinopyroxene have similar $\beta^{\mathrm{Mg}}$ factors and therefore, when liquid is given the same $\beta^{\mathrm{Mg}}$ factor as orthopyroxene, the coexisting liquid and clinopyroxene are only minimally isotopically fractionated from each other. These results highlight how important accurate experimental $\alpha_{\text {mineral-melt }}$ are for understanding the behaviour of stable isotope systems, and the important role analytical precision plays in being able to identify these effects in nature. Magnesium stable isotopes would benefit from further work in both of these areas.

\section{$4.2 \mathrm{Ca}$}

The $\beta^{\mathrm{Ca}}$ value approach reduces uncertainties associated with an ionic model, as the bond lengths and $\mathrm{Ca}, \mathrm{O}$ coordination numbers in the relevant mineral structures required for the ionic model are variable in the literature (e.g., Feng et al., 2014; Huang et al., 2019). Huang et al. (2019) present an alternative set of $\beta^{\mathrm{Ca}}$ values for the Ca-bearing minerals we are concerned with, although Antonelli et al. (2019) argue that the PBE functionals used in their own study better represent $\mathrm{Ca}$ isotope fractionation between species than the less accurate LDA functionals used by Huang et al. (2019). Additionally, Antonelli et al. (2019) calculate $\beta^{\mathrm{Ca}}$ for pyrope garnet, which is more representative of mantle garnet than the grossular endmember used in Huang et al. (2019). Our model uses $\beta_{\text {plagioclase }}^{\mathrm{Ca}}<\beta_{\text {melt }}^{\mathrm{Ca}}<\beta_{\text {clinopyroxene }}^{\mathrm{Ca}}$ (see explanation in Section 

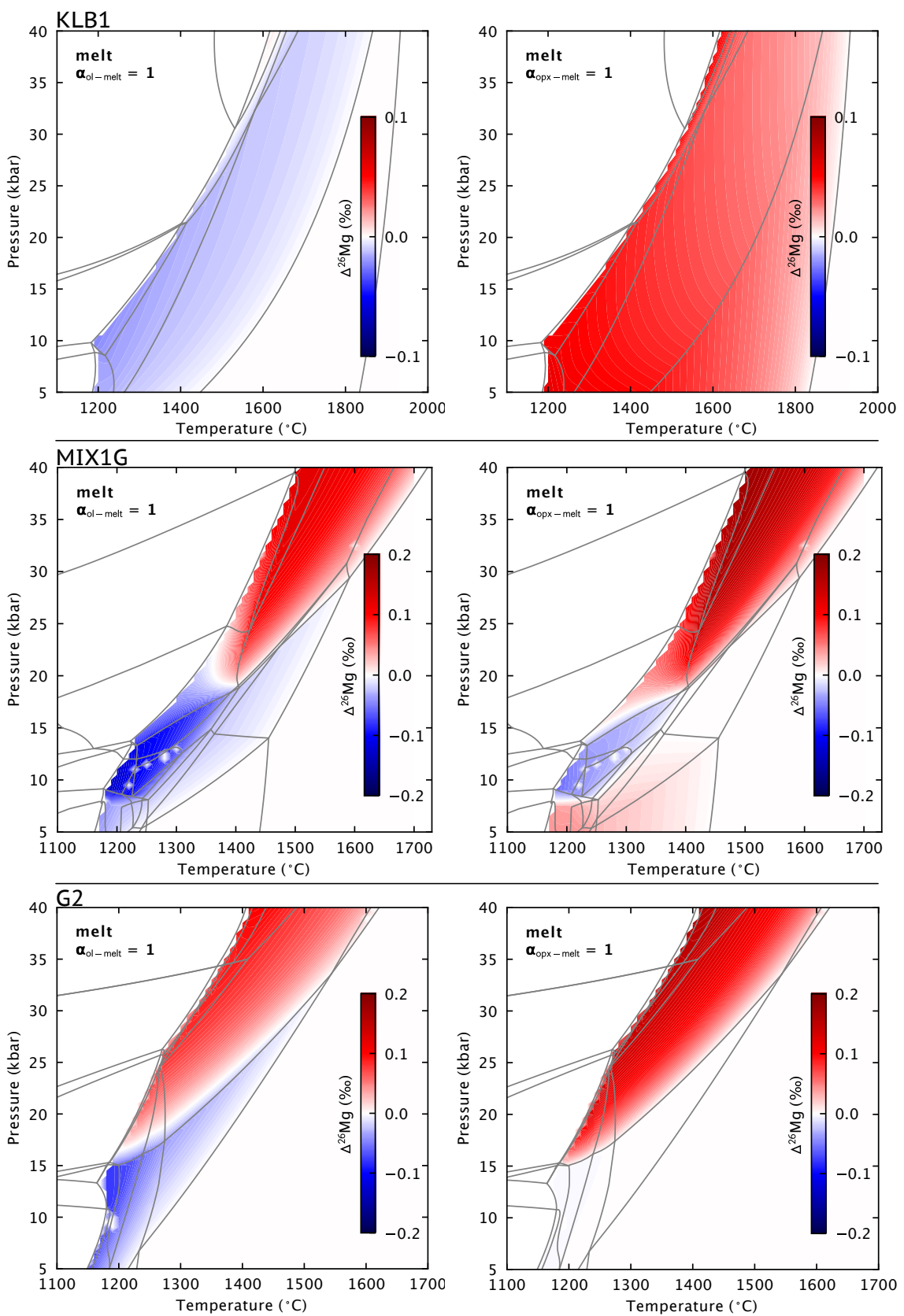

Figure S5: $\Delta^{26} \mathrm{Mg}_{\text {melt-source }}$ compared for a model where $\alpha_{\text {olivine-melt }}=1$ (left hand plots) and $\alpha_{\text {orthopyroxene-melt }}$ $=1$ (right hand plots) for all three lithologies considered.

3.2), but some studies do suggest that $\beta_{\mathrm{melt}}^{\mathrm{Ca}}=\beta_{\text {clinopyroxene }}^{\mathrm{Ca}}$ (e.g., Chen et al., 2019) based on observations from natural equilibrated peridotite and pyroxenite samples that there is minimal Ca isotope fractionation between clinopyroxene and basaltic melt. Independent estimates of the force constants in silicate liquids and further experimental constraints on the behaviour of $\mathrm{Ca}$ isotopes in silicate melts are therefore needed to improve the $\mathrm{Ca}$ isotope fractionation model.

Fig. S6 shows the results of using the $\beta^{\mathrm{Ca}}$ values from Huang et al. (2019) with $\beta_{\text {melt }}^{\mathrm{Ca}}=$ $\beta_{\text {clinopyroxene }}^{\mathrm{Ca}}$ (equivalent to $\alpha_{\text {clinopyroxene-melt }}=1$ ). The use of isotopically lighter grossular garnet and isotopically heavier melt (relative to the Antonelli et al. (2019) inputs) result in overall less negative melt-source isotope fractionation than in the main model, making all $\mathrm{Ca}$ 
isotope fractionations harder to resolve with current analytical precision. However, none of the conclusions presented in the main text are altered by these alternative parameter choices.
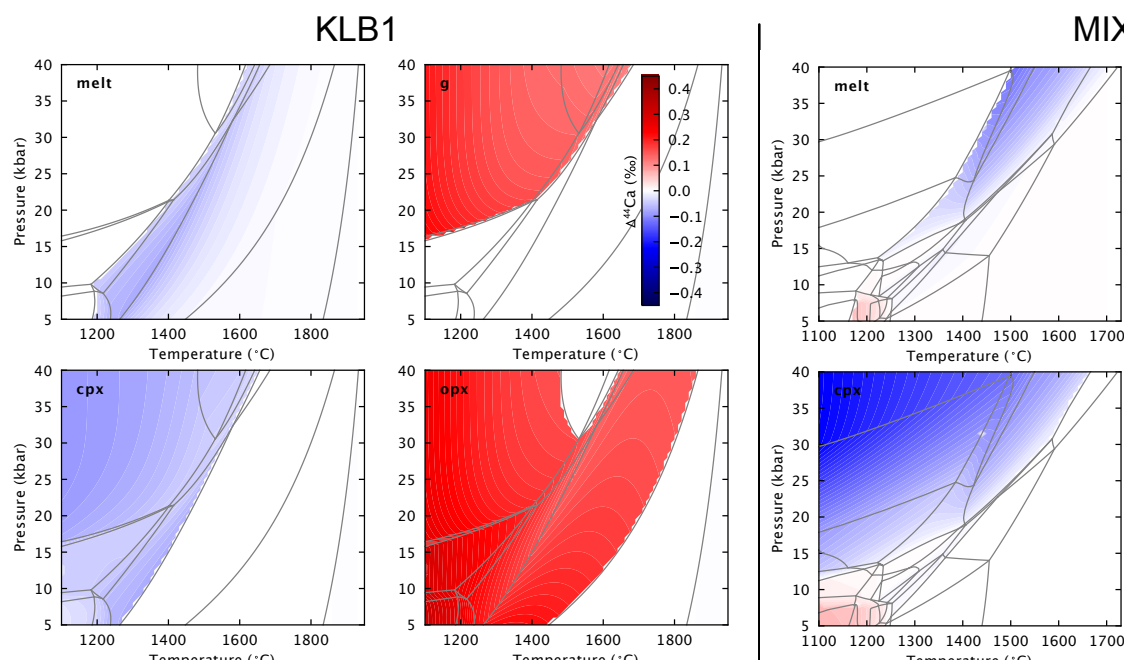

MIX1G
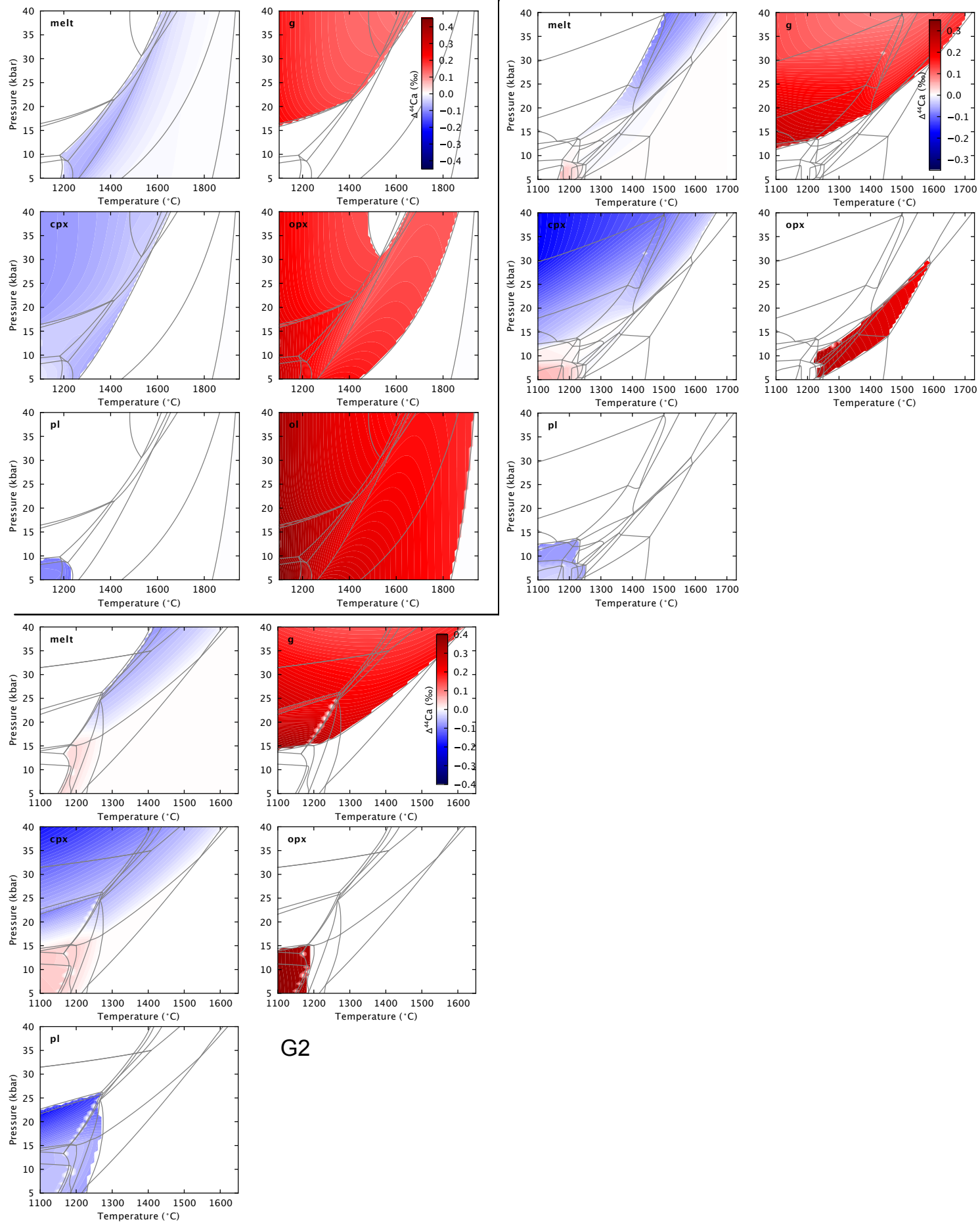

G2

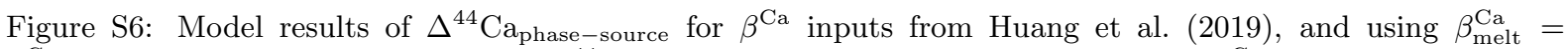

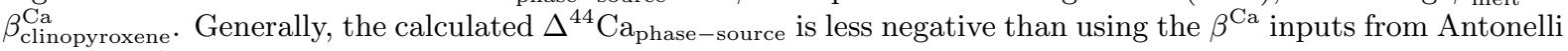
et al. (2019) as shown in Fig. S2.

The composition of the phases involved further complicates models of Ca isotope fractionation. Feng et al. (2014) and Wang et al. (2017) show that Ca-O bond strength, hence isotopic fractionation, in orthopyroxene is dependent on the $\mathrm{Ca}$ and $\mathrm{Fe}$ content of the pyroxene, al- 
though the concentrations of these elements in natural orthopyroxenes may produce negligible concentration effects on isotopic fractionation (Wang et al., 2017). The isotopic fractionation associated with garnet, in particular, is sensitive to Ca content for typical mantle compositions, with a garnet-composition-sensitive fractionation factor produces smaller melting fractionations in eclogite than using a fixed composition model (Chen et al., 2020a). Our model has not implemented composition-specific fractionation factors, although does use the pyrope garnet endmember which is most representative of mantle garnet. We also note that Antonelli et al. (2019) calculate compositional effects for olivine and pyroxene solid solutions that are smaller than those predicted using LDA functionals (e.g., Feng et al., 2014; Wang et al., 2017).

\section{$4.3 \quad \mathrm{Fe}$}

The model inputs for Fe isotope fractionation are relatively well constrained. The bonding environment of Fe in mineral phases is well studied, making an ionic model approach possible (e.g., Sossi and O'Neill, 2017). The model based on ionic inputs produces isotopic fractionation and force constant predictions consistent with predictions by other methods and observations (e.g., Dauphas et al., 2014; Macris et al., 2015). In addition, the Fe-O force constants in basaltic glass as a function of $\mathrm{Fe}^{3+}$ content have been experimentally determined (Dauphas et al., 2014), allowing the melt isotopic fractionation to be independently parameterised into the model (although we note the potential complication induced by quenching effects, and by melt generation in the mantle at non-atmospheric pressure). As discussed by Sossi and O'Neill (2017), some terms in the ionic model approach (such as the ionicity of the bonds) are less well constrained than the bonding environment of Fe in mineral structures, however the resultant fractionation factors are minimally affected by these uncertainties.

\section{$4.4 \mathrm{~V}: \mathrm{V}_{\text {melt }}^{5+}=[4]$ coordinated}

It has been suggested that vanadium isotopes may track magmatic redox (Prytulak et al., 2013, 2017; Sossi et al., 2018b; Wu et al., 2018) due to the existence of three valence states $(3+, 4+$, $5+$ ) in terrestrial magmatic systems (Canil, 1999), though a better understanding of V isotope behaviour during magmatic processes is required to exploit the system's full potential as a redox tracer (Prytulak et al., 2017). The successful modelling of V isotope fractionation therefore relies on an understanding of the behaviour of each valence state of $\mathrm{V}$.

Although slightly variable $\mathrm{V}$ partition coefficients for each valence state into mineral phases can be found from experimental studies (Mallmann and O'Neill, 2009), these variations make no significant difference to the calculated melt isotopic compositions. The main uncertainty in the $\mathrm{V}$ fractionation model inputs is the coordination of $\mathrm{V}^{4+}$ and $\mathrm{V}^{5+}$ in silicate melts (and associated $\beta^{V}$ factors). $\mathrm{V}^{4+}$ in silicate liquid is [5-6] coordinated (Sutton et al., 2005), and $\mathrm{V}^{4+}$ coordination of both [5.33] and [6] have been used in existing studies discussing $\mathrm{V}$ isotope behaviour during melting (Qi et al., 2019; Wu et al., 2018 respectively). $\mathrm{V}^{5+}$ coordination in silicate melts is [4-6] (Sutton et al., 2005; Righter et al., 2006), with Qi et al. (2019) quoting an average of [5] coordination. As one of the main causes of $\mathrm{V}$ isotope fractionation during melting is predicted to be the relative compatibility of $\mathrm{V}^{5+}$ (and to a lesser extent $\mathrm{V}^{4+}$ ) in melts relative to minerals (e.g., Canil, 2002; Mallmann and O'Neill, 2009; Wu et al., 2018), the bonding environment and force constants of $\mathrm{V}$ species in the melt is a particularly important input. The choice of coordination number for the $\mathrm{V}$ species controls the $\ln \beta$ value chosen for that species: $\beta^{\mathrm{V}}$ values are taken from those calculated for different bonding environments in 
aqueous solutions (Wu et al., 2015), assumed to be a good approximation to the case of silicate melts following $\mathrm{Wu}$ et al. (2018). [5] coordination of $\mathrm{V}^{5+}$ is not modelled in $\mathrm{Wu}$ et al. (2015), and therefore only the cases of $\mathrm{V}^{5+}$ in [4] and [6] coordination can be used, for which $\beta^{\mathrm{V}}$ values have been calculated. No calculations are available for $\mathrm{V}^{4+}$ in [5] coordination, and therefore the model only considers $\mathrm{V}^{4+}$ in [6] coordination.

Fig. S7 compares the $\Delta^{51} \mathrm{~V}_{\text {melt-source }}$ for an input of $\mathrm{V}_{\text {melt }}^{5+}=[6]$-fold coordination (left hand panels; these are the results used in the main text) with an input of $\mathrm{V}_{\text {melt }}^{5+}=[4]$-fold coordination (right hand panels). There are two aqueous complexes with 4 -fold $\mathrm{V}^{5+}$ in $\mathrm{Wu}$ et al. (2015). Here we have chosen the $\beta^{\mathrm{V}}$ factors for the $\left[\mathrm{V}^{5+} \mathrm{O}_{2}(\mathrm{OH})_{2}\right]^{-}$(Table S10) complex since this complex has the greatest $\ln \beta^{\mathrm{V}}$ difference from the [6]-fold coordinated case, therefore covering the greatest range of input uncertainty.
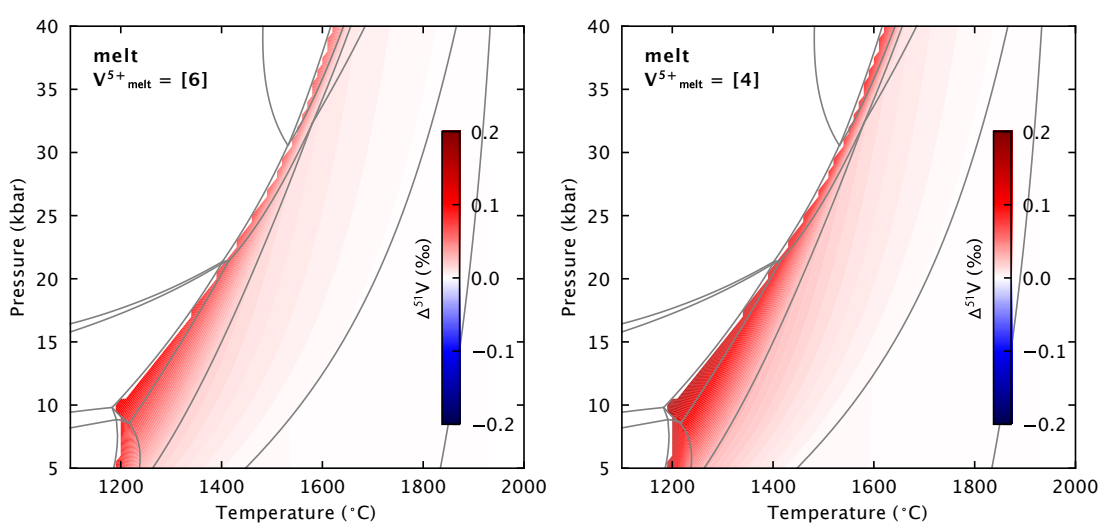

Figure S7: $\Delta^{51} \mathrm{~V}_{\text {melt-source }}$ compared for a model where $\mathrm{V}_{\text {melt }}^{5+}=[6]$ coordinated (left hand plots) and $\mathrm{V}_{\text {melt }}^{5+}=$ [4] coordinated (right hand plots) for KLB1.

Table S10: Alternate parameters for $\mathrm{V}$ isotope $\beta^{\mathrm{V}}$ factors from $\mathrm{Wu}$ et al. (2015). $1000 \ln \beta=\mathrm{a} / \mathrm{T}^{6}+\mathrm{b} / \mathrm{T}^{4}+$ $\mathrm{c} / \mathrm{T}^{2}$, where $\mathrm{T}=$ temperature (Kelvin).

\begin{tabular}{lrrrr}
\hline Mineral & Valence & $\mathrm{a}$ & $\mathrm{b}$ & $\mathrm{c}$ \\
\hline melt & $\mathrm{V}^{5+}$ & $7.00 \times 10^{14}$ & $-3.25 \times 10^{10}$ & $1.42 \times 10^{6}$ \\
\hline
\end{tabular}

The model discussed in the main text is the result of using the upper limit of [6] coordinated $\mathrm{V}^{5+}$ : this will provide the minimum melting fractionation, since a higher coordination number results in weaker V-O bonds, and less extreme isotopic fractionation. Using an input of [4] coordinated $\mathrm{V}^{5+}$ results in isotopically heavier melts, with the maximum KLB1 melting stable isotope fractionation increasing from $\approx 0.1 \%$ in the $[6]$ coordinated case to $\approx 0.15 \%$ close to the solidus around $10 \mathrm{kbar}$ (Fig. S6 for full results) in the [4] coordinated case. However, the difference between the two models decreases at higher temperature, and for the temperature range of interest here (potential temperatures from $1300-1530^{\circ} \mathrm{C}$ ), at $5 \mathrm{kbar}$ the difference in melt isotopic composition between the two models is $\approx 0.01 \%$, and therefore negligible. However, to improve understanding of high temperature $\mathrm{V}$ behaviour and link natural data to specific processes, experimental and/or theoretical work on equilibrium isotopic fractionation factors for silicate melt and minerals for different $\mathrm{V}$ species is needed. 


\section{5 $\mathrm{Cr}: \mathrm{Cr}_{\mathrm{melt}}^{2+}=[6]$ coordinated}

As chromium is a first-group transition element, the properties controlling isotopic fractionation behaviour (e.g., valence, ionic radius hence bonding environment) of $\mathrm{Cr}^{2+}$ and $\mathrm{Cr}^{3+}$ ions may be expected to be similar to $\mathrm{Fe}^{2+}$ and $\mathrm{Fe}^{3+}$ ions (Xia et al., 2017). The main Cr-bearing phases in the mantle are spinel, garnet and pyroxenes, although some $\mathrm{Cr}$ will partition into olivine (Mallmann and O'Neill, 2009), and as with vanadium, partition coefficients depend on the valence state of Cr (Mallmann and O'Neill, 2009).

As a set of $\beta^{\mathrm{Cr}}$ factors for mantle minerals does not exist, our models of Cr stable isotope fractionation use force constants in each mineral calculated from an ionic bonding model (Shen et al., 2018), following the approach used for Fe isotopes. An ionic model has been shown to produce inter-mineral fractionation in agreement with the magnitude of isotope fractionation inferred from studies of lherzolite mineral pairs (Shen et al., 2018). As with V isotopes, the main uncertainty relating to species coordination is in liquid. $\mathrm{Cr}^{2+}$ in silicate melt is reported to be in [4] coordination (Miletich et al., 1999; O'Neill and Berry, 2006; Shen et al., 2020), but may also be in [6] coordination in a square planar arrangement (O'Neill and Berry, 2006). The isotope fractionation model presented here calculates force constants using effective anionic and cationic radii based on Shannon (1976), following the approach outlined in Shen et al. (2018), and these radii depend negatively on the coordination number chosen (Gibbs et al., 2014).

Fig. S8 compares the $\Delta^{53} \mathrm{Cr}_{\text {melt-source }}$ for an input of $\mathrm{Cr}_{\text {melt }}^{2+}=[4]$ coordinated (left hand panels; these are the results used in the main text) with an input of $\mathrm{Cr}_{\text {melt }}^{2+}=[6]$ coordinated (right hand panels). The input parameters for the [6] coordinated case are in Table S8.

Table S11: Alternate parameters for Cr isotopic fractionation model. Mineral site and bonding information is based on Shen et al. (2018).

\begin{tabular}{lrrrrr}
\hline Mineral & Cr species & Site & Cr coordination & Bond length $(\AA)$ & O coordination \\
\hline melt & $2+$ & n/a & 6 & 2.18 & 4 \\
\hline
\end{tabular}

The model presented in the main text uses an input of $\mathrm{Cr}^{2+}$ in [4] coordination in the melt. Inputting [6] coordinated $\mathrm{Cr}^{2+}$ in the melt results in isotopically lighter peridotite melts across all of P-T space (Fig. S8) than the [4] coordinated case as a consequence of weaker Cr-O bonds in a [6] coordinated environment than [4] coordinated. A similar effect is seen in MIX1G and G2 melts. The melt-source isotopic fractionation is always negative, consistent with modelling by Shen et al. (2018), and melts get progressively isotopically heavier (towards $0 \%$ fractionation from the source) with increasing degree of melting, consistent with observations from OIB (Bonnand et al., 2020). The cationic radii are likely to be overestimates, as the radii for [6] coordinated Cr used in Shen et al. (2018) assume octahedral, not square planar, coordination. Square planar bonds would be expected to be longer than octahedral, and this would result in even isotopically lighter melts. Therefore, although the model uses the most appropriate available inputs for the more commonly quoted [4] coordination of $\mathrm{Cr}^{2+}$ in melts, our understanding of the behaviour of $\mathrm{Cr}$ isotopes in silicate melts would benefit from further work on the force constants of $\mathrm{Cr}^{2+}$ in glasses, or the inputs required to calculate these such as bonding environment or effective $\mathrm{Cr}-\mathrm{O}$ bond lengths. 

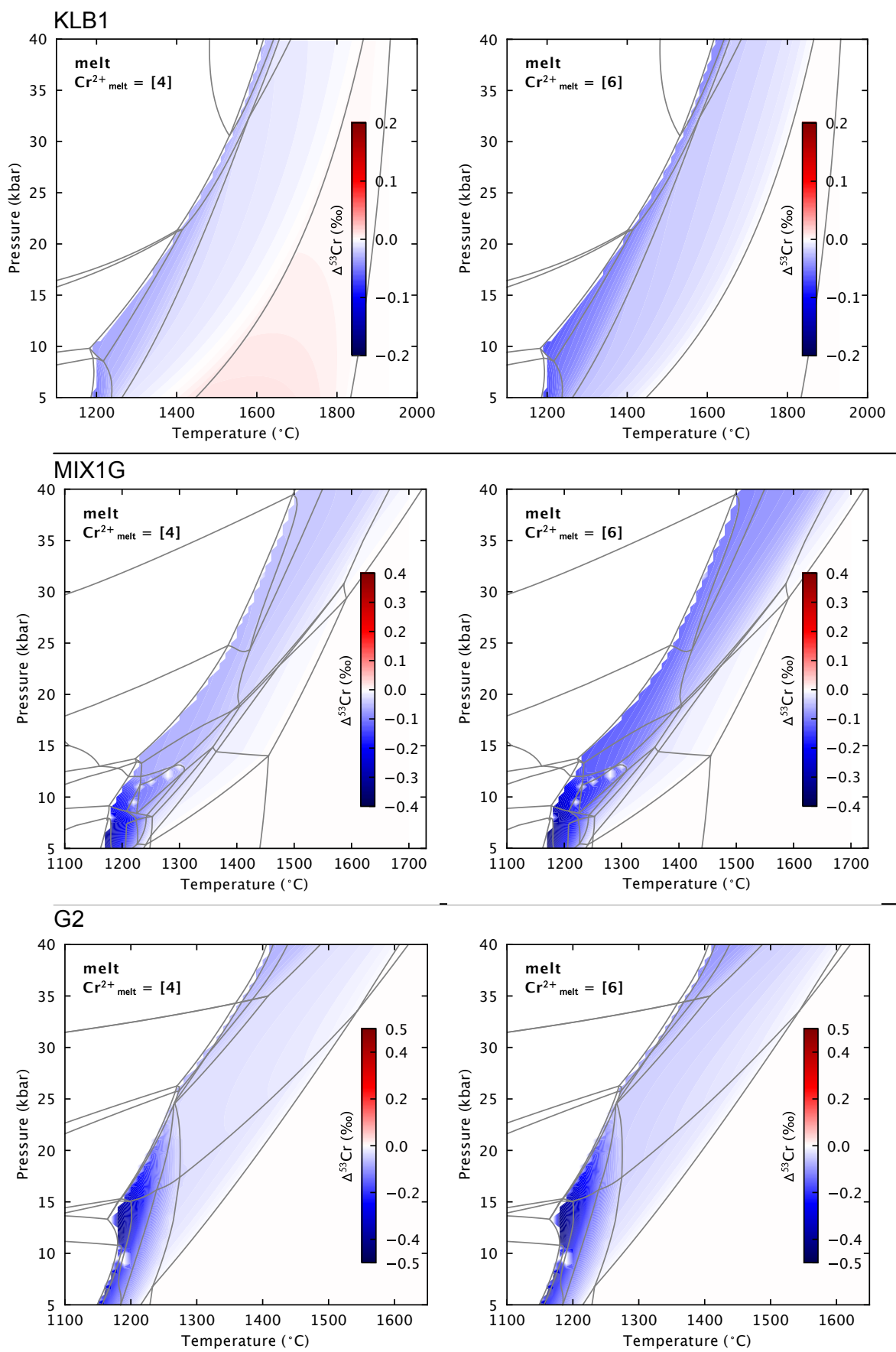

Figure S8: $\Delta^{53} \mathrm{Cr}_{\text {melt-source }}$ compared for a model where $\mathrm{Cr}_{\text {melt }}^{2+}=[4]$ coordinated (left hand plots) and $\mathrm{Cr}_{\text {melt }}^{2+}=$ [6] coordinated (right hand plots) for all three lithologies.

\section{Other potential isotopes}

Other stable isotope systems not considered here might also have potential for investigating mantle heterogeneity (in either lithology or temperature). However, we require a better understanding of the bonding environment in melts or relevant minerals before these isotope systems can be implemented into the stable isotope fractionation models used here.

Like other stable isotope systems, the equilibrium $\delta^{30} \mathrm{Si}$ value of a phase will depend on the 
strength of the Si-O bonds. A more polymerised (or, more Si-rich) phase will have more $\mathrm{Si}-\mathrm{O}$ bonds, therefore a stronger average $\mathrm{Si}-\mathrm{O}$ bond force constant, hence high $\delta^{30} \mathrm{Si}$ (Grant, 1954). However, density functional theory (DFT) calculations show this simple prediction is complicated by the role of other network-modifying cations in silicates (Méheut et al., 2009; Méheut and Schauble, 2014). Silicon isotope fractionation factors have been calculated using DFT for appropriate mantle minerals (Huang et al., 2014), however there is a lack of work on the crucial mineral-melt fractionation information required for the equilibrium fractionation model here. Furthermore, it has been suggested that $\mathrm{Si}$ isotopic fractionation in liquids may be correlated with chemical composition (Qin et al., 2016), an effect that is too complicated (and underconstrained) to model here. This knowledge gap could provide scope for future work, however the mantle is currently thought to be homogeneous in Si isotopes (within current limits of analytical precision), and there seems to be only a small partial melting effect (Savage et al., 2014).

Titanium stable isotopes have been suggested as tracer of magmatic processes (Millet et al., 2016), since Ti can exist in multiple coordination states in silicate melts and Ti-oxides (Farges and Brown Jr, 1997). However, Ti stable isotope fractionation in magmatic systems is dominated by the behaviour of Fe-Ti oxides, with no partial melting fractionation from mantle lithologies expected unless under conditions of Ti-oxide saturation. DFT calculations predict no significant Ti isotope fractionation between pyroxenes, olivine or garnet (Wang et al., 2020), and both eclogites and MORB have the same measured $\delta^{49} \mathrm{Ti}$ value (Millet et al., 2016). Therefore, Ti isotopes are not discussed further here, as there is no existing data to support for their use in tracing temperature or lithological heterogeneity in the mantle associated with MORB or OIB.

\section{Average depth of melting}

The mean melt pressure, $\overline{\mathrm{P}}$, for isentropic melting at any $\mathrm{T}_{p}$ is calculated by the following integral, based on Asimow et al. (2001) with an additional geometric weighting factor to account for the triangular shape of the melting region

$$
\overline{\mathrm{P}}=\frac{\int_{\mathrm{P}_{0}}^{\mathrm{P}_{\mathrm{f}}} \mathrm{P} \Delta \mathrm{FgdP}}{\int_{\mathrm{P}_{0}}^{\mathrm{P}_{\mathrm{f}}} \Delta \mathrm{Fg} \mathrm{dP}}
$$

where $\mathrm{P}_{0}$ and $\mathrm{P}_{\mathrm{f}}$ are the initial and final pressures of melting respectively, $\Delta \mathrm{F}$ is the amount of melt produced at each pressure step $(\mathrm{dP})$ along the isentropic melting path, and $\mathrm{g}$ is the geometric weighting factor. $\mathrm{P}_{0}$ is taken as the intersection of the isentrope with the solidus, $\mathrm{P}_{\mathrm{f}}$ is used as $5 \mathrm{kbar}$ in this model as melt compositions have not been calculated for shallower pressures - this is an overestimate (i.e., final melting will be shallower) for $\mathrm{T}_{p}=1300^{\circ} \mathrm{C}$ and an underestimate for $\mathrm{T}_{p}=1530^{\circ} \mathrm{C}$ (Asimow et al., 2001), but will provide the correct behaviour. Pressure steps used are the $0.5 \mathrm{kbar}$ intervals used in the P-T grid. $\Delta \mathrm{F}$ is calculated for each step from the difference in melt fractions calculated by THERMOCALC for consecutive dP steps. The geometric weighting factor is a linear scaling running from 1 at the base of the melting region to 0 at the top, to account for the wider base of the triangular melting region beneath ridges. We calculate the average melting pressure for the three $\mathrm{T}_{p} \mathrm{~s}$ for which we have calculated isentropes in KLB1, and lineally interpolate between them (this will not be a linear relationship in reality, e.g., Asimow et al., 2001, but our approach will provide a good approximation) to get average melt pressures for temperatures between $\mathrm{T}_{p}=1300^{\circ} \mathrm{C}$ and $1530^{\circ} \mathrm{C}$. For KLB1, we calculate an average melting pressure of approximately $12 \mathrm{kbar}$ at $\mathrm{T}_{p}=1300^{\circ} \mathrm{C}$, and $28 \mathrm{kbar}$ at $\mathrm{T}_{p}=1530^{\circ} \mathrm{C}$. The average $\Delta_{\text {melt-source }}$ for each $\mathrm{T}_{p}$ is then taken as the $\Delta_{\text {melt-source }}$ at the 
calculated average melting pressure.

The approach above, however, uses an equilibrium melt isotope composition at a single pressure to approximate the fractional, multibaric melting thought to occur in the mantle (McKenzie, 1984; von Bargen and Waff, 1986; Langmuir et al., 1992; Asimow et al., 2001). To assess the suitability of the equilibrium melting at single pressure approach, we have also calculated the average melt isotopic composition by considering the stable isotope composition and elemental concentration for each new step of melt generated during isentropic decompression at $\mathrm{T}_{p}=$ $1300^{\circ} \mathrm{C}$ and $1530^{\circ} \mathrm{C}$ by

$$
\bar{\Delta}_{\text {melt-source }}=\frac{\int_{\mathrm{P}_{0}}^{\mathrm{P}_{\mathrm{f}}} \Delta_{\mathrm{x}} \mathrm{c} \Delta \mathrm{Fg} \mathrm{dP}}{\int_{\mathrm{P}_{0}}^{\mathrm{P}_{\mathrm{f}}} \mathrm{c} \Delta \mathrm{Fg} \mathrm{dP}}
$$

where $\Delta_{\mathrm{x}}$ is the $\Delta_{\text {melt-source }}$ of the melt produced in the pressure step, and c is the wt $\%$ of the element being considered in the melt, and other terms as above. The approach of equation 7 , while considering polybaric melting, is still not a fractional melting model, but fractional melting is beyond the scope of this work. Nonetheless, the chemical composition of pooled fractional melts from a ridge melting regime has been shown to closely resemble that of a simple equilibrium batch melt (Langmuir et al., 1992). Equation 7 therefore allows us to broadly assess whether the approach taken in equation 6 produces estimates of mean melt isotope ratios very different from a more realistic polybaric approach, although it should be noted that the polybaric method of equation 7 only allows us to calculate the average melt isotopic composition for the two $\mathrm{T}_{p} \mathrm{~s}$ for which we have calculated isentropes.

Fig. S9 shows the comparison of the two calculations of average $\Delta_{\text {melt-source }}$ The dots show the average melt isotope composition when calculated as a sum along the isentrope; the solid lines show the approximation using the melt composition at the average pressure of melting. The calculation using the average melt pressure is a good approximation of the calculated average melt isotope compositions. Therefore we use this pressure approach in the main text: the limitation of the calculated average melt isotope composition is that we only have information for the $\mathrm{T}_{p} \mathrm{~s}$ for which we have calculated isentropes, hence use a linear interpolation between them, whereas the average pressure approach allows us to use more information from the calculated P-T map of melt compositions, reflecting the changing of stable mineral assemblage, for example.

\section{Trace element calculations}

Table S12 gives the mineral-melt partition coefficients and mantle concentrations for Sm and $\mathrm{Yb}$ used in this model.

Table S12: Input parameters (partition coefficients relative to melt, mantle concentrations) for calculating the $\mathrm{Sm}$, Dy and $\mathrm{Yb}$ concentration of trace elements in the model melts. $\mathrm{D}_{\mathrm{gt}, \mathrm{cpx}, \mathrm{ol} \text {, opx }}$ and element concentrations from Gibson and Geist (2010); $\mathrm{D}_{\text {spinel }}$ from Liu et al. (2019) (average values from high P experiments); $\mathrm{D}_{\text {plag }}$ from Aigner-Torres et al. (2007) (from 'run 31'); D rutile from Klemme et al. (2005) (Sm), Foley et al. (2000) (Dy, Yb); $\mathrm{D}_{\mathrm{ilmenite}}$ from Zack and Brumm (1998). Conc.DM $=$ concentration in depleted mantle; mineral abbreviations as previous with rut. $=$ rutile, ilm. $=$ ilmenite.

\begin{tabular}{lrrrrrrrrr}
\hline Element & $\mathrm{D}_{\text {gt }}$ & $\mathrm{D}_{\text {cpx }}$ & $\mathrm{D}_{\text {ol }}$ & $\mathrm{D}_{\text {opx }}$ & $\mathrm{D}_{\text {spn }}$ & $\mathrm{D}_{\text {plag }}$ & $\mathrm{D}_{\text {rut }}$ & $\mathrm{D}_{\text {ilm }}$ & Conc.DM \\
\hline $\mathrm{Sm}$ & 0.25 & 0.293 & 0.0011 & 0.02 & 0.198 & 0.081 & 0.00135 & 0.00059 & 0.299 \\
$\mathrm{Dy}$ & 2.2 & 0.4 & 0.0027 & 0.011 & 0.069 & 0.049 & 0.00076 & 0.01 & 0.525 \\
$\mathrm{Yb}$ & 6.6 & 0.4 & 2 & 0.08 & 0.812 & 0.025 & 0.0093 & 0.17 & 0.347 \\
\hline
\end{tabular}




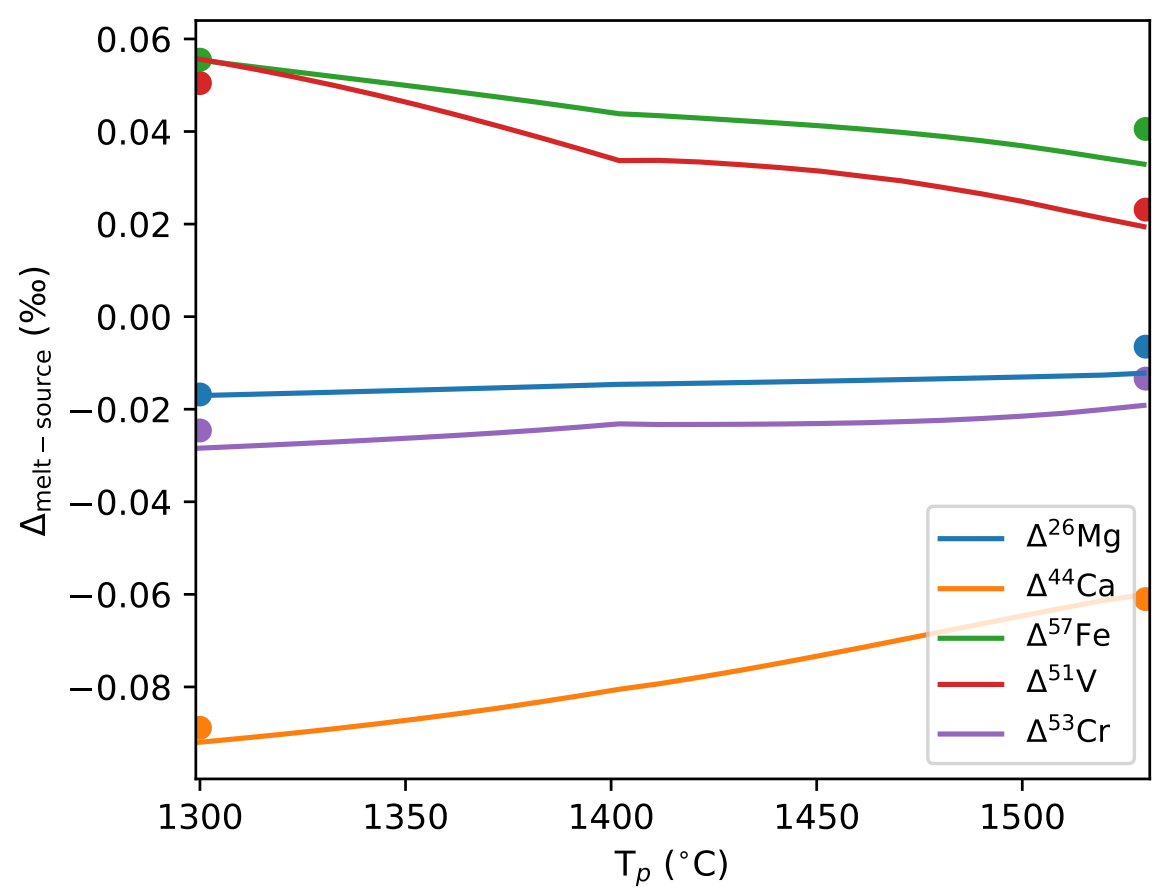

Figure S9: $\Delta_{\text {melt-source }}$ for KLB1 calculated by taking the isotopic fractionation at the average melt pressure (solid lines) compared to a calculation of the average melt composition by considering polybaric melts (equation 7), shown as coloured dots.

The concentration of each element in the melt was calculated at each P-T point by:

$$
\mathrm{C}_{\text {liquid }}=\frac{\mathrm{C}_{\text {bulk }}}{\sum \mathrm{D}_{\text {mineral }} \mathrm{F}_{\text {mineral }}+\mathrm{F}_{\text {liquid }}}
$$

where $\mathrm{C}=$ concentration, $\mathrm{D}=$ partition coefficient, $\mathrm{F}=$ fraction of phase.

\section{Additional reference figures}

Fig. S10 provides a reference for how oxygen fugacity, melt fraction, and selected trace element ratios vary along the isentropes shown in Figs. 1 and 4 of the main text. The trace element concentrations are calculated using depleted mantle (DM) inputs for KLB1, and plume inputs for the enriched MIX1G and G2 lithologies (see Table S12).

We choose to use peridotite isentropic decompression paths for the two pyroxenite lithologies, as discussed in the main text. Figs. S11, S12 show results for the other endmember case for the two pyroxenite lithologies, i.e., where the lithologies decompress along isentropic paths calculated for each pure pyroxenite lithology.

Fig. S13 compares the melt-source isotope fractionation with progressive melting (along peridotite isentropes) for pairs of isotopes in each lithology, allowing assessment of the 'direct' sensitivity to lithology. By direct lithological sensitivity, we refer to sensitivity related to mineralogy - these isotope systems may still trace lithology via each lithology's different bulk isotope composition. On balance, given that melts from any pyroxenite lithology are likely to be diluted with ambient peridotite melts when extracted from the mantle (e.g., Hirschmann and Stolper, 

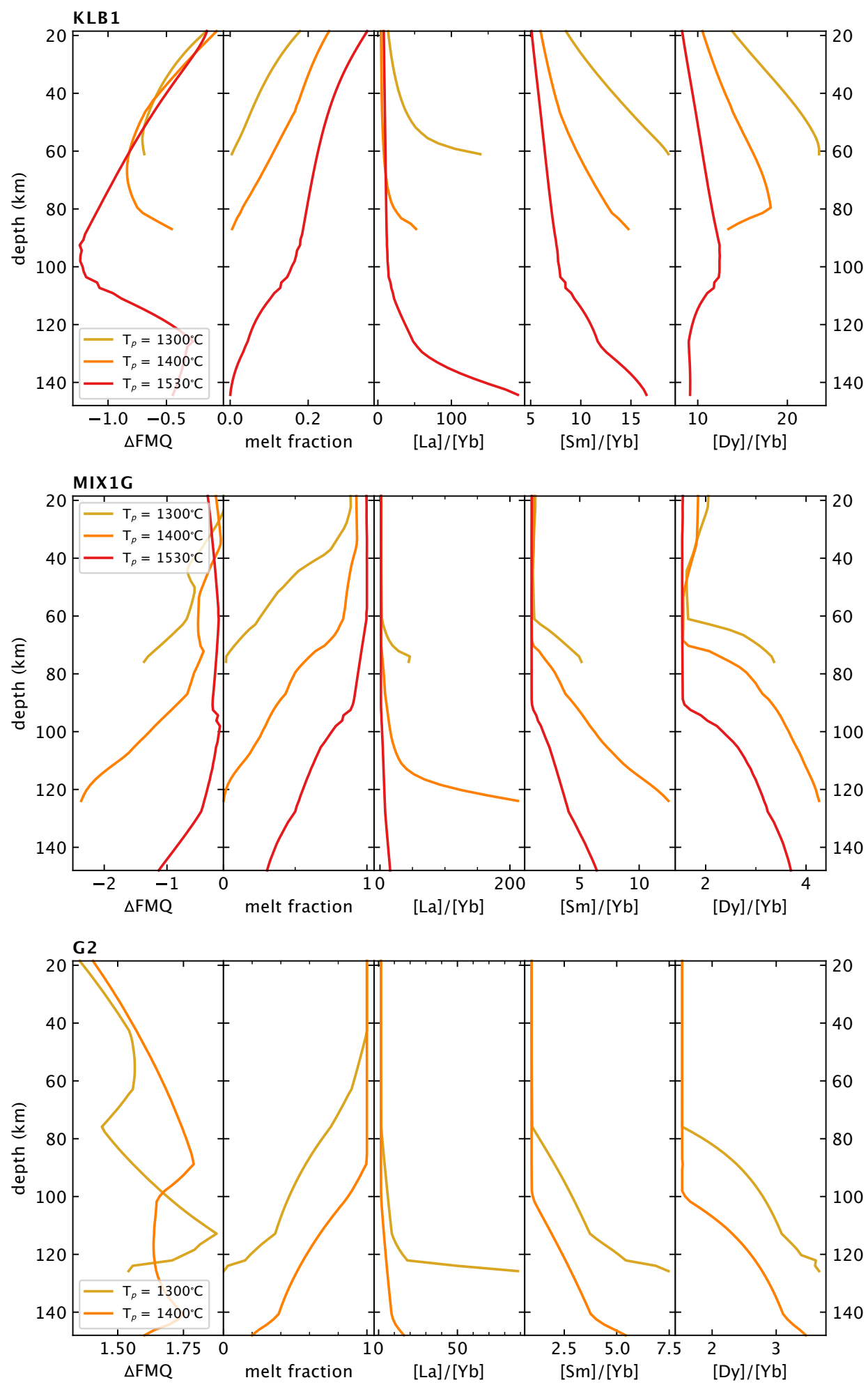

Figure S10: Parameters along the peridotite isentropic decompression paths for all three lithologies: oxygen fugacity (from the $\mathrm{fO}_{2}$ melt software; Holland et al., 2018), melt fraction (from THERMOCALC output), and selected trace element ratios in the melts (calculated using the model described in the section above). The isentropes match those in Figs. 2 and 5 in the main text. 


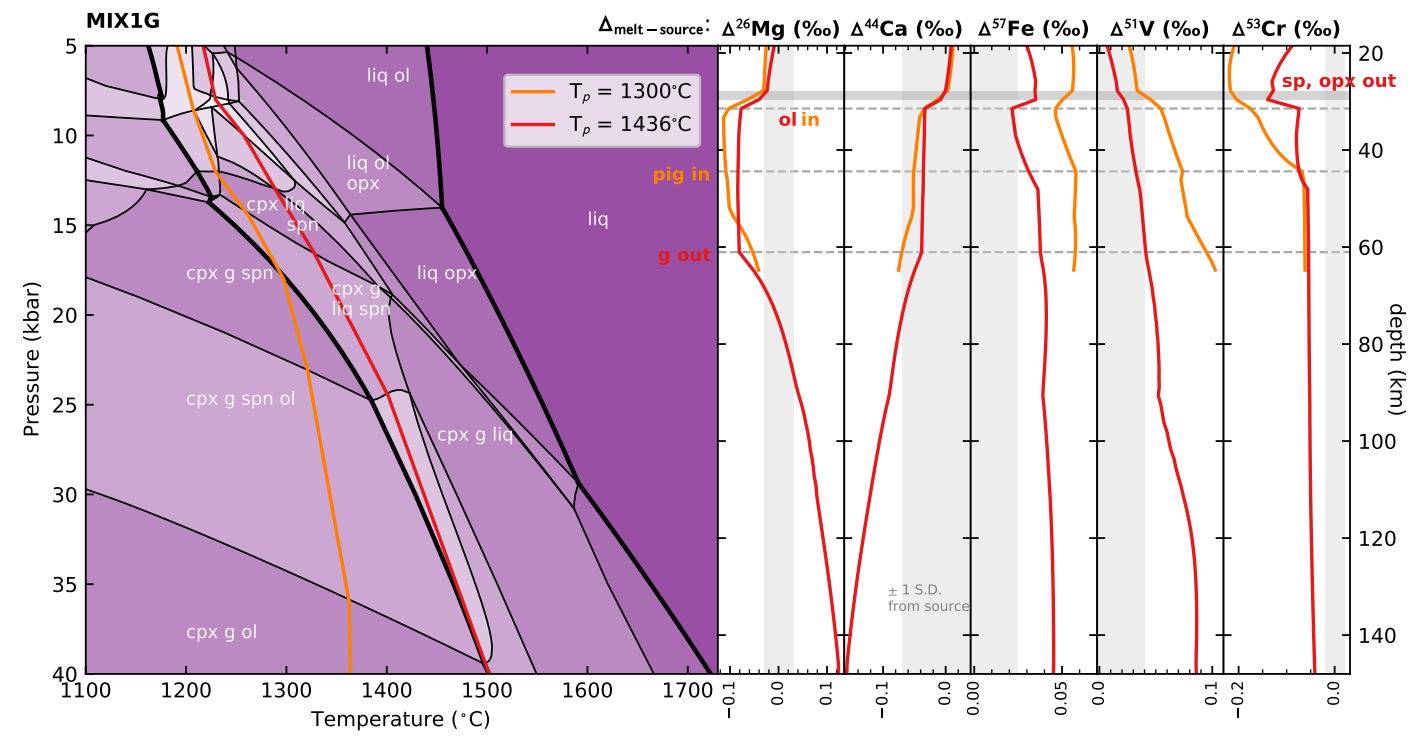

Figure S11: Isentropic melting paths for pure MIX1G, and $\Delta_{\text {melt-source }}$ along these isentropes. Errors are shown as 1 S.D. long-term uncertainty.

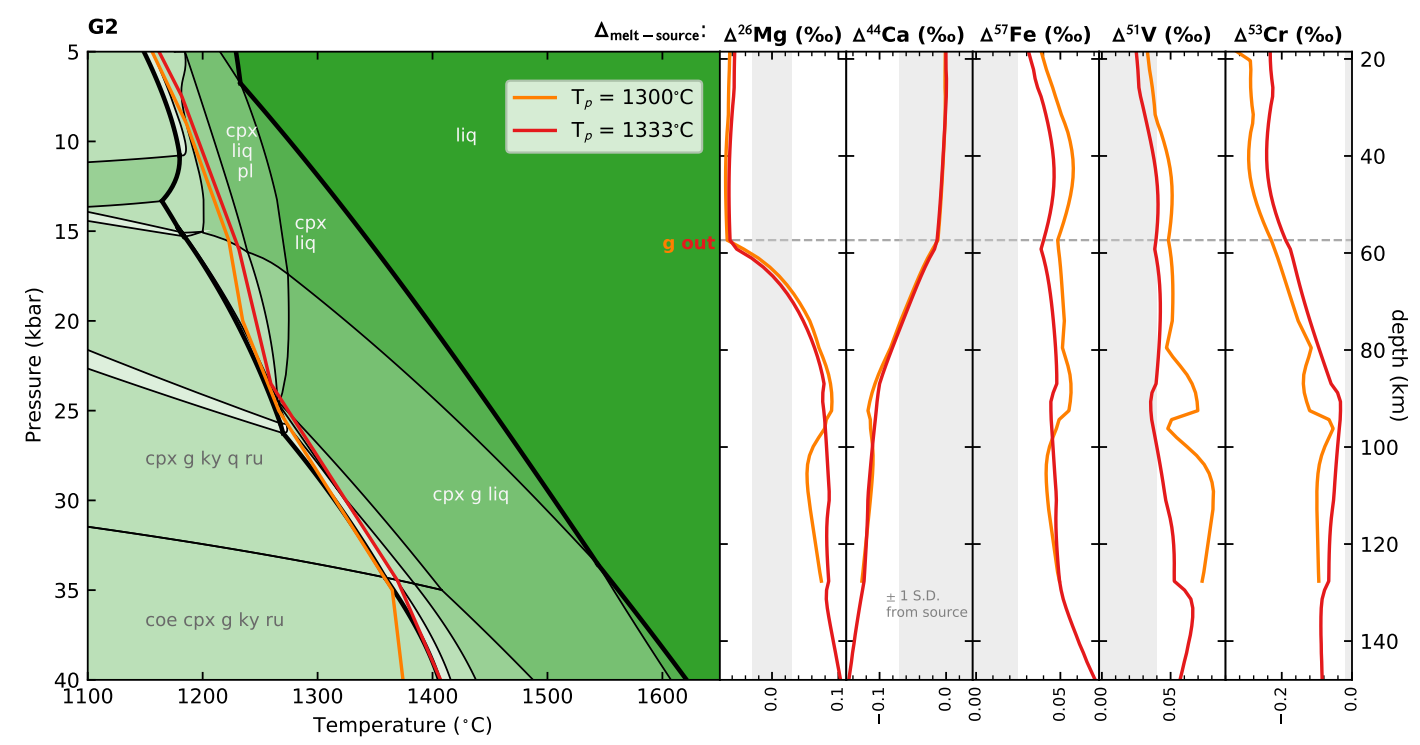

Figure S12: Isentropic melting paths for pure G2, and $\Delta_{\text {melt-source }}$ along these isentropes. Errors are shown as 1 S.D. long-term uncertainty. 


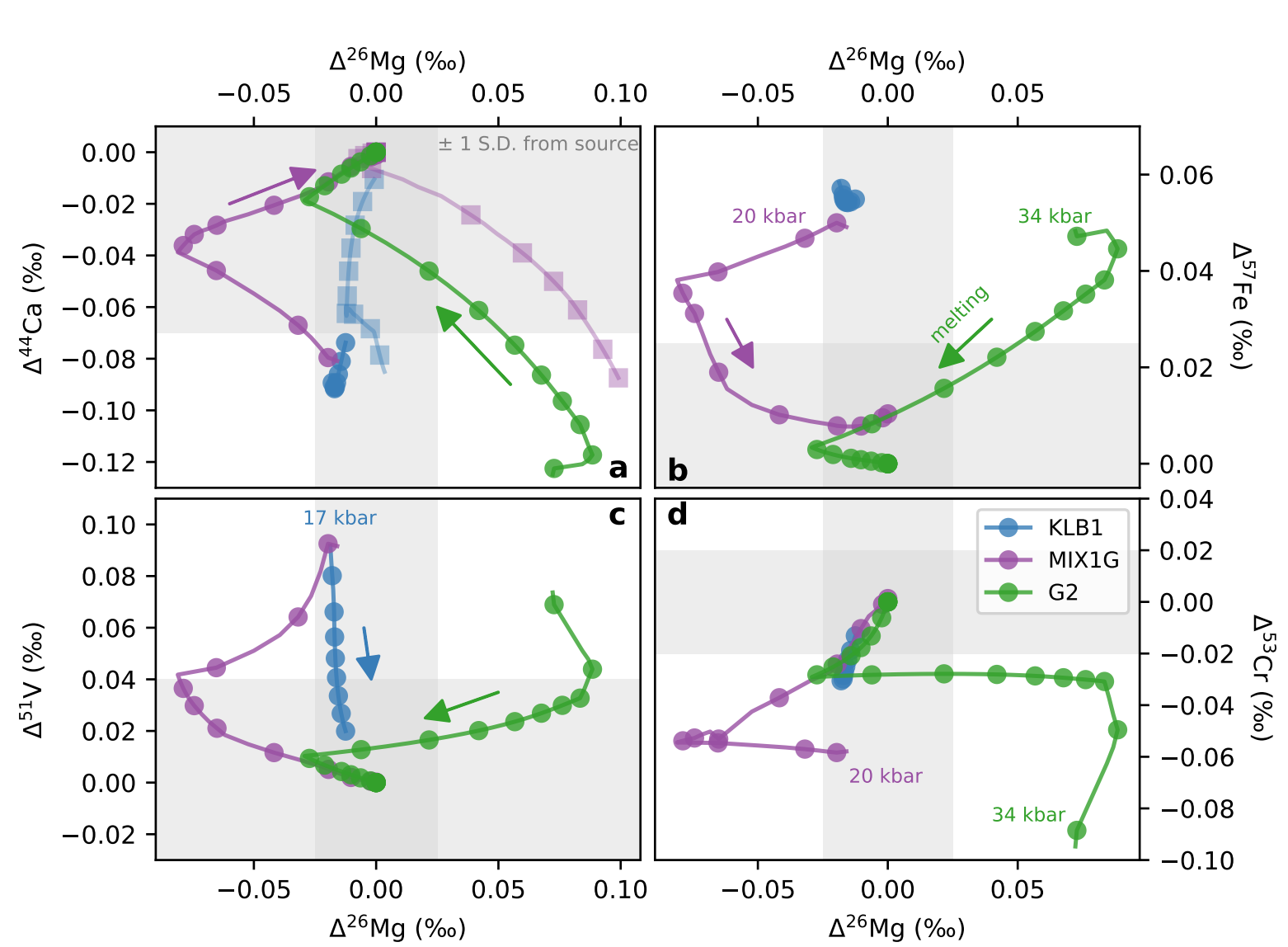

1996; Sobolev et al., 2005; Shorttle and Maclennan, 2011; Soderman et al., 2021), our results in Fig. S13 are probably representative of maximum isotope fractionation signatures we might see in natural systems, and Fig. 7 in the main text (which takes into account both this dilution effect and non-identical bulk isotope compositions of the lithologies) may better represent the predicted resolvability of each isotope system to lithology. Generally, Fig. S13 suggests that the stable isotopes considered here may have poor direct sensitivity to lithological heterogeneity in the source regions of basalts, assuming equilibrium fractionation behaviour and in the absence of any pre-imposed source heterogeneity (i.e., where all lithologies have the same bulk isotope ratio).

Figure S13: Melting fractionation $\left(\Delta_{\text {melt-source }}\right)$ plotted along the $\mathrm{T}_{p}=1300^{\circ} \mathrm{C}$ isentrope; squares in $\mathrm{Mg}-\mathrm{Ca}$ space show $\mathrm{T}_{p}=1530^{\circ} \mathrm{C}$ isentrope for reference. High or low pressure end of isentrope is marked, and arrows show the direction of progressive melting (decompression). Markers are plotted every 3 pressure steps (each pressure step is $0.5 \mathrm{kbar})$. Grey shaded regions show the source $(0 \%) \pm$ typical long-term analytical 1 S.D. (see Table S2 for details).

\section{Element budgeting between lithologies}

To produce Fig. 7 in the main text, we use a mass balance calculation for each isotopic system, $\mathrm{X}$, where

$$
\delta \mathrm{X}_{\text {bulk }}=\left(\mathrm{F}_{\text {pyroxenite }}^{\mathrm{X}} \times \delta \mathrm{X}_{\text {pyroxenite }}\right)+\left(\mathrm{F}_{\text {peridotite }}^{\mathrm{X}} \times \delta \mathrm{X}_{\text {peridotite }}\right)
$$

and $\mathrm{F}^{\mathrm{X}}$ is the fraction of the total element in the final melt coming from each lithology, $\delta \mathrm{X}_{\text {lithology }}$ is the isotopic composition of each lithology (bulk isotope composition of lithology + melt-source isotope fractionation). The $\mathrm{F}$ term considers both the amount of the element in the melt from 
Table S13: Inputs used to calculate bulk melt-source isotope fractionation in Figs. 7 and S14. * indicates inputs using the pure pyroxenite isentropes at that $\mathrm{T}_{p}$, rather than peridotite isentropes. The MIX1G 1400* inputs are actually for an isentrope of $\mathrm{T}_{p}=1436^{\circ} \mathrm{C}$. The $\mathrm{P}-\mathrm{T}$ given are the closest $\mathrm{P}-\mathrm{T}$ pair in the model output files to the average P-T of melting along each isentrope, as calculated in Section 6. For $\mathrm{V}$ and $\mathrm{Cr}$, where element partitioning is not calculated by THERMOCALC, the melt element concentrations are calculated as described in Appendix Section 3, using the following bulk compositions for each lithology: $\mathrm{KLB} 1 \mathrm{Cr}_{2} \mathrm{O}_{3}=0.32 \mathrm{wt} \%$, G2 $\mathrm{Cr}_{2} \mathrm{O}_{3}=0.08 \mathrm{wt} \%$, MIX1G $\mathrm{Cr}_{2} \mathrm{O}_{3}=0.11 \mathrm{wt} \%$ (Jennings et al., 2016); KLB1 V $=85$ ppm (typical primitive mantle value from Lee et al., 2003; Prytulak et al., 2013), MIX1G and G2 V = 350 ppm (typical MORB value; Prytulak et al., 2013).

\begin{tabular}{|c|c|c|c|c|c|c|c|c|}
\hline \multirow[b]{2}{*}{$\mathrm{T}_{p}\left({ }^{\circ} \mathrm{C}\right):$} & \multirow{2}{*}{$\begin{array}{r}\text { KLB1 } \\
1300 \\
\end{array}$} & \multicolumn{3}{|c|}{ MIX1G } & \multirow[b]{2}{*}{1400} & \multicolumn{3}{|c|}{ G2 } \\
\hline & & 1400 & 1300 & $1300^{*}$ & & $1400^{*}$ & 1300 & $1300^{*}$ \\
\hline Pressure (kbar) & 12 & 17.5 & 15 & 13.5 & 24.5 & 22 & 27 & 25.5 \\
\hline Temperature $\left({ }^{\circ} \mathrm{C}\right)$ & 1300 & 1400 & 1317 & 1248 & 1440 & 1380 & 1345 & 1269 \\
\hline Melt fraction & 0.061 & 0.099 & 0.323 & 0.093 & 0.369 & 0.155 & 0.458 & 0.048 \\
\hline \multicolumn{9}{|l|}{ Melt element conc. } \\
\hline $\begin{array}{l}\mathrm{Mg} \text { (mol\% oxide) } \\
\mathrm{Ca} \text { (mol \% oxide) }\end{array}$ & $\begin{array}{l}16.50 \\
12.72\end{array}$ & $\begin{array}{l}20.43 \\
13.62\end{array}$ & $\begin{array}{l}15.44 \\
1266\end{array}$ & $\begin{array}{l}11.01 \\
10.63\end{array}$ & $\begin{array}{l}19.42 \\
13.09\end{array}$ & $\begin{array}{l}16.59 \\
11.83\end{array}$ & $\begin{array}{l}5.92 \\
9.47\end{array}$ & $\begin{array}{l}4.48 \\
7.53\end{array}$ \\
\hline $\mathrm{Fe}$ (mol \% oxide) & 6.36 & 7.64 & 8.93 & 7.46 & 9.27 & 10.21 & 4.22 & 3.07 \\
\hline $\mathrm{V}$ (wt \% element) & 0.002 & 0.003 & 0.014 & 0.008 & 0.015 & 0.009 & 0.021 & 0.011 \\
\hline $\mathrm{Cr}$ (wt \% element) & 0.005 & 0.009 & 0.004 & 0.001 & 0.007 & 0.002 & 0.004 & 0.001 \\
\hline \multicolumn{9}{|c|}{ Melt-source isotopic fractionation $(\%)$} \\
\hline$\Delta^{26} \mathrm{Mg}$ & -0.02 & -0.02 & -0.08 & -0.10 & 0.08 & 0.02 & 0.06 & 0.09 \\
\hline$\Delta^{44} \mathrm{Ca}$ & -0.09 & -0.08 & -0.04 & -0.05 & -0.08 & -0.08 & -0.08 & -0.12 \\
\hline$\Delta^{57} \mathrm{Fe}$ & 0.06 & 0.04 & 0.03 & 0.06 & 0.03 & 0.04 & 0.03 & 0.06 \\
\hline$\Delta^{51} \mathrm{~V}$ & 0.05 & 0.03 & 0.03 & 0.08 & 0.02 & 0.05 & 0.03 & 0.07 \\
\hline$\Delta^{53} \mathrm{Cr}$ & -0.03 & -0.02 & -0.05 & -0.06 & -0.04 & -0.05 & -0.03 & -0.12 \\
\hline \multicolumn{9}{|c|}{ Bulk isotopic composition of lithology $(\% 0)$} \\
\hline$\delta^{26} \mathrm{Mg}$ & -0.24 & & -0.25 & & & & -0.25 & \\
\hline$\delta^{44} \mathrm{Ca}$ & 0.94 & & 0.83 & & & & 0.83 & \\
\hline$\delta^{57} \mathrm{Fe}$ & 0.05 & & 0.14 & & & & 0.14 & \\
\hline$\delta^{51} \mathrm{~V}$ & -0.91 & & -0.92 & & & & -0.92 & \\
\hline$\delta^{53} \mathrm{Cr}$ & -0.12 & & -0.15 & & & & -0.15 & \\
\hline
\end{tabular}

each lithology, and the melt fraction of each lithology. Table S13 gives the inputs used: these inputs are taken from the full model results at the average P-T melting condition (as in Section 6) for each $\mathrm{T}_{p}$. This calculation cannot be done for a $\mathrm{T}_{p}$ of $1530^{\circ} \mathrm{C}(\mathrm{MIX} 1 \mathrm{G} \& \mathrm{G} 2)$ or $1400^{\circ} \mathrm{C}$ (G2) because the isentropic melting paths intersect the solidus at pressures below the base of our model, so an accurate average pressure of melting cannot be calculated. The bulk isotope compositions of each lithology are the BSE values for peridotite (see Fig. 1 caption in main text for sources), and average MORB composition for pyroxenite (except for $\mathrm{Cr}$ where no known MORB data are published and the modelled aggregate KLB1 melt isotope composition for $\mathrm{T}_{p}$ $=1300{ }^{\circ} \mathrm{C}$ is used).

Fig. S14 is an alternative to Fig. 7 in the main text, with the right hand panels scaled to typical current 1 S.D. analytical precision. 


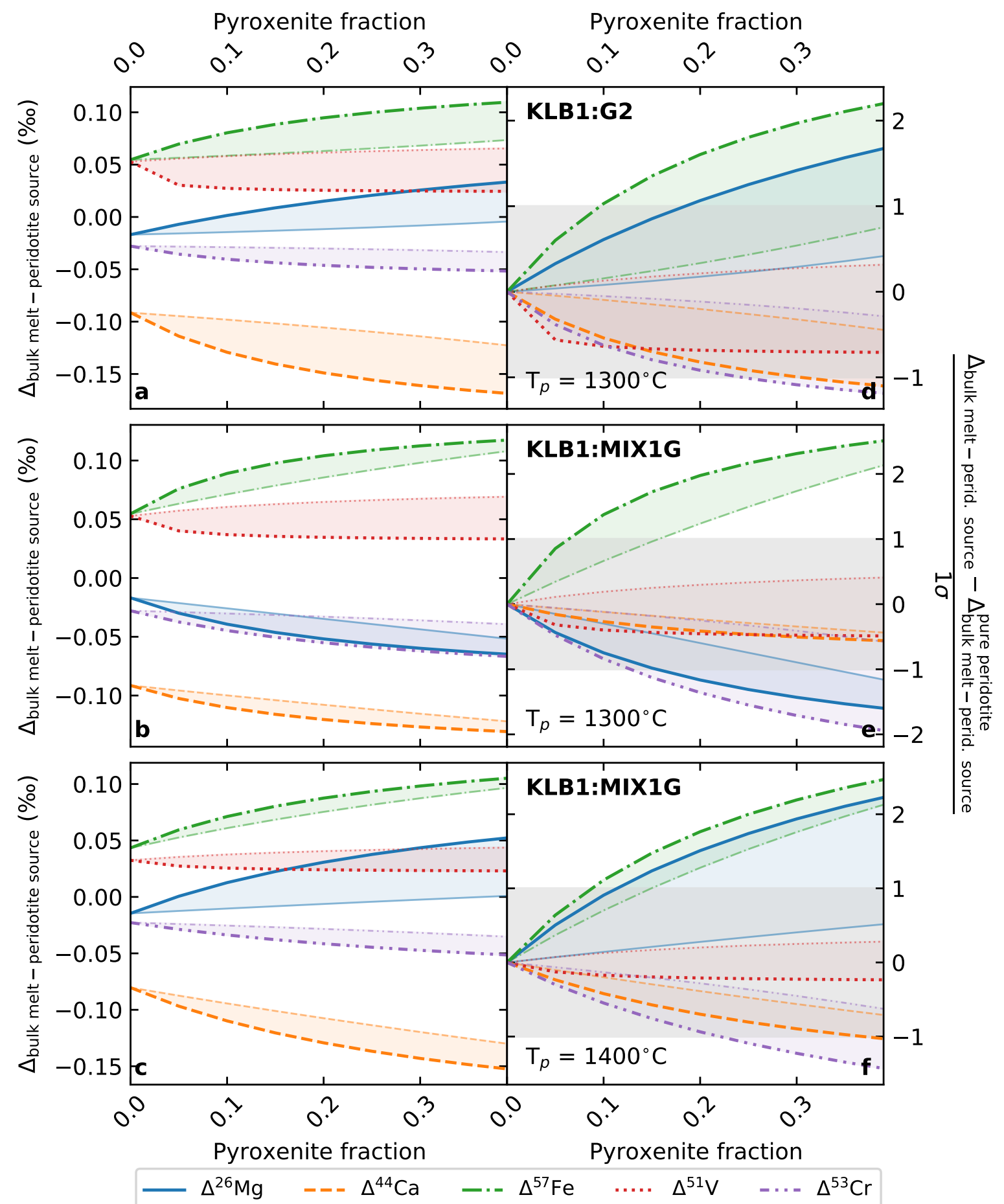

Figure S14: Aggregate bulk melt isotope fractionation (relative to a pure peridotite source, left hand panels; relative to a pure peridotite melt and scaled to current typical long-term analytical 1 S.D., right hand panels) for multi-lithologic mantle. At each $\mathrm{T}_{p}$, the aggregate melt composition (including isotope composition, and element proportion) at the average pressure and temperature of melting for each lithology is used to calculate the resulting bulk melt isotope composition by mass balance. A range of bulk melt-source isotope fractionations are given for each isotope system, reflecting two endmembers for the thermal behaviour of pyroxenite upwelling in a peridotite host. The bolder line represents the case for pyroxenite following peridotite geotherms (as used throughout this study); the paler line reflects pyroxenite following its own geotherm, as in Figs. S10 and S11. Grey horizontal bars in the right hand panels highlight 1 S.D. 


\section{References}

Aigner-Torres, M., Blundy, J., Ulmer, P. and Pettke, T. (2007), 'Laser ablation ICPMS study of trace element partitioning between plagioclase and basaltic melts: an experimental approach', Contributions to Mineralogy and Petrology 153(6), 647-667.

Antonelli, M. A., Kendrick, J., Yakymchuk, C., Guitreau, M., Mittal, T. and Moynier, F. (2021), 'Calcium isotope evidence for early Archaean carbonates and subduction of oceanic crust', Nature Communications 12(1), 1-8.

Antonelli, M. A., Mittal, T., McCarthy, A., Tripoli, B., Watkins, J. M. and DePaolo, D. J. (2019b), 'Ca isotopes record rapid crystal growth in volcanic and subvolcanic systems', Proceedings of the National Academy of Sciences 116(41), 20315-20321.

Antonelli, M. A., Schiller, M., Schauble, E. A., Mittal, T., DePaolo, D. J., Chacko, T., Grew, E. S. and Tripoli, B. (2019), 'Kinetic and equilibrium Ca isotope effects in high-T rocks and minerals', Earth and Planetary Science Letters 517, 71-82.

Asimow, P. D., Hirschmann, M. M. and Stolper, E. M. (2001), 'Calculation of peridotite partial melting from thermodynamic models of minerals and melts, IV. Adiabatic decompression and the composition and mean properties of mid-ocean ridge basalts', Journal of Petrology 42(5), 963-998.

Berry, A. J., O'Neill, H. S. C. and Foran, G. J. (2021), 'The effects of temperature and pressure on the oxidation state of chromium in silicate melts', Contributions to Mineralogy and Petrology 176(5), 1-14.

Bonnand, P., Doucelance, R., Boyet, M., Bachèlery, P., Bosq, C., Auclair, D. and Schiano, P. (2020), 'The influence of igneous processes on the chromium isotopic compositions of Ocean Island basalts', Earth and Planetary Science Letters 532, 116028.

Bourdon, B., Tipper, E. T., Fitoussi, C. and Stracke, A. (2010), 'Chondritic Mg isotope composition of the Earth', Geochimica et Cosmochimica Acta 74(17), 5069-5083.

Canil, D. (1999), 'Vanadium partitioning between orthopyroxene, spinel and silicate melt and the redox states of mantle source regions for primary magmas', Geochimica et Cosmochimica Acta 63(3-4), 557-572.

Canil, D. (2002), 'Vanadium in peridotites, mantle redox and tectonic environments: Archean to present', Earth and Planetary Science Letters 195(1-2), 75-90.

Chen, C., Ciazela, J., Li, W., Dai, W., Wang, Z., Foley, S. F., Li, M., Hu, Z. and Liu, Y. (2020b), 'Calcium isotopic compositions of oceanic crust at various spreading rates', Geochimica et Cosmochimica Acta 278, 272-288.

Chen, C., Dai, W., Wang, Z., Liu, Y., Li, M., Becker, H. and Foley, S. F. (2019), 'Calcium isotope fractionation during magmatic processes in the upper mantle', Geochimica et Cosmochimica Acta 249, $121-137$.

Chen, C., Huang, J.-X., Foley, S. F., Wang, Z., Moynier, F., Liu, Y., Dai, W. and Li, M. (2020a), 'Compositional and pressure controls on calcium and magnesium isotope fractionation in magmatic systems', Geochimica et Cosmochimica Acta 290, 257-270.

Dauphas, N., Roskosz, M., Alp, E. E., Neuville, D. R., Hu, M. Y., Sio, C. K., Tissot, F. L. H., Zhao, J., Tissandier, L., Médard, E. and Cordier, C. (2014), 'Magma redox and structural controls on iron isotope variations in Earth's mantle and crust', Earth and Planetary Science Letters 398, 127-140.

Davis, F. A., Tangeman, J. A., Tenner, T. J. and Hirschmann, M. M. (2009), 'The composition of KLB-1 peridotite', American Mineralogist 94(1), 176-180.

Deer, W. A., Howie, R. A. and Zussman, J. (2013), An Introduction to the Rock-Forming Minerals, Mineralogical Society of Great Britain and Ireland.

Ding, X., Helz, R. T., Qi, Y. and Huang, F. (2020), 'Vanadium isotope fractionation during differentiation of Kilauea Iki lava lake, Hawaii', Geochimica et Cosmochimica Acta 289, 114-129.

Duffy, J. A. (1993), 'A review of optical basicity and its applications to oxidic systems', Geochimica et Cosmochimica Acta 57(16), 3961-3970.

Farges, F. and Brown Jr, G. E. (1997), 'Coordination chemistry of titanium (IV) in silicate glasses and melts: IV. XANES studies of synthetic and natural volcanic glasses and tektites at ambient temperature and pressure', Geochimica et Cosmochimica Acta 61(9), 1863-1870. 
Feng, C., Qin, T., Huang, S., Wu, Z. and Huang, F. (2014), 'First-principles investigations of equilibrium calcium isotope fractionation between clinopyroxene and Ca-doped orthopyroxene', Geochimica et Cosmochimica Acta 143, $132-142$.

Feng, L.-p., Zhou, L., Yang, L., DePaolo, D. J., Tong, S.-Y., Liu, Y.-S., Owens, T. L. and Gao, S. (2017), 'Calcium isotopic compositions of sixteen USGS reference materials', Geostandards and Geoanalytical Research 41(1), 93-106.

Foley, S. F., Barth, M. G. and Jenner, G. A. (2000), 'Rutile/melt partition coefficients for trace elements and an assessment of the influence of rutile on the trace element characteristics of subduction zone magmas', Geochimica et cosmochimica acta 64(5), 933-938.

George, A. M. and Stebbins, J. F. (1998), 'Structure and dynamics of magnesium in silicate melts: A hightemperature 25Mg NMR study', American Mineralogist 83(9-10), 1022-1029.

Gibbs, G. V., Ross, N. L., Cox, D. F., Rosso, K. M., Iversen, B. B. and Spackman, M. (2014), 'Pauling bond strength, bond length and electron density distribution', Physics and Chemistry of Minerals 41(1), 17-25.

Gibson, S. A. and Geist, D. (2010), 'Geochemical and geophysical estimates of lithospheric thickness variation beneath Galápagos', Earth and Planetary Science Letters 300(3-4), 275-286.

Gleeson, M. L. M., Gibson, S. A. and Williams, H. M. (2020), 'Novel insights from Fe-isotopes into the lithological heterogeneity of Ocean Island Basalts and plume-influenced MORBs', Earth and Planetary Science Letters $\mathbf{5 3 5 .}$

Grant, F. S. (1954), 'The geological significance of variations in the abundances of the isotopes of silicon in rocks', Geochimica et Cosmochimica Acta 5(5), 225-242.

Hirschmann, M. M., Kogiso, T., Baker, M. B. and Stolper, E. M. (2003), 'Alkalic magmas generated by partial melting of garnet pyroxenite', Geology 31(6), 481-484.

Hirschmann, M. M. and Stolper, E. M. (1996), 'A possible role for garnet pyroxenite in the origin of the "garnet signature" in MORB', Contributions to Mineralogy and Petrology 124(2), 185-208.

Holland, T. J. B., Green, E. C. R. and Powell, R. (2018), 'Melting of Peridotites through to Granites: A Simple Thermodynamic Model in the System KNCFMASHTOCr', Journal of Petrology 59(5), 881-900.

Holland, T. J. B. and Powell, R. (2011), 'An improved and extended internally consistent thermodynamic dataset for phases of petrological interest, involving a new equation of state for solids', Journal of Metamorphic Geology $\mathbf{2 9}(3), 333-383$.

Huang, F., Chen, L., Wu, Z. and Wang, W. (2013), 'First-principles calculations of equilibrium Mg isotope fractionations between garnet, clinopyroxene, orthopyroxene, and olivine: implications for $\mathrm{Mg}$ isotope thermometry', Earth and Planetary Science Letters 367, 61-70.

Huang, F., Wu, Z., Huang, S. and Wu, F. (2014), 'First-principles calculations of equilibrium silicon isotope fractionation among mantle minerals', Geochimica et Cosmochimica Acta 140, 509-520.

Huang, F., Zhou, C., Wang, W., Kang, J. and Wu, Z. (2019), 'First-principles calculations of equilibrium Ca isotope fractionation: Implications for oldhamite formation and evolution of lunar magma ocean', Earth and Planetary Science Letters 510, 153-160.

Huang, S., Farkaš, J. and Jacobsen, S. B. (2011b), 'Stable calcium isotopic compositions of Hawaiian shield lavas: evidence for recycling of ancient marine carbonates into the mantle', Geochimica et Cosmochimica Acta 75(17), 4987-4997.

Humphreys, M. C. S., Brooker, R. A., Fraser, D. G., Burgisser, A., Mangan, M. T. and McCammon, C. (2015), 'Coupled interactions between volatile activity and fe oxidation state during arc crustal processes', Journal of Petrology 56(4), 795-814.

Jennings, E. S., Holland, T. J. B., Shorttle, O., Maclennan, J. and Gibson, S. A. (2016), 'The composition of melts from a heterogeneous mantle and the origin of ferropicrite: application of a thermodynamic model', Journal of Petrology 57(11-12), 2289-2310.

Klemme, S., Prowatke, S., Hametner, K. and Günther, D. (2005), 'Partitioning of trace elements between rutile and silicate melts: implications for subduction zones', Geochimica et Cosmochimica Acta 69(9), 2361-2371. 
Konter, J. G., Pietruszka, A. J., Hanan, B. B., Finlayson, V. A., Craddock, P. R., Jackson, M. G. and Dauphas, N. (2016), 'Unusual $\delta^{56}$ Fe values in Samoan rejuvenated lavas generated in the mantle', Earth and Planetary Science Letters 450, 221-232.

Lambart, S., Baker, M. B. and Stolper, E. M. (2016), 'The role of pyroxenite in basalt genesis: Melt-PX, a melting parameterization for mantle pyroxenites between 0.9 and 5 GPa', Journal of Geophysical Research: Solid Earth 121(8), 5708-5735.

Langmuir, C. H., Klein, E. M. and Plank, T. (1992), Petrological systematics of mid-ocean ridge basalts: constraints on melt generation beneath ocean ridges, in J. Phipps Morgan, D. K. Blackman and S. J. M, eds, 'Mantle Flow and Melt Generation at Mid-Ocean Ridges', Vol. 71, AGU American Geophysical Union, pp. 183280 .

Lee, C.-T. A., Brandon, A. D. and Norman, M. (2003), 'Vanadium in peridotites as a proxy for paleo-fO2 during partial melting: prospects, limitations, and implications', Geochimica et Cosmochimica Acta 67(16), 30453064 .

Liu, L., Ma, Y., Yan, W. and Liu, X. (2019), 'Trace element partitioning between MgAl2O4-spinel and carbonatitic silicate melt from 3 to $6 \mathrm{GPa}$, with emphasis on the role of cation order-disorder', Solid Earth Sciences 4(2), 4365

Macris, C. A., Manning, C. E. and Young, E. D. (2015), 'Crystal chemical constraints on inter-mineral Fe isotope fractionation and implications for Fe isotope disequilibrium in San Carlos mantle xenoliths', Geochimica et Cosmochimica Acta 154, 168-185.

Mallmann, G. and O'Neill, H. S. C. (2007), 'The effect of oxygen fugacity on the partitioning of Re between crystals and silicate melt during mantle melting', Geochimica et Cosmochimica Acta 71(11), 2837-2857.

Mallmann, G. and O'Neill, H. S. C. (2009), 'The crystal/melt partitioning of V during mantle melting as a function of oxygen fugacity compared with some other elements (Al, P, Ca, Sc, Ti, Cr, Fe, Ga, Y, Zr and Nb)', Journal of Petrology 50(9), 1765-1794.

McKenzie, D. (1984), 'The generation and compaction of partially molten rock', Journal of Petrology 25(3), 713765 .

Méheut, M., Lazzeri, M., Balan, E. and Mauri, F. (2009), 'Structural control over equilibrium silicon and oxygen isotopic fractionation: a first-principles density-functional theory study', Chemical Geology 258(1-2), 28-37.

Méheut, M. and Schauble, E. A. (2014), 'Silicon isotope fractionation in silicate minerals: insights from firstprinciples models of phyllosilicates, albite and pyrope', Geochimica et Cosmochimica Acta 134, 137-154.

Miletich, R., Nowak, M., Seifert, F., Angel, R. and Brandstätter, G. (1999), 'High-pressure crystal chemistry of chromous orthosilicate, $\mathrm{Cr}_{2} \mathrm{SiO}_{4}$. A single-crystal X-ray diffraction and electronic absorption spectroscopy study', Physics and chemistry of minerals 26(6), 446-459.

Millet, M.-A., Dauphas, N., Greber, N. D., Burton, K. W., Dale, C. W., Debret, B., Macpherson, C. G., Nowell, G. M. and Williams, H. M. (2016), 'Titanium stable isotope investigation of magmatic processes on the Earth and Moon', Earth and Planetary Science Letters 449, 197-205.

Mills, K. C. (1993), 'The influence of structure on the physico-chemical properties of slags', ISIJ international 33(1), 148-155.

Nebel, O., Arculus, R. J., Sossi, P. A., Jenner, F. E. and Whan, T. H. (2013), 'Iron isotopic evidence for convective resurfacing of recycled arc-front mantle beneath back-arc basins', Geophysical Research Letters 40(22), 58495853.

Nebel, O., Sossi, P. A., Bénard, A., Arculus, R. J., Yaxley, G. M., Woodhead, J. D., Davies, D. R. and Ruttor, S. (2019), 'Reconciling petrological and isotopic mixing mechanisms in the Pitcairn mantle plume using stable Fe isotopes', Earth and Planetary Science Letters 521, 60-67.

Novella, D., Maclennan, J., Shorttle, O., Prytulak, J. and Murton, B. J. (2020), 'A multi-proxy investigation of mantle oxygen fugacity along the Reykjanes Ridge', Earth and Planetary Science Letters 531, 115973.

O'Neill, H. S. C. and Berry, A. J. (2006), 'Activity coefficients at low dilution of $\mathrm{CrO}, \mathrm{NiO}$ and $\mathrm{CoO}$ in melts in the system $\mathrm{CaO}-\mathrm{MgO}-\mathrm{Al} 2 \mathrm{O} 3-\mathrm{SiO} 2$ at $1400 \mathrm{C}$ : using the thermodynamic behaviour of transition metal oxides in silicate melts to probe their structure', Chemical Geology 231(1-2), 77-89. 
Peters, B. J., Shahar, A., Carlson, R. W., Day, J. M. and Mock, T. D. (2019), 'A sulfide perspective on iron isotope fractionation during ocean island basalt petrogenesis', Geochimica et Cosmochimica Acta 245, 59-78.

Powell, R., Holland, T. J. B. and Worley, B. (1998), 'Calculating phase diagrams involving solid solutions via non-linear equations, with examples using THERMOCALC', Journal of Metamorphic Geology 16(4), 577-588.

Prytulak, J., Nielsen, S. G., Ionov, D. A., Halliday, A. N., Harvey, J., Kelley, K. A., Niu, Y. L., Peate, D. W., Shimizu, K. and Sims, K. W. W. (2013), 'The stable vanadium isotope composition of the mantle and mafic lavas', Earth and Planetary Science Letters 365, 177-189.

Prytulak, J., Sossi, P. A., Halliday, A. N., Plank, T., Savage, P. S. and Woodhead, J. D. (2017), 'Stable vanadium isotopes as a redox proxy in magmatic systems?', Geochemical Perspectives Letters 3(1), 75-84.

Qi, Y.-H., Wu, F., Ionov, D. A., Puchtel, I. S., Carlson, R. W., Nicklas, R. W., Yu, H.-M., Kang, J.-T., Li, C.-H. and Huang, F. (2019), 'Vanadium isotope composition of the Bulk Silicate Earth: Constraints from peridotites and komatiites', Geochimica et Cosmochimica Acta 259, 288-301.

Qin, T., Wu, F., Wu, Z. and Huang, F. (2016), 'First-principles calculations of equilibrium fractionation of O and $\mathrm{Si}$ isotopes in quartz, albite, anorthite, and zircon', Contributions to Mineralogy and Petrology 171(11), 1-14.

Righter, K., Sutton, S. R., Newville, M., Le, L., Schwandt, C. S., Uchida, H., Lavina, B. and Downs, R. T. (2006), 'An experimental study of the oxidation state of vanadium in spinel and basaltic melt with implications for the origin of planetary basalt', American Mineralogist 91(10), 1643-1656.

Salters, V. J. M. and Stracke, A. (2004), 'Composition of the depleted mantle', Geochemistry, Geophysics, Geosystems 5(5).

Savage, P. S., Armytage, R. M., Georg, R. B. and Halliday, A. N. (2014), 'High temperature silicon isotope geochemistry', Lithos 190, 500-519.

Schauble, E. A. (2011), 'First-principles estimates of equilibrium magnesium isotope fractionation in silicate, oxide, carbonate and hexaaquamagnesium (2+) crystals', Geochimica et Cosmochimica Acta 75(3), 844-869.

Schuessler, J. A., Schoenberg, R. and Sigmarsson, O. (2009), 'Iron and lithium isotope systematics of the Hekla volcano, Iceland - evidence for Fe isotope fractionation during magma differentiation', Chemical Geology 258(12), 78-91.

Shannon, R. D. (1976), 'Revised effective ionic radii and systematic studies of interatomic distances in halides and chalcogenides', Acta crystallographica section A: crystal physics, diffraction, theoretical and general crystallography 32(5), 751-767.

Shen, J., Qin, L., Fang, Z., Zhang, Y., Liu, J., Liu, W., Wang, F., Xiao, Y., Yu, H. and Wei, S. (2018), 'Hightemperature inter-mineral Cr isotope fractionation: A comparison of ionic model predictions and experimental investigations of mantle xenoliths from the North China Craton', Earth and Planetary Science Letters 499, 278290 .

Shen, J., Xia, J., Qin, L., Carlson, R. W., Huang, S., Helz, R. T. and Mock, T. D. (2020), 'Stable chromium isotope fractionation during magmatic differentiation: Insights from Hawaiian basalts and implications for planetary redox conditions', Geochimica et Cosmochimica Acta 278, 289-304.

Shimoda, K., Tobu, Y., Hatakeyama, M., Nemoto, T. and Saito, K. (2007), 'Structural investigation of Mg local environments in silicate glasses by ultra-high field 25Mg 3QMAS NMR spectroscopy', American Mineralogist 92(4), 695-698.

Shorttle, O. and Maclennan, J. (2011), 'Compositional trends of Icelandic basalts: Implications for short-length scale lithological heterogeneity in mantle plumes', Geochemistry, Geophysics, Geosystems 12(11).

Sobolev, A. V., Hofmann, A. W., Sobolev, S. V. and Nikogosian, I. K. (2005), 'An olivine-free mantle source of Hawaiian shield basalts', Nature 434(7033), 590-597.

Soderman, C. R., Matthews, S., Shorttle, O., Jackson, M. G., Ruttor, S., Nebel, O., Turner, S., Beier, C., Millet, M.-A., Widom, E. et al. (2021), 'Heavy $\delta^{57} \mathrm{Fe}$ in ocean island basalts: A non-unique signature of processes and source lithologies in the mantle', Geochimica et Cosmochimica Acta 292, 309-332.

Sossi, P. A., Moynier, F. and Van Zuilen, K. (2018), 'Volatile loss following cooling and accretion of the Moon revealed by chromium isotopes', Proceedings of the National Academy of Sciences 115(43), 10920-10925. 
Sossi, P. A. and O'Neill, H. S. C. (2017), 'The effect of bonding environment on iron isotope fractionation between minerals at high temperature', Geochimica et Cosmochimica Acta 196, 121-143.

Sossi, P. A., Prytulak, J. and O'Neill, H. S. C. (2018b), 'Experimental calibration of vanadium partitioning and stable isotope fractionation between hydrous granitic melt and magnetite at $800 \mathrm{c}$ and 0.5 gpa', Contributions to mineralogy and petrology $\mathbf{1 7 3}(4), 1-18$.

Stracke, A., Tipper, E. T., Klemme, S. and Bizimis, M. (2018), 'Mg isotope systematics during magmatic processes: Inter-mineral fractionation in mafic to ultramafic Hawaiian xenoliths', Geochimica et Cosmochimica Acta 226, 192-205.

Sun, P., Niu, Y., Guo, P., Duan, M., Chen, S., Gong, H., Wang, X. and Xiao, Y. (2020), 'Large iron isotope variation in the eastern Pacific mantle as a consequence of ancient low-degree melt metasomatism', Geochimica et Cosmochimica Acta 286, 269-288.

Sutton, S. R., Karner, J., Papike, J., Delaney, J. S., Shearer, C., Newville, M., Eng, P., Rivers, M. and Dyar, M. D. (2005), 'Vanadium K edge XANES of synthetic and natural basaltic glasses and application to microscale oxygen barometry', Geochimica et Cosmochimica Acta 69(9), 2333-2348.

Sutton, S., Righter, K., Berthet, S. and Newville, M. (2008), Experimental Constraints on the Partitioning and Valence of V and $\mathrm{Cr}$ in Garnet and Coexisting Glass, in 'AGU Fall Meeting Abstracts', Vol. 2008, pp. MR43A1808.

Teng, F.-Z., Dauphas, N. and Helz, R. T. (2008), 'Iron Isotope Fractionation During Magmatic Differentiation in Kilauea Iki Lava Lake', Science 320(5883), 1620-1622.

Teng, F.-Z., Dauphas, N., Huang, S. and Marty, B. (2013), 'Iron isotopic systematics of oceanic basalts', Geochimica et Cosmochimica Acta 107, 12-26.

Teng, F.-Z., Li, W.-Y., Ke, S., Marty, B., Dauphas, N., Huang, S., Wu, F.-Y. and Pourmand, A. (2010), 'Magnesium isotopic composition of the Earth and chondrites', Geochimica et Cosmochimica Acta 74(14), 4150-4166.

Toplis, M. J. and Corgne, A. (2002), 'An experimental study of element partitioning between magnetite, clinopyroxene and iron-bearing silicate liquids with particular emphasis on vanadium', Contributions to Mineralogy and Petrology 144(1), 22-37.

Valdes, M. C., Debaille, V., Berger, J. and Armytage, R. M. G. (2019), 'The effects of high-temperature fractional crystallization on calcium isotopic composition', Chemical Geology 509, 77-91.

Valdes, M. C., Moreira, M., Foriel, J. and Moynier, F. (2014), 'The nature of Earth's building blocks as revealed by calcium isotopes', Earth and Planetary Science Letters 394, 135-145.

von Bargen, N. and Waff, H. S. (1986), 'Permeabilities, interfacial areas and curvatures of partially molten systems: results of numerical computations of equilibrium microstructures', Journal of Geophysical Research: Solid Earth 91(B9), 9261-9276.

Wang, W., Huang, S., Huang, F., Zhao, X. and Wu, Z. (2020), 'Equilibrium inter-mineral titanium isotope fractionation: Implication for high-temperature titanium isotope geochemistry', Geochimica et Cosmochimica Acta 269, 540-553.

Wang, W., Zhou, C., Qin, T., Kang, J.-T., Huang, S., Wu, Z. and Huang, F. (2017), 'Effect of Ca content on equilibrium $\mathrm{Ca}$ isotope fractionation between orthopyroxene and clinopyroxene', Geochimica et Cosmochimica Acta 219, 44-56.

Wang, X.-J., Chen, L.-H., Hanyu, T., Zhong, Y., Shi, J.-H., Liu, X.-W., Kawabata, H., Zeng, G. and Xie, L.-W. (2021), 'Magnesium isotopic fractionation during basalt differentiation as recorded by evolved magmas', Earth and Planetary Science Letters 565, 116954.

Wiechert, U. and Halliday, A. N. (2007), 'Non-chondritic magnesium and the origins of the inner terrestrial planets', Earth and Planetary Science Letters 256(3-4), 360-371.

Wu, F., Qi, Y., Perfit, M. R., Gao, Y., Langmuir, C. H., Wanless, V. D., Yu, H. and Huang, F. (2018), 'Vanadium isotope compositions of mid-ocean ridge lavas and altered oceanic crust', Earth and Planetary Science Letters 493, 128-139. 
Wu, F., Qin, T., Li, X., Liu, Y., Huang, J.-H., Wu, Z. and Huang, F. (2015), 'First-principles investigation of vanadium isotope fractionation in solution and during adsorption', Earth and Planetary Science Letters 426, 216-224.

Xia, J., Qin, L., Shen, J., Carlson, R. W., Ionov, D. A. and Mock, T. D. (2017), 'Chromium isotope heterogeneity in the mantle', Earth and Planetary Science Letters 464, 103-115.

Zack, T. and Brumm, R. (1998), Ilmenite/liquid partition coefficients of 26 trace elements determined through ilmenite/clinopyroxene partitioning in garnet pyroxenites, in 'International Kimberlite Conference: Extended Abstracts', Vol. 7, pp. 986-988.

Zhang, H., Wang, Y., He, Y., Teng, F.-Z., Jacobsen, S. B., Helz, R. T., Marsh, B. D. and Huang, S. (2018), 'No measurable calcium isotopic fractionation during crystallization of Kilauea Iki lava lake', Geochemistry, Geophysics, Geosystems 19(9), 3128-3139.

Zhong, Y., Chen, L.-H., Wang, X.-J., Zhang, G.-L., Xie, L.-W. and Zeng, G. (2017), 'Magnesium isotopic variation of oceanic island basalts generated by partial melting and crustal recycling', Earth and Planetary Science Letters 463, $127-135$.

Zhong, Y., Zhang, G.-L., Jin, Q.-Z., Huang, F., Wang, X.-J. and Xie, L.-W. (2021b), 'Sub-basin scale inhomogeneity of mantle in the South China Sea revealed by magnesium isotopes', Science Bulletin 66(7), 740-748.

Zhong, Y., Zhang, G.-L., Lv, W.-X. and Huang, F. (2021), 'Iron isotope constraints on the lithological heterogeneity of the upper mantle in the South China Sea', Journal of Asian Earth Sciences p. 104934.

Zhu, H., Du, L., Zhang, Z. and Sun, W. (2020a), 'Calcium isotopic signatures of depleted mid-ocean ridge basalts from the northeastern Pacific', Journal of Oceanology and Limnology 38, 1476-1487.

Zhu, H., Liu, F., Li, X., Wang, G., Zhang, Z. and Sun, W. (2018), 'Calcium isotopic compositions of normal MidOcean Ridge basalts from the southern Juan de Fuca Ridge', Journal of Geophysical Research: Solid Earth 123(2), 1303-1313. 


\section{Data sources}

4 The data sources used in the natural data compilation in Figs. 1 and 8 in the main text are

5 given in Table $\mathrm{S} 1$.

Table S1: Literature data sources for stable isotope data compilation.

\begin{tabular}{lll}
\hline Isotope & Type & Literature sources \\
\hline$\delta^{26} \mathrm{Mg}$ & MORB & Wiechert and Halliday (2007); Bourdon et al. (2010); Teng et al. (2010); Zhong et al. (2021b) \\
& OIB & Bourdon et al. (2010); Teng et al. (2010); Zhong et al. (2017); Wang et al. (2021) \\
\hline$\delta^{44} \mathrm{Ca}$ & MORB & Zhu et al. (2018); Chen et al. (2020b); Zhu et al. (2020a) \\
& OIB & Huang et al. (2011b); Valdes et al. (2014, 2019); Feng et al. (2017); Chen et al. (2020b) \\
\hline$\delta^{57} \mathrm{Fe}$ & MORB & Teng et al. (2013); Nebel et al. (2013); Zhong et al. (2021) (seamounts: Sun et al., 2020) \\
& OIB & Teng et al. (2008); Schuessler et al. (2009); Konter et al. (2016); Nebel et al. (2019) \\
& & Peters et al. (2019); Gleeson et al. (2020); Soderman et al. (2021) \\
\hline$\delta^{51} \mathrm{~V}$ & MORB & Prytulak et al. (2013); Wu et al. (2018); Novella et al. (2020) \\
& OIB & Prytulak et al. (2013); Ding et al. (2020) \\
\hline$\delta^{53} \mathrm{Cr}$ & OIB & Bonnand et al. (2020); Shen et al. (2020) \\
\hline
\end{tabular}

6 Table S2 gives the references for the typical sample 2 S.E. and long-term 2 S.D. used throughout the manuscript.

Table S2: Literature data sources for stable isotope data errors.

\begin{tabular}{llrl}
\hline Isotope & Type & Value (\%) & Literature sources \\
\hline$\delta^{26} \mathrm{Mg}$ & sample 2 S.E. & 0.02 & Wang et al. (2021) \\
& long-term 2 S.D. & 0.06 & Wang et al. (2021) \\
\hline$\delta^{44} \mathrm{Ca}$ & sample 2 S.E. & 0.05 & Zhu et al. (2018, 2020a) \\
& long-term 2 S.D. & 0.14 & Chen et al. (2019) \\
\hline$\delta^{57} \mathrm{Fe}$ & sample 2 S.E. & 0.02 & Soderman et al. (2021) \\
& long-term 2 S.D. & 0.05 & Soderman et al. (2021) \\
\hline$\delta^{51} \mathrm{~V}$ & sample 2 S.E. & 0.05 & Wu et al. (2018); Novella et al. (2020) \\
& long-term 2 S.D. & 0.08 & Qi et al. (2019) \\
\hline$\delta^{53} \mathrm{Cr}$ & sample 2 S.E. & 0.01 & Sossi et al. (2018) \\
& long-term 2 S.D. & 0.04 & Xia et al. (2017); Sossi et al. (2018) \\
\hline
\end{tabular}




\section{Phase equilibria calculations}

9 In order to explore stable isotope fractionation taking place during the melting of pyroxenite and peridotite lithologies within the mantle, we first constructed pseudosections and calculated mineral chemistries for MIX1G (KLB1 and G2 calculations are presented in Soderman et al., 2021). The calculations were performed in the KNCFMASTOCr system using THERMOCALC v3.47 (Powell et al., 1998), and the latest version of the thermodynamic dataset of Holland and Powell (2011) with the a-X models of Holland et al. (2018).

The composition of the MIX1G lithology (Hirschmann et al., 2003; Lambart et al., 2016) used in the phase-equilibria calculations is given in Table S3. The ferric iron content is taken as between that of KLB1 peridotite and MORB, following the approach used for KG1 by Jennings et al. (2016), where $\mathrm{Fe}^{3+} / \mathrm{Fe}_{\mathrm{T}}=0.1$.

Table S3: MIX1G composition, in KNCFMASTOCr system (mol \% oxides). Composition from Lambart et al. (2016), renormalised without $\mathrm{MnO}$.

\begin{tabular}{cccccccccc}
\hline & \multicolumn{9}{c}{ mole \% oxide } \\
$\mathrm{SiO}_{2}$ & $\mathrm{Al}_{2} \mathrm{O}_{3}$ & $\mathrm{CaO}$ & $\mathrm{MgO}$ & $\mathrm{FeO}_{t}$ & $\mathrm{~K}_{2} \mathrm{O}$ & $\mathrm{Na}_{2} \mathrm{O}$ & $\mathrm{TiO}_{2}$ & $\mathrm{Cr}_{2} \mathrm{O}_{3}$ & $\mathrm{O}$ \\
\hline 38.5 & 1.78 & 2.82 & 50.58 & 5.52 & 0.01 & 0.25 & 0.07 & 0.11 & 0.09 \\
\hline
\end{tabular}

After calculation of the phase boundaries, THERMOCALC was run over a grid of P-T space, from $5-40 \mathrm{kbar}$ and $1100-1730^{\circ} \mathrm{C}$.

\section{Details and results of the main stable isotope fractionation model}

The equilibrium isotopic composition of the phases present at any point in P-T space (including melts) was calculated for each isotope system, based on calculated equilibrium isotope fractionation factors, $\alpha^{\mathrm{A}-\mathrm{B}}$, between the phases that are present. $\alpha^{\mathrm{A}-\mathrm{B}}$ was calculated either from reduced partition function ratios ( $\beta$ factors), or from calculated cation-oxygen force constants, as outlined for $\mathrm{Mg}, \mathrm{Ca}, \mathrm{V}$ and $\mathrm{Cr}$ isotopes below. The Fe isotope fractionation input parameters are presented in the supplementary information of Soderman et al. (2021). The mineral abbreviations used in the figures in the following subsections are: olivine (ol), clinopyroxene (cpx), orthopyroxene (opx), spinel (spn), garnet (g), plagioclase (pl).

\section{1 $\mathrm{Mg}$}

The $\beta^{\mathrm{Mg}}$ factors used for Mg-bearing mantle minerals (spinel, clinopyroxene, orthopyroxene, olivine, garnet) are given in Table S4. These $\beta^{\mathrm{Mg}}$ factors are taken from Huang et al. (2013), with the exception of spinel, which is taken from Schauble (2011) and scaled relative to a reference $\beta^{\mathrm{Mg}}$ of olivine which is calculated in both studies. Pigeonite (a stable phase in MIX1G) is modelled with the same $\beta^{\mathrm{Mg}}$ as clinopyroxene; liquid (melt) is taken as having no fractionation from olivine in the main model (Stracke et al., 2018, see Appendix Section 4 for discussion), so $\beta_{\text {melt }}^{\mathrm{Mg}}=\beta_{\text {olivine }}^{\mathrm{Mg}}$.

The full results of the Mg model, showing the isotopic composition of each phase calculated in 
Table S4: Parameters for $\beta^{\mathrm{Mg}}$ factors from Huang et al. (2013). $1000 \ln \beta=\mathrm{a} / \mathrm{T}^{6}+\mathrm{b} / \mathrm{T}^{4}+\mathrm{c} / \mathrm{T}^{2}$, where $\mathrm{T}=$ temperature (Kelvin).

\begin{tabular}{lrrr}
\hline Mineral & $\mathrm{a}$ & $\mathrm{b}$ & $\mathrm{c}$ \\
spinel & $-2.74 \times 10^{16}$ & $2.08 \times 10^{11}$ & $2.93 \times 10^{6}$ \\
orthopyroxene & $-8.10 \times 10^{15}$ & $6.65 \times 10^{10}$ & $2.25 \times 10^{6}$ \\
clinopyroxene & $-1.17 \times 10^{16}$ & $1.03 \times 10^{11}$ & $2.24 \times 10^{6}$ \\
olivine & $-1.19 \times 10^{16}$ & $1.05 \times 10^{11}$ & $2.07 \times 10^{6}$ \\
garnet & $-5.50 \times 10^{15}$ & $4.92 \times 10^{10}$ & $1.30 \times 10^{6}$ \\
melt & $-1.19 \times 10^{16}$ & $1.05 \times 10^{11}$ & $2.07 \times 10^{6}$ \\
\hline
\end{tabular}

KLB1, MIX1G and G2, are in Fig. S1.

KLB1
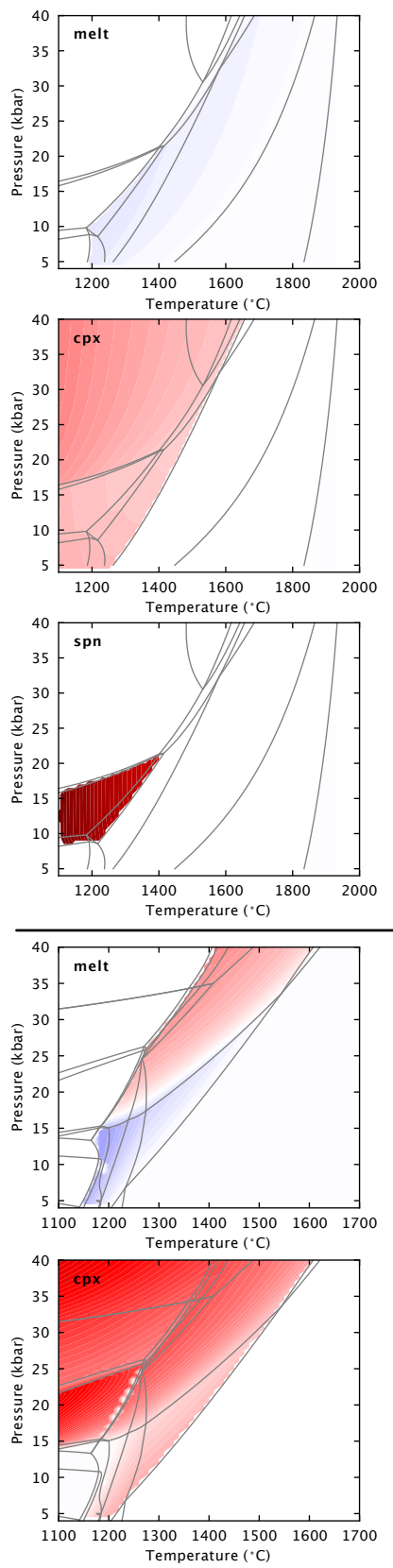
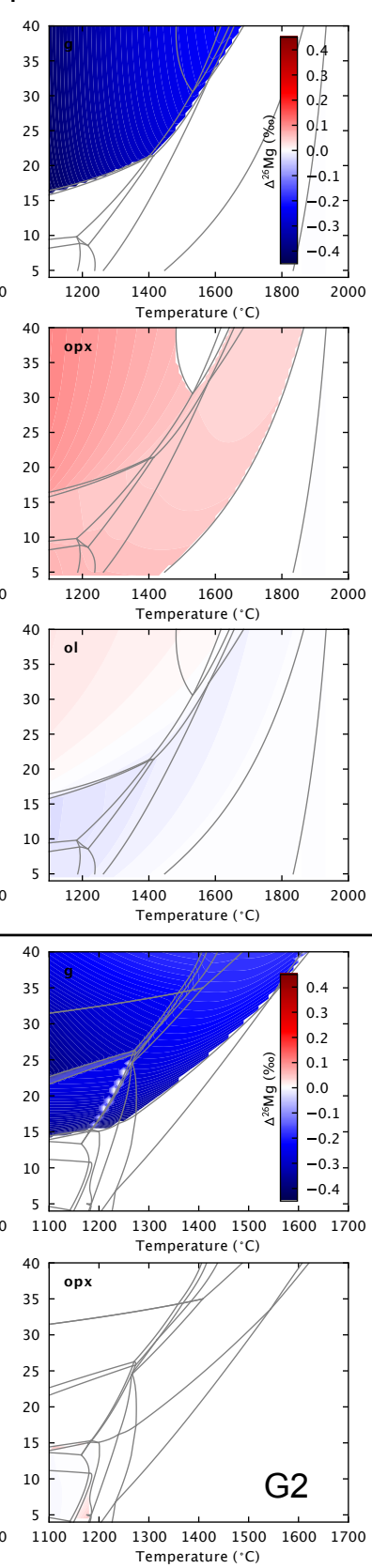

MIX1G
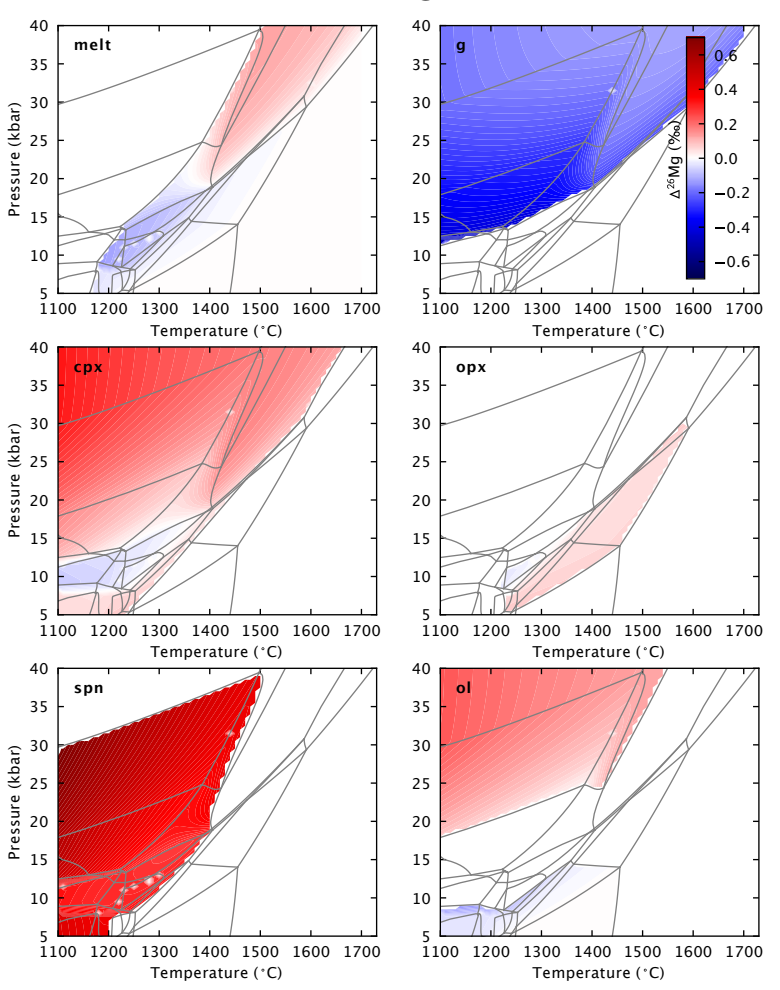

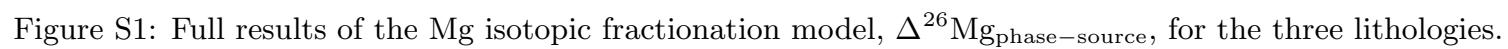


Table S5: $\beta^{\mathrm{Ca}}$ factors (given as $1000 \ln \beta$, at a temperature of $1000 \mathrm{~K}$ ) from Antonelli et al. (2019).

\begin{tabular}{llr}
\hline Mineral & Structure used & $1000 \ln \beta$ \\
\hline plagioclase & anorthite & 1.06 \\
orthopyroxene & $\mathrm{Ca} / \mathrm{Mg}=1 / 32$ & 1.84 \\
clinopyroxene & diopside & 1.32 \\
olivine & forsterite $\mathrm{Ca} / \mathrm{Mg}=1 / 64$ & 2.11 \\
garnet & pyrope $\mathrm{Ca} / \mathrm{Mg}=1 / 24$ & 2.00 \\
liquid & & 1.19 \\
\hline
\end{tabular}

\section{$3.2 \mathrm{Ca}$}

The $\beta^{\mathrm{Ca}}$ factors used for Ca-bearing mantle minerals (plagioclase, clinopyroxene, orthopyroxene, olivine, garnet) are given in Table S5, and are taken from Antonelli et al. (2019). Where options exist for minerals with different structures and/or compositions, we use those with most similar $\mathrm{Ca} / \mathrm{Mg}$ to the typical phase compositions calculated by THERMOCALC for KLB1. Pigeonite (a stable phase in MIX1G) is modelled with the same $\beta^{\mathrm{Ca}}$ as clinopyroxene; liquid is taken as having $\beta^{\mathrm{Ca}}$ intermediate between clinopyroxene and plagioclase (anorthite), following observations from natural samples (Zhang et al., 2018; Antonelli et al., 2019b) and consistent with the approach used by Antonelli et al. (2021). $\beta^{\text {Ca }}$ factors are made temperature-dependent by

$$
\ln \beta_{(\mathrm{T})}=\ln \beta_{(1000 \mathrm{~K})} \times \frac{10^{6}}{\mathrm{~T}^{2}}
$$

50 following Antonelli et al. (2021).

The full results of the Ca model, showing the isotopic composition of each phase calculated in KLB1, MIX1G and G2, are in Fig. S2. 
KLB1
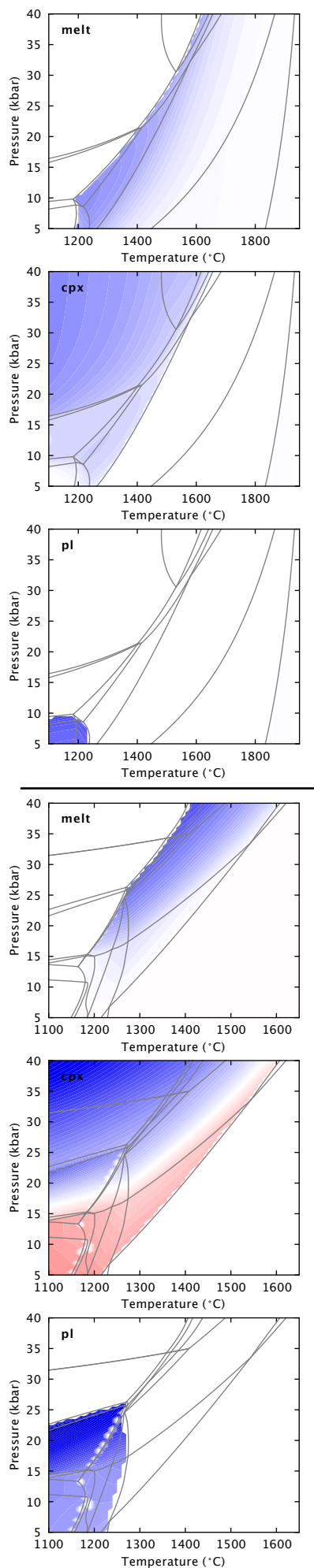

\section{MIX1G}
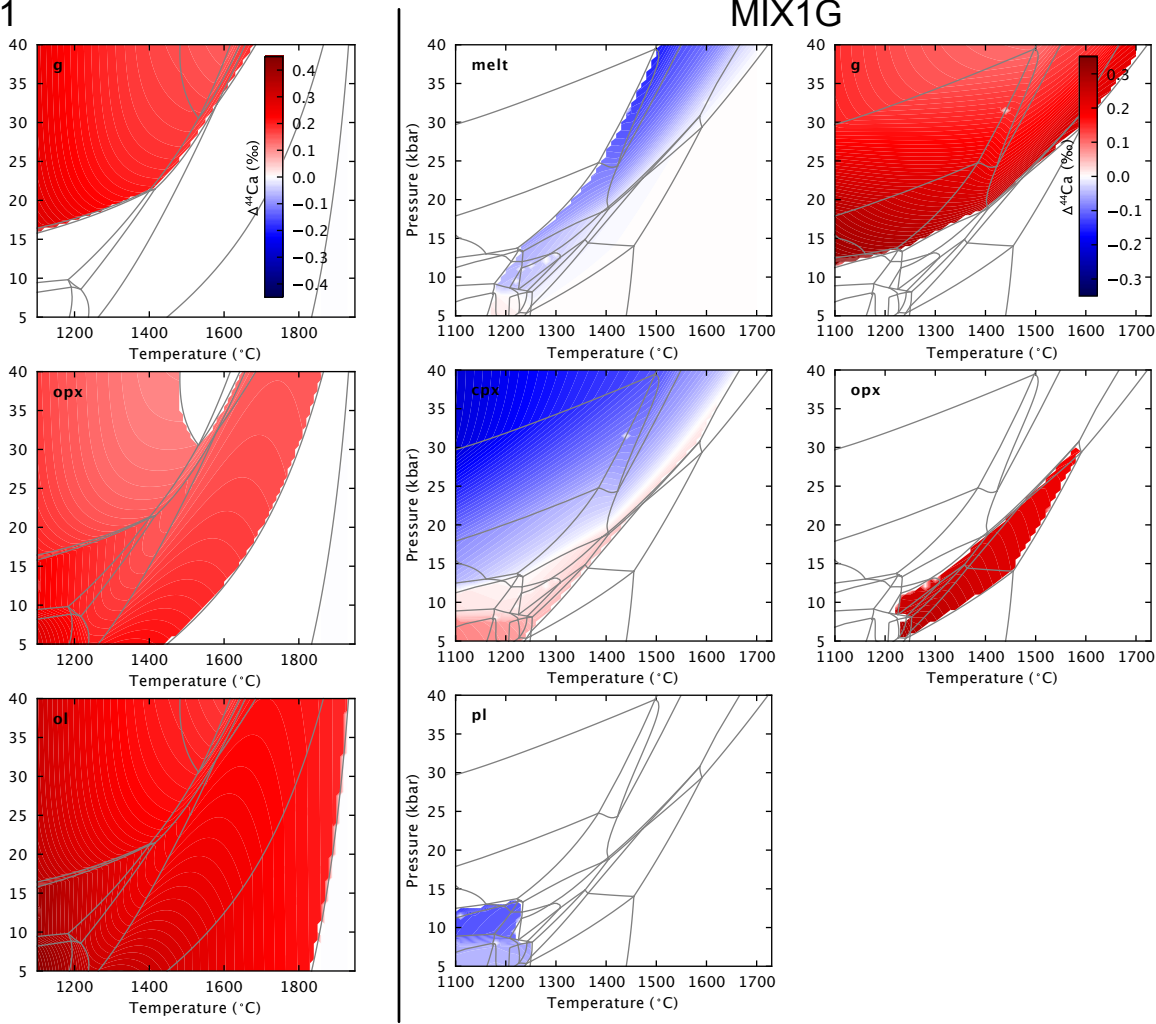
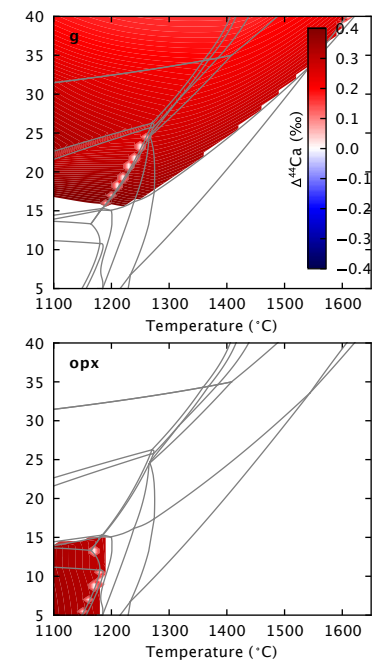

G2

Figure S2: Full results of the Ca isotopic fractionation model, $\Delta^{44} \mathrm{Ca}_{\text {phase-source }}$, for the three lithologies. 
Table S6: Parameters for V partitioning and isotopic fractionation. Partition coefficients (D) from Mallmann and O'Neill (2009). $\beta^{\mathrm{V}}$ factors are from Wu et al. (2015). $1000 \ln \beta=\mathrm{a} / \mathrm{T}^{6}+\mathrm{b} / \mathrm{T}^{4}+\mathrm{c} / \mathrm{T}^{2}$, where $\mathrm{T}=$ temperature (Kelvin)

The proportion of $\mathrm{V}^{3+/ 4+/ 5+}$ was calculated following Toplis and Corgne (2002), using the $\mathrm{FeO} / \mathrm{Fe}_{2} \mathrm{O}_{3}$ ratio of the melt (calculated by THERMOCALC) at each point in P-T space with

$$
\log \left(\mathrm{XV}^{3+} / \mathrm{XV}^{4+}\right)=\log \left(\mathrm{XFe}^{2+} / \mathrm{XFe}^{3+}\right)-2.4
$$

and

$$
\log \left(\mathrm{XV}^{4+} / \mathrm{XV}^{5+}\right)=\log \left(\mathrm{XFe}^{2+} / \mathrm{XFe}^{3+}\right)-0.3
$$

where $\mathrm{X}$ is the mole fraction of cation.

The partition coefficients and $\beta^{\mathrm{V}}$ factors of each valence state of $\mathrm{V}$ in the $\mathrm{V}$-bearing mantle minerals (olivine, clinopyroxene, orthopyroxene, garnet, spinel) are given in Table S6. Partition coefficients are from Mallmann and O'Neill (2009), with garnet assumed to have similar V partitioning to clinopyroxene (Mallmann and O'Neill, 2007, 2009). The $\beta^{\mathrm{V}}$ factors are taken from $\mathrm{Wu}$ et al. (2015) for $\mathrm{V}$ in different coordination environments in solution systems; alternative choices of $\beta^{\mathrm{V}}$ due to uncertainties in $\mathrm{V}$ coordination number are discussed in Section 4 below. Pigeonite (a stable phase in MIX1G) is modelled as clinopyroxene.

\begin{tabular}{lcrrrrr}
\hline Mineral & Valence & $\mathrm{D}_{\text {min-liq }}$ & $\mathrm{a}$ & $\mathrm{b}$ & $\mathrm{c}$ \\
\hline olivine & $\mathrm{V}^{3+}$ & 0.18 & $1.0 \times 10^{14}$ & $-7.70 \times 10^{9}$ & $6.28 \times 10^{5}$ \\
& $\mathrm{~V}^{4+}$ & 0.0227 & $4.0 \times 10^{14}$ & $-1.80 \times 10^{10}$ & $9.43 \times 10^{5}$ \\
\multirow{3}{*}{ orthopyroxene } & $\mathrm{V}^{5+}$ & 0.00255 & $7.0 \times 10^{14}$ & $-3.06 \times 10^{10}$ & $1.26 \times 10^{6}$ \\
& $\mathrm{~V}^{3+}$ & 1 & $1.0 \times 10^{14}$ & $-7.70 \times 10^{9}$ & $6.28 \times 10^{5}$ \\
& $\mathrm{~V}^{4+}$ & 0.674 & $4.0 \times 10^{14}$ & $-1.80 \times 10^{10}$ & $9.43 \times 10^{5}$ \\
clinopyroxene & $\mathrm{V}^{5+}$ & 0.00338 & $7.0 \times 10^{14}$ & $-3.06 \times 10^{10}$ & $1.26 \times 10^{6}$ \\
& $\mathrm{~V}^{3+}$ & 3.88 & $1.0 \times 10^{14}$ & $-7.70 \times 10^{9}$ & $6.28 \times 10^{5}$ \\
spinel & $\mathrm{V}^{4+}$ & 1.13 & $4.0 \times 10^{14}$ & $-1.80 \times 10^{10}$ & $9.43 \times 10^{5}$ \\
& $\mathrm{~V}^{5+}$ & 0.0142 & $7.0 \times 10^{14}$ & $-3.06 \times 10^{10}$ & $1.26 \times 10^{6}$ \\
& $\mathrm{~V}^{3+}$ & 15.3 & $1.0 \times 10^{14}$ & $-7.70 \times 10^{9}$ & $6.28 \times 10^{5}$ \\
garnet & $\mathrm{V}^{4+}$ & 1.44 & $4.0 \times 10^{14}$ & $-1.80 \times 10^{10}$ & $9.43 \times 10^{5}$ \\
& $\mathrm{~V}^{5+}$ & 0.00303 & $7.0 \times 10^{14}$ & $-3.06 \times 10^{10}$ & $1.26 \times 10^{6}$ \\
& $\mathrm{~V}^{3+}$ & 3.88 & $1.0 \times 10^{14}$ & $-7.70 \times 10^{9}$ & $6.28 \times 10^{5}$ \\
melt & $\mathrm{V}^{4+}$ & 1.13 & $4.0 \times 10^{14}$ & $-1.80 \times 10^{10}$ & $9.43 \times 10^{5}$ \\
& $\mathrm{~V}^{5+}$ & 0.0142 & $7.0 \times 10^{14}$ & $-3.06 \times 10^{10}$ & $1.26 \times 10^{6}$ \\
& $\mathrm{~V}^{3+}$ & 1 & $1.0 \times 10^{14}$ & $-7.70 \times 10^{9}$ & $6.28 \times 10^{5}$ \\
& $\mathrm{~V}^{4+}$ & 1 & $4.0 \times 10^{14}$ & $-1.80 \times 10^{10}$ & $9.43 \times 10^{5}$ \\
& $\mathrm{~V}^{5+}$ & 1 & $7.0 \times 10^{14}$ & $-3.06 \times 10^{10}$ & $1.26 \times 10^{6}$ \\
\hline
\end{tabular}

\section{$3.3 \mathrm{~V}$}

The full results of the $\mathrm{V}$ isotope model, showing the isotopic composition of each phase calculated in KLB1, MIX1G and G2, are in Fig. S3. Note that stable isotope fractionation can only be calculated where there is liquid present, i.e., where the proportion of each $\mathrm{V}$ valence state can be calculated.

\section{$3.4 \mathrm{Cr}$}

The proportion of $\mathrm{Cr}^{2+/ 3+}$ was calculated using the parameterisation given in Berry et al. (2021)

$$
\frac{\mathrm{Cr}^{2+}}{\mathrm{Cr}_{\mathrm{T}}}=\frac{1}{1+10^{\left(0.25 \operatorname{logfO} \mathrm{g}_{2}+\log \mathrm{K}^{\prime}\right)}}
$$



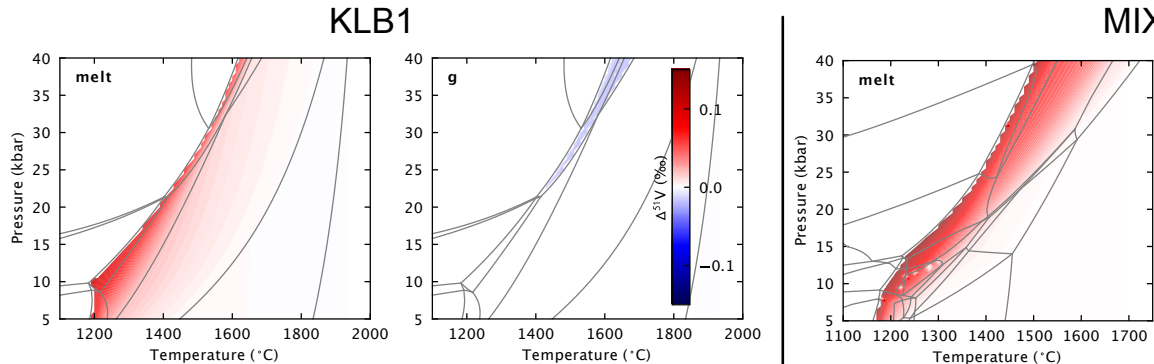

MIX1G
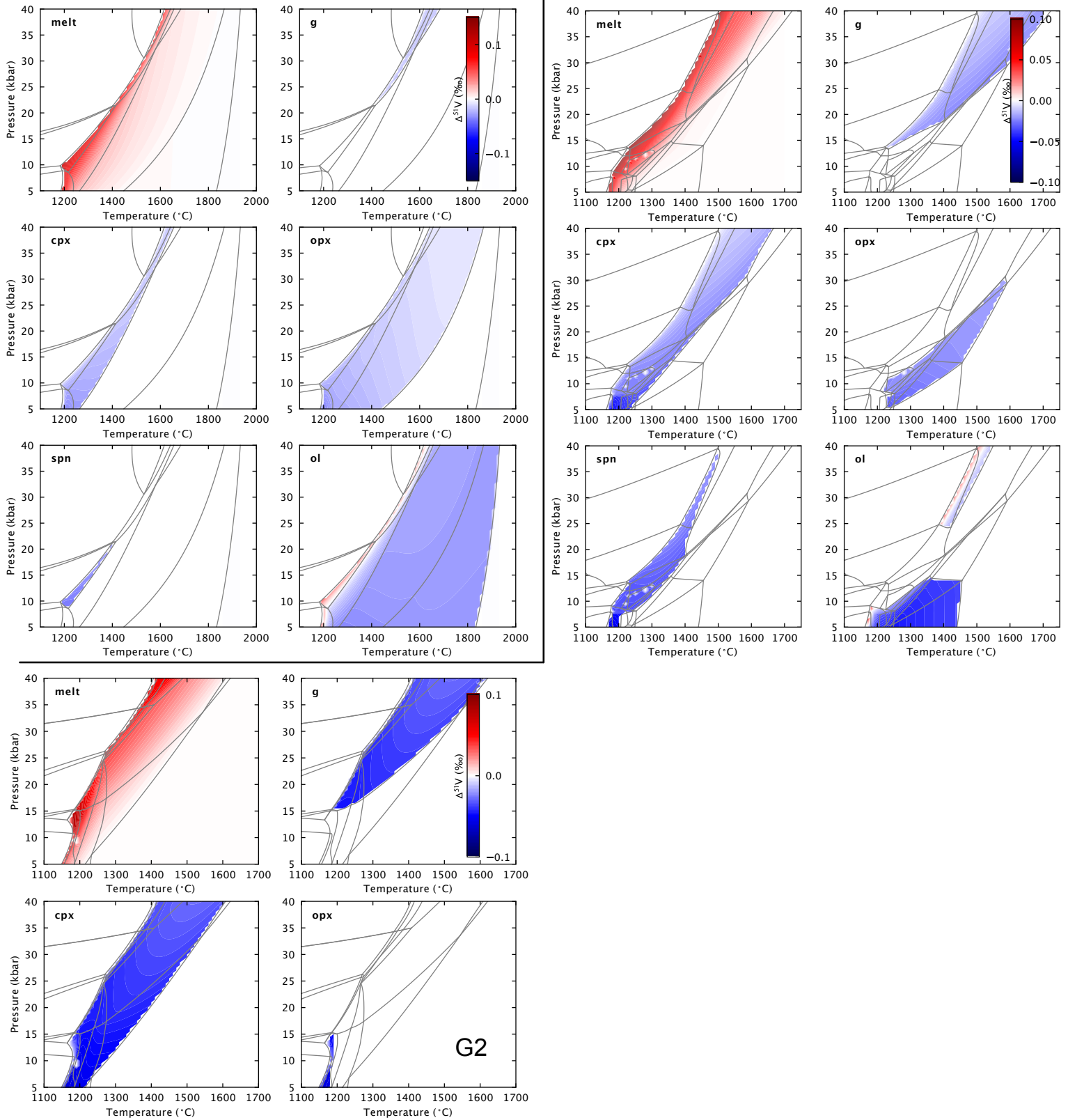

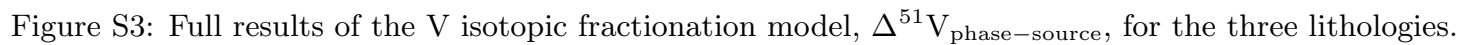


Table S7: Optical basicity values for each oxide, from Mills (1993).

\begin{tabular}{cccccccccc}
\hline \multicolumn{8}{c}{ optical basicity, $\Lambda$} \\
$\mathrm{SiO}_{2}$ & $\mathrm{TiO}_{2}$ & $\mathrm{Al}_{2} \mathrm{O}_{3}$ & $\mathrm{Fe}_{2} \mathrm{O}_{3}$ & $\mathrm{Cr}_{2} \mathrm{O}_{3}$ & $\mathrm{FeO}$ & $\mathrm{CaO}$ & $\mathrm{MgO}$ & $\mathrm{Na}_{2} \mathrm{O}$ & $\mathrm{K}_{2} \mathrm{O}$ \\
\hline 0.48 & 0.61 & 0.60 & 0.75 & 0.58 & 1 & 1 & 0.78 & 1.15 & 1.4 \\
\hline
\end{tabular}

with $\mathrm{fO}_{2}$ calculated at each P-T point using the $\mathrm{fO}_{2}$ melt software (Holland et al., 2018), and the modified equilibrium constant calculated by

$$
\log \mathrm{K}^{\prime}=\frac{9770}{\mathrm{~T}}-7.69+6.22 \Lambda+\frac{\left(900 \mathrm{P}-172 \mathrm{P}^{2}\right)}{\mathrm{T}}
$$

where $\mathrm{T}$ is in Kelvin, $\mathrm{P}$ is in GPa. $\Lambda$ is the optical basicity, a composition-dependent term (Duffy, 1993) which reflects equilibrium between bridging oxygens, non-bridging oxygens and free oxide anions in a melt (Humphreys et al., 2015). Since optical basicity values can be assigned to individual oxides (Duffy, 1993), an ideal optical basicity for a melt can be calculated, following Mills (1993), as

$$
\Lambda=\frac{\sum \mathrm{X}_{\mathrm{i}} \mathrm{n}_{\mathrm{i}} \Lambda_{\mathrm{i}}}{\sum \mathrm{X}_{\mathrm{i}} \mathrm{n}_{\mathrm{i}}}
$$

where $\mathrm{X}_{\mathrm{i}}$ is the mole fraction of oxide $\mathrm{i}, \mathrm{n}$ is the number of $\mathrm{O}$ associated with oxide $\mathrm{i}$, and $\Lambda$ is the theoretical $\Lambda$ of oxide i (see Table S7). At each P-T point, the calculated $\Lambda$ was used with equations 3 and 4 to calculate $\mathrm{Cr}$ redox state.

The partition coefficients of each valence state of $\mathrm{Cr}$ in the Cr-bearing mantle minerals (olivine, clinopyroxene, orthopyroxene, garnet, spinel) are given in Table S8. Partition coefficients for olivine, clinopyroxene, orthopyroxene are from (Mallmann and O'Neill, 2009); for spinel from the supplement of Shen et al. (2018), for garnet from Sutton et al. (2008). The ionic model inputs (Table S8) are based on the supplement of Shen et al. (2018); for garnet, where no ionic inputs are presented in Shen et al. (2018), we take coordination information from Deer et al. (2013), and use the relevant ionic radii as used by Shen et al. (2018). The force constants for Cr-O bonds were then calculated based on the equations presented in Sossi and O'Neill (2017) for Fe isotopes.

Table S8: Parameters for Cr partitioning and isotopic fractionation model. Partition coefficients (D) from Mallmann and O'Neill (2009); Shen et al. (2018); Sutton et al. (2008). Mineral site and bonding information is based on Shen et al. (2018). cpx = clinopyroxene, opx = orthopyroxene.

\begin{tabular}{lrrlrrrr}
\hline Mineral & Cr species & $\mathrm{D}_{\text {min-melt }}$ & Site & Cr coordination & Bond length $(\AA)$ & O coordination & No. sites \\
\hline spinel & $2+$ & 0 & $\mathrm{n} / \mathrm{a}$ & $\mathrm{n} / \mathrm{a}$ & $\mathrm{n} / \mathrm{a}$ & $\mathrm{n} / \mathrm{a}$ & $\mathrm{n} / \mathrm{a}$ \\
spinel & $3+$ & 220 & $\mathrm{M}$ & 6 & 1.995 & 4 & 2 \\
garnet & $2+$ & 0 & $\mathrm{n} / \mathrm{a}$ & $\mathrm{n} / \mathrm{a}$ & 6 & $\mathrm{n} / \mathrm{a}$ & $\mathrm{n} / \mathrm{a}$ \\
garnet & $3+$ & 12 & $\mathrm{M} 2$ & 6 & 2.995 & 4 & 2 \\
olivine & $2+$ & 0.85 & $\mathrm{M} 2$ & 6 & 1.995 & 4 & 1 \\
olivine & $3+$ & 0.85 & $\mathrm{M} 1$ & 7 & 2.305 & 3 & 1 \\
opx & $2+$ & 0.843 & $\mathrm{M} 2$ & 6 & 1.988 & 3.57 & 1 \\
opx & $3+$ & 3.52 & $\mathrm{M} 1$ & 7 & 2.305 & 3.57 & 1 \\
cpx & $2+$ & 0.587 & $\mathrm{M} 2$ & 6 & 1.988 & 3.67 & 1 \\
cpx & $3+$ & 12.6 & $\mathrm{M} 1$ & 4 & 1.913 & 4 & 1 \\
liquid & $2+$ & 1 & & 6 & 1.995 & 4 & \\
liquid & $3+$ & 1 & & & & & \\
\hline
\end{tabular}

The full results of the $\mathrm{Cr}$ model, showing the isotopic composition of each phase calculated in KLB1, MIX1G and G2, are in Fig. S4. Note that stable isotope fractionation can only be calculated where there is liquid present, i.e., where the proportion of each $\mathrm{Cr}$ valence state can be calculated. 

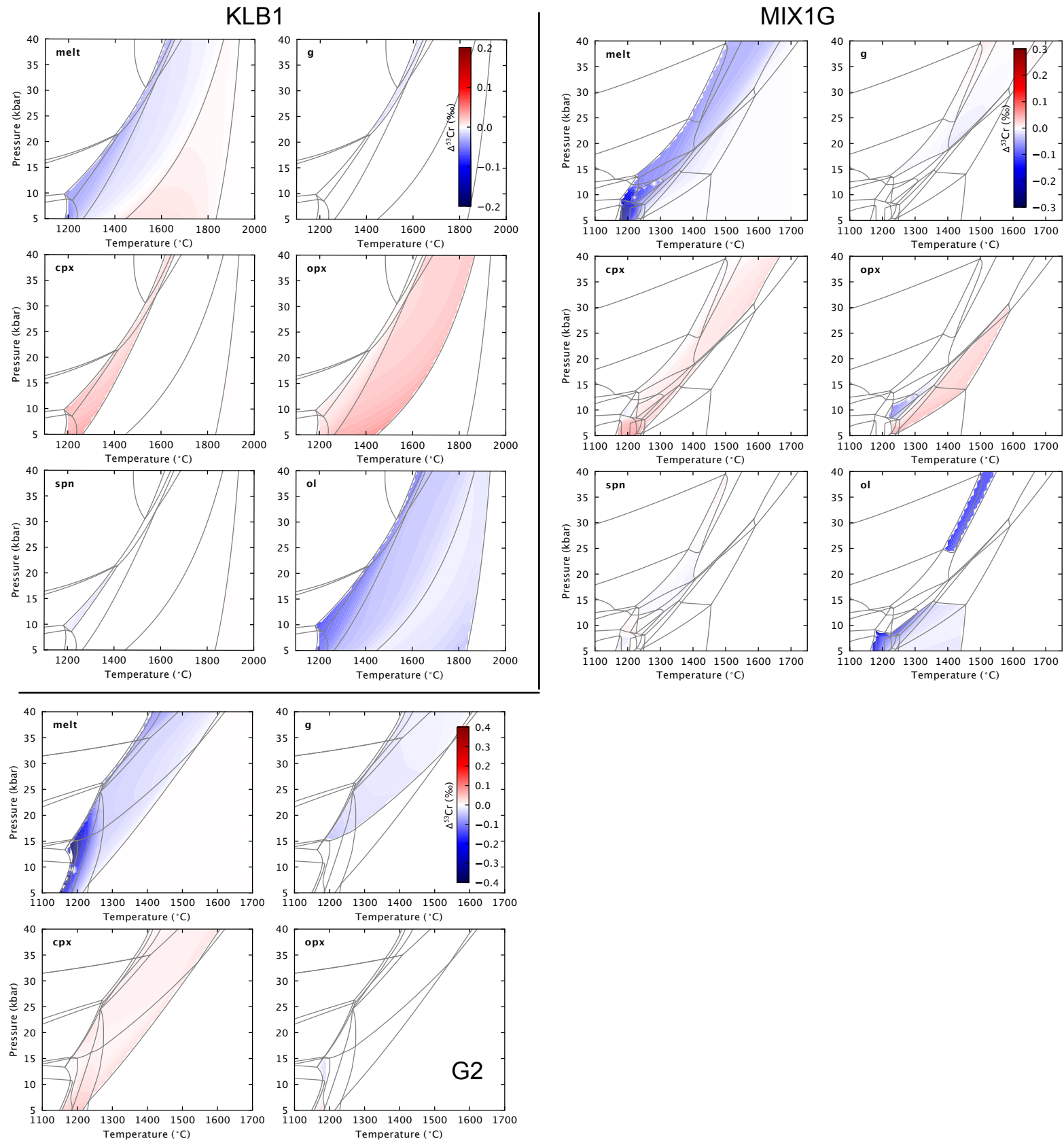

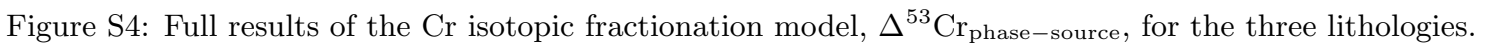




\subsection{Consistency of valence state calculations}

As discussed in the main text, the calculated $\mathrm{Fe}^{3+} / \mathrm{Fe}_{\mathrm{T}}, \mathrm{Cr}^{3+} / \mathrm{Cr}_{\mathrm{T}}$ and $\mathrm{V}^{4+, 5+} / \mathrm{V}_{\mathrm{T}}$ are not fully self-consistent, as the speciation of both $\mathrm{Cr}$ and $\mathrm{V}$ are calculated based on the $\mathrm{Fe}^{3+} / \mathrm{Fe}_{\mathrm{T}}$ at any point. This means that $\mathrm{O}$ (oxygen) is being partitioned into the oxidised $\mathrm{Cr}$ and $\mathrm{V}$ oxides without affecting Fe redox state. We consider tying the $\mathrm{Cr}$ and $\mathrm{V}$ valence states to the Fe redox equilibria to be reasonable, as Fe is the dominant redox-sensitive element in the mantle with an abundance considerably greater than that of $\mathrm{Cr}$ or $\mathrm{V}$. To quantify this, we have calculated the fraction of oxygen associated with oxidised valence states of the each redox-sensitive element out of the total oxygen associated with the oxidised valence states, e.g.,

$$
\frac{\mathrm{O}_{\mathrm{Fe}^{3+}}}{\mathrm{O}_{\mathrm{Fe}^{3+}}+\mathrm{O}_{\mathrm{Cr}^{3+}}+\mathrm{O}_{\mathrm{V}^{4+}}+\mathrm{O}_{\mathrm{V}^{5+}}}
$$

where $\mathrm{O}_{\mathrm{X}}$ represents the number of moles of oxygen associated with cation $\mathrm{X}$ at any given $\mathrm{P}-\mathrm{T}$ point. At $\mathrm{T}=1300{ }^{\circ} \mathrm{C}$ and $\mathrm{P}=12 \mathrm{kbar}$, we calculate that $73 \%$ of the oxygen associated with oxidised cations is associated with $\mathrm{Fe}^{3+}, 27 \%$ with $\mathrm{Cr}^{3+}$, and $<0.01 \%$ with $\mathrm{V}^{4+, 5+}$, for total Fe, Cr and V contents in peridotite (Davis et al., 2009; Salters and Stracke, 2004).

However, although our use of the Fe redox equilibria to calculate $\mathrm{Cr}$ and $\mathrm{V}$ speciation is a reasonable approximation, it is important to note that considering the combined Fe-Cr-V redox equilibria as in real systems would reduce the variability in the redox state of each element across P-T space compared to our model. This is because the combined effect of considering three redox equilibria able to accommodate oxygen via their oxidised cations together is that each system will have to shift its redox equilibria less compared to a scenario where only one redox-sensitive element is considered. To approximately quantify the effect of this redox feedback, we took an extreme case of reducing all the $\mathrm{Cr}_{2} \mathrm{O}_{3}$ in the melt at a given P-T point, accommodating the released oxygen by increasing the amount of $\mathrm{Fe}_{2} \mathrm{O}_{3}$ and reducing the amount of $\mathrm{FeO}$ accordingly. We then calculated the $\mathrm{fO}_{2}$ of this new composition through the $\mathrm{fO}_{2}$ melt software (Holland et al., 2018), and recalculated the expected $\mathrm{Cr}^{3+} / \mathrm{Cr}_{\mathrm{T}}$ given the new $\mathrm{fO}_{2}$. We find that, for this calculation performed using at $\mathrm{T}=1350{ }^{\circ} \mathrm{C}$ and $\mathrm{P}=12 \mathrm{kbar}$, the $\mathrm{fO}_{2}$ change produces a $1 \%$ change in $\mathrm{Cr}^{3+} / \mathrm{Cr}_{\mathrm{T}}$ and negligible impact on the calculated $\delta^{53} \mathrm{Cr}$.

\section{Alternative input parameters and results}

The inputs into the isotope fractionation models are better constrained for some of the stable isotope systems considered relative to others. These uncertainties limit our ability to predict the behaviour of some isotope systems in high temperature settings, and therefore limit the utility of stable isotopes as a tool for exploring global basalt systematics. Here we discuss the results of using alternative inputs.

\subsection{Mg: $\alpha_{\text {orthopyroxene-melt }}=1$}

While the bonding of $\mathrm{Mg}$ in crystal lattices can be used to calculate a self-consistent set of $\beta^{\mathrm{Mg}}$ factors (Schauble, 2011; Huang et al., 2013) to input into the melting model, $\beta^{\mathrm{Mg}}$ factors do not exist for silicate liquid. However, Stracke et al. (2018) show that $\alpha_{\text {olivine, orthopyroxene-melt }} \sim 1$ based on equilibrated peridotite xenoliths. $\mathrm{Mg}$ is also similarly coordinated ([5-6] fold) in melt and olivine/orthopyroxene (George and Stebbins, 1998; Shimoda et al., 2007; Stracke et al., 
2018), providing further evidence for minimal olivine/orthopyroxene - melt Mg stable isotope fractionation at magmatic temperatures.

We have chosen to use $\alpha_{\text {olivine-melt }}=1$; i.e., using the same $\beta^{\mathrm{Mg}}$ values for liquid as for olivine. The alternative is to use $\alpha_{\text {orthopyroxene-melt }}=1$. Fig. S5 compares the $\Delta^{26} \mathrm{Mg}$ melt-source for an input of $\alpha_{\text {olivine-melt }}=1$ (left hand panels; these are the results used in the main text) with an input of $\alpha_{\text {orthopyroxene-melt }}=1$ (right hand panels). The new input parameters replace the melt in Table S4 with Table S9.

Table S9: Alternate parameters for $\mathrm{Mg}$ isotope $\beta^{\mathrm{Mg}}$ factors from Huang et al. (2013). 1000ln $\beta=\mathrm{a} / \mathrm{T}^{6}+\mathrm{b} / \mathrm{T}^{4}$ $+\mathrm{c} / \mathrm{T}^{2}$, where $\mathrm{T}=$ temperature (Kelvin).

\begin{tabular}{lrrr}
\hline Mineral & $\mathrm{a}$ & $\mathrm{b}$ & $\mathrm{c}$ \\
\hline melt & $-8.10 \times 10^{15}$ & $6.65 \times 10^{10}$ & $2.25 \times 10^{6}$ \\
\hline
\end{tabular}

For KLB1 peridotite, the magnitude of the difference in melt isotope composition between the two models is $\approx 0.05 \%$ (small compared to the average analytical uncertainty of $0.1 \%$ suggested in Stracke et al., 2018, and similar to the long-term 2 S.D. of $0.06 \%$ given in Wang et al., 2021), however the direction of partial melting fractionation is different. In the case of $\alpha_{\text {olivine-melt }}=1$, KLB1 melts are isotopically lighter than the bulk, and get heavier with increasing degree of melting (the latter part of this behaviour is consistent with fractional melting modelled by Stracke et al., 2018). For $\alpha_{\text {orthopyroxene-melt }}=1$, partial melts are isotopically heavier than the bulk, and get progressively lighter with increasing degree of melting (the former part of this behaviour is consistent with Stracke et al., 2018).

For KLB1, the similar differences in modelled melting isotopic fractionation relative to the analytical uncertainty means that the choice of $\alpha_{\text {olivine-melt }}=1$ or $\alpha_{\text {orthopyroxene-melt }}=1$ for liquid does not greatly alter any conclusions drawn from the peridotite melting. Minimal difference between the models is also seen for MIX1G. However, low pressure melts from G2 $(<15 \mathrm{kbar})$ show effectively no stable isotope fractionation when $\alpha_{\text {orthopyroxene-melt }}=1$ is used, compared to fractionations as large as $\Delta^{26} \mathrm{Mg}=-0.1 \%$ with $\alpha_{\text {olivine-melt }}=1$. This is because, for these shallow depths, the only stable Mg-bearing phases in G2 are clinopyroxene and liquid (garnet is not stable). Orthopyroxene and clinopyroxene have similar $\beta^{\mathrm{Mg}}$ factors and therefore, when liquid is given the same $\beta^{\mathrm{Mg}}$ factor as orthopyroxene, the coexisting liquid and clinopyroxene are only minimally isotopically fractionated from each other. These results highlight how important accurate experimental $\alpha_{\text {mineral-melt }}$ are for understanding the behaviour of stable isotope systems, and the important role analytical precision plays in being able to identify these effects in nature. Magnesium stable isotopes would benefit from further work in both of these areas.

\section{$4.2 \mathrm{Ca}$}

The $\beta^{\mathrm{Ca}}$ value approach reduces uncertainties associated with an ionic model, as the bond lengths and $\mathrm{Ca}, \mathrm{O}$ coordination numbers in the relevant mineral structures required for the ionic model are variable in the literature (e.g., Feng et al., 2014; Huang et al., 2019). Huang et al. (2019) present an alternative set of $\beta^{\mathrm{Ca}}$ values for the Ca-bearing minerals we are concerned with, although Antonelli et al. (2019) argue that the PBE functionals used in their own study better represent $\mathrm{Ca}$ isotope fractionation between species than the less accurate LDA functionals used by Huang et al. (2019). Additionally, Antonelli et al. (2019) calculate $\beta^{\mathrm{Ca}}$ for pyrope garnet, which is more representative of mantle garnet than the grossular endmember used in Huang et al. (2019). Our model uses $\beta_{\text {plagioclase }}^{\mathrm{Ca}}<\beta_{\text {melt }}^{\mathrm{Ca}}<\beta_{\text {clinopyroxene }}^{\mathrm{Ca}}$ (see explanation in Section 

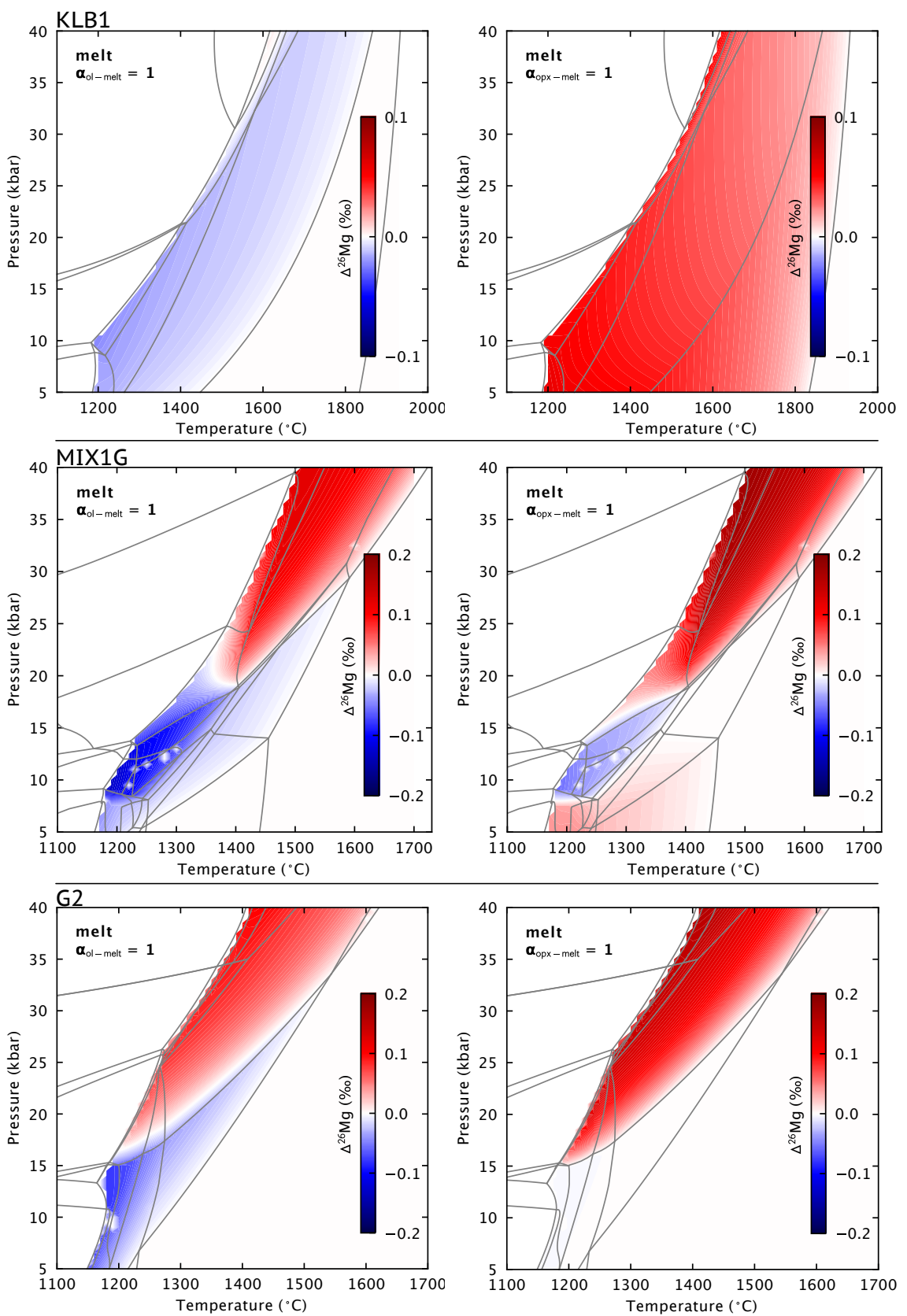

Figure S5: $\Delta^{26} \mathrm{Mg}_{\text {melt-source }}$ compared for a model where $\alpha_{\text {olivine-melt }}=1$ (left hand plots) and $\alpha_{\text {orthopyroxene-melt }}$ $=1$ (right hand plots) for all three lithologies considered.

3.2), but some studies do suggest that $\beta_{\mathrm{melt}}^{\mathrm{Ca}}=\beta_{\text {clinopyroxene }}^{\mathrm{Ca}}$ (e.g., Chen et al., 2019) based on observations from natural equilibrated peridotite and pyroxenite samples that there is minimal Ca isotope fractionation between clinopyroxene and basaltic melt. Independent estimates of the force constants in silicate liquids and further experimental constraints on the behaviour of $\mathrm{Ca}$ isotopes in silicate melts are therefore needed to improve the $\mathrm{Ca}$ isotope fractionation model.

Fig. S6 shows the results of using the $\beta^{\mathrm{Ca}}$ values from Huang et al. (2019) with $\beta_{\text {melt }}^{\mathrm{Ca}}=$ $\beta_{\text {clinopyroxene }}^{\mathrm{Ca}}$ (equivalent to $\alpha_{\text {clinopyroxene-melt }}=1$ ). The use of isotopically lighter grossular garnet and isotopically heavier melt (relative to the Antonelli et al. (2019) inputs) result in overall less negative melt-source isotope fractionation than in the main model, making all $\mathrm{Ca}$ 
isotope fractionations harder to resolve with current analytical precision. However, none of the conclusions presented in the main text are altered by these alternative parameter choices.

KLB1
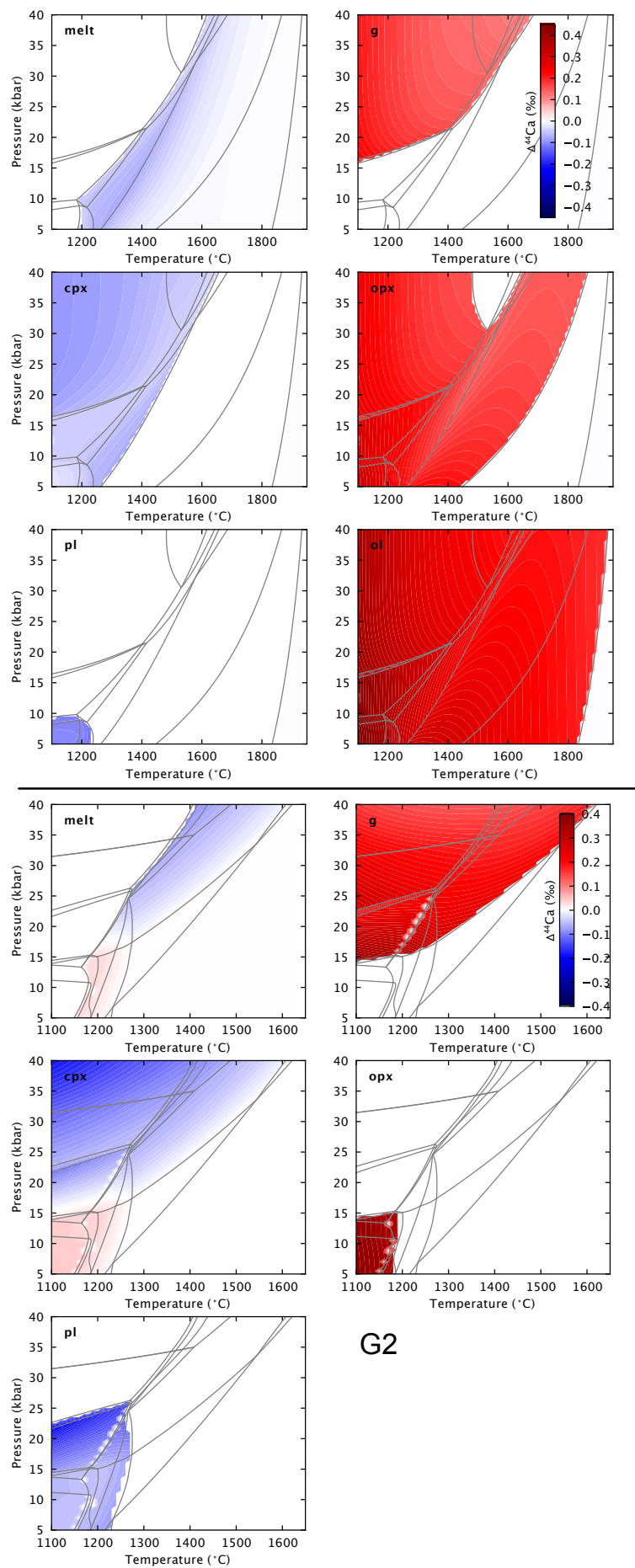
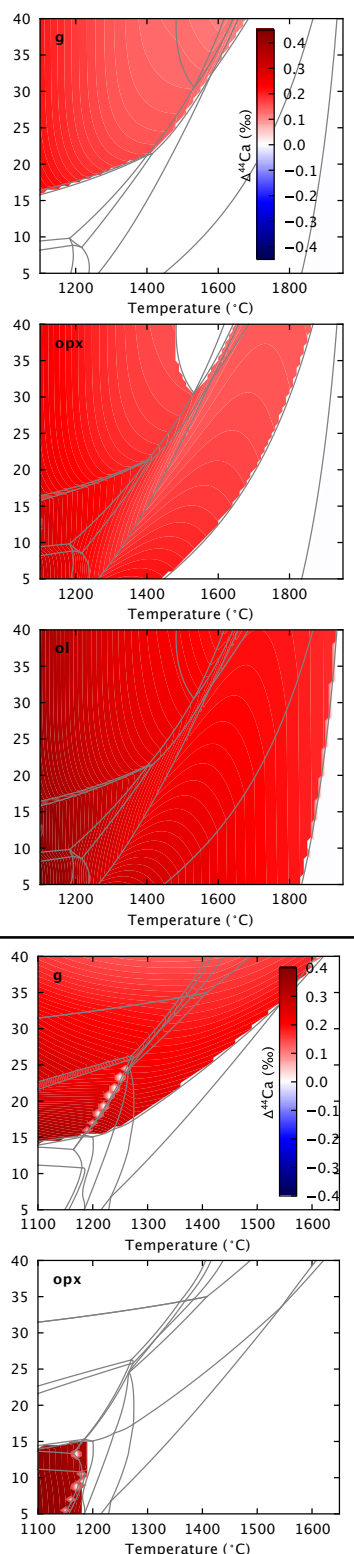

G2

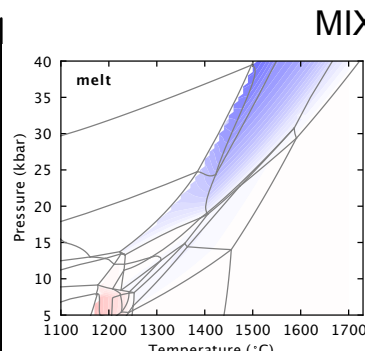

MIX1G
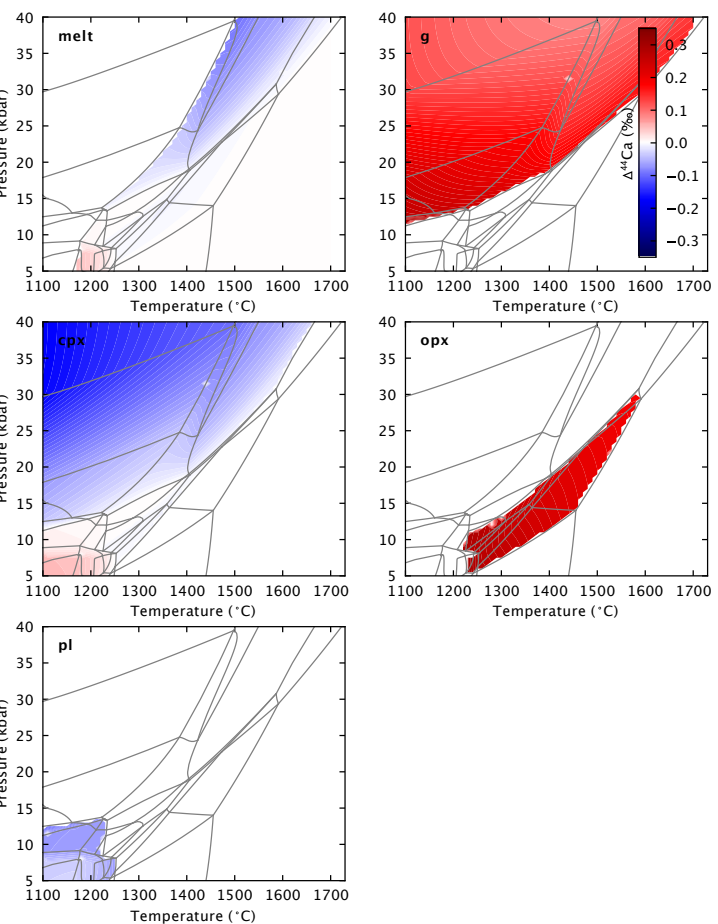

Temperature ( $\left({ }^{\circ} \mathrm{C}\right)$

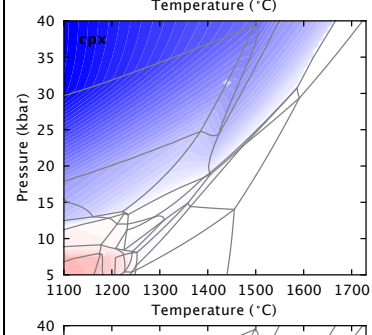

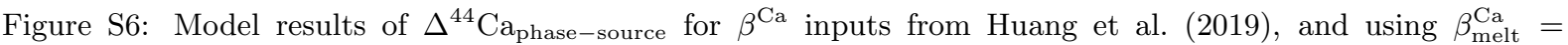

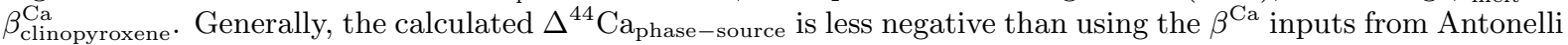
et al. (2019) as shown in Fig. S2.

The composition of the phases involved further complicates models of Ca isotope fractionation. Feng et al. (2014) and Wang et al. (2017) show that Ca-O bond strength, hence isotopic fractionation, in orthopyroxene is dependent on the $\mathrm{Ca}$ and $\mathrm{Fe}$ content of the pyroxene, al- 
though the concentrations of these elements in natural orthopyroxenes may produce negligible concentration effects on isotopic fractionation (Wang et al., 2017). The isotopic fractionation associated with garnet, in particular, is sensitive to Ca content for typical mantle compositions, with a garnet-composition-sensitive fractionation factor produces smaller melting fractionations in eclogite than using a fixed composition model (Chen et al., 2020a). Our model has not implemented composition-specific fractionation factors, although does use the pyrope garnet endmember which is most representative of mantle garnet. We also note that Antonelli et al. (2019) calculate compositional effects for olivine and pyroxene solid solutions that are smaller than those predicted using LDA functionals (e.g., Feng et al., 2014; Wang et al., 2017).

\section{$4.3 \quad \mathrm{Fe}$}

The model inputs for Fe isotope fractionation are relatively well constrained. The bonding environment of Fe in mineral phases is well studied, making an ionic model approach possible (e.g., Sossi and O'Neill, 2017). The model based on ionic inputs produces isotopic fractionation and force constant predictions consistent with predictions by other methods and observations (e.g., Dauphas et al., 2014; Macris et al., 2015). In addition, the Fe-O force constants in basaltic glass as a function of $\mathrm{Fe}^{3+}$ content have been experimentally determined (Dauphas et al., 2014), allowing the melt isotopic fractionation to be independently parameterised into the model (although we note the potential complication induced by quenching effects, and by melt generation in the mantle at non-atmospheric pressure). As discussed by Sossi and O'Neill (2017), some terms in the ionic model approach (such as the ionicity of the bonds) are less well constrained than the bonding environment of Fe in mineral structures, however the resultant fractionation factors are minimally affected by these uncertainties.

\section{$4.4 \mathrm{~V}: \mathrm{V}_{\text {melt }}^{5+}=[4]$ coordinated}

It has been suggested that vanadium isotopes may track magmatic redox (Prytulak et al., 2013, 2017; Sossi et al., 2018b; Wu et al., 2018) due to the existence of three valence states $(3+, 4+$, $5+$ ) in terrestrial magmatic systems (Canil, 1999), though a better understanding of V isotope behaviour during magmatic processes is required to exploit the system's full potential as a redox tracer (Prytulak et al., 2017). The successful modelling of V isotope fractionation therefore relies on an understanding of the behaviour of each valence state of $\mathrm{V}$.

Although slightly variable $\mathrm{V}$ partition coefficients for each valence state into mineral phases can be found from experimental studies (Mallmann and O'Neill, 2009), these variations make no significant difference to the calculated melt isotopic compositions. The main uncertainty in the $\mathrm{V}$ fractionation model inputs is the coordination of $\mathrm{V}^{4+}$ and $\mathrm{V}^{5+}$ in silicate melts (and associated $\beta^{V}$ factors). $\mathrm{V}^{4+}$ in silicate liquid is [5-6] coordinated (Sutton et al., 2005), and $\mathrm{V}^{4+}$ coordination of both [5.33] and [6] have been used in existing studies discussing $\mathrm{V}$ isotope behaviour during melting (Qi et al., 2019; Wu et al., 2018 respectively). $\mathrm{V}^{5+}$ coordination in silicate melts is [4-6] (Sutton et al., 2005; Righter et al., 2006), with Qi et al. (2019) quoting an average of [5] coordination. As one of the main causes of $\mathrm{V}$ isotope fractionation during melting is predicted to be the relative compatibility of $\mathrm{V}^{5+}$ (and to a lesser extent $\mathrm{V}^{4+}$ ) in melts relative to minerals (e.g., Canil, 2002; Mallmann and O'Neill, 2009; Wu et al., 2018), the bonding environment and force constants of $\mathrm{V}$ species in the melt is a particularly important input. The choice of coordination number for the $\mathrm{V}$ species controls the $\ln \beta$ value chosen for that species: $\beta^{\mathrm{V}}$ values are taken from those calculated for different bonding environments in 
aqueous solutions (Wu et al., 2015), assumed to be a good approximation to the case of silicate melts following $\mathrm{Wu}$ et al. (2018). [5] coordination of $\mathrm{V}^{5+}$ is not modelled in $\mathrm{Wu}$ et al. (2015), and therefore only the cases of $\mathrm{V}^{5+}$ in [4] and [6] coordination can be used, for which $\beta^{\mathrm{V}}$ values have been calculated. No calculations are available for $\mathrm{V}^{4+}$ in [5] coordination, and therefore the model only considers $\mathrm{V}^{4+}$ in [6] coordination.

Fig. S7 compares the $\Delta^{51} \mathrm{~V}_{\text {melt-source }}$ for an input of $\mathrm{V}_{\text {melt }}^{5+}=[6]$-fold coordination (left hand panels; these are the results used in the main text) with an input of $\mathrm{V}_{\text {melt }}^{5+}=[4]$-fold coordination (right hand panels). There are two aqueous complexes with 4 -fold $\mathrm{V}^{5+}$ in $\mathrm{Wu}$ et al. (2015). Here we have chosen the $\beta^{\mathrm{V}}$ factors for the $\left[\mathrm{V}^{5+} \mathrm{O}_{2}(\mathrm{OH})_{2}\right]^{-}$(Table S10) complex since this complex has the greatest $\ln \beta^{\mathrm{V}}$ difference from the [6]-fold coordinated case, therefore covering the greatest range of input uncertainty.
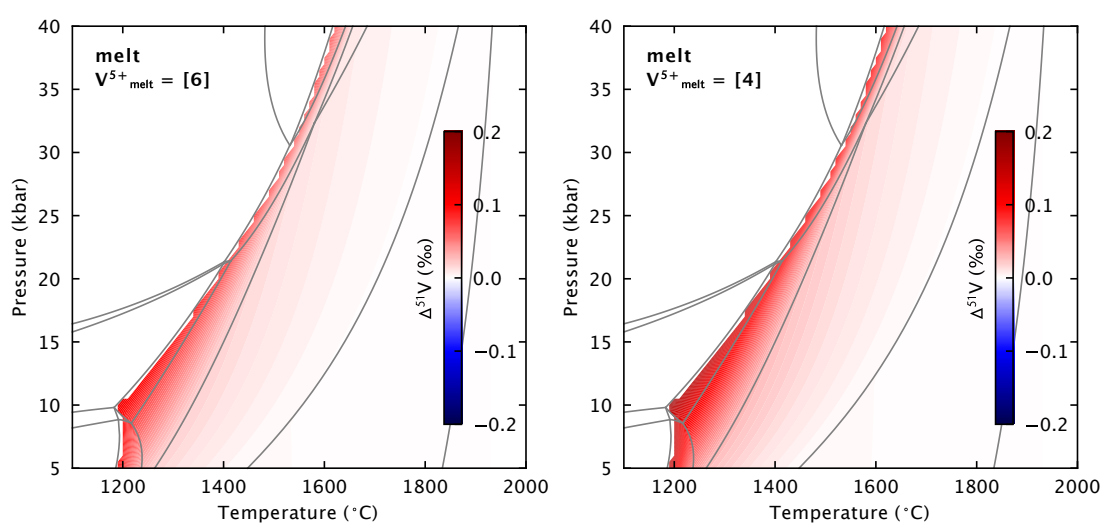

Figure S7: $\Delta^{51} \mathrm{~V}_{\text {melt-source }}$ compared for a model where $\mathrm{V}_{\text {melt }}^{5+}=[6]$ coordinated (left hand plots) and $\mathrm{V}_{\text {melt }}^{5+}=$ [4] coordinated (right hand plots) for KLB1.

Table S10: Alternate parameters for $\mathrm{V}$ isotope $\beta^{\mathrm{V}}$ factors from $\mathrm{Wu}$ et al. (2015). $1000 \ln \beta=\mathrm{a} / \mathrm{T}^{6}+\mathrm{b} / \mathrm{T}^{4}+$ $\mathrm{c} / \mathrm{T}^{2}$, where $\mathrm{T}=$ temperature (Kelvin).

\begin{tabular}{lrrrr}
\hline Mineral & Valence & $\mathrm{a}$ & $\mathrm{b}$ & $\mathrm{c}$ \\
\hline melt & $\mathrm{V}^{5+}$ & $7.00 \times 10^{14}$ & $-3.25 \times 10^{10}$ & $1.42 \times 10^{6}$ \\
\hline
\end{tabular}

The model discussed in the main text is the result of using the upper limit of [6] coordinated $\mathrm{V}^{5+}$ : this will provide the minimum melting fractionation, since a higher coordination number results in weaker V-O bonds, and less extreme isotopic fractionation. Using an input of [4] coordinated $\mathrm{V}^{5+}$ results in isotopically heavier melts, with the maximum KLB1 melting stable isotope fractionation increasing from $\approx 0.1 \%$ in the $[6]$ coordinated case to $\approx 0.15 \%$ close to the solidus around $10 \mathrm{kbar}$ (Fig. S6 for full results) in the [4] coordinated case. However, the difference between the two models decreases at higher temperature, and for the temperature range of interest here (potential temperatures from $1300-1530{ }^{\circ} \mathrm{C}$ ), at $5 \mathrm{kbar}$ the difference in melt isotopic composition between the two models is $\approx 0.01 \%$, and therefore negligible. However, to improve understanding of high temperature $\mathrm{V}$ behaviour and link natural data to specific processes, experimental and/or theoretical work on equilibrium isotopic fractionation factors for silicate melt and minerals for different $\mathrm{V}$ species is needed. 


\section{5 $\mathrm{Cr}: \mathrm{Cr}_{\text {melt }}^{2+}=[6]$ coordinated}

As chromium is a first-group transition element, the properties controlling isotopic fractionation behaviour (e.g., valence, ionic radius hence bonding environment) of $\mathrm{Cr}^{2+}$ and $\mathrm{Cr}^{3+}$ ions may be expected to be similar to $\mathrm{Fe}^{2+}$ and $\mathrm{Fe}^{3+}$ ions (Xia et al., 2017). The main Cr-bearing phases in the mantle are spinel, garnet and pyroxenes, although some $\mathrm{Cr}$ will partition into olivine (Mallmann and O'Neill, 2009), and as with vanadium, partition coefficients depend on the valence state of Cr (Mallmann and O'Neill, 2009).

As a set of $\beta^{\mathrm{Cr}}$ factors for mantle minerals does not exist, our models of $\mathrm{Cr}$ stable isotope fractionation use force constants in each mineral calculated from an ionic bonding model (Shen et al., 2018), following the approach used for Fe isotopes. An ionic model has been shown to produce inter-mineral fractionation in agreement with the magnitude of isotope fractionation inferred from studies of lherzolite mineral pairs (Shen et al., 2018). As with V isotopes, the main uncertainty relating to species coordination is in liquid. $\mathrm{Cr}^{2+}$ in silicate melt is reported to be in [4] coordination (Miletich et al., 1999; O'Neill and Berry, 2006; Shen et al., 2020), but may also be in [6] coordination in a square planar arrangement (O'Neill and Berry, 2006). The isotope fractionation model presented here calculates force constants using effective anionic and cationic radii based on Shannon (1976), following the approach outlined in Shen et al. (2018), and these radii depend negatively on the coordination number chosen (Gibbs et al., 2014).

Fig. S8 compares the $\Delta^{53} \mathrm{Cr}_{\text {melt-source }}$ for an input of $\mathrm{Cr}_{\text {melt }}^{2+}=[4]$ coordinated (left hand panels; these are the results used in the main text) with an input of $\mathrm{Cr}_{\text {melt }}^{2+}=[6]$ coordinated (right hand panels). The input parameters for the [6] coordinated case are in Table S8.

Table S11: Alternate parameters for Cr isotopic fractionation model. Mineral site and bonding information is based on Shen et al. (2018).

\begin{tabular}{lrrrrr}
\hline Mineral & Cr species & Site & Cr coordination & Bond length $(\AA)$ & O coordination \\
\hline melt & $2+$ & n/a & 6 & 2.18 & 4 \\
\hline
\end{tabular}

The model presented in the main text uses an input of $\mathrm{Cr}^{2+}$ in [4] coordination in the melt. Inputting [6] coordinated $\mathrm{Cr}^{2+}$ in the melt results in isotopically lighter peridotite melts across all of P-T space (Fig. S8) than the [4] coordinated case as a consequence of weaker Cr-O bonds in a [6] coordinated environment than [4] coordinated. A similar effect is seen in MIX1G and G2 melts. The melt-source isotopic fractionation is always negative, consistent with modelling by Shen et al. (2018), and melts get progressively isotopically heavier (towards $0 \%$ fractionation from the source) with increasing degree of melting, consistent with observations from OIB (Bonnand et al., 2020). The cationic radii are likely to be overestimates, as the radii for [6] coordinated Cr used in Shen et al. (2018) assume octahedral, not square planar, coordination. Square planar bonds would be expected to be longer than octahedral, and this would result in even isotopically lighter melts. Therefore, although the model uses the most appropriate available inputs for the more commonly quoted [4] coordination of $\mathrm{Cr}^{2+}$ in melts, our understanding of the behaviour of $\mathrm{Cr}$ isotopes in silicate melts would benefit from further work on the force constants of $\mathrm{Cr}^{2+}$ in glasses, or the inputs required to calculate these such as bonding environment or effective $\mathrm{Cr}-\mathrm{O}$ bond lengths. 

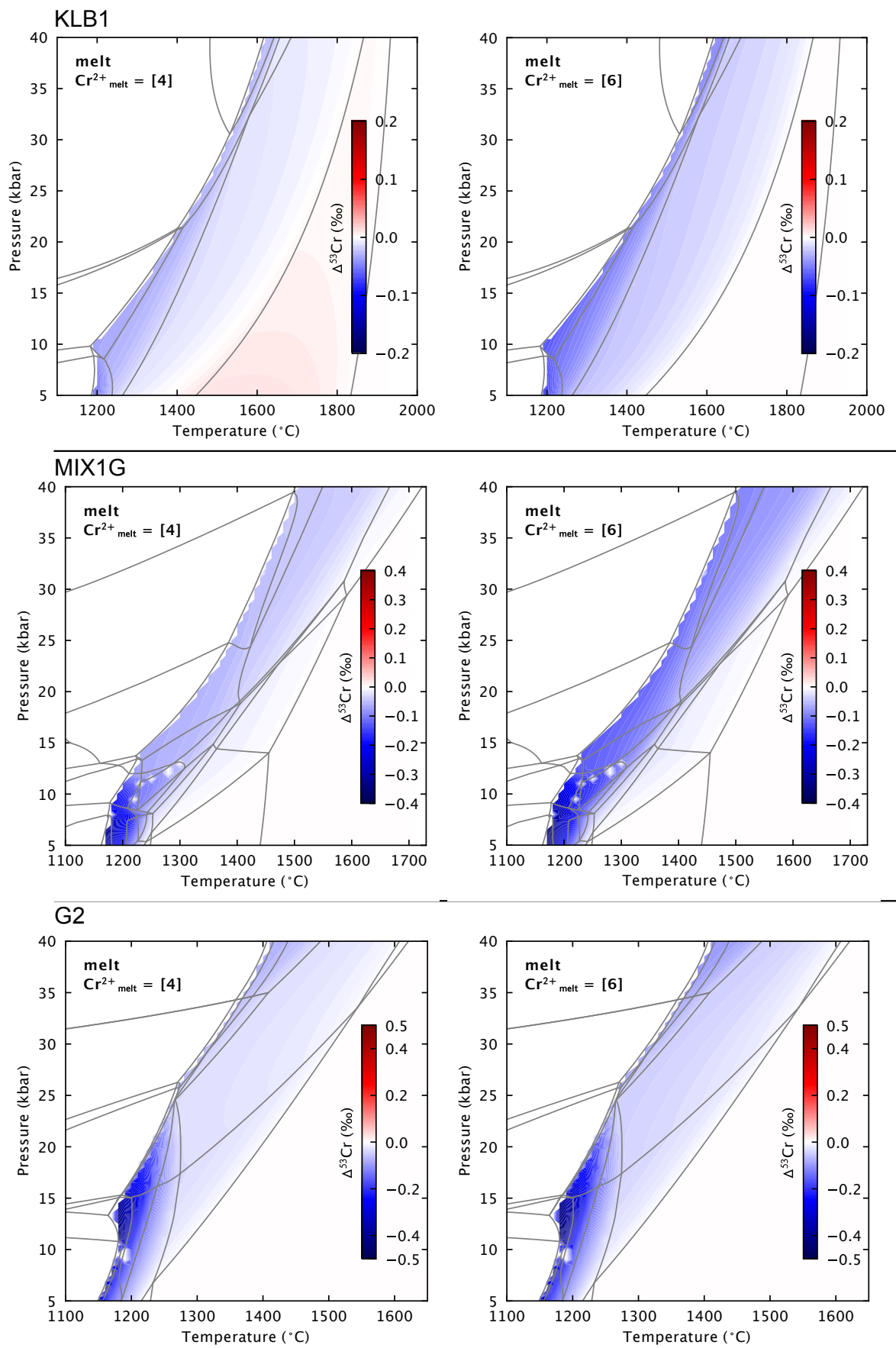

Figure S8: $\Delta^{53} \mathrm{Cr}_{\text {melt-source }}$ compared for a model where $\mathrm{Cr}_{\text {melt }}^{2+}=[4]$ coordinated (left hand plots) and $\mathrm{Cr}_{\text {melt }}^{2+}=$ [6] coordinated (right hand plots) for all three lithologies.

\section{Other potential isotopes}

Other stable isotope systems not considered here might also have potential for investigating mantle heterogeneity (in either lithology or temperature). However, we require a better understanding of the bonding environment in melts or relevant minerals before these isotope systems can be implemented into the stable isotope fractionation models used here.

Like other stable isotope systems, the equilibrium $\delta^{30} \mathrm{Si}$ value of a phase will depend on the 
strength of the $\mathrm{Si}-\mathrm{O}$ bonds. A more polymerised (or, more $\mathrm{Si}$-rich) phase will have more $\mathrm{Si}-\mathrm{O}$ bonds, therefore a stronger average $\mathrm{Si}-\mathrm{O}$ bond force constant, hence high $\delta^{30} \mathrm{Si}$ (Grant, 1954). However, density functional theory (DFT) calculations show this simple prediction is complicated by the role of other network-modifying cations in silicates (Méheut et al., 2009; Méheut and Schauble, 2014). Silicon isotope fractionation factors have been calculated using DFT for appropriate mantle minerals (Huang et al., 2014), however there is a lack of work on the crucial mineral-melt fractionation information required for the equilibrium fractionation model here. Furthermore, it has been suggested that $\mathrm{Si}$ isotopic fractionation in liquids may be correlated with chemical composition (Qin et al., 2016), an effect that is too complicated (and underconstrained) to model here. This knowledge gap could provide scope for future work, however the mantle is currently thought to be homogeneous in Si isotopes (within current limits of analytical precision), and there seems to be only a small partial melting effect (Savage et al., 2014).

Titanium stable isotopes have been suggested as tracer of magmatic processes (Millet et al., 2016), since Ti can exist in multiple coordination states in silicate melts and Ti-oxides (Farges and Brown Jr, 1997). However, Ti stable isotope fractionation in magmatic systems is dominated by the behaviour of Fe-Ti oxides, with no partial melting fractionation from mantle lithologies expected unless under conditions of Ti-oxide saturation. DFT calculations predict no significant Ti isotope fractionation between pyroxenes, olivine or garnet (Wang et al., 2020), and both eclogites and MORB have the same measured $\delta^{49} \mathrm{Ti}$ value (Millet et al., 2016). Therefore, Ti isotopes are not discussed further here, as there is no existing data to support for their use in tracing temperature or lithological heterogeneity in the mantle associated with MORB or OIB.

\section{Average depth of melting}

The mean melt pressure, $\overline{\mathrm{P}}$, for isentropic melting at any $\mathrm{T}_{p}$ is calculated by the following integral, based on Asimow et al. (2001) with an additional geometric weighting factor to account for the triangular shape of the melting region

$$
\overline{\mathrm{P}}=\frac{\int_{\mathrm{P}_{0}}^{\mathrm{P}_{\mathrm{f}}} \mathrm{P} \Delta \mathrm{FgdP}}{\int_{\mathrm{P}_{0}}^{\mathrm{P}_{\mathrm{f}}} \Delta \mathrm{Fg} \mathrm{dP}}
$$

where $\mathrm{P}_{0}$ and $\mathrm{P}_{\mathrm{f}}$ are the initial and final pressures of melting respectively, $\Delta \mathrm{F}$ is the amount of melt produced at each pressure step $(\mathrm{dP})$ along the isentropic melting path, and $\mathrm{g}$ is the geometric weighting factor. $\mathrm{P}_{0}$ is taken as the intersection of the isentrope with the solidus, $\mathrm{P}_{\mathrm{f}}$ is used as $5 \mathrm{kbar}$ in this model as melt compositions have not been calculated for shallower pressures - this is an overestimate (i.e., final melting will be shallower) for $\mathrm{T}_{p}=1300^{\circ} \mathrm{C}$ and an underestimate for $\mathrm{T}_{p}=1530^{\circ} \mathrm{C}$ (Asimow et al., 2001), but will provide the correct behaviour. Pressure steps used are the $0.5 \mathrm{kbar}$ intervals used in the P-T grid. $\Delta \mathrm{F}$ is calculated for each step from the difference in melt fractions calculated by THERMOCALC for consecutive dP steps. The geometric weighting factor is a linear scaling running from 1 at the base of the melting region to 0 at the top, to account for the wider base of the triangular melting region beneath ridges. We calculate the average melting pressure for the three $\mathrm{T}_{p} \mathrm{~s}$ for which we have calculated isentropes in KLB1, and lineally interpolate between them (this will not be a linear relationship in reality, e.g., Asimow et al., 2001, but our approach will provide a good approximation) to get average melt pressures for temperatures between $\mathrm{T}_{p}=1300^{\circ} \mathrm{C}$ and $1530^{\circ} \mathrm{C}$. For KLB1, we calculate an average melting pressure of approximately $12 \mathrm{kbar}$ at $\mathrm{T}_{p}=1300^{\circ} \mathrm{C}$, and $28 \mathrm{kbar}$ at $\mathrm{T}_{p}=1530^{\circ} \mathrm{C}$. The average $\Delta_{\text {melt-source }}$ for each $\mathrm{T}_{p}$ is then taken as the $\Delta_{\text {melt-source }}$ at the 
calculated average melting pressure.

The approach above, however, uses an equilibrium melt isotope composition at a single pressure to approximate the fractional, multibaric melting thought to occur in the mantle (McKenzie, 1984; von Bargen and Waff, 1986; Langmuir et al., 1992; Asimow et al., 2001). To assess the suitability of the equilibrium melting at single pressure approach, we have also calculated the average melt isotopic composition by considering the stable isotope composition and elemental concentration for each new step of melt generated during isentropic decompression at $\mathrm{T}_{p}=$ $1300^{\circ} \mathrm{C}$ and $1530^{\circ} \mathrm{C}$ by

$$
\bar{\Delta}_{\text {melt-source }}=\frac{\int_{\mathrm{P}_{0}}^{\mathrm{P}_{\mathrm{f}}} \Delta_{\mathrm{x}} \mathrm{c} \Delta \mathrm{Fg} \mathrm{dP}}{\int_{\mathrm{P}_{0}}^{\mathrm{P}_{\mathrm{f}}} \mathrm{c} \Delta \mathrm{Fg} \mathrm{dP}}
$$

where $\Delta_{\mathrm{x}}$ is the $\Delta_{\text {melt-source }}$ of the melt produced in the pressure step, and c is the wt $\%$ of the element being considered in the melt, and other terms as above. The approach of equation 7 , while considering polybaric melting, is still not a fractional melting model, but fractional melting is beyond the scope of this work. Nonetheless, the chemical composition of pooled fractional melts from a ridge melting regime has been shown to closely resemble that of a simple equilibrium batch melt (Langmuir et al., 1992). Equation 7 therefore allows us to broadly assess whether the approach taken in equation 6 produces estimates of mean melt isotope ratios very different from a more realistic polybaric approach, although it should be noted that the polybaric method of equation 7 only allows us to calculate the average melt isotopic composition for the two $\mathrm{T}_{p} \mathrm{~s}$ for which we have calculated isentropes.

Fig. S9 shows the comparison of the two calculations of average $\Delta_{\text {melt-source }}$ The dots show the average melt isotope composition when calculated as a sum along the isentrope; the solid lines show the approximation using the melt composition at the average pressure of melting. The calculation using the average melt pressure is a good approximation of the calculated average melt isotope compositions. Therefore we use this pressure approach in the main text: the limitation of the calculated average melt isotope composition is that we only have information for the $\mathrm{T}_{p} \mathrm{~s}$ for which we have calculated isentropes, hence use a linear interpolation between them, whereas the average pressure approach allows us to use more information from the calculated P-T map of melt compositions, reflecting the changing of stable mineral assemblage, for example.

\section{Trace element calculations}

Table S12 gives the mineral-melt partition coefficients and mantle concentrations for Sm and $\mathrm{Yb}$ used in this model.

Table S12: Input parameters (partition coefficients relative to melt, mantle concentrations) for calculating the $\mathrm{Sm}$, Dy and $\mathrm{Yb}$ concentration of trace elements in the model melts. $\mathrm{D}_{\mathrm{gt}, \mathrm{cpx}, \mathrm{ol} \text {,opx }}$ and element concentrations from Gibson and Geist (2010); $\mathrm{D}_{\text {spinel }}$ from Liu et al. (2019) (average values from high P experiments); $\mathrm{D}_{\text {plag }}$ from Aigner-Torres et al. (2007) (from 'run 31'); D rutile from Klemme et al. (2005) (Sm), Foley et al. (2000) (Dy, Yb); $\mathrm{D}_{\text {ilmenite }}$ from Zack and Brumm (1998). Conc. $\mathrm{DM}=$ concentration in depleted mantle; mineral abbreviations as previous with rut. $=$ rutile, ilm. = ilmenite.

\begin{tabular}{lrrrrrrrrr}
\hline Element & $\mathrm{D}_{\mathrm{gt}}$ & $\mathrm{D}_{\text {cpx }}$ & $\mathrm{D}_{\text {ol }}$ & $\mathrm{D}_{\text {opx }}$ & $\mathrm{D}_{\text {spn }}$ & $\mathrm{D}_{\text {plag }}$ & $\mathrm{D}_{\text {rut }}$ & $\mathrm{D}_{\text {ilm }}$ & Conc.DM \\
\hline $\mathrm{Sm}$ & 0.25 & 0.293 & 0.0011 & 0.02 & 0.198 & 0.081 & 0.00135 & 0.00059 & 0.299 \\
$\mathrm{Dy}$ & 2.2 & 0.4 & 0.0027 & 0.011 & 0.069 & 0.049 & 0.00076 & 0.01 & 0.525 \\
$\mathrm{Yb}$ & 6.6 & 0.4 & 2 & 0.08 & 0.812 & 0.025 & 0.0093 & 0.17 & 0.347 \\
\hline
\end{tabular}




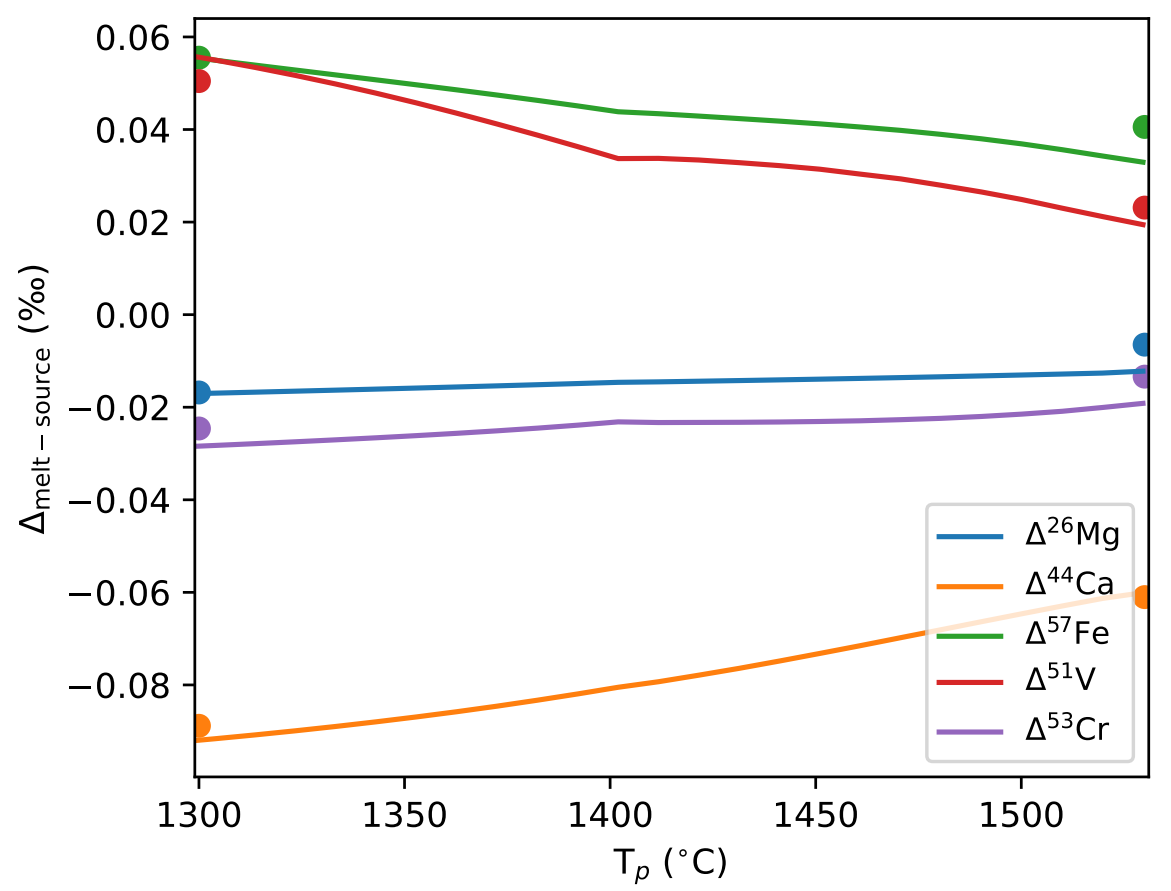

Figure S9: $\Delta_{\text {melt-source }}$ for KLB1 calculated by taking the isotopic fractionation at the average melt pressure (solid lines) compared to a calculation of the average melt composition by considering polybaric melts (equation 7), shown as coloured dots.

The concentration of each element in the melt was calculated at each P-T point by:

$$
\mathrm{C}_{\text {liquid }}=\frac{\mathrm{C}_{\text {bulk }}}{\sum \mathrm{D}_{\text {mineral }} \mathrm{F}_{\text {mineral }}+\mathrm{F}_{\text {liquid }}}
$$

where $\mathrm{C}=$ concentration, $\mathrm{D}=$ partition coefficient, $\mathrm{F}=$ fraction of phase.

\section{Additional reference figures}

Fig. S10 provides a reference for how oxygen fugacity, melt fraction, and selected trace element ratios vary along the isentropes shown in Figs. 1 and 4 of the main text. The trace element concentrations are calculated using depleted mantle (DM) inputs for KLB1, and plume inputs for the enriched MIX1G and G2 lithologies (see Table S12).

We choose to use peridotite isentropic decompression paths for the two pyroxenite lithologies, as discussed in the main text. Figs. S11, S12 show results for the other endmember case for the two pyroxenite lithologies, i.e., where the lithologies decompress along isentropic paths calculated for each pure pyroxenite lithology.

Fig. S13 compares the melt-source isotope fractionation with progressive melting (along peridotite isentropes) for pairs of isotopes in each lithology, allowing assessment of the 'direct' sensitivity to lithology. By direct lithological sensitivity, we refer to sensitivity related to mineralogy - these isotope systems may still trace lithology via each lithology's different bulk isotope composition. On balance, given that melts from any pyroxenite lithology are likely to be diluted with ambient peridotite melts when extracted from the mantle (e.g., Hirschmann and Stolper, 

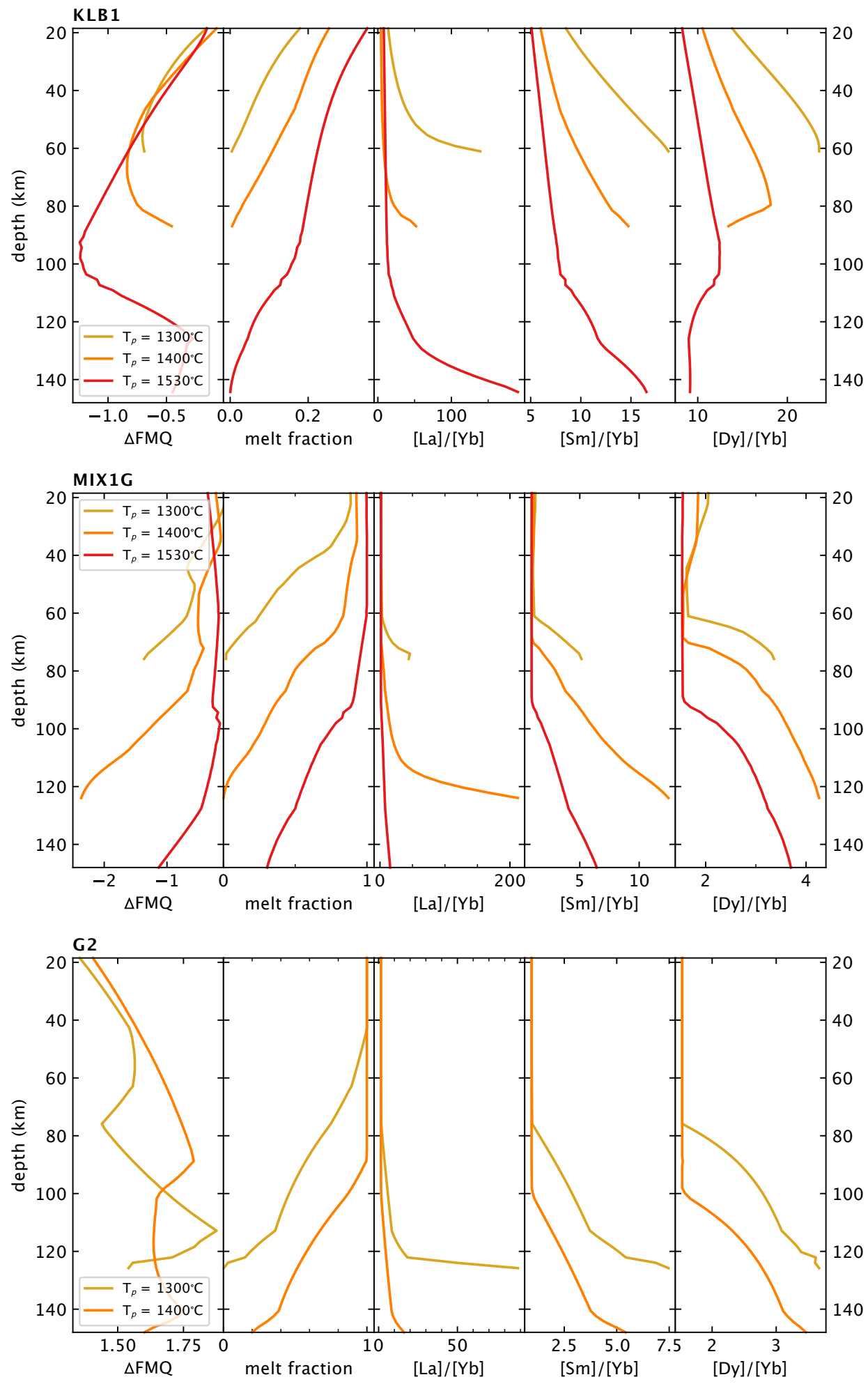

Figure S10: Parameters along the peridotite isentropic decompression paths for all three lithologies: oxygen fugacity (from the $\mathrm{fO}_{2}$ melt software; Holland et al., 2018), melt fraction (from THERMOCALC output), and selected trace element ratios in the melts (calculated using the model described in the section above). The isentropes match those in Figs. 2 and 5 in the main text. 


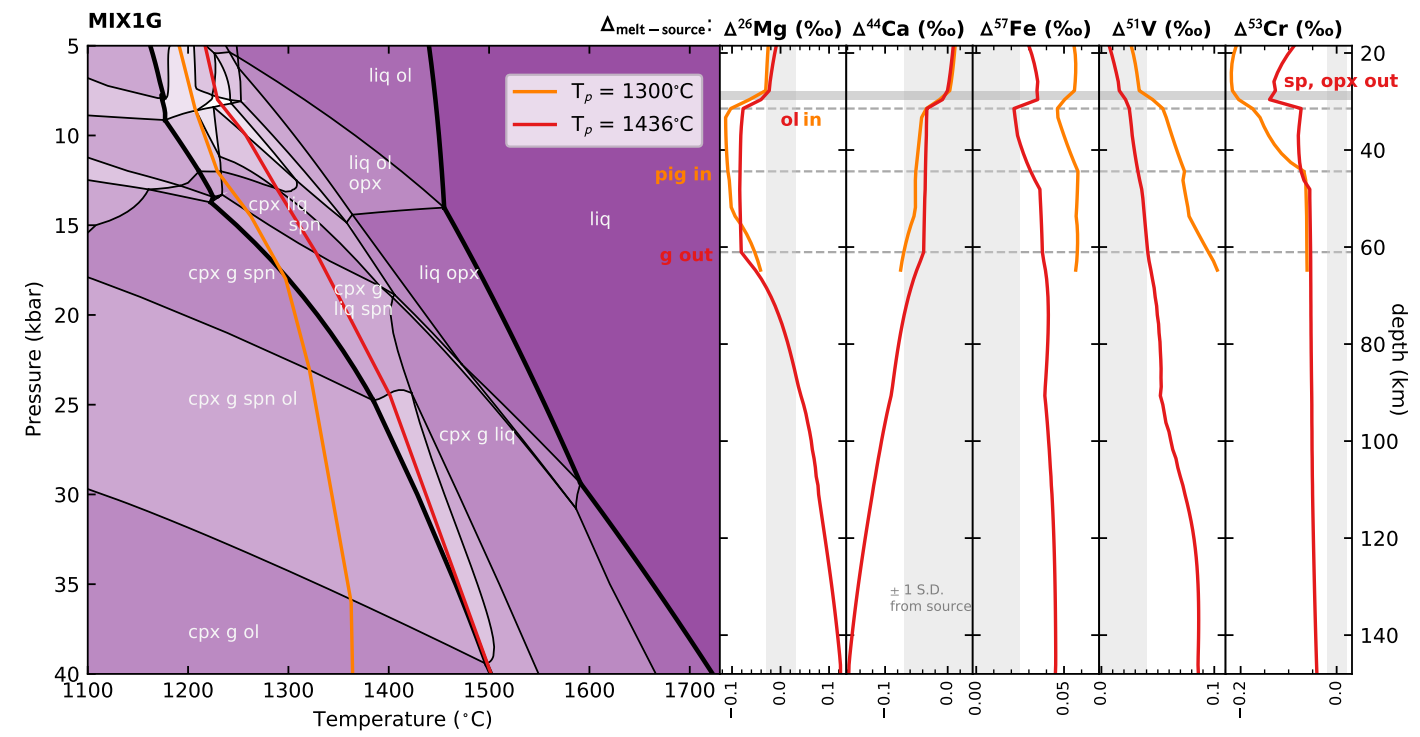

Figure S11: Isentropic melting paths for pure MIX1G, and $\Delta_{\text {melt-source }}$ along these isentropes. Errors are shown as 1 S.D. long-term uncertainty.

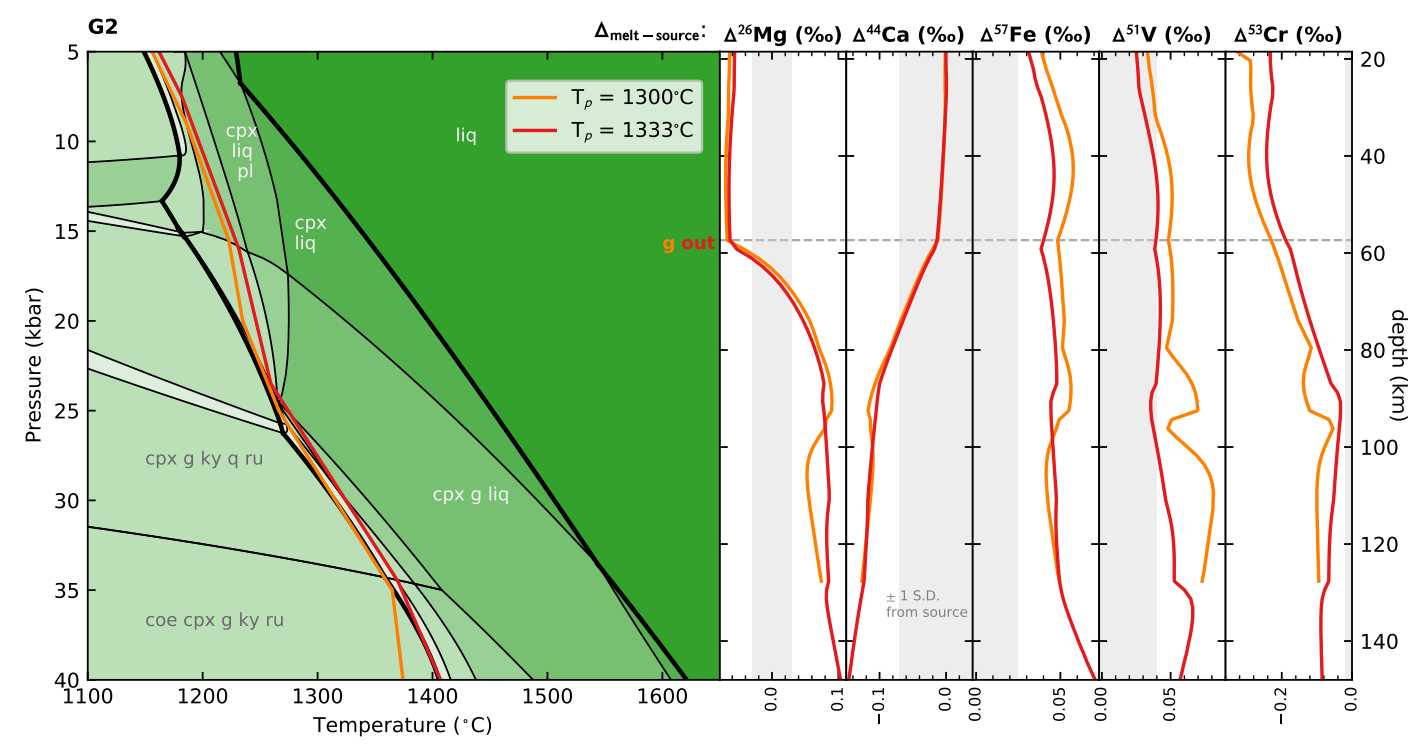

Figure S12: Isentropic melting paths for pure G2, and $\Delta_{\text {melt-source }}$ along these isentropes. Errors are shown as 1 S.D. long-term uncertainty. 


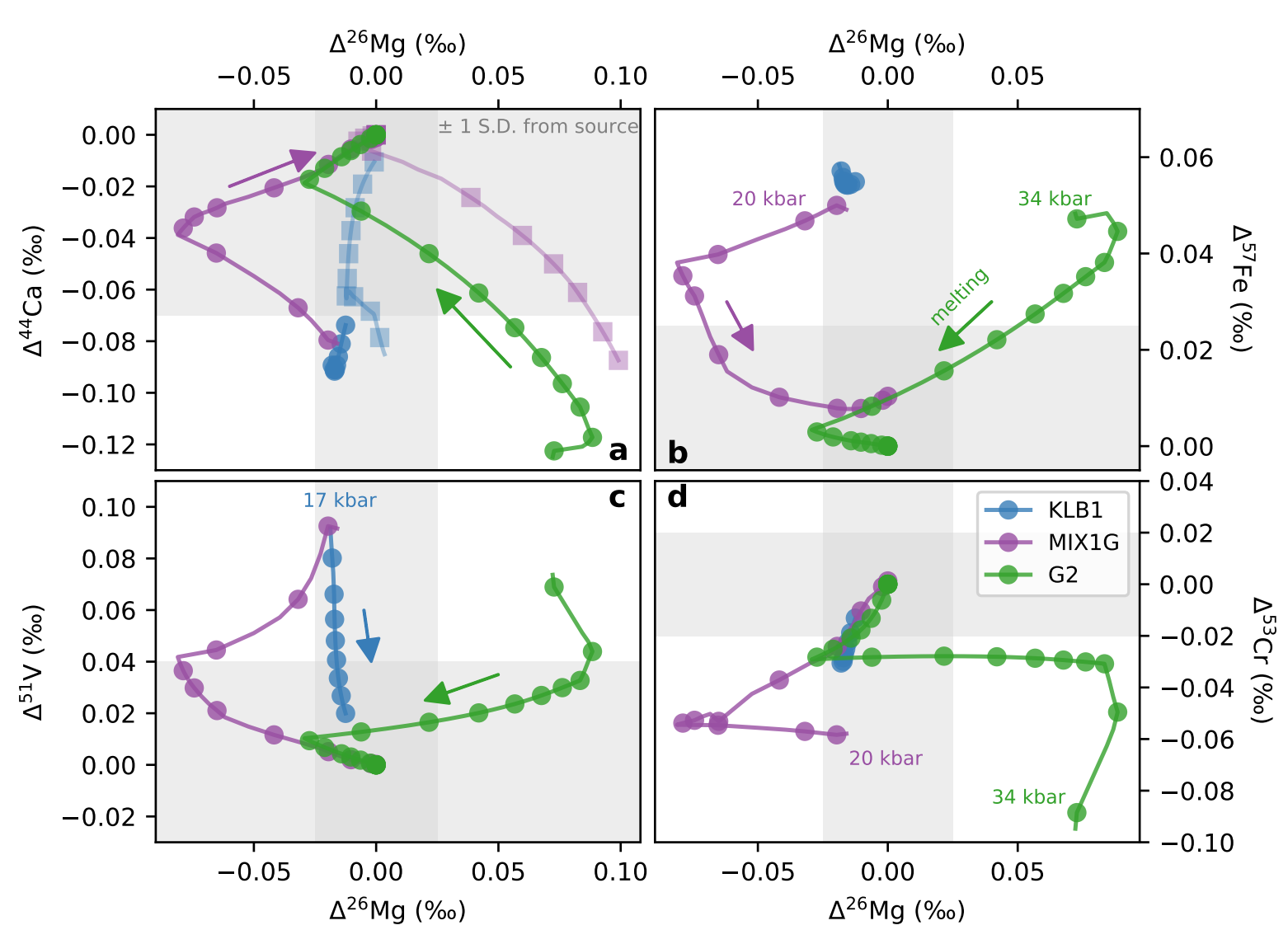

1996; Sobolev et al., 2005; Shorttle and Maclennan, 2011; Soderman et al., 2021), our results in Fig. S13 are probably representative of maximum isotope fractionation signatures we might see in natural systems, and Fig. 7 in the main text (which takes into account both this dilution effect and non-identical bulk isotope compositions of the lithologies) may better represent the predicted resolvability of each isotope system to lithology. Generally, Fig. S13 suggests that the stable isotopes considered here may have poor direct sensitivity to lithological heterogeneity in the source regions of basalts, assuming equilibrium fractionation behaviour and in the absence of any pre-imposed source heterogeneity (i.e., where all lithologies have the same bulk isotope ratio).

Figure S13: Melting fractionation $\left(\Delta_{\text {melt-source }}\right)$ plotted along the $\mathrm{T}_{p}=1300^{\circ} \mathrm{C}$ isentrope; squares in $\mathrm{Mg}-\mathrm{Ca}$ space show $\mathrm{T}_{p}=1530^{\circ} \mathrm{C}$ isentrope for reference. High or low pressure end of isentrope is marked, and arrows show the direction of progressive melting (decompression). Markers are plotted every 3 pressure steps (each pressure step is $0.5 \mathrm{kbar})$. Grey shaded regions show the source $(0 \%) \pm$ typical long-term analytical 1 S.D. (see Table S2 for details).

\section{$9 \quad$ Element budgeting between lithologies}

To produce Fig. 7 in the main text, we use a mass balance calculation for each isotopic system, $\mathrm{X}$, where

$$
\delta \mathrm{X}_{\text {bulk }}=\left(\mathrm{F}_{\text {pyroxenite }}^{\mathrm{X}} \times \delta \mathrm{X}_{\text {pyroxenite }}\right)+\left(\mathrm{F}_{\text {peridotite }}^{\mathrm{X}} \times \delta \mathrm{X}_{\text {peridotite }}\right)
$$

and $\mathrm{F}^{\mathrm{X}}$ is the fraction of the total element in the final melt coming from each lithology, $\delta \mathrm{X}_{\text {lithology }}$ is the isotopic composition of each lithology (bulk isotope composition of lithology + melt-source isotope fractionation). The $\mathrm{F}$ term considers both the amount of the element in the melt from 
Table S13: Inputs used to calculate bulk melt-source isotope fractionation in Figs. 7 and S14. * indicates inputs using the pure pyroxenite isentropes at that $\mathrm{T}_{p}$, rather than peridotite isentropes. The MIX1G 1400* inputs are actually for an isentrope of $\mathrm{T}_{p}=1436^{\circ} \mathrm{C}$. The $\mathrm{P}-\mathrm{T}$ given are the closest $\mathrm{P}-\mathrm{T}$ pair in the model output files to the average $\mathrm{P}-\mathrm{T}$ of melting along each isentrope, as calculated in Section 6. For $\mathrm{V}$ and $\mathrm{Cr}$, where element partitioning is not calculated by THERMOCALC, the melt element concentrations are calculated as described in Appendix Section 3, using the following bulk compositions for each lithology: KLB1 $\mathrm{Cr}_{2} \mathrm{O}_{3}=0.32 \mathrm{wt} \%$, G2 $\mathrm{Cr}_{2} \mathrm{O}_{3}=0.08 \mathrm{wt} \%$, MIX1G $\mathrm{Cr}_{2} \mathrm{O}_{3}=0.11 \mathrm{wt} \%$ (Jennings et al., 2016); KLB1 V $=85$ ppm (typical primitive mantle value from Lee et al., 2003; Prytulak et al., 2013), MIX1G and G2 V = 350 ppm (typical MORB value; Prytulak et al., 2013).

\begin{tabular}{|c|c|c|c|c|c|c|c|c|}
\hline \multirow[b]{2}{*}{$\mathrm{T}_{p}\left({ }^{\circ} \mathrm{C}\right):$} & \multirow{2}{*}{$\begin{array}{r}\text { KLB1 } \\
1300 \\
\end{array}$} & \multicolumn{3}{|c|}{ MIX1G } & \multirow[b]{2}{*}{1400} & \multicolumn{3}{|c|}{ G2 } \\
\hline & & 1400 & 1300 & $1300^{*}$ & & $1400^{*}$ & 1300 & $1300^{*}$ \\
\hline Pressure (kbar) & 12 & 17.5 & 15 & 13.5 & 24.5 & 22 & 27 & 25.5 \\
\hline Temperature $\left({ }^{\circ} \mathrm{C}\right)$ & 1300 & 1400 & 1317 & 1248 & 1440 & 1380 & 1345 & 1269 \\
\hline Melt fraction & 0.061 & 0.099 & 0.323 & 0.093 & 0.369 & 0.155 & 0.458 & 0.048 \\
\hline \multicolumn{9}{|l|}{ Melt element conc. } \\
\hline $\begin{array}{l}\mathrm{Mg} \text { (mol\% oxide) } \\
\mathrm{Ca} \text { (mol \% oxide) }\end{array}$ & $\begin{array}{l}16.50 \\
12.72\end{array}$ & $\begin{array}{l}20.43 \\
13.62\end{array}$ & $\begin{array}{l}15.44 \\
1266\end{array}$ & $\begin{array}{l}11.01 \\
10.63\end{array}$ & $\begin{array}{l}19.42 \\
13.09\end{array}$ & $\begin{array}{l}16.59 \\
11.83\end{array}$ & $\begin{array}{l}5.92 \\
9.47\end{array}$ & $\begin{array}{l}4.48 \\
7.53\end{array}$ \\
\hline $\mathrm{Fe}$ (mol \% oxide) & 6.36 & 7.64 & 8.93 & 7.46 & 9.27 & 10.21 & 4.22 & 3.07 \\
\hline $\mathrm{V}$ (wt \% element) & 0.002 & 0.003 & 0.014 & 0.008 & 0.015 & 0.009 & 0.021 & 0.011 \\
\hline $\mathrm{Cr}$ (wt \% element) & 0.005 & 0.009 & 0.004 & 0.001 & 0.007 & 0.002 & 0.004 & 0.001 \\
\hline \multicolumn{9}{|c|}{ Melt-source isotopic fractionation $(\%)$} \\
\hline$\Delta^{26} \mathrm{Mg}$ & -0.02 & -0.02 & -0.08 & -0.10 & 0.08 & 0.02 & 0.06 & 0.09 \\
\hline$\Delta^{44} \mathrm{Ca}$ & -0.09 & -0.08 & -0.04 & -0.05 & -0.08 & -0.08 & -0.08 & -0.12 \\
\hline$\Delta^{57} \mathrm{Fe}$ & 0.06 & 0.04 & 0.03 & 0.06 & 0.03 & 0.04 & 0.03 & 0.06 \\
\hline$\Delta^{51} \mathrm{~V}$ & 0.05 & 0.03 & 0.03 & 0.08 & 0.02 & 0.05 & 0.03 & 0.07 \\
\hline$\Delta^{53} \mathrm{Cr}$ & -0.03 & -0.02 & -0.05 & -0.06 & -0.04 & -0.05 & -0.03 & -0.12 \\
\hline \multicolumn{9}{|c|}{ Bulk isotopic composition of lithology $(\% 0)$} \\
\hline$\delta^{26} \mathrm{Mg}$ & -0.24 & & -0.25 & & & & -0.25 & \\
\hline$\delta^{44} \mathrm{Ca}$ & 0.94 & & 0.83 & & & & 0.83 & \\
\hline$\delta^{57} \mathrm{Fe}$ & 0.05 & & 0.14 & & & & 0.14 & \\
\hline$\delta^{51} \mathrm{~V}$ & -0.91 & & -0.92 & & & & -0.92 & \\
\hline$\delta^{53} \mathrm{Cr}$ & -0.12 & & -0.15 & & & & -0.15 & \\
\hline
\end{tabular}

each lithology, and the melt fraction of each lithology. Table S13 gives the inputs used: these inputs are taken from the full model results at the average P-T melting condition (as in Section 6) for each $\mathrm{T}_{p}$. This calculation cannot be done for a $\mathrm{T}_{p}$ of $1530^{\circ} \mathrm{C}(\mathrm{MIX} 1 \mathrm{G} \& \mathrm{G} 2)$ or $1400^{\circ} \mathrm{C}$ (G2) because the isentropic melting paths intersect the solidus at pressures below the base of our model, so an accurate average pressure of melting cannot be calculated. The bulk isotope compositions of each lithology are the BSE values for peridotite (see Fig. 1 caption in main text for sources), and average MORB composition for pyroxenite (except for $\mathrm{Cr}$ where no known MORB data are published and the modelled aggregate KLB1 melt isotope composition for $\mathrm{T}_{p}$ $=1300{ }^{\circ} \mathrm{C}$ is used).

Fig. S14 is an alternative to Fig. 7 in the main text, with the right hand panels scaled to typical current 1 S.D. analytical precision. 


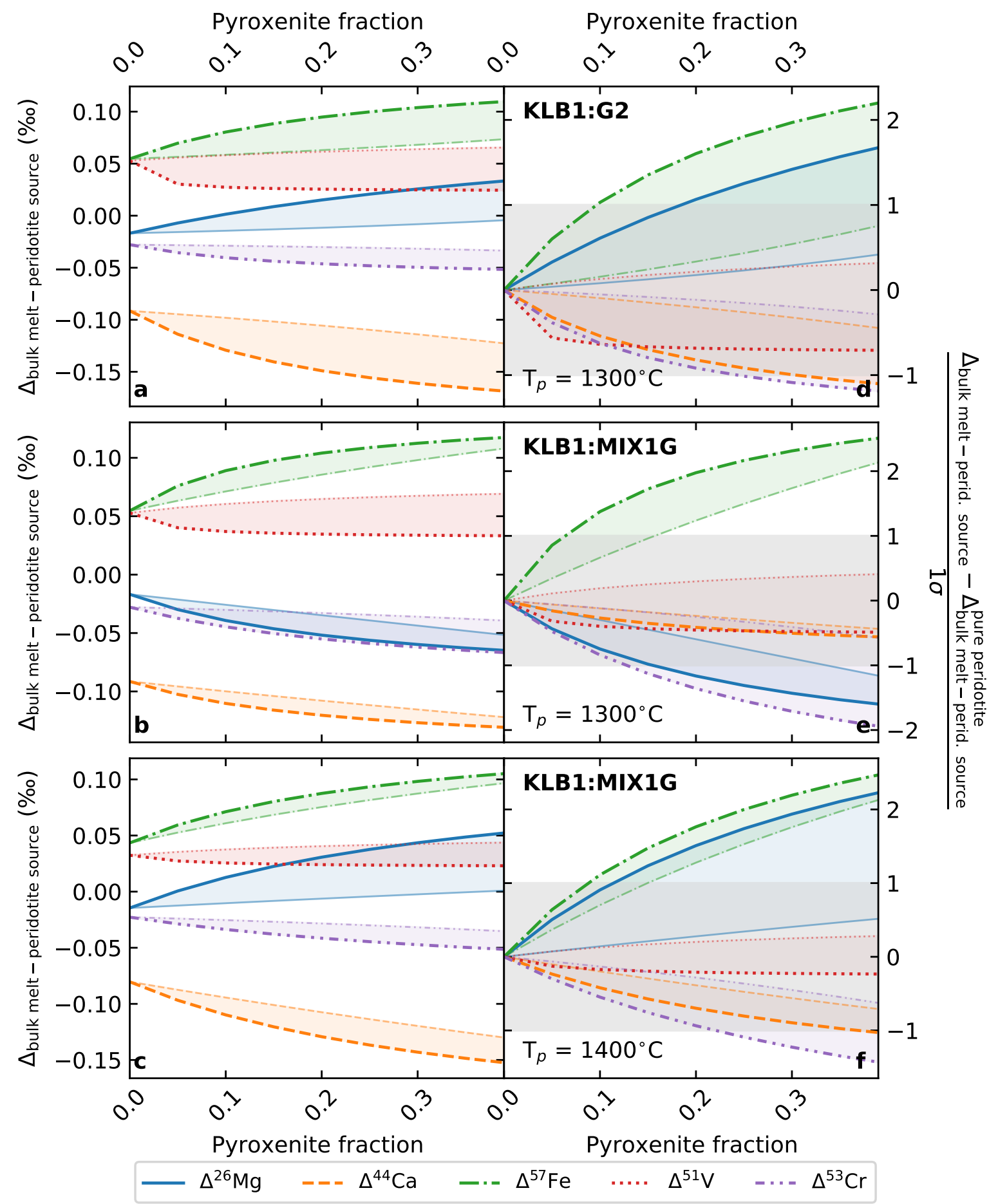

Figure S14: Aggregate bulk melt isotope fractionation (relative to a pure peridotite source, left hand panels; relative to a pure peridotite melt and scaled to current typical long-term analytical 1 S.D., right hand panels) for multi-lithologic mantle. At each $\mathrm{T}_{p}$, the aggregate melt composition (including isotope composition, and element proportion) at the average pressure and temperature of melting for each lithology is used to calculate the resulting bulk melt isotope composition by mass balance. A range of bulk melt-source isotope fractionations are given for each isotope system, reflecting two endmembers for the thermal behaviour of pyroxenite upwelling in a peridotite host. The bolder line represents the case for pyroxenite following peridotite geotherms (as used throughout this study); the paler line reflects pyroxenite following its own geotherm, as in Figs. S10 and S11. Grey horizontal bars in the right hand panels highlight 1 S.D. 


\section{References}

Aigner-Torres, M., Blundy, J., Ulmer, P. and Pettke, T. (2007), 'Laser ablation ICPMS study of trace element partitioning between plagioclase and basaltic melts: an experimental approach', Contributions to Mineralogy and Petrology 153(6), 647-667.

Antonelli, M. A., Kendrick, J., Yakymchuk, C., Guitreau, M., Mittal, T. and Moynier, F. (2021), 'Calcium isotope evidence for early Archaean carbonates and subduction of oceanic crust', Nature Communications 12(1), 1-8.

Antonelli, M. A., Mittal, T., McCarthy, A., Tripoli, B., Watkins, J. M. and DePaolo, D. J. (2019b), 'Ca isotopes record rapid crystal growth in volcanic and subvolcanic systems', Proceedings of the National Academy of Sciences 116(41), 20315-20321.

Antonelli, M. A., Schiller, M., Schauble, E. A., Mittal, T., DePaolo, D. J., Chacko, T., Grew, E. S. and Tripoli, B. (2019), 'Kinetic and equilibrium Ca isotope effects in high-T rocks and minerals', Earth and Planetary Science Letters 517, 71-82.

Asimow, P. D., Hirschmann, M. M. and Stolper, E. M. (2001), 'Calculation of peridotite partial melting from thermodynamic models of minerals and melts, IV. Adiabatic decompression and the composition and mean properties of mid-ocean ridge basalts', Journal of Petrology 42(5), 963-998.

Berry, A. J., O'Neill, H. S. C. and Foran, G. J. (2021), 'The effects of temperature and pressure on the oxidation state of chromium in silicate melts', Contributions to Mineralogy and Petrology 176(5), 1-14.

Bonnand, P., Doucelance, R., Boyet, M., Bachèlery, P., Bosq, C., Auclair, D. and Schiano, P. (2020), 'The influence of igneous processes on the chromium isotopic compositions of Ocean Island basalts', Earth and Planetary Science Letters 532, 116028.

Bourdon, B., Tipper, E. T., Fitoussi, C. and Stracke, A. (2010), 'Chondritic Mg isotope composition of the Earth', Geochimica et Cosmochimica Acta 74(17), 5069-5083.

Canil, D. (1999), 'Vanadium partitioning between orthopyroxene, spinel and silicate melt and the redox states of mantle source regions for primary magmas', Geochimica et Cosmochimica Acta 63(3-4), 557-572.

Canil, D. (2002), 'Vanadium in peridotites, mantle redox and tectonic environments: Archean to present', Earth and Planetary Science Letters 195(1-2), 75-90.

Chen, C., Ciazela, J., Li, W., Dai, W., Wang, Z., Foley, S. F., Li, M., Hu, Z. and Liu, Y. (2020b), 'Calcium isotopic compositions of oceanic crust at various spreading rates', Geochimica et Cosmochimica Acta 278, $272-288$.

Chen, C., Dai, W., Wang, Z., Liu, Y., Li, M., Becker, H. and Foley, S. F. (2019), 'Calcium isotope fractionation during magmatic processes in the upper mantle', Geochimica et Cosmochimica Acta 249, $121-137$.

Chen, C., Huang, J.-X., Foley, S. F., Wang, Z., Moynier, F., Liu, Y., Dai, W. and Li, M. (2020a), 'Compositional and pressure controls on calcium and magnesium isotope fractionation in magmatic systems', Geochimica et Cosmochimica Acta 290, 257-270.

Dauphas, N., Roskosz, M., Alp, E. E., Neuville, D. R., Hu, M. Y., Sio, C. K., Tissot, F. L. H., Zhao, J., Tissandier, L., Médard, E. and Cordier, C. (2014), 'Magma redox and structural controls on iron isotope variations in Earth's mantle and crust', Earth and Planetary Science Letters 398, 127-140.

Davis, F. A., Tangeman, J. A., Tenner, T. J. and Hirschmann, M. M. (2009), 'The composition of KLB-1 peridotite', American Mineralogist 94(1), 176-180.

Deer, W. A., Howie, R. A. and Zussman, J. (2013), An Introduction to the Rock-Forming Minerals, Mineralogical Society of Great Britain and Ireland.

Ding, X., Helz, R. T., Qi, Y. and Huang, F. (2020), 'Vanadium isotope fractionation during differentiation of Kilauea Iki lava lake, Hawaii', Geochimica et Cosmochimica Acta 289, 114-129.

Duffy, J. A. (1993), 'A review of optical basicity and its applications to oxidic systems', Geochimica et Cosmochimica Acta 57(16), 3961-3970.

Farges, F. and Brown Jr, G. E. (1997), 'Coordination chemistry of titanium (IV) in silicate glasses and melts: IV. XANES studies of synthetic and natural volcanic glasses and tektites at ambient temperature and pressure', Geochimica et Cosmochimica Acta 61(9), 1863-1870. 
Feng, C., Qin, T., Huang, S., Wu, Z. and Huang, F. (2014), 'First-principles investigations of equilibrium calcium isotope fractionation between clinopyroxene and Ca-doped orthopyroxene', Geochimica et Cosmochimica Acta 143, $132-142$.

Feng, L.-p., Zhou, L., Yang, L., DePaolo, D. J., Tong, S.-Y., Liu, Y.-S., Owens, T. L. and Gao, S. (2017), 'Calcium isotopic compositions of sixteen USGS reference materials', Geostandards and Geoanalytical Research 41(1), 93-106.

Foley, S. F., Barth, M. G. and Jenner, G. A. (2000), 'Rutile/melt partition coefficients for trace elements and an assessment of the influence of rutile on the trace element characteristics of subduction zone magmas', Geochimica et cosmochimica acta 64(5), 933-938.

George, A. M. and Stebbins, J. F. (1998), 'Structure and dynamics of magnesium in silicate melts: A hightemperature 25Mg NMR study', American Mineralogist 83(9-10), 1022-1029.

Gibbs, G. V., Ross, N. L., Cox, D. F., Rosso, K. M., Iversen, B. B. and Spackman, M. (2014), 'Pauling bond strength, bond length and electron density distribution', Physics and Chemistry of Minerals 41(1), 17-25.

Gibson, S. A. and Geist, D. (2010), 'Geochemical and geophysical estimates of lithospheric thickness variation beneath Galápagos', Earth and Planetary Science Letters 300(3-4), 275-286.

Gleeson, M. L. M., Gibson, S. A. and Williams, H. M. (2020), 'Novel insights from Fe-isotopes into the lithological heterogeneity of Ocean Island Basalts and plume-influenced MORBs', Earth and Planetary Science Letters $\mathbf{5 3 5 .}$

Grant, F. S. (1954), 'The geological significance of variations in the abundances of the isotopes of silicon in rocks', Geochimica et Cosmochimica Acta 5(5), 225-242.

Hirschmann, M. M., Kogiso, T., Baker, M. B. and Stolper, E. M. (2003), 'Alkalic magmas generated by partial melting of garnet pyroxenite', Geology 31(6), 481-484.

Hirschmann, M. M. and Stolper, E. M. (1996), 'A possible role for garnet pyroxenite in the origin of the "garnet signature" in MORB', Contributions to Mineralogy and Petrology 124(2), 185-208.

Holland, T. J. B., Green, E. C. R. and Powell, R. (2018), 'Melting of Peridotites through to Granites: A Simple Thermodynamic Model in the System KNCFMASHTOCr', Journal of Petrology 59(5), 881-900.

Holland, T. J. B. and Powell, R. (2011), 'An improved and extended internally consistent thermodynamic dataset for phases of petrological interest, involving a new equation of state for solids', Journal of Metamorphic Geology $\mathbf{2 9}(3), 333-383$.

Huang, F., Chen, L., Wu, Z. and Wang, W. (2013), 'First-principles calculations of equilibrium Mg isotope fractionations between garnet, clinopyroxene, orthopyroxene, and olivine: implications for $\mathrm{Mg}$ isotope thermometry', Earth and Planetary Science Letters 367, 61-70.

Huang, F., Wu, Z., Huang, S. and Wu, F. (2014), 'First-principles calculations of equilibrium silicon isotope fractionation among mantle minerals', Geochimica et Cosmochimica Acta 140, 509-520.

Huang, F., Zhou, C., Wang, W., Kang, J. and Wu, Z. (2019), 'First-principles calculations of equilibrium Ca isotope fractionation: Implications for oldhamite formation and evolution of lunar magma ocean', Earth and Planetary Science Letters 510, 153-160.

Huang, S., Farkaš, J. and Jacobsen, S. B. (2011b), 'Stable calcium isotopic compositions of Hawaiian shield lavas: evidence for recycling of ancient marine carbonates into the mantle', Geochimica et Cosmochimica Acta 75(17), 4987-4997.

Humphreys, M. C. S., Brooker, R. A., Fraser, D. G., Burgisser, A., Mangan, M. T. and McCammon, C. (2015), 'Coupled interactions between volatile activity and fe oxidation state during arc crustal processes', Journal of Petrology 56(4), 795-814.

Jennings, E. S., Holland, T. J. B., Shorttle, O., Maclennan, J. and Gibson, S. A. (2016), 'The composition of melts from a heterogeneous mantle and the origin of ferropicrite: application of a thermodynamic model', Journal of Petrology 57(11-12), 2289-2310.

Klemme, S., Prowatke, S., Hametner, K. and Günther, D. (2005), 'Partitioning of trace elements between rutile and silicate melts: implications for subduction zones', Geochimica et Cosmochimica Acta 69(9), 2361-2371. 
Konter, J. G., Pietruszka, A. J., Hanan, B. B., Finlayson, V. A., Craddock, P. R., Jackson, M. G. and Dauphas, N. (2016), 'Unusual $\delta^{56}$ Fe values in Samoan rejuvenated lavas generated in the mantle', Earth and Planetary Science Letters 450, 221-232.

Lambart, S., Baker, M. B. and Stolper, E. M. (2016), 'The role of pyroxenite in basalt genesis: Melt-PX, a melting parameterization for mantle pyroxenites between 0.9 and 5 GPa', Journal of Geophysical Research: Solid Earth 121(8), 5708-5735.

Langmuir, C. H., Klein, E. M. and Plank, T. (1992), Petrological systematics of mid-ocean ridge basalts: constraints on melt generation beneath ocean ridges, in J. Phipps Morgan, D. K. Blackman and S. J. M, eds, 'Mantle Flow and Melt Generation at Mid-Ocean Ridges', Vol. 71, AGU American Geophysical Union, pp. 183280.

Lee, C.-T. A., Brandon, A. D. and Norman, M. (2003), 'Vanadium in peridotites as a proxy for paleo-fO2 during partial melting: prospects, limitations, and implications', Geochimica et Cosmochimica Acta 67(16), 30453064.

Liu, L., Ma, Y., Yan, W. and Liu, X. (2019), 'Trace element partitioning between MgAl2O4-spinel and carbonatitic silicate melt from 3 to $6 \mathrm{GPa}$, with emphasis on the role of cation order-disorder', Solid Earth Sciences 4(2), 4365

Macris, C. A., Manning, C. E. and Young, E. D. (2015), 'Crystal chemical constraints on inter-mineral Fe isotope fractionation and implications for Fe isotope disequilibrium in San Carlos mantle xenoliths', Geochimica et Cosmochimica Acta 154, 168-185.

Mallmann, G. and O'Neill, H. S. C. (2007), 'The effect of oxygen fugacity on the partitioning of Re between crystals and silicate melt during mantle melting', Geochimica et Cosmochimica Acta 71(11), 2837-2857.

Mallmann, G. and O'Neill, H. S. C. (2009), 'The crystal/melt partitioning of V during mantle melting as a function of oxygen fugacity compared with some other elements (Al, P, Ca, Sc, Ti, Cr, Fe, Ga, Y, Zr and Nb)', Journal of Petrology 50(9), 1765-1794.

McKenzie, D. (1984), 'The generation and compaction of partially molten rock', Journal of Petrology 25(3), 713765 .

Méheut, M., Lazzeri, M., Balan, E. and Mauri, F. (2009), 'Structural control over equilibrium silicon and oxygen isotopic fractionation: a first-principles density-functional theory study', Chemical Geology 258(1-2), 28-37.

Méheut, M. and Schauble, E. A. (2014), 'Silicon isotope fractionation in silicate minerals: insights from firstprinciples models of phyllosilicates, albite and pyrope', Geochimica et Cosmochimica Acta 134, 137-154.

Miletich, R., Nowak, M., Seifert, F., Angel, R. and Brandstätter, G. (1999), 'High-pressure crystal chemistry of chromous orthosilicate, $\mathrm{Cr}_{2} \mathrm{SiO}_{4}$. A single-crystal X-ray diffraction and electronic absorption spectroscopy study', Physics and chemistry of minerals 26(6), 446-459.

Millet, M.-A., Dauphas, N., Greber, N. D., Burton, K. W., Dale, C. W., Debret, B., Macpherson, C. G., Nowell, G. M. and Williams, H. M. (2016), 'Titanium stable isotope investigation of magmatic processes on the Earth and Moon', Earth and Planetary Science Letters 449, 197-205.

Mills, K. C. (1993), 'The influence of structure on the physico-chemical properties of slags', ISIJ international 33(1), 148-155.

Nebel, O., Arculus, R. J., Sossi, P. A., Jenner, F. E. and Whan, T. H. (2013), 'Iron isotopic evidence for convective resurfacing of recycled arc-front mantle beneath back-arc basins', Geophysical Research Letters 40(22), 58495853.

Nebel, O., Sossi, P. A., Bénard, A., Arculus, R. J., Yaxley, G. M., Woodhead, J. D., Davies, D. R. and Ruttor, S. (2019), 'Reconciling petrological and isotopic mixing mechanisms in the Pitcairn mantle plume using stable Fe isotopes', Earth and Planetary Science Letters 521, 60-67.

Novella, D., Maclennan, J., Shorttle, O., Prytulak, J. and Murton, B. J. (2020), 'A multi-proxy investigation of mantle oxygen fugacity along the Reykjanes Ridge', Earth and Planetary Science Letters 531, 115973.

O'Neill, H. S. C. and Berry, A. J. (2006), 'Activity coefficients at low dilution of $\mathrm{CrO}, \mathrm{NiO}$ and $\mathrm{CoO}$ in melts in the system $\mathrm{CaO}-\mathrm{MgO}-\mathrm{Al} 2 \mathrm{O} 3-\mathrm{SiO} 2$ at $1400 \mathrm{C}$ : using the thermodynamic behaviour of transition metal oxides in silicate melts to probe their structure', Chemical Geology 231(1-2), 77-89. 
Peters, B. J., Shahar, A., Carlson, R. W., Day, J. M. and Mock, T. D. (2019), 'A sulfide perspective on iron isotope fractionation during ocean island basalt petrogenesis', Geochimica et Cosmochimica Acta 245, 59-78.

Powell, R., Holland, T. J. B. and Worley, B. (1998), 'Calculating phase diagrams involving solid solutions via non-linear equations, with examples using THERMOCALC', Journal of Metamorphic Geology 16(4), 577-588.

Prytulak, J., Nielsen, S. G., Ionov, D. A., Halliday, A. N., Harvey, J., Kelley, K. A., Niu, Y. L., Peate, D. W., Shimizu, K. and Sims, K. W. W. (2013), 'The stable vanadium isotope composition of the mantle and mafic lavas', Earth and Planetary Science Letters 365, 177-189.

Prytulak, J., Sossi, P. A., Halliday, A. N., Plank, T., Savage, P. S. and Woodhead, J. D. (2017), 'Stable vanadium isotopes as a redox proxy in magmatic systems?', Geochemical Perspectives Letters 3(1), 75-84.

Qi, Y.-H., Wu, F., Ionov, D. A., Puchtel, I. S., Carlson, R. W., Nicklas, R. W., Yu, H.-M., Kang, J.-T., Li, C.-H. and Huang, F. (2019), 'Vanadium isotope composition of the Bulk Silicate Earth: Constraints from peridotites and komatiites', Geochimica et Cosmochimica Acta 259, 288-301.

Qin, T., Wu, F., Wu, Z. and Huang, F. (2016), 'First-principles calculations of equilibrium fractionation of O and $\mathrm{Si}$ isotopes in quartz, albite, anorthite, and zircon', Contributions to Mineralogy and Petrology 171(11), 1-14.

Righter, K., Sutton, S. R., Newville, M., Le, L., Schwandt, C. S., Uchida, H., Lavina, B. and Downs, R. T. (2006), 'An experimental study of the oxidation state of vanadium in spinel and basaltic melt with implications for the origin of planetary basalt', American Mineralogist 91(10), 1643-1656.

Salters, V. J. M. and Stracke, A. (2004), 'Composition of the depleted mantle', Geochemistry, Geophysics, Geosystems $\mathbf{5}(5)$.

Savage, P. S., Armytage, R. M., Georg, R. B. and Halliday, A. N. (2014), 'High temperature silicon isotope geochemistry', Lithos 190, 500-519.

Schauble, E. A. (2011), 'First-principles estimates of equilibrium magnesium isotope fractionation in silicate, oxide, carbonate and hexaaquamagnesium (2+) crystals', Geochimica et Cosmochimica Acta 75(3), 844-869.

Schuessler, J. A., Schoenberg, R. and Sigmarsson, O. (2009), 'Iron and lithium isotope systematics of the Hekla volcano, Iceland - evidence for Fe isotope fractionation during magma differentiation', Chemical Geology 258(12), 78-91.

Shannon, R. D. (1976), 'Revised effective ionic radii and systematic studies of interatomic distances in halides and chalcogenides', Acta crystallographica section A: crystal physics, diffraction, theoretical and general crystallography 32(5), 751-767.

Shen, J., Qin, L., Fang, Z., Zhang, Y., Liu, J., Liu, W., Wang, F., Xiao, Y., Yu, H. and Wei, S. (2018), 'Hightemperature inter-mineral Cr isotope fractionation: A comparison of ionic model predictions and experimental investigations of mantle xenoliths from the North China Craton', Earth and Planetary Science Letters 499, 278290 .

Shen, J., Xia, J., Qin, L., Carlson, R. W., Huang, S., Helz, R. T. and Mock, T. D. (2020), 'Stable chromium isotope fractionation during magmatic differentiation: Insights from Hawaiian basalts and implications for planetary redox conditions', Geochimica et Cosmochimica Acta 278, 289-304.

Shimoda, K., Tobu, Y., Hatakeyama, M., Nemoto, T. and Saito, K. (2007), 'Structural investigation of Mg local environments in silicate glasses by ultra-high field 25Mg 3QMAS NMR spectroscopy', American Mineralogist 92(4), 695-698.

Shorttle, O. and Maclennan, J. (2011), 'Compositional trends of Icelandic basalts: Implications for short-length scale lithological heterogeneity in mantle plumes', Geochemistry, Geophysics, Geosystems 12(11).

Sobolev, A. V., Hofmann, A. W., Sobolev, S. V. and Nikogosian, I. K. (2005), 'An olivine-free mantle source of Hawaiian shield basalts', Nature 434(7033), 590-597.

Soderman, C. R., Matthews, S., Shorttle, O., Jackson, M. G., Ruttor, S., Nebel, O., Turner, S., Beier, C., Millet, M.-A., Widom, E. et al. (2021), 'Heavy $\delta^{57} \mathrm{Fe}$ in ocean island basalts: A non-unique signature of processes and source lithologies in the mantle', Geochimica et Cosmochimica Acta 292, 309-332.

Sossi, P. A., Moynier, F. and Van Zuilen, K. (2018), 'Volatile loss following cooling and accretion of the Moon revealed by chromium isotopes', Proceedings of the National Academy of Sciences 115(43), 10920-10925. 
Sossi, P. A. and O'Neill, H. S. C. (2017), 'The effect of bonding environment on iron isotope fractionation between minerals at high temperature', Geochimica et Cosmochimica Acta 196, 121-143.

Sossi, P. A., Prytulak, J. and O'Neill, H. S. C. (2018b), 'Experimental calibration of vanadium partitioning and stable isotope fractionation between hydrous granitic melt and magnetite at 800 c and 0.5 gpa', Contributions to mineralogy and petrology $\mathbf{1 7 3}(4), 1-18$.

Stracke, A., Tipper, E. T., Klemme, S. and Bizimis, M. (2018), 'Mg isotope systematics during magmatic processes: Inter-mineral fractionation in mafic to ultramafic Hawaiian xenoliths', Geochimica et Cosmochimica Acta 226, 192-205.

Sun, P., Niu, Y., Guo, P., Duan, M., Chen, S., Gong, H., Wang, X. and Xiao, Y. (2020), 'Large iron isotope variation in the eastern Pacific mantle as a consequence of ancient low-degree melt metasomatism', Geochimica et Cosmochimica Acta 286, 269-288.

Sutton, S. R., Karner, J., Papike, J., Delaney, J. S., Shearer, C., Newville, M., Eng, P., Rivers, M. and Dyar, M. D. (2005), 'Vanadium K edge XANES of synthetic and natural basaltic glasses and application to microscale oxygen barometry', Geochimica et Cosmochimica Acta 69(9), 2333-2348.

Sutton, S., Righter, K., Berthet, S. and Newville, M. (2008), Experimental Constraints on the Partitioning and Valence of V and $\mathrm{Cr}$ in Garnet and Coexisting Glass, in 'AGU Fall Meeting Abstracts', Vol. 2008, pp. MR43A1808.

Teng, F.-Z., Dauphas, N. and Helz, R. T. (2008), 'Iron Isotope Fractionation During Magmatic Differentiation in Kilauea Iki Lava Lake', Science 320(5883), 1620-1622.

Teng, F.-Z., Dauphas, N., Huang, S. and Marty, B. (2013), 'Iron isotopic systematics of oceanic basalts', Geochimica et Cosmochimica Acta 107, 12-26.

Teng, F.-Z., Li, W.-Y., Ke, S., Marty, B., Dauphas, N., Huang, S., Wu, F.-Y. and Pourmand, A. (2010), 'Magnesium isotopic composition of the Earth and chondrites', Geochimica et Cosmochimica Acta 74(14), 4150-4166.

Toplis, M. J. and Corgne, A. (2002), 'An experimental study of element partitioning between magnetite, clinopyroxene and iron-bearing silicate liquids with particular emphasis on vanadium', Contributions to Mineralogy and Petrology 144(1), 22-37.

Valdes, M. C., Debaille, V., Berger, J. and Armytage, R. M. G. (2019), 'The effects of high-temperature fractional crystallization on calcium isotopic composition', Chemical Geology 509, 77-91.

Valdes, M. C., Moreira, M., Foriel, J. and Moynier, F. (2014), 'The nature of Earth's building blocks as revealed by calcium isotopes', Earth and Planetary Science Letters 394, 135-145.

von Bargen, N. and Waff, H. S. (1986), 'Permeabilities, interfacial areas and curvatures of partially molten systems: results of numerical computations of equilibrium microstructures', Journal of Geophysical Research: Solid Earth 91(B9), 9261-9276.

Wang, W., Huang, S., Huang, F., Zhao, X. and Wu, Z. (2020), 'Equilibrium inter-mineral titanium isotope fractionation: Implication for high-temperature titanium isotope geochemistry', Geochimica et Cosmochimica Acta 269, 540-553.

Wang, W., Zhou, C., Qin, T., Kang, J.-T., Huang, S., Wu, Z. and Huang, F. (2017), 'Effect of Ca content on equilibrium $\mathrm{Ca}$ isotope fractionation between orthopyroxene and clinopyroxene', Geochimica et Cosmochimica Acta 219, 44-56.

Wang, X.-J., Chen, L.-H., Hanyu, T., Zhong, Y., Shi, J.-H., Liu, X.-W., Kawabata, H., Zeng, G. and Xie, L.-W. (2021), 'Magnesium isotopic fractionation during basalt differentiation as recorded by evolved magmas', Earth and Planetary Science Letters 565, 116954.

Wiechert, U. and Halliday, A. N. (2007), 'Non-chondritic magnesium and the origins of the inner terrestrial planets', Earth and Planetary Science Letters 256(3-4), 360-371.

Wu, F., Qi, Y., Perfit, M. R., Gao, Y., Langmuir, C. H., Wanless, V. D., Yu, H. and Huang, F. (2018), 'Vanadium isotope compositions of mid-ocean ridge lavas and altered oceanic crust', Earth and Planetary Science Letters 493, 128-139. 
Wu, F., Qin, T., Li, X., Liu, Y., Huang, J.-H., Wu, Z. and Huang, F. (2015), 'First-principles investigation of vanadium isotope fractionation in solution and during adsorption', Earth and Planetary Science Letters 426, 216-224.

Xia, J., Qin, L., Shen, J., Carlson, R. W., Ionov, D. A. and Mock, T. D. (2017), 'Chromium isotope heterogeneity in the mantle', Earth and Planetary Science Letters 464, 103-115.

Zack, T. and Brumm, R. (1998), Ilmenite/liquid partition coefficients of 26 trace elements determined through ilmenite/clinopyroxene partitioning in garnet pyroxenites, in 'International Kimberlite Conference: Extended Abstracts', Vol. 7, pp. 986-988.

Zhang, H., Wang, Y., He, Y., Teng, F.-Z., Jacobsen, S. B., Helz, R. T., Marsh, B. D. and Huang, S. (2018), 'No measurable calcium isotopic fractionation during crystallization of Kilauea Iki lava lake', Geochemistry, Geophysics, Geosystems 19(9), 3128-3139.

Zhong, Y., Chen, L.-H., Wang, X.-J., Zhang, G.-L., Xie, L.-W. and Zeng, G. (2017), 'Magnesium isotopic variation of oceanic island basalts generated by partial melting and crustal recycling', Earth and Planetary Science Letters 463, $127-135$.

Zhong, Y., Zhang, G.-L., Jin, Q.-Z., Huang, F., Wang, X.-J. and Xie, L.-W. (2021b), 'Sub-basin scale inhomogeneity of mantle in the South China Sea revealed by magnesium isotopes', Science Bulletin 66(7), 740-748.

Zhong, Y., Zhang, G.-L., Lv, W.-X. and Huang, F. (2021), 'Iron isotope constraints on the lithological heterogeneity of the upper mantle in the South China Sea', Journal of Asian Earth Sciences p. 104934.

Zhu, H., Du, L., Zhang, Z. and Sun, W. (2020a), 'Calcium isotopic signatures of depleted mid-ocean ridge basalts from the northeastern Pacific', Journal of Oceanology and Limnology 38, 1476-1487.

Zhu, H., Liu, F., Li, X., Wang, G., Zhang, Z. and Sun, W. (2018), 'Calcium isotopic compositions of normal MidOcean Ridge basalts from the southern Juan de Fuca Ridge', Journal of Geophysical Research: Solid Earth 123(2), 1303-1313. 